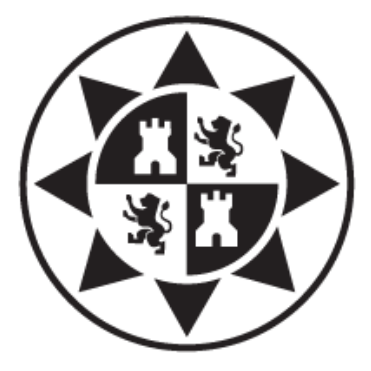

UNIVERSIDAD POLITÉCNICA DE CARTAGENA

Departamento de Tecnología Electrónica

\title{
PROPUESTA DE UNA RED DE SENSORES INALÁMBRICA PARA UN SISTEMA DE OBSERVACIÓN COSTERO
}

Tesis Doctoral

D. ${ }^{a}$ Cristina Albaladejo Pérez

Ingeniera en Telecomunicaciones

Directores

Dr. D. Andrés Iborra García

Dr. D. Fulgencio Soto Valles 



\title{
PROPUESTA DE UNA RED DE SENSORES INALÁMBRICA PARA UN SISTEMA DE OBSERVACIÓN COSTERO.
}

\author{
Autor: $\quad$ Cristina Albaladejo Pérez
}

Directores: Andrés Iborra García

Fulgencio Soto Valles

Contacto:

Copyright 2011 @ Cristina Albaladejo Pérez 



\section{Agradecimientos}

Qué mejor momento para agradecer a las personas que, directa o indirectamente, han participado en el desarrollo de esta Tesis. Unas leyendo, opinando y corrigiendo. Otras colmándose de paciencia, dando ánimo, acompañando en los momentos de crisis y en los momentos de felicidad. A todas ellas les quiero dedicar un agradecimiento.

Gracias en primer lugar a mis directores, Andrés Iborra y Pencho Soto, por su gran apoyo y confianza en mí. Gracias, no solo por guiarme en el trabajo, sino por hacerme crecer como persona.

Gracias al "grupo motero", Pencho, Roque, Honorio y Juan Antonio, con los que tantos momentos he disfrutado.

Gracias a Manolo Jiménez, por su enorme ayuda en mi aprendizaje.

Gracias a Ana Toledo, por convertirse en mi compañera de viajes.

Gracias a Pedro Sánchez Palma, a quien agradezco su ayuda y confianza en mí.

Gracias a Fernando Losilla, con quien inicié mi andadura en las redes de sensores.

Gracias a José Juan, un patrón indiscutible.

Gracias a Jesús Rubio y a Raúl Borraz, por su colaboración en esta Tesis.

Gracias al Departamento de Tecnología Electrónica al completo y al grupo DSIE, gracias por hacerme sentir como en casa.

Gracias a Pedro García Raja, por las sesiones de videos y fotos que plasman el arduo trabajo desarrollado.

Gracias a Javier Gilabert y Francisco López por su colaboración en los despliegues en el mar.

Gracias al Club Náutico de San Pedro del Pinatar y al Club de Regatas de Cartagena por cedernos sus instalaciones, sin las cuales hubiese sido complicado realizar las pruebas de esta Tesis.

Gracias a mi familia, mis padres, Juan y Cari, y mi hermano, Juan David, quienes me han "llevado de la mano" y a quienes agradezco enormemente su continuo cariño. A mi cuñada Mónica, mi sobrina Sofía, mis abuelitos, titos, padrinos y primos.

Gracias a Manolo, por su paciencia, apoyo y alegría en tan largo camino. 

"Recordarás algo de lo que leas, bastante de lo que oigas, mucho de lo que veas, y todo lo que hagas" JOHN LITTLE 



\section{Resumen}

Durante esta última década la monitorización del medio marino se ha convertido en un importante campo de interés científico. Los sistemas marinos costeros son particularmente vulnerables a la influencia de la actividad humana debido principalmente al desarrollo industrial, turístico y urbanístico, y es por ello por lo que estas aguas se convierten en objetivos ideales en el ámbito de la investigación cuya finalidad es analizar el entorno marino costero. Así surge la necesidad de crear sistemas de observación oceanográficos que permitan llevar a cabo dicho estudio.

Es habitual encontrar en la literatura gran cantidad de aplicaciones dedicadas a la monitorización del entorno en diversas disciplinas. En esta Tesis se dedica especial atención a las tecnologías que actualmente se utilizan para la observación del medio acuático. Para ello, se utilizan desde redes de sensores a pequeña escala hasta complejos sistemas de observación costeros. Dentro de las redes a pequeña escala, las redes de sensores inalámbricas constituyen una solución muy atractiva por su facilidad de despliegue, operación y repliegue, así como su reducido coste, y se presentan como una solución alternativa e innovadora para la observación oceanográfica. Éstas permiten obtener una mayor resolución espacio-temporal de la información recogida a través de un despliegue con mayor densidad de nodos y menor coste que los sistemas tradicionales.

El impacto del medio marino sobre una red de sensores limita y condiciona su desarrollo, y es por ello que ofrece nuevos retos frente al caso terrestre. Dentro de la monitorización inalámbrica se diferencian dos tecnologías dependiendo del medio de transmisión de datos que utilicen, las redes de sensores inalámbricas submarinas y las aéreas. En general, las submarinas se adoptan como solución únicamente para hacer viable la monitorización oceanográfica a grandes profundidades, siendo las aéreas empleadas en aguas someras. Puesto que la zona de estudio tratada tiene como objetivo la monitorización de una laguna costera somera, la Tesis Doctoral se centra en el desarrollo de una red de sensores inalámbrica aérea para monitorización de zonas costeras poco profundas.

Tras realizar un estudio de las infraestructuras e instrumentación dedicadas a la observación del medio marino, se han extraído una serie de características en las que se centra la investigación e implementación realizada en la presente Tesis Doctoral. Resumiendo el trabajo realizado, se ha llevado a cabo el diseño hardware y software de los dispositivos que forman una red de sensores, la fabricación de la estructura mecánica de una boya para la monitorización de aguas someras, y finalmente, la implementación del sistema de monitorización que alberga y gestiona la información proveniente de la red. El correcto funcionamiento del sistema completo ha sido validado mediante pruebas en el laboratorio y despliegues realizados en el mar. 



\section{Summary}

Monitoring of the marine environment has come to be a field of scientific interest in the last ten years. Coastal marine systems are particularly vulnerable to the effects of human activity attendant on industrial, tourist and urban development, and so these waters become ideal aims in the field of research aimed at analyzing the environment coastal marine. Thus arises the need for ocean observing systems to realize this study.

It is common to find in literature many applications dedicated to environmental monitoring in different disciplines. In this $\mathrm{PhD}$ special attention is given to the technologies currently used for monitoring the aquatic environment. For this, the instruments used have ranged from small-scale sensor networks to complex observation systems. Among small-scale networks, Wireless Sensor Networks (WSNs) are a highly attractive solution in that they are easy to deploy, operate and dismantle and are relatively inexpensive, and are presented as an alternative and innovative oceanographic observation. These allow for greater spatial and temporal resolution of the information collected through a deployment of nodes with higher density and lower cost than traditional systems.

The design, implementation and deployment of a WSN for oceanographic applications poses new challenges different to the ones that arise on land, as the impact of the marine environment on the sensor network limits and affects their development. In the scientific literature we can distinguish two broad categories of marine wireless networks depending on the data transmission medium that they use, Under-Water WSNs and the aerial. In general, the submarine is taken as a viable solution only for oceanographic monitoring at great depths; the aerial is being used in shallow waters. Since the study area treated is aimed at monitoring a shallow coastal lagoon, the $\mathrm{PhD}$ focuses on the development of an aerial wireless sensor network for monitoring shallow coastal areas.

Following a study of infrastructure and instrumentation dedicated to the observation of the marine environment, have drawn a series of concepts that are central to the research and implementation done in this $\mathrm{PhD}$. In short, it has carried out the hardware and software design of the devices that form a sensor network, the fabrication of the mechanical structure of a buoy for monitoring shallow water, and finally, implementation of monitoring system that holds and manages the information from the network. The well functioning of the all system has been validated by laboratory tests and deployments made at sea. 



\section{ACRÓNIMOS}

\begin{tabular}{|c|c|}
\hline AGL & Augusto González de Linares \\
\hline ALACE & Autonomous Lagrangian Circulation Explorer \\
\hline APS & APplication Support \\
\hline AUV & Autonomous Underwater Vehicle \\
\hline A-WSN & Aerial-Wireless Sensor Network \\
\hline CR & Carriage Return \\
\hline CTD & Conductivity, Temperature and Depth \\
\hline DSIE & División de Sistemas e Ingeniería Electrónica \\
\hline GOOS & Global Ocean Observing System \\
\hline ICTS & Infraestructura Cientifico Tecnológica Singular \\
\hline LNA & Low Noise Amplifier \\
\hline MAC & Media Access Control \\
\hline MAREAS & Marine Advanced Research center for Environment And Security \\
\hline MARS & Monterey Accelerated Research System \\
\hline MBARI & Monterey Bay Aquarium Research Institute \\
\hline MEWIN & MultiEnviromental Wireless Node \\
\hline MMP & McLane Moored Profiler \\
\hline MVCO & Martha's Vineyard Coastal Observatory \\
\hline NEPTUNE & North-East Pacific Time-series Undersea Networked Experiment \\
\hline NWK & NetWorK \\
\hline OBSEA & OBservatorio Submarino ExpAnsible \\
\hline OO & Oceanografía Operacional \\
\hline OOCMur & Observatorio Oceanográfico Costero de la Región de Murcia \\
\hline PALACE & Profiler Autonomous LAgrangian Circulation Explorer \\
\hline PE & Puertos del Estado \\
\hline PHY & PHYsical \\
\hline $\mathbf{R F}$ & Radio Frequency \\
\hline ROV & Remote Operated Vebicle \\
\hline RTC & Real Time Clock \\
\hline SOBIC & Sistema de Observación Costero de las Islas Baleares \\
\hline SOC & Sistema de Observación Costero \\
\hline SST & Sea Supercial Temperature \\
\hline TI & Texas Instruments \\
\hline UAV & Unmanned Aerial Vebicle \\
\hline UPCT & Universidad Politécnica de Cartagena \\
\hline UW-ASN & UnderW ater-Acoustic Sensor Network \\
\hline VENUS & Victoria Experimental Network Under the Sea \\
\hline VI & Virtual Instrument \\
\hline WHOI & Woods Hole Oceanographic Institute \\
\hline WPAN & Wireless Personal Area Network \\
\hline
\end{tabular}


WSN Wireless Sensor Network

XIOM Xarxa d'Instruments Oceanogräfics i Meteorològics

ZDO Zigbee Device Objects

ZC ZigBee Coordinator

ZED ZigBee End Device

ZR ZigBee Router 


\section{Índice General}

Capítulo 1. Planteamiento y objetivo..........................................................................1

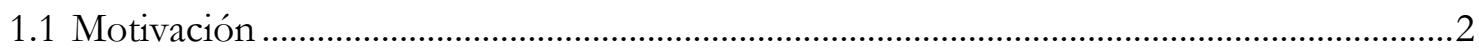

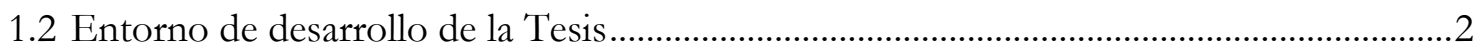

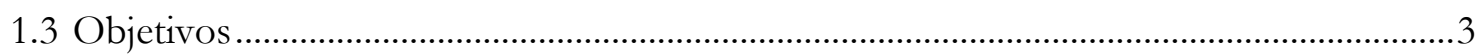

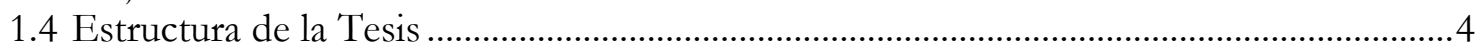

Capítulo 2. Sistemas de observación costeros........................................................ 7

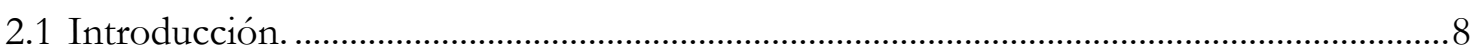

2.2 Sistemas de observación costeros a nivel internacional ................................................... 8

2.2.1 Observatorio oceanográfico "Victoria Experimental Network Under the

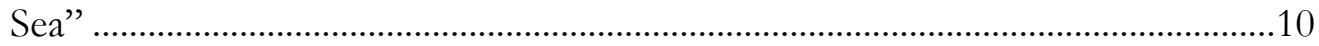

2.2.2 Observatorio oceanográfico de la bahía de Monterey .............................................12

2.2.3 Observatorio oceanográfico de Martha's Vineyard...............................................13

2.2.4 Observatorio oceanográfico "North-East Pacific Time-series Undersea

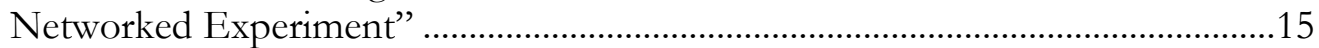

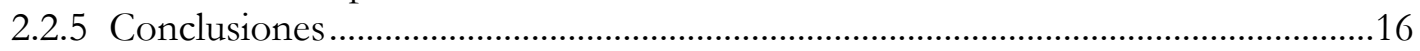

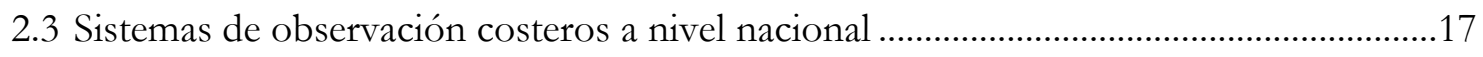

2.3.1 Redes de observación para control y observación marítima. .................................18

2.3.1.1 Puertos del Estado .....................................................................................18

2.3.1.2 Red de instrumentación oceanográfica y meteorológica de la Generalitat de Catalunya ...............................................................................20

2.3.1.3 Estaciones océano-meteorológicas de la Comunidad Autónoma del

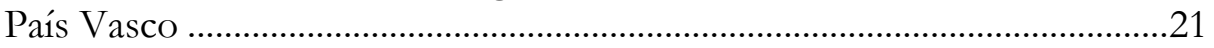

2.3.1.4 Red de vigilancia integral de las aguas de la Comunidad de Cantabria ......21

2.3.1.5 Red experimental de alerta, control y observación marina del Gobierno de Canarias .................................................................................22

2.3.2 Redes de observación para investigación ....................................................................23

2.3.2.1 Observatorio submarino expansible del CSIC.............................................23

2.3.2.2 Boya oceanográfica Augusto González de Linares del Instituto Español de Oceanografía .............................................................................25

2.3.3 Otras grandes infraestructuras científico tecnológicas en el ámbito

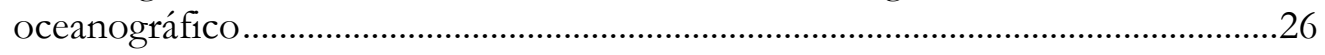

2.3.3.1 Observatorio Oceanográfico Costero de la Región de Murcia ....................26

2.3.3.2 Sistema de Observación Costero de las Islas Baleares ...................................27

2.3.3.3 Sistema de observación costero "Marine Research Facilities for Environment and Security" ............................................................................28

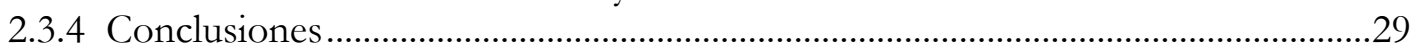

Capítulo 3. Tecnologías aplicadas a los sistemas de observación costeros ...............31

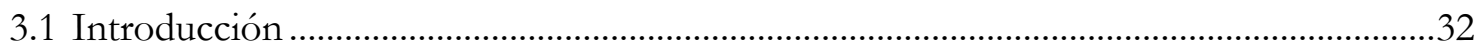

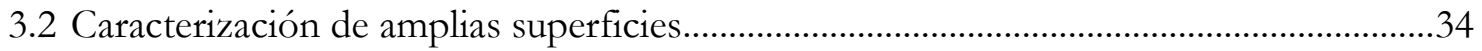

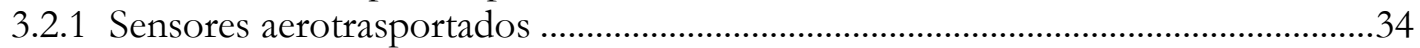

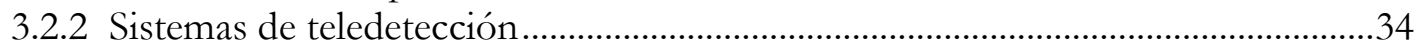

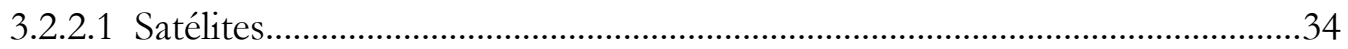

3.2.2.2 Comparación de diferentes sistemas de teledetección....................................35

3.2.2.3 Aplicaciones de los sistemas de teledetección....................................................36

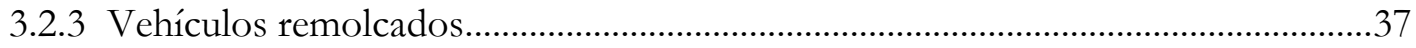

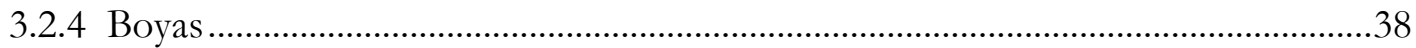


3.2.4.1 Características mecánicas ...............................................................................38

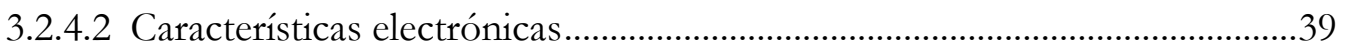

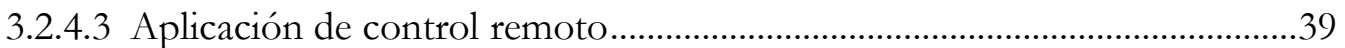

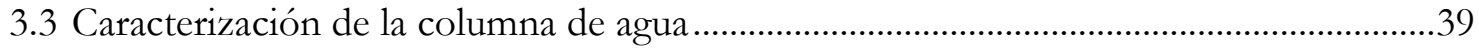

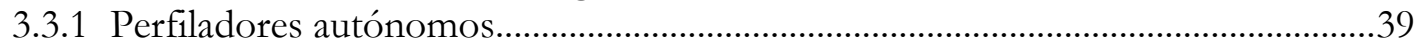

3.3.2 Vehículos autónomos submarinos........................................................................41

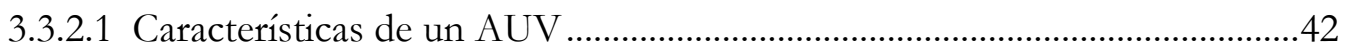

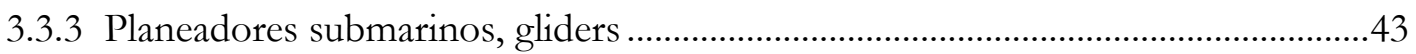

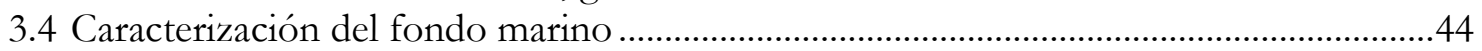

3.4.1 Sistemas de observación de percepción remota ...................................................44

3.4.2 Sistemas de observación mediante instrumentación in situ.................................44

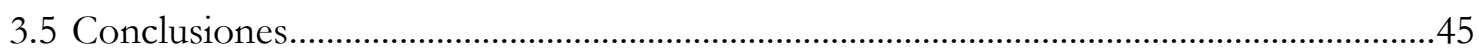

\section{Capítulo 4. Redes de sensores inalámbricas aéreas para observación}

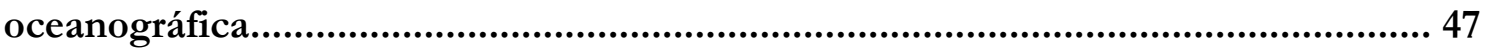

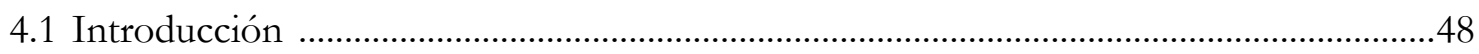

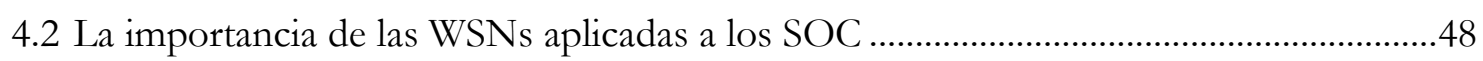

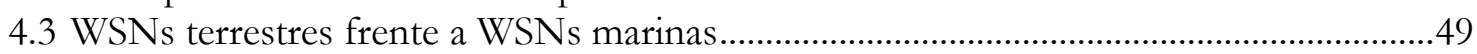

4.4 Redes de sensores inalámbricas submarinas vs. aéreas ........................................................50

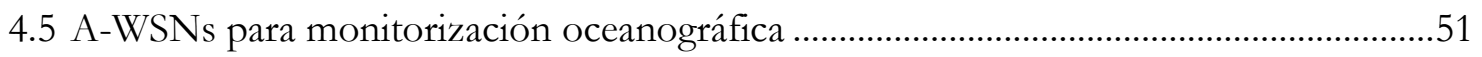

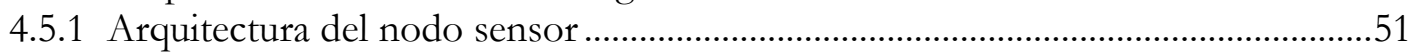

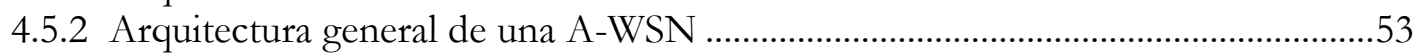

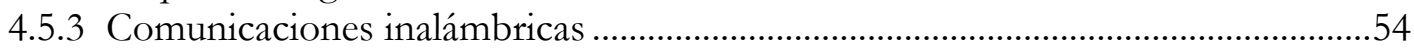

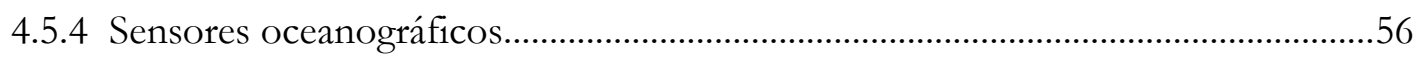

4.5.5 Implementación hardware y software del nodo ……...........................................57

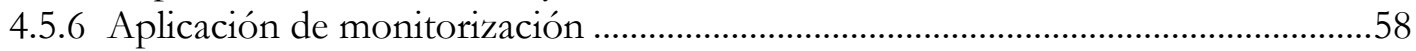

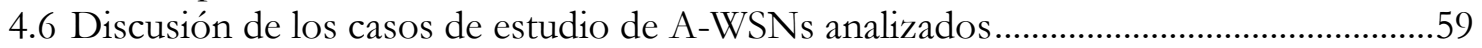

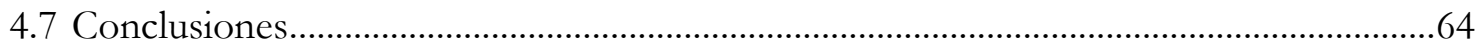

Capítulo 5. Propuesta de una arquitectura de red de sensores inalámbrica aérea ... 67

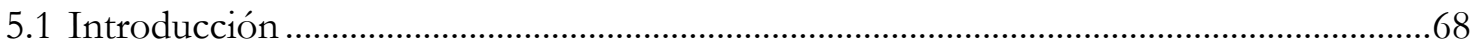

5.2 Propuesta de una arquitectura para una A-WSN en observación costera............................70

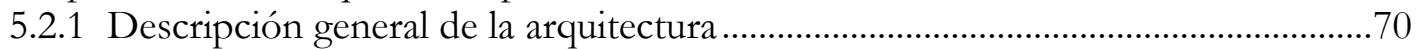

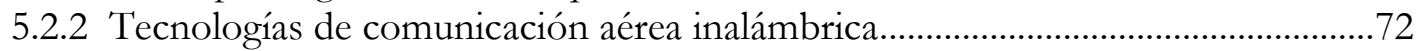

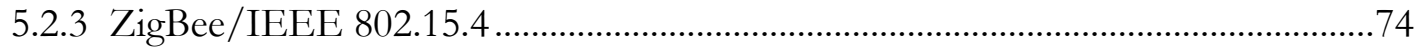

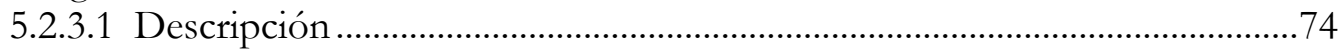

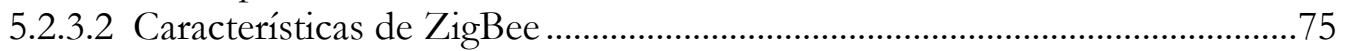

5.2.3.3 Tipos de dispositivos en una red ZigBee........................................................ 75

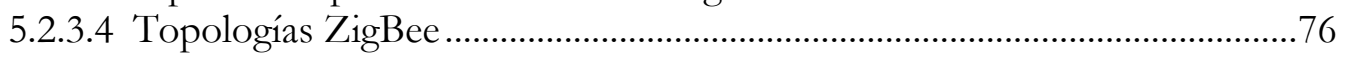

5.2.3.5 Estrategias de conexión de los dispositivos en una red ZigBee....................77

5.2.3.6 Arquitectura de red ..........................................................................................

5.2.4 Descripción funcional de los diferentes componentes..........................................79

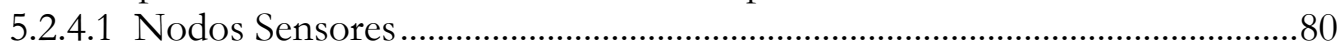

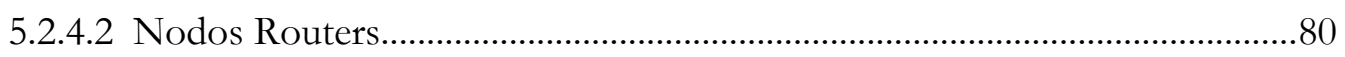

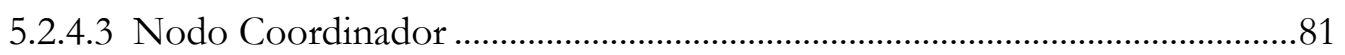

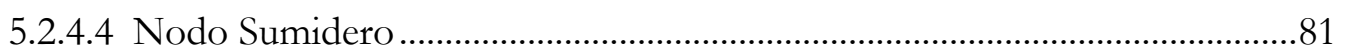

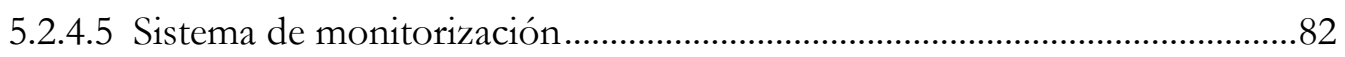

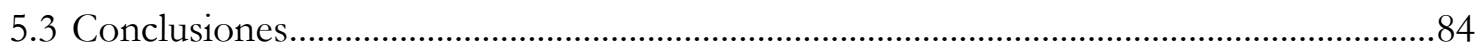


Capítulo 6. Implementación de la arquitectura de red propuesta ........................... 87

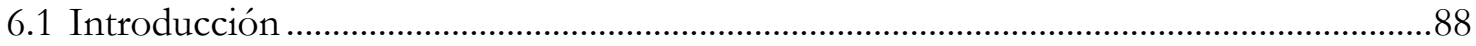

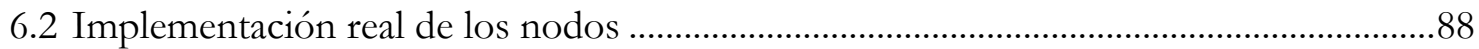

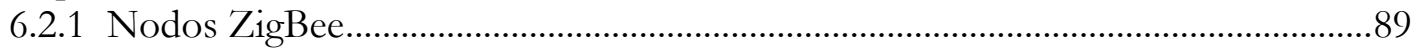

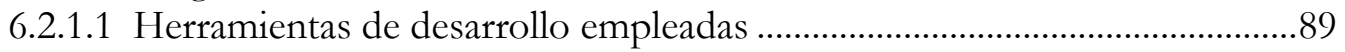

6.2.1.2 Características del nodo ZigBee diseñado ..........................................................90

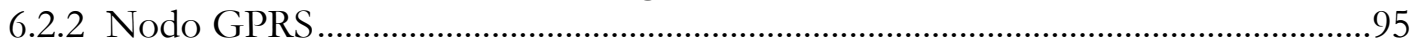

6.2.2.1 Herramientas de desarrollo empleadas ............................................................99

6.2.2.2 Características del nodo GPRS diseñado....................................................96

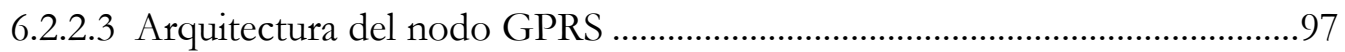

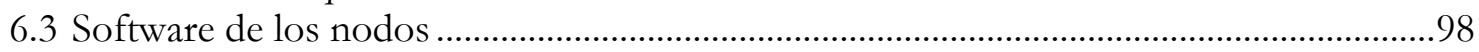

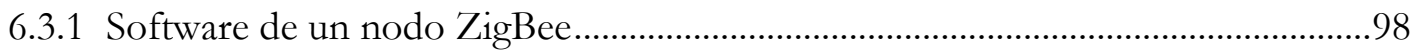

6.3.1.1 IAR Embedded Workbench para MSP430 .....................................................99

6.3.1.2 Elección de un protocolo de comunicación inalámbrica ................................99

6.3.1.3 Modificaciones software de la pila Z-Stack de Texas Instruments........... 101

6.3.1.4 Implementaciones software adicionales..................................................... 102

6.3.1.5 Aplicaciones software de los nodos ............................................................ 102

6.3.2 Software de un nodo GPRS ............................................................................. 109

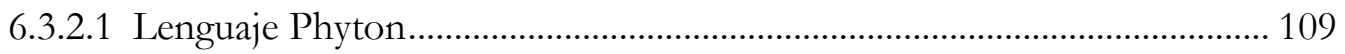

6.3.2.2 Python en el módulo Telit ............................................................................ 110

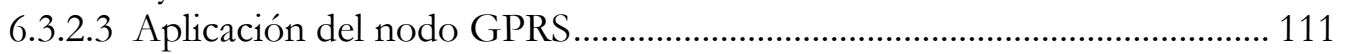

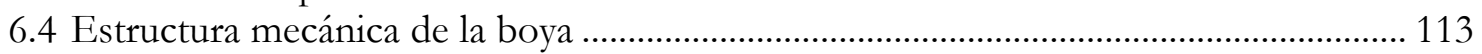

6.5 Diseño de un protocolo para el intercambio de mensajes.............................................. 114

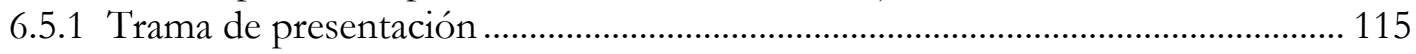

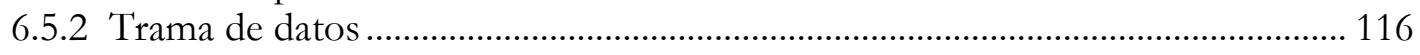

6.6 Aplicación gráfica de usuario del sistema de monitorización.......................................... 117

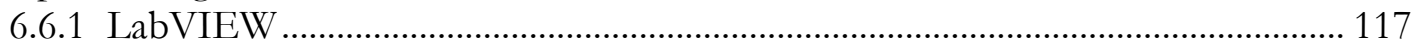

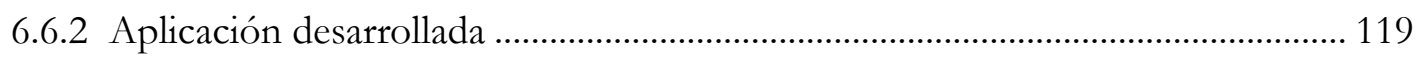

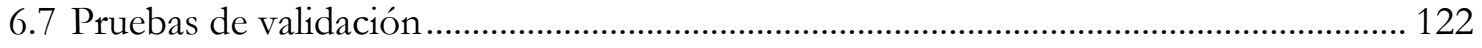

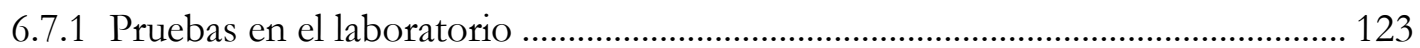

6.7.1.1 Pruebas de la arquitectura de la WSN ......................................................... 123

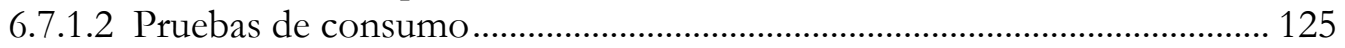

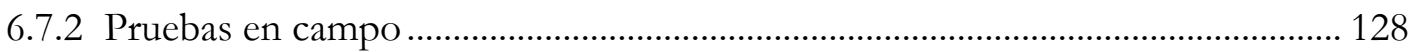

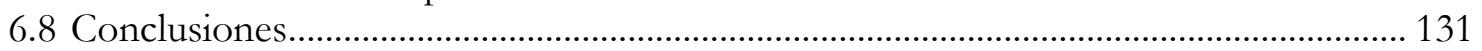

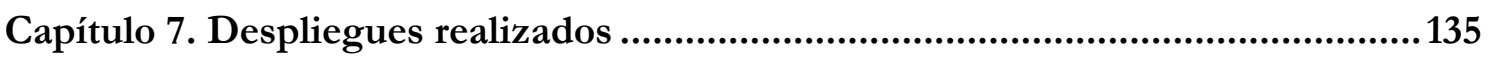

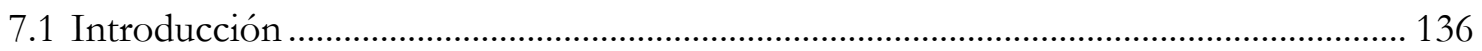

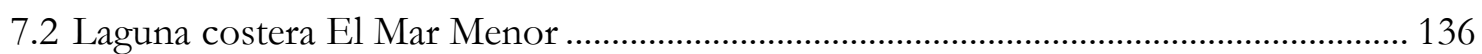

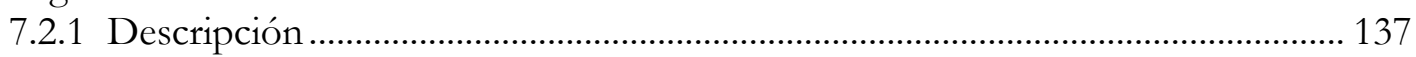

7.2.2 Diseño de una WSN para la monitorización completa del Mar Menor ............ 137

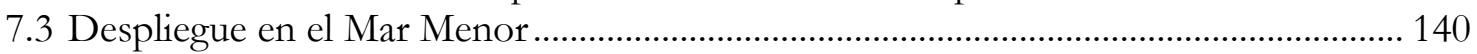

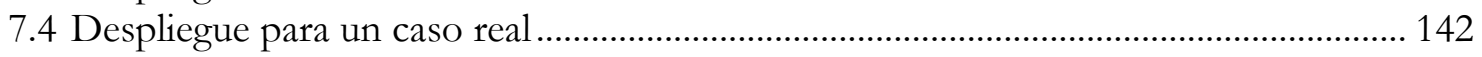

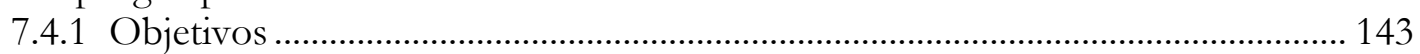

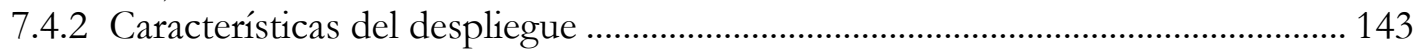

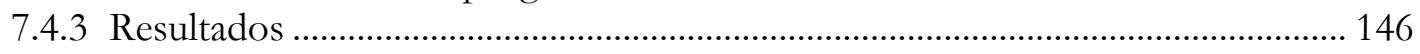

7.5 Planificación de un despliegue en el Mar Menor para la campaña de invierno............. 147

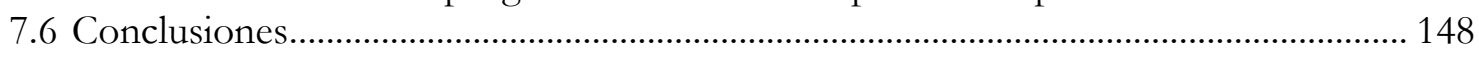

Capítulo 8. Conclusiones, aportaciones y líneas de trabajo futuras ....................... 151

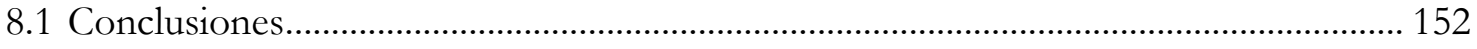




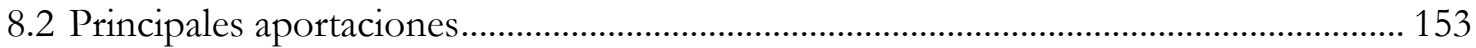

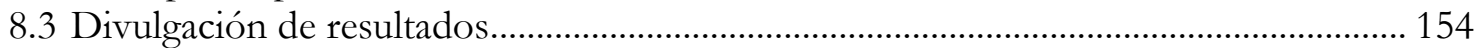

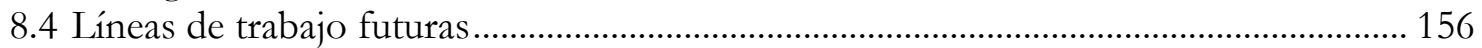

Anexo 1. Configuración de la pila Z-Stack con los módulos CC2520 -

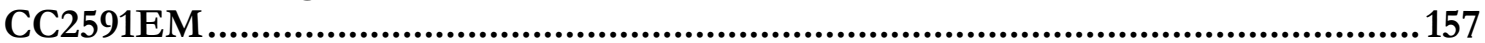

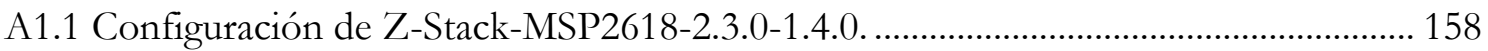

Anexo 2. Modificaciones realizadas en la pila Z-Stack de ZigBee......................... 161

A2.1 Gestión de pérdidas de conexión de los ZED con el nodo padre.................................. 162

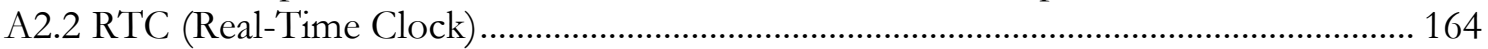

A2.3 Almacenamiento de información en formato FAT.......................................................... 168

Anexo 3. Diagramas de bloques LabVIEW de la interfaz gráfica del sistema de monitorización...............................................................................................169

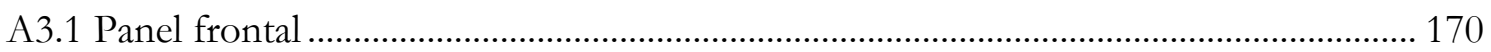

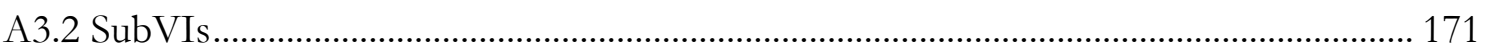

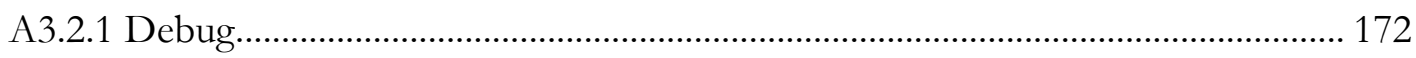

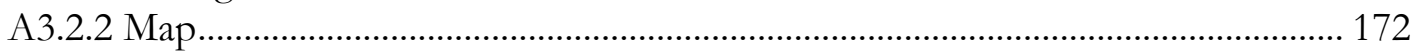

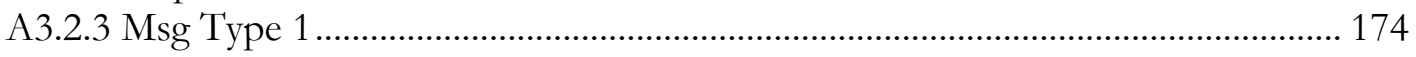

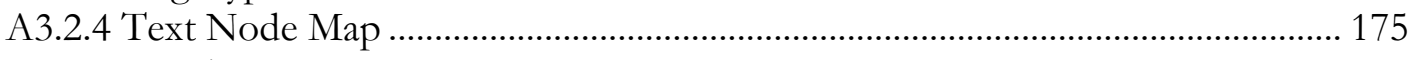

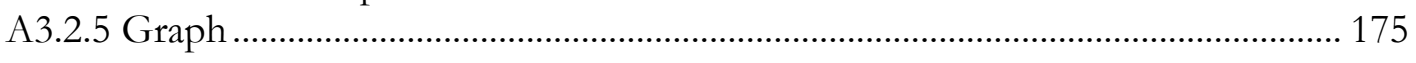

Anexo 4. Estructura mecánica de la boya...........................................................177

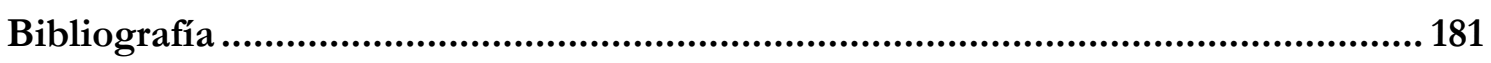




\section{Índice de Figuras}

Figura 2.1

Figura 2.2

Figura 2.3

Figura 2.4

Figura 2.5

Figura 2.6

Figura 2.7

Figura 2.8

Figura 2.9

Figura 2.10

Figura 2.11

Figura 2.12

Figura 2.13

Figura 2.14

Figura 2.15

Figura 2.16

Figura 2.17

Figura 2.18

Figura 2.19

Figura 2.20

Figura 2.21

Figura 2.22

Figura 2.23

Figura 2.24

Figura 2.25

Figura 2.26

Figura 3.1

Figura 3.2

Figura 3.3

Figura 3.4

Figura 3.5

Figura 3.6

Figura 3.7

Figura 3.8

Figura 3.9

Figura 3.10

Figura 3.11

Figura 3.12

Figura 3.13

Figura 4.1

Figura 4.2

Figura 4.3

Figura 4.4

Figura 4.5
SOC

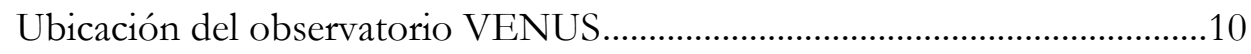

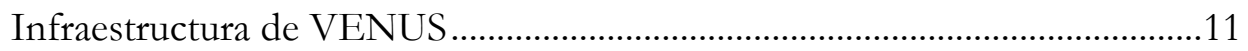

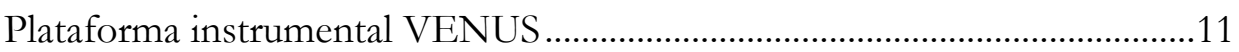

(a) Ubicación geográfica del MBARI. (b) Despliegue del MBARI.................12

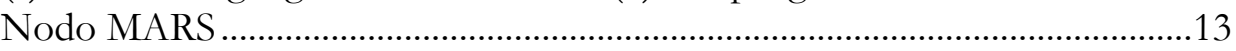

(a) Ubicación geográfica de MVCO. (b) Despliegue del MVCO ....................13

Algunos de los observatorios y de los sistemas costeros de observación

a lo largo del litoral del noreste de EEUU ............................................................14

Componentes de MVCO ........................................................................................14

(a) Ubicación geográfica de NEPTUNE. (b) Despliegue de NEPTUNE ...15

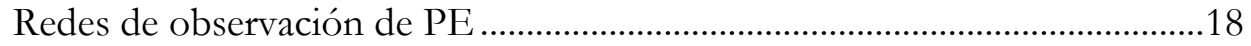

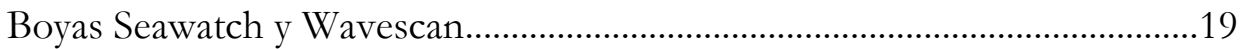

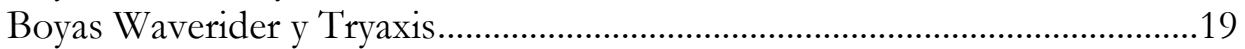

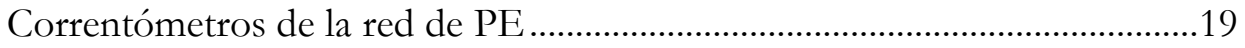

(a) Sistema de boyas del litoral catalán. (b) Boya tipo Waverider ...................20

Red de estaciones océano-meteorológicas en los puertos del País Vasco....21

Esquema de una estación tipo y la torreta meteorológica.................................21

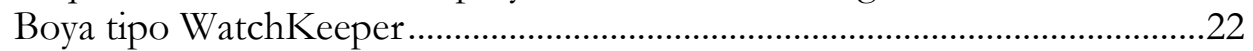

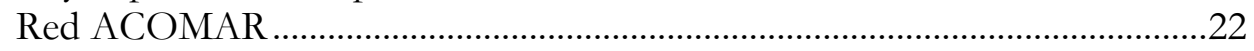

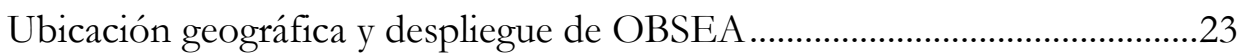

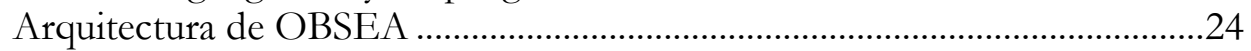

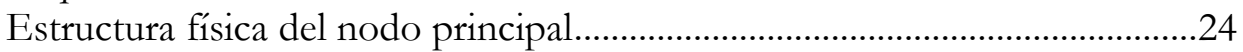

(a) Localización de la boya AGL. (b) Boya AGL fondeada.................................25

Esquema de la boya AGL.............................................................................26

Despliegue de la infraestructura de observación de OOCMur .......................27

Elementos y funcionamiento de SOCIB ........................................................28

Cobertura espacial y temporal de varios sistemas de observación...................32

Componentes de la oceanografía operacional .....................................................33

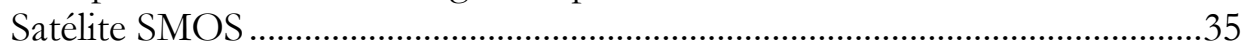

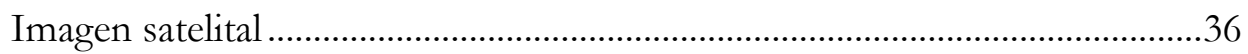

Evolución de la autonomía de vuelo en función de la altura máxima ...........36

Aplicaciones hiperespectrales. (a) Clasificación de los fondos (b) SST.

(c) Detección de mamíferos marinos. (d)-(f) Distribución de

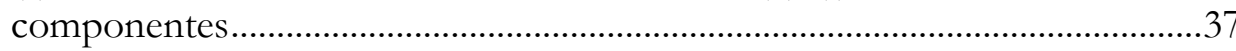

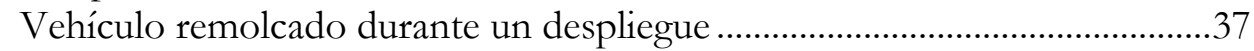

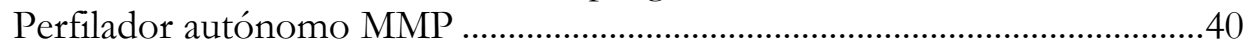

Perfilador autónomo PALACE ........................................................................40

Perfilador autónomo ALACE............................................................................41

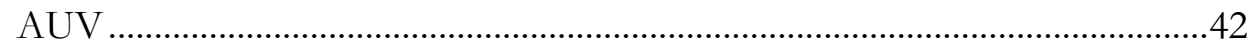

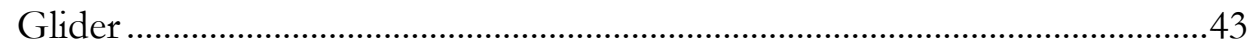

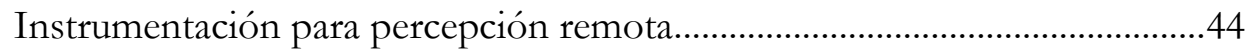

Esquema general de un nodo sensor para oceanografía ................................52

Estructura general de una A-WSN para monitorización oceanográfica........53

Ejemplo de aplicación de usuario de una A-WSN oceanográfica ...................58

Mapamundi con ubicación de los despliegues estudiados ...............................59

Diferentes modelos de boyas encontrados en la literatura. (a) Boya estática con línea de amarre y carcasa flotante. (b) Boya estática con 
línea de amarre y carcasa de fondo. (c) Boya estática. (d) Boya no estática.

Figura 5.1

Figura 5.2

Figura 5.3

Figura 5.4

Figura 5.5

Figura 5.6

Figura 5.7

Figura 5.8

Figura 6.1

Figura 6.2

Figura 6.3

Figura 6.4

Figura 6.5

Figura 6.6

Figura 6.7

Figura 6.8

Figura 6.9

Figura 6.10

Figura 6.11

Figura 6.12

Figura 6.13

Figura 6.14

Figura 6.15

Figura 6.16

Figura 6.17

Figura 6.18

Figura 6.19

Figura 6.20

Figura 6.21

Figura 6.22

Figura 6.23

Figura 6.24

Figura 6.25

Figura 6.26

Figura 6.27

Figura 6.28

Figura 6.29

Figura 7.1

Figura 7.2

Figura 7.3

Figura 7.4

Figura 7.5

Figura 7.6

Figura 7.7

Figura 7.8

Figura 7.9

Figura 7.10

Figura 7.11
Arquitectura propuesta para una A-WSN en observación oceanográfica ....71

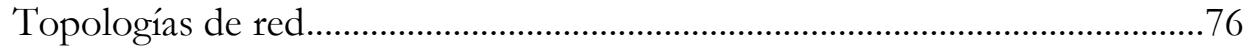

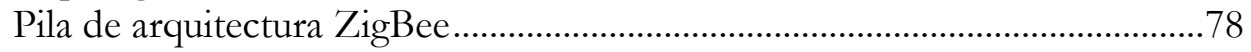

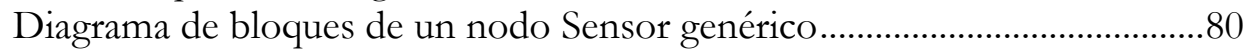

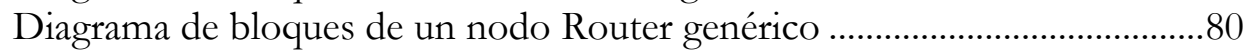

Diagrama de bloques de un nodo Coordinador genérico ..................................81

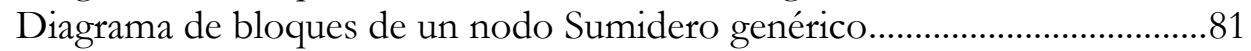

Diagrama de casos de uso del sistema de monitorización ..............................82

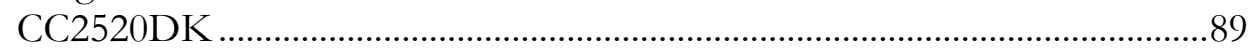

Diagrama de bloques MEWiN Main-Board ………………………….............90

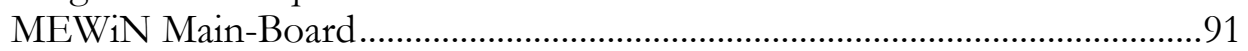

Diagrama de bloques MEWiN Sea-Board ..................................................... 94

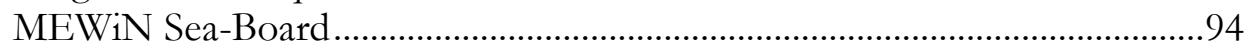

MEWiN Main\&Sea Board............................................................................... 95

Módulo Telit - Starter-Kit STK-AARLOGIC-C01 …....................................96

Diagrama de bloques del nodo GPRS ………..........................................97

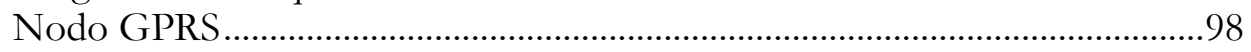

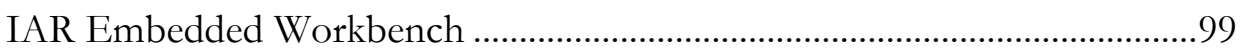

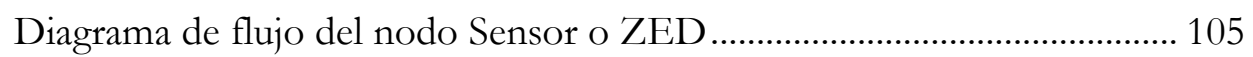

Diagrama de flujo End Device - Programa Principal..................................... 106

Diagrama de flujo End Device - Otras funciones........................................... 107

Diagrama de flujo del nodo Coordinador o ZC................................................ 108

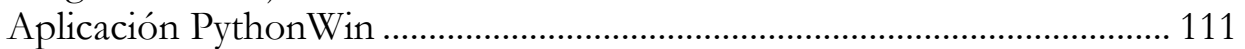

Diagrama de flujo del software del nodo GPRS ............................................. 112

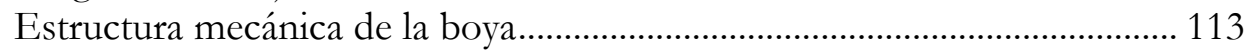

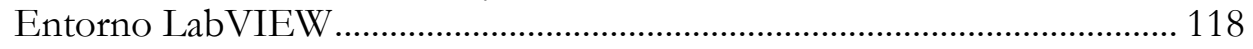

Aplicación gráfica de usuario - "Deployment View".................................... 119

Aplicación gráfica de usuario - "Graph" ..................................................... 120

Aplicación gráfica de usuario - "Debug"........................................................ 121

Aplicación gráfica de usuario - "FTP"........................................................... 122

Arquitectura del sistema para las pruebas en el laboratorio............................ 123

Consumo del nodo Sensor tipo ID1 ......................................................... 126

Consumo del nodo Sensor tipo ID2 .......................................................... 128

Ubicación de las pruebas en el Puerto de Cartagena ...................................... 129

Evolución de la tensión de batería ................................................................... 130

Evolución de la temperatura en el interior de la caja...................................... 130

Pruebas en el Puerto de Cartagena ............................................................... 131

Laguna costera Mar Menor. Canales de comunicación del Mar Menor

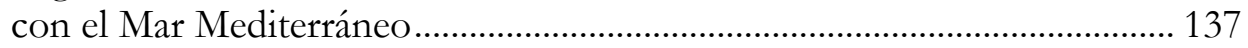

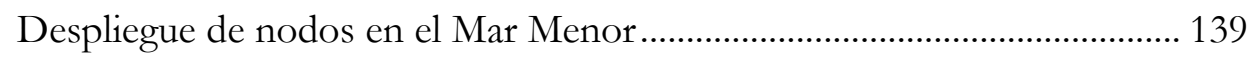

Embarcación utilizada para las pruebas de despliegue .................................... 141

Despliegue de boyas en el Mar Menor............................................................. 142

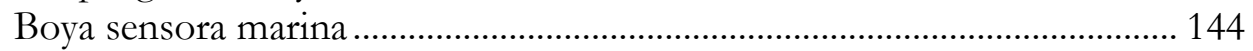

Ubicación geográfica del despliegue en San Pedro del Pinatar.................... 144

Datos de profundidad del mar en la aplicación LabVIEW .......................... 145

Datos de presión atmosférica de la boya en la aplicación LabVIEW ........ 145

Modelado hidrodinámico del comportamiento del Mar Menor frente al

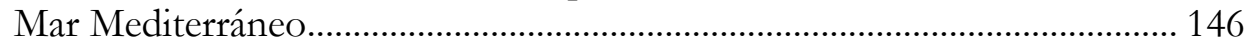

Comportamiento de la pluma hipersalina durante el experimento............. 146

Ubicación geográfica del despliegue planificado .............................................. 147 
Figura 7.12 Arquitectura de una A-WSN con topología en árbol .................................... 147

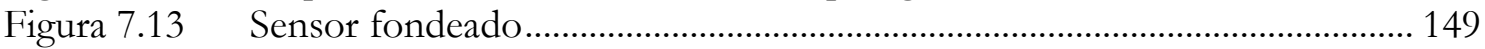

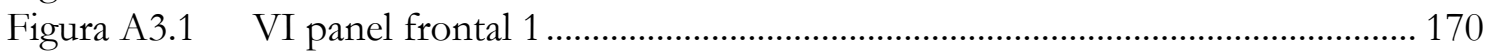

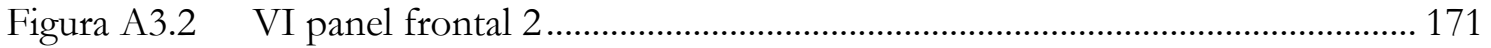

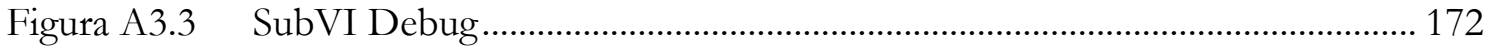

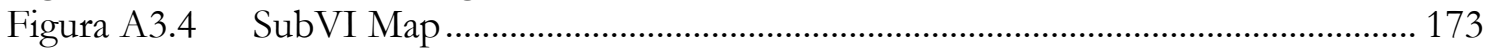

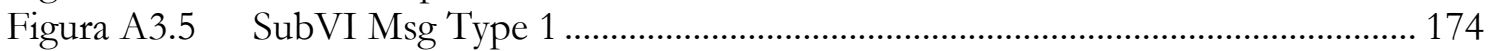

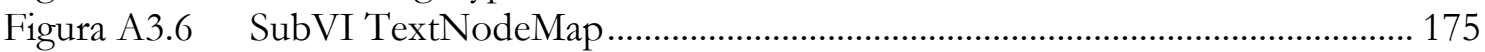

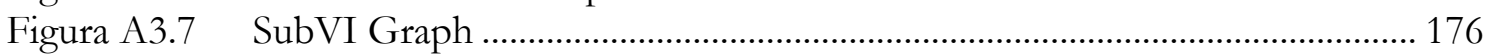




\section{Índice de Tablas}

Tabla 2.1 Algunos ejemplos de SOCs en el ámbito internacional .....................................

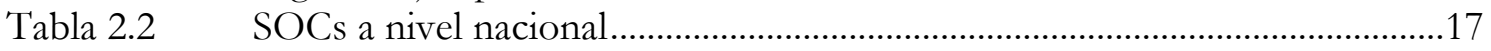

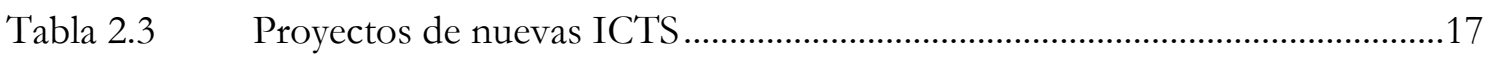

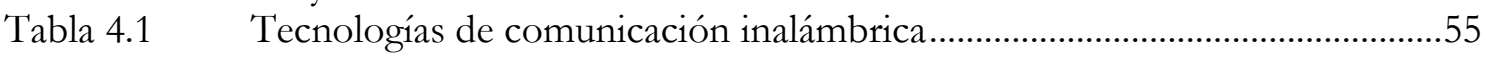

Tabla 4.2 Sensores oceanográficos habituales .....................................................................56

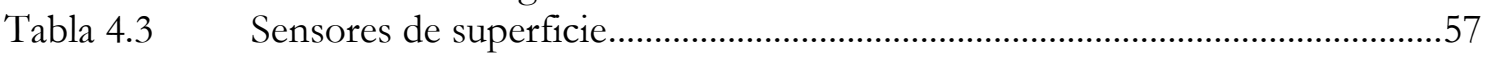

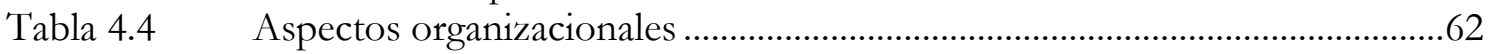

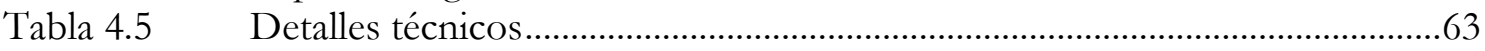

Tabla 5.1 Comparativa de tecnologías inalámbricas............................................................73

Tabla 5.2 Comparativa de las tecnologías inalámbricas GSM y GPRS ...........................74

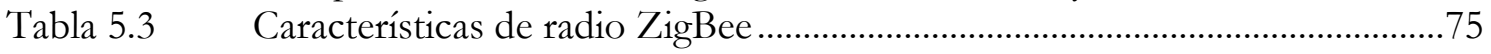

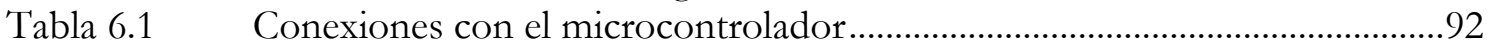

Tabla 6.2 Pines del conector de expansión.........................................................................

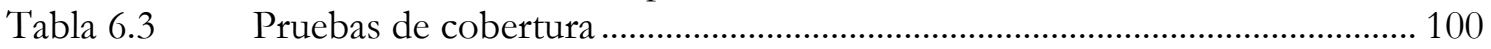

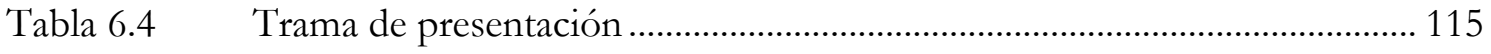

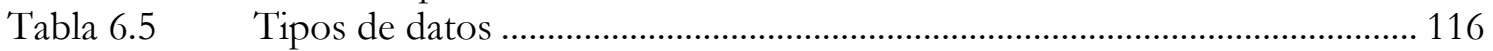

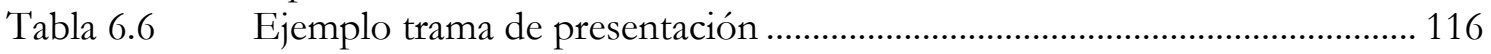

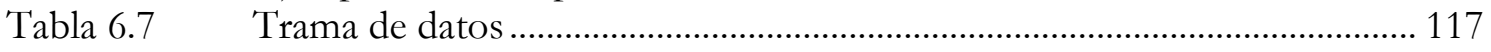

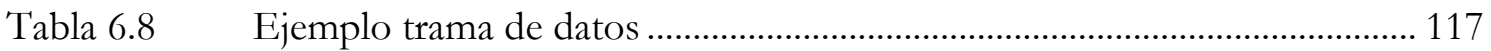

Tabla 6.9 Resumen de los dispositivos usados en las pruebas en el laboratorio......... 124

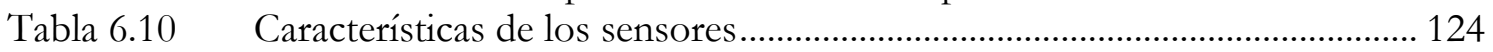

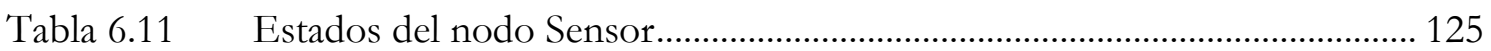

Tabla 7.1 Nodos Sensores para la monitorización completa del Mar Menor ............. 138

Tabla A1.1 Tabla de potencias de transmisión de un nodo ................................................ 159

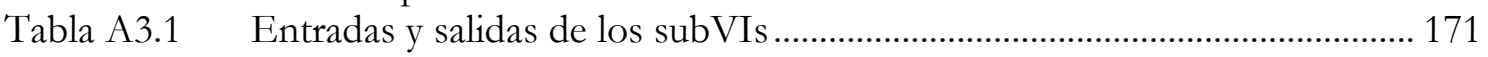




\section{Capítulo 1}

\section{Planteamiento y objetivos}

ste capitulo expone en primer lugar, la motivación que ha llevado al desarrollo de esta Tesis
Doctoral junto con los objetivos que se persiguen. En segundo lugar, se presenta la estructura de la presente memoria, describiendo de manera concisa el contenido. 


\subsection{Motivación.}

La monitorización del medio marino viene siendo un campo de interés científico durante esta última década. Los sistemas marinos costeros son particularmente vulnerables a la influencia de la actividad humana debido principalmente al desarrollo industrial, turístico y urbanístico, y es por ello por lo que estas aguas se convierten en objetivos primordiales en el ámbito de la investigación. La finalidad es analizar el entorno marino costero proporcionando un mayor entendimiento del comportamiento del mar. Así surge la necesidad de crear sistemas de observación oceanográficos, tanto in situ como remotos, que permitan llevar a cabo dicho estudio.

Es habitual encontrar en la literatura gran cantidad de aplicaciones dedicadas a la monitorización del entorno en diversas disciplinas, como por ejemplo la agricultura de precisión [López, 2009] y la medicina [Hande et al., 2006]. En esta Tesis se dedica especial atención a las tecnologías que actualmente se utilizan para la observación del medio acuático. Se utilizan desde redes de sensores a pequeña escala hasta complejos sistemas de observación. Dentro de las redes a pequeña escala, las redes de sensores inalámbricas (Wireless Sensor Network, en adelante WSN) [Akyildiz et al., 2002; Buratti et al., 2009] constituyen una solución muy atractiva por su facilidad de despliegue, operación y repliegue, así como su reducido coste, y están siendo utilizadas recientemente para monitorizar diferentes espacios naturales (lagos [Jaradat et al., 2008], ríos [Kuang et al., 2008] y zonas marinas de extensión reducida [Xiping et al., 2002]). Además, existen sistemas de observación de mayor envergadura que también serán analizados. Finalmente, es en los sistemas basados en WSNs donde se centra la investigación e implementación realizada en la presente Tesis Doctoral.

\subsection{Entorno de desarrollo de la Tesis.}

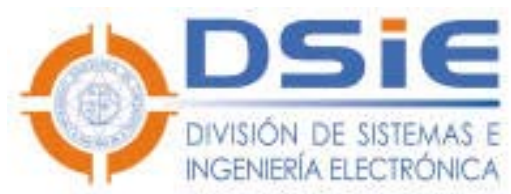

Esta Tesis Doctoral se enmarca dentro de los trabajos realizados por el grupo de investigación "División de Sistemas e Ingeniería Electrónica" (en adelante DSIE) de la Universidad Politécnica de Cartagena (en adelante UPCT).

El DSIE nació en 1999 como grupo de investigación multidisciplinar e integra profesores e investigadores de los Departamentos de Tecnología Electrónica (DTE), Ingeniería de Sistemas y Automática (DISA) y Tecnologías de la Información y las Comunicaciones (TIC) de la UPCT. El DSIE desarrolla su labor de investigación, entre otras, en las siguientes áreas tecnológicas:

- Sistemas de control y robótica para aplicaciones industriales.

- Robots de servicio. 
- Sistemas de inspección visual automatizados.

- Tecnología electrónica para robótica y visión artificial.

- Electrónica de potencia.

- WSNs.

Esta Tesis Doctoral profundiza en el desarrollo e implementación de una WSN para la monitorización de zonas marinas costeras. La línea de trabajo en redes de sensores fue iniciada por los doctores D. Andrés Iborra García, D. Fulgencio Soto Valles y D. Juan Antonio López Riquelme, en cuya tesis [López, 2011] propuso el desarrollo de una WSN centrada en el ámbito de la agricultura de precisión.

Los trabajos que han posibilitado la consecución de esta Tesis se enmarcan en el proyecto "Monitorización Costera para el Mar Menor, CMS (463.01-08_CLUSTER)" del Plan de Ciencia y Tecnología de la Región de Murcia 2007-2010, considerado como un primer paso para implantar el Observatorio Oceanográfico Costero de la Región de Murcia (en adelante OOCMur). El principal objetivo del proyecto CMS es diseñar e implementar una WSN para la monitorización de la laguna costera del Mar Menor y las aguas adyacentes del Mar Mediterráneo.

\subsection{Objetivos.}

El principal objetivo de esta Tesis es diseñar una WSN para la monitorización de un Sistema de Observación Costero (en adelante SOC), centrando el caso de estudio en la laguna costera del Mar Menor situada al sureste de la Península Ibérica, en la Región de Murcia, frente a las aguas próximas adyacentes del Mar Mediterráneo. De forma más específica se pueden concretar los siguientes objetivos parciales:

- Estudiar la infraestructura y las características de los SOCs existentes a nivel mundial, así como las tecnologías aplicadas a dichos sistemas. Este estudio permitirá obtener una visión global de las plataformas tecnológicas utilizadas para la monitorización del medio marino.

- Analizar la importancia de utilizar una WSN aérea (Aerial-WSN, en adelante AWSN) marina frente a una submarina (UnderWater-Acoustic Sensor Network, en adelante UW-ASN) como medio para implementar un SOC. Además, puesto que en la puesta en marcha de una WSN en el ámbito oceanográfico surgen nuevos retos y dificultades frente a una WSN terrestre, es necesario estudiar las características de la zona de estudio para realizar un sistema con las especificaciones adecuadas. 
- Proponer una arquitectura de A-WSN detallando las características y funcionalidad de los diferentes elementos que lo forman, y seleccionando la tecnología de comunicación inalámbrica aérea más adecuada de las existentes en el mercado.

- Implementar la arquitectura de red propuesta, lo que implica la consecución de los siguientes objetivos parciales:

- Análisis de las herramientas de desarrollo software y hardware disponibles para seleccionar las adecuadas como medio de trabajo.

- Desarrollo hardware de los diferentes dispositivos que forman la A-WSN.

- Desarrollo software de las aplicaciones que dotan de funcionalidad a los dispositivos fabricados.

- Estudio de la tecnología de comunicaciones inalámbrica utilizada entre los dispositivos de la A-WSN.

- Diseño de una estructura mecánica que soporte la electrónica desarrollada y que se adecúe a las características del medio en el que se despliega.

- Desarrollo de un sistema de monitorización que albergará toda la información relativa a la A-WSN.

- Por último, y para validar el correcto funcionamiento del sistema completo propuesto, se llevarán a cabo pruebas en el laboratorio y en condiciones reales en el mar.

\subsection{Estructura de la tesis.}

Esta memoria se ha dividido en un total de ocho capítulos. Además, contiene cuatro anexos con información adicional. Para finalizar el presente documento, se recogen las referencias bibliográficas.

A continuación, se presenta la estructura detallada de la Tesis Doctoral junto con un breve resumen de cada capítulo.

\section{Capítulo 1. Planteamiento y objetivos.}

En este capítulo, se ha realizado una breve introducción en la que se presentan la motivación y objetivos perseguidos en el desarrollo de esta Tesis. Asimismo, se ha presentado el marco de trabajo en el cual se encuadra esta investigación. Además, se expone una breve descripción del contenido de cada uno de los capítulos.

\section{Capítulo 2. Sistemas de observación costeros.}

En el segundo capítulo, se expone el estado del arte de los SOCs existentes a nivel mundial. Se profundiza en los SOCs a nivel internacional que se han considerado de especial 
relevancia, a la vez que se obtienen una serie de conclusiones en cuanto a tipos de observatorios y componentes que lo conforman. Del mismo modo, se ha estudiado con más detalle la situación en España. Se ha examinado la totalidad de iniciativas existentes así como las recientes Infraestructuras Científico Tecnológicas Singulares (en adelante ICTS) aprobadas en el ámbito de las Ciencias Marinas, extrayendo un conjunto de conclusiones.

\section{Capítulo 3. Tecnologías aplicadas a los sistemas de observación costeros.}

El tercer capítulo, se dedica a las tecnologías existentes aplicadas a los SOCs. Para la observación y monitorización del medio marino a corto y largo plazo, es necesaria una instrumentación oceanográfica adecuada y construida con los requisitos que el medio marino impone. Existen numerosos instrumentos y plataformas de las cuales se detallarán las comúnmente usadas en la monitorización de las zonas costeras, diferenciando entre la caracterización de la superficie del mar, la columna de agua y el fondo marino.

\section{Capítulo 4. Redes de sensores inalámbricas aéreas para observación oceanográfica.}

En el cuarto capítulo, se presentan las WSNs como un nuevo paradigma para oceanografía y en concreto para la observación oceanográfica en los SOCs. Se analizan las ventajas e inconvenientes de esta tecnología, y se expone el estudio realizado sobre diferentes casos de estudio de monitorización de ecosistemas marinos utilizando A-WSNs.

\section{Capítulo 5. Propuesta de una arquitectura de red de sensores inalámbrica.}

En el quinto capítulo, se expone la necesidad de emplear un sistema basado en A-WSNs para la observación de las aguas costeras. Se detallan las características de los elementos que lo forman y la funcionalidad de los mismos, las tecnologías de comunicación inalámbrica existentes en el mercado, así como las diferentes alternativas para la implementación del sistema de monitorización que gestiona la información.

\section{Capítulo 6. Implementación de la arquitectura de red propuesta.}

En el sexto capítulo, se describe cómo se ha llevado a cabo la implementación de una arquitectura de red basada en A-WSNs para la monitorización costera. Se presenta la implementación real de los nodos que componen la red, la estructura mecánica de la boya que contiene el mote, un protocolo de comunicaciones para el intercambio de mensajes, una aplicación gráfica que muestra al usuario los datos procesados, y finalmente, las pruebas de validación realizadas. 


\section{Capítulo 7. Despliegues realizados.}

En el séptimo capítulo, se exponen los despliegues que se han realizado. En primer lugar, se llevaron a cabo pruebas de despliegue y repliegue en la laguna costera del Mar Menor, con el objetivo de validar la comunicación entre nodos. A continuación, el sistema fue utilizado en un caso real de monitorización marina. Y finalmente, se presentan las características de un despliegue que se realizará en la campaña de invierno, para la monitorización a largo plazo de zonas cercanas a la isla del Ciervo, en el Mar Menor, mediante varias boyas.

\section{Capítulo 8. Conclusiones, aportaciones y líneas de trabajo futuras.}

En el octavo y último capítulo, se hace una recapitulación de los resultados obtenidos en cada uno de los capítulos anteriores. En primer lugar se expondrán de forma resumida las conclusiones obtenidas en esta Tesis Doctoral. Le seguirá un apartado donde serán resaltadas las principales aportaciones que ofrece y los resultados concretos obtenidos durante su realización. Y para finalizar, se indicarán algunas sugerencias para futuros trabajos de investigación relacionados con la materia aquí tratada.

\section{Anexo 1. Configuración de la pila Z-Stack con los módulos CC2520 - CC2591EM.}

En el primer anexo, se detalla la configuración del software utilizado para obtener un mayor alcance de comunicaciones entre los dispositivos de la A-WSN.

\section{Anexo 2. Modificaciones realizadas en la pila Z-Stack de ZigBee.}

El segundo anexo recoge las modificaciones realizadas en el software empleado para una correcta implementación de las aplicaciones de los nodos de una red ZigBee.

Anexo 3. Diagramas de bloques LabVIEW de la interfaz gráfica del sistema de monitorización.

El tercer anexo incluye los diagramas de bloques LabVIEW de los subVIs que se han considerado más relevantes en el desarrollo del Sistema de Monitorización del sistema.

\section{Anexo 4. Planos de la estructura mecánica de la boya.}

En el cuarto y último anexo, se exponen los planos de la estructura mecánica de la boya que se ha diseñado para contener la electrónica diseñada.

\section{Bibliografía.}

Para finalizar el documento, se incluyen las referencias bibliográficas que se han tenido en cuenta en la presente Tesis Doctoral. 


\title{
Capítulo 2
}

\section{Sistemas de observación costeros}

\author{
$\Psi n$ este capitulo, se expone una revisión de la literatura de los SOCs tanto a nivel internacional \\ como a nivel nacional. Dentro del ámbito internacional se describen las iniciativas más relevantes
} a la vez que se obtienen una serie de conclusiones en cuanto a tipos de observatorios y componentes que lo conforman. Del mismo modo se ha estudiado con más detalle la situación en España, examinando la totalidad de iniciativas existentes asi como las recientes ICTS aprobadas en el ámbito de las Ciencias Marinas, extrayendo un conjunto de conclusiones. 


\subsection{Introducción.}

Los SOCs son sistemas de observación oceanográfica cuyo objetivo es llevar a cabo la monitorización de las zonas costeras permitiendo de esta forma investigar, entre otras cosas, el impacto de los océanos en la variabilidad de las costas, el impacto del hombre, la presencia de nutrientes y de otros elementos en las aguas costeras, los ecosistemas, la morfología de las costas y la erosión de las playas.

Un SOC puede incluir múltiples componentes de distinta naturaleza (ver Figura 2.1): boyas de superficie, perfiladores autónomos o gliders, vehículos submarinos autónomos (Autonomous Underwater Vehicles, en adelante AUVs), vehículos operados de forma remota (Remote Operated Vebicles, en adelante ROVs), radares costeros, buques, aviones, vehículos aéreos autónomos (Unmanned Aerial Vehicles, en adelante UAVs) y satélites. Algunos de los cuales serán analizados en capítulos posteriores.

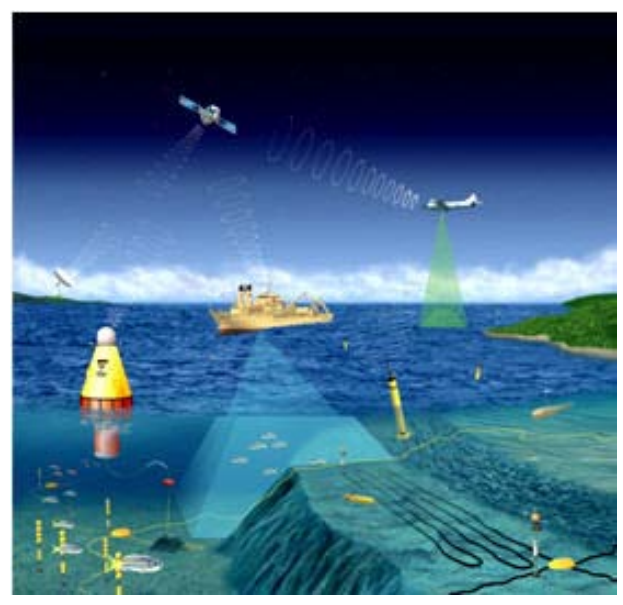

Figura 2.1 SOC.

Actualmente existen distintas plataformas tecnológicas de observación marina geográficamente distribuidas en distintas zonas del planeta [Hart y Martinez, 2006], siendo en el ámbito internacional donde mayor desarrollo y complejidad presentan frente a la situación nacional en la cual se está iniciando el desarrollo de dichas tecnologías. Aún así, todas ellas comparten un denominador común: son infraestructuras basadas en sistemas de observación in situ, complementados por sistemas de observación telemétricos y métodos de procesamiento que incluyen sofisticados modelos numéricos.

\subsection{Sistemas de observación costeros a nivel internacional.}

Existen distintos observatorios y redes de muestreo a nivel internacional aunque su nivel de complejidad y objetivos es muy dispar (ver Tabla 2.1). Así, mientras que el nivel de desarrollo alcanzado en EEUU [Fletcher et al., 2009; Pettigrew y Neville, 2008], Canadá [Dewey et al., 2007] y Japón [Fujiwara et al., 1998] es bastante elevado, y los observatorios son capaces de abordar problemas multidisciplinares mediante sistemas de adquisición de datos y análisis más elaborados, las plataformas observacionales europeas se encuentran aún en fase de desarrollo y están dedicadas a objetivos más sectoriales (clima marítimo y biología). En Francia, los puntos de observación están agregados en una red nacional que 
se implementa de forma relativamente paralela a lo largo de distintos puntos de la costa mediterránea [OOV; OOB] y atlántica [IFREMER].

Tabla 2.1 Algunos ejemplos de SOCs en el ámbito internacional.

\begin{tabular}{|c|c|c|c|}
\hline País & Acrónimo & Observatorio & WEB \\
\hline Australia & IMOS & Integrated Marine Observing System & http://imos.org.au/ \\
\hline China & PEIOS & $\begin{array}{l}\text { Pearl River Estuary Integrated Observation } \\
\text { System }\end{array}$ & http://envf.ust.hk/cis \\
\hline Canadá & VENUS & $\begin{array}{l}\text { Victoria Experimental Network Under the } \\
\text { Sea }\end{array}$ & http://www.venus.uvic.ca \\
\hline EEUU & COOL & Coastal Ocean Observation Lab & http://rucool.marine.rutgers.edu/ \\
\hline EEUU & DFRF & Duck Field Research Facility & http://www.frf.usace.army.mil/ \\
\hline EEUU & GoMoOS & Gulf of Marine Ocean Observing System & http://www.gomoos.org/ \\
\hline EEUU & LEO-15 & Long-term Ecosystem Observatory & $\begin{array}{l}\text { http://marine.rutgers.edu/mrs/LE } \\
\text { O/LEO15.html }\end{array}$ \\
\hline EEUU & MARS & Monterey Accelerated Research System & http://www.mbari.org/mars/ \\
\hline EEUU & MOOS & Monterey Ocean Observing System & http://www.mbari.org/muse/ \\
\hline EEUU & MVCO & Martha's Vineyard Coastal Observatory & $\begin{array}{l}\text { http://mvcodata.whoi.edu/cgi- } \\
\text { bin/mvco/mvco.cgi }\end{array}$ \\
\hline EEUU & NEPTUNE & $\begin{array}{l}\text { North East Pacific Time-series Undersea } \\
\text { Networked Experiment }\end{array}$ & $\begin{array}{l}\text { http://www.neptune.washington. } \\
\text { edu }\end{array}$ \\
\hline EEUU & Orcoos & Oregon Coastal Ocean Observing System & http://www.orcoos.org/ \\
\hline EEUU & RcoOs & $\begin{array}{l}\text { Carolinas Regional Coastal Ocean } \\
\text { Observing System }\end{array}$ & http://carolinasrcoos.org/ \\
\hline EEUU & SEACOOS & $\begin{array}{l}\text { Southeast Atlantic Coastal Ocean Observing } \\
\text { System }\end{array}$ & http://seacoos.org/ \\
\hline EEUU & SDCOOS & San Diego Coastal Ocean Observing System & $\begin{array}{l}\text { http://www.sdcoos.ucsd.edu/inde } \\
\text { x.php }\end{array}$ \\
\hline Francia & IFREMER & Institut National de Recherches Marines & http://www.ifremer.fr/ \\
\hline Francia & OOV & $\begin{array}{l}\text { Observatoire Océanologique de Villefranche } \\
\text { sur mer }\end{array}$ & http://www.obs-vlfr.fr \\
\hline Francia & OOB & Observatoire Océanologique de Banyuls & http://www.obs-banyuls.fr/ \\
\hline Alemania & MARNET & $\begin{array}{l}\text { Marine Environmental Monitoring Network } \\
\text { in the North Sea and Baltic Sea }\end{array}$ & http://www.bsh.de \\
\hline Grecia & POSEIDON & POSEIDON system & http://www.poseidon.ncmr.gr \\
\hline Israel & MedGLOOS & $\begin{array}{l}\text { Systematic Sea Level Measurements in the } \\
\text { Mediterranean and Black Sea }\end{array}$ & http://medgloss.ocean.org.il/ \\
\hline Japón & JAMSTEC & $\begin{array}{l}\text { Japan Agency for Marine-Earth Science and } \\
\text { Technology }\end{array}$ & http://www.jamstec.go.jp/ \\
\hline $\begin{array}{l}\text { Reino } \\
\text { Unido }\end{array}$ & $\mathrm{CCO}$ & Channel Coastal Observatory & http://www.channelcoast.org \\
\hline $\begin{array}{l}\text { Reino } \\
\text { Unido }\end{array}$ & LBCO & Liverpool Bay Coastal Observatory & http://cobs.pol.ac.uk/ \\
\hline
\end{tabular}


Cabe destacar que en la actualidad, las distintas redes de observación, fruto de la cooperación internacional, tienden a converger y coordinarse en un sistema global de monitorización del océano. El programa Global Ocean Observing System (en adelante GOOS) [Malone y Cole, 2000; Malone et al., 2003] está compuesto por dos módulos interdependientes y convergentes, uno global para todo el océano y otro regional para las zonas costeras y estuáricas. La función principal del módulo global es monitorizar y predecir el clima marítimo y su relación con los cambios atmosféricos. El objetivo del módulo regional es más amplio y complejo, ya que se encarga de facilitar los datos e información necesaria para predecir los efectos del cambio climático, las amenazas de catástrofes naturales y los efectos antropogénicos sobre la salud, el estado de los ecosistemas marinos y los recursos marinos. Esto implica la toma de una gran cantidad de datos físicos, químicos y biológicos, estando mucha de la tecnología necesaria para ello aún en fase de desarrollo.

Los problemas en la implementación del módulo regional son responsables de grandes diferencias entre los diferentes sistemas regionales que conforma GOOS. Programas como MedGOOS [MedGOOS], destinado al desarrollo de la oceanografía operacional en el Mediterráneo, aun están en una fase muy temprana de desarrollo, y otros como Integrated Ocean Observing System (IOOS) [Willis, 2008], centrado en la zona estadounidense, se han desarrollado de forma espectacular.

A continuación, a modo de ejemplos, se describen algunos de los observatorios de la Tabla 2.1 que se han considerado más relevantes.

\subsubsection{Observatorio oceanográfico "Victoria Experimental Network Under the Sea".}

El observatorio oceanográfico cableado Victoria Experimental Network Under the Sea (en adelante VENUS) [Dewey et al., 2007] es una de las primeras generaciones de plataformas de observación del océano. Está formado por dos partes independientes localizadas en aguas costeras del sur de British Columbia en Canadá (ver Figura 2.2).

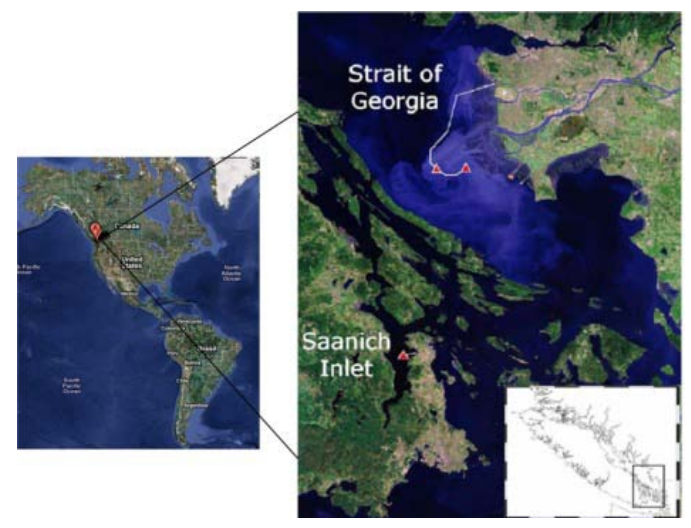

Figura 2.2 Ubicación del observatorio VENUS. 
La primera está en Saanich Inlet con un nodo a $96 \mathrm{~m}$ de profundidad cerca de la entrada de la bahía Patricia. La segunda parte está ubicada en el estrecho de Georgia, con dos nodos en el suroeste del río Fraser, un nodo a una profundidad de $300 \mathrm{~m}$ y otro nodo a $170 \mathrm{~m}$.

La infraestructura del observatorio cableado VENUS se muestra en la Figura 2.3.

La infraestructura permanente constituye el núcleo del observatorio y está formada por los componentes necesarios para suministrar energía y comunicaciones a los instrumentos y sensores. Los servidores de la estación terrena aseguran la conexión entre los nodos e instrumentación marina mediante fibra óptica, y el exterior del despliegue a través de Internet. Cada nodo consiste en dos partes, la parte inferior permanente del nodo conectado al cable submarino principal, y una parte desmontable que contiene la alimentación, el hardware de comunicaciones y los sistemas de monitorización y distribución.

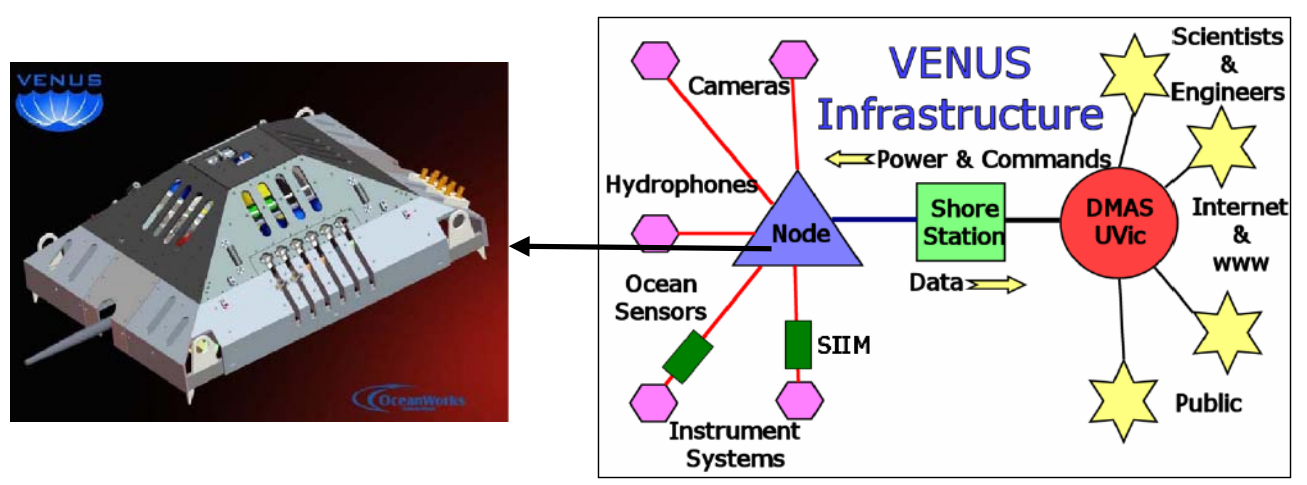

Figura 2.3 Infraestructura de VENUS.

El observatorio ha sido diseñado para soportar un amplio rango de sistemas sensores y de instrumentos desarrollados específicamente para observatorios cableados. Debido a la profundidad de los dos nodos, todas las operaciones de observación son dirigidas usando ROVs, siendo el diseño de los instrumentos crítico para asegurar un fácil despliegue, la conexión a un nodo remoto y la recuperación del nodo. Además, cuenta con una estructura de soporte y protección para la instrumentación oceanográfica como la mostrada en la Figura 2.4 .
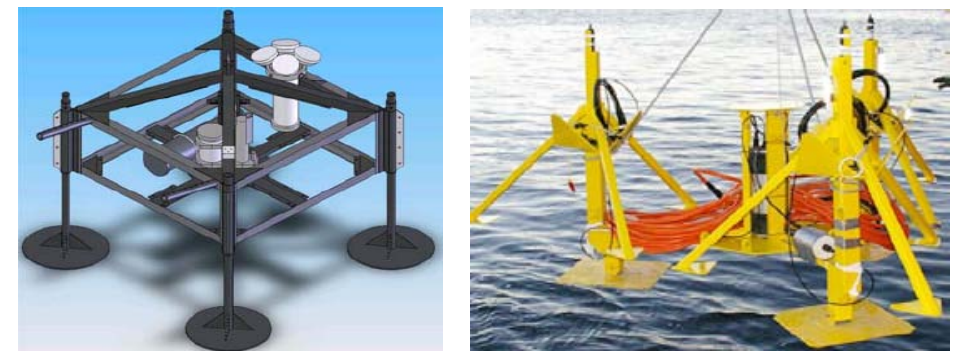

Figura 2.4 Plataforma instrumental VENUS. 
La adquisición, el almacenamiento, la recuperación y el envío de datos son dirigidos por el sistema de archivos DMAS (Data Management and Archive System). La estación terrena está conectada a un sistema de base de datos central ubicado en la Universidad de Victoria mediante una conexión ISP (Internet Service Provider). Además, la estación terrena incorpora un sistema de detección de eventos y respuesta ante éstos, de forma que el usuario recibirá una notificación mediante correo electrónico si se produce alguna anomalía.

\subsubsection{Observatorio oceanográfico de la bahía de Monterey.}

El observatorio de aguas profundas del Monterey Bay Aquarium Research Institute (en adelante MBARI), en California, es el primer sistema cableado del mundo en aguas profundas. El nodo principal MARS (Monterey Accelerated Research System) se encuentra situado a $900 \mathrm{~m}$ de profundidad y conectado a tierra por un cable de $52 \mathrm{~km}$ (ver Figura 2.5) [MARS, 2009], a través del cual se proporciona la alimentación al sistema y la comunicación con los diferentes instrumentos que puede incorporar dicho nodo.

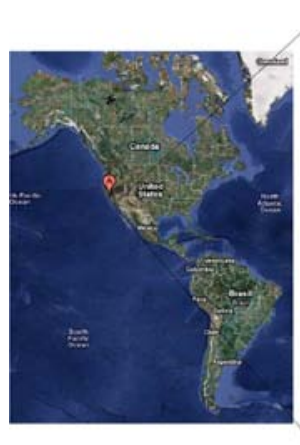

(a)

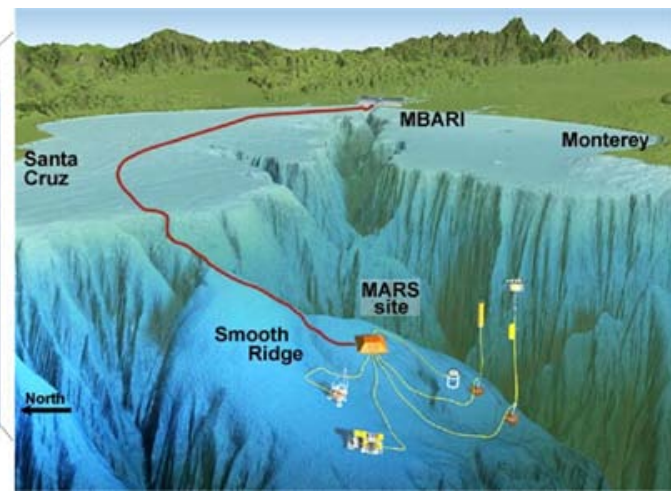

(b)

Figura 2.5 (a) Ubicación geográfica del MBARI. (b) Despliegue del MBARI.

El nodo MARS está formado por dos partes: (1) una gran estructura piramidal de láminas de acero con una base de 3,7 por 4,6 m de ancho y 1,2 $\mathrm{m}$ de altura resistente a movimientos marinos y a la pesca de arrastre, y (2) la electrónica para controlar la alimentación de los instrumentos y el enrutamiento de datos, la cual está encapsulada en carcasas cilíndricas de titanio y ubicadas dentro de dicha estructura (ver Figura 2.6).

La alimentación proporcionada al nodo mediante el cable submarino directamente al nodo MARS es de $10.000 \mathrm{~V}$. Este elevado voltaje minimiza las pérdidas de potencia que tendrán lugar debido a la gran longitud de dicho cable. Además, son necesarios convertidores encargados de transformar los $10.000 \mathrm{~V}$ en 375 y $48 \mathrm{~V}_{\mathrm{DC}}$.

En cuanto al sistema de intercambio de información entre el nodo y el centro de datos, a través de cada uno de los 8 puertos que tiene el nodo se puede enviar información con una tasa de hasta 100 Mbps. Además, desde el centro de datos se pueden enviar comandos al nodo para reprogramar o resetear sus instrumentos. 


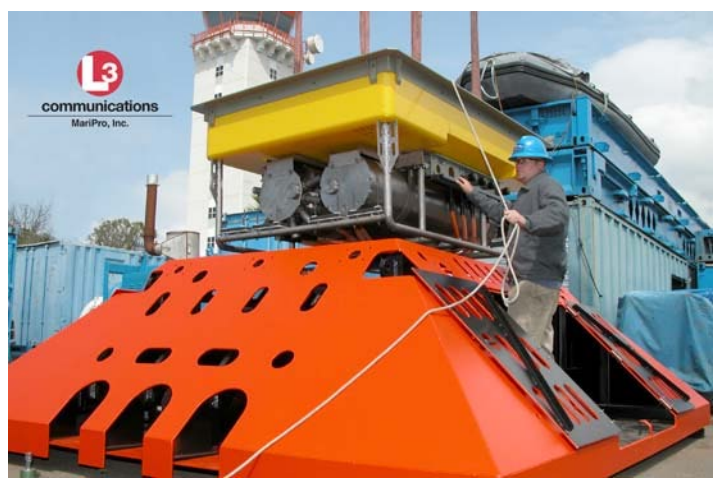

Figura 2.6 Nodo MARS.

Este proyecto lleva activo desde noviembre de 2008 y es usado en varios proyectos como FOCE [FOCE] u ORCA's Eye-in-the-Sea [ORCA]. El primero estudia cómo afecta la acidificación del mar por el incremento de dióxido de carbono a los animales marinos. El segundo consiste en una cámara subacuática con una tenue luz roja que permite la grabación de animales abisales en su medio natural.

\subsubsection{Observatorio oceanográfico de Martha's Vineyard.}

El Martha's Vineyard Coastal Observatory (en adelante MVCO) [Austin et al., 2002] está situado a lo largo de la costa meridional de Martha's Vineyard en EEUU (ver Figura 2.7). Esta línea de la costa está caracterizada por $25 \mathrm{~km}$ de largo en la que, junto con otros observatorios que se encuentran a lo largo del litoral del este (ver Figura 2.8), permiten investigar procesos costeros ya que proporcionan una exposición ideal para los vientos predominantes del suroeste y las tormentas costeras severas durante los meses del invierno.

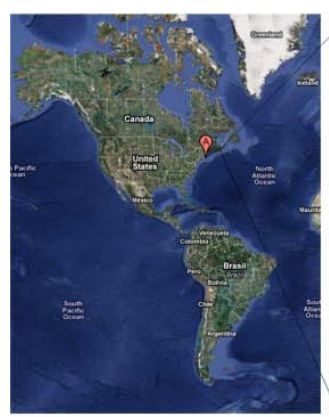

(a)

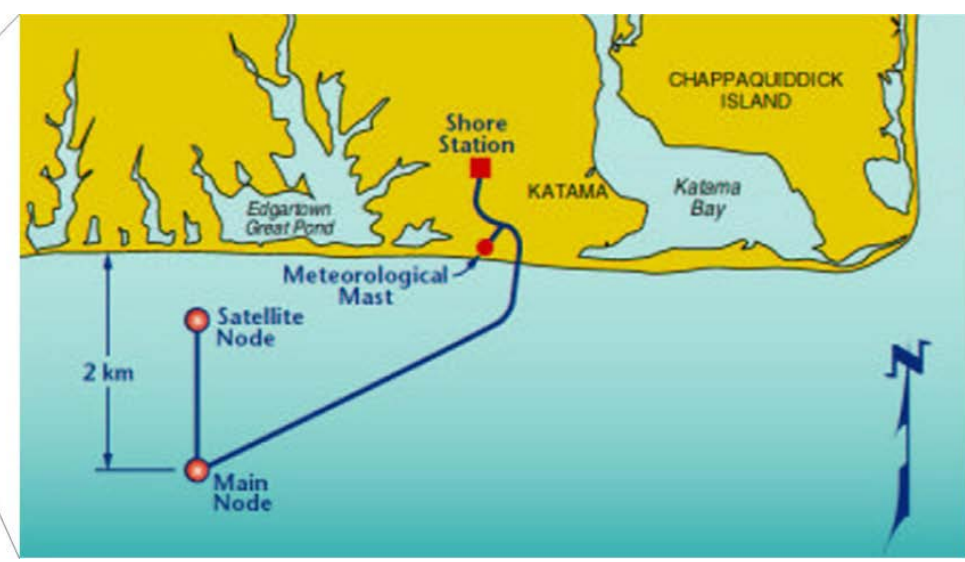

(b)

Figura 2.7 (a) Ubicación geográfica de MVCO. (b) Despliegue del MVCO.

El MVCO constituye una de las plataformas tecnológicas de observación marina más sofisticadas ya que sus recursos de observación incluyen satélites, aviones, barcos oceanográficos, anclajes con cableado submarino y torres de observación meteorológica. 
Está destinada al estudio de la variabilidad fitoplanctónica en aguas muy próximas a la costa y poco profundas.

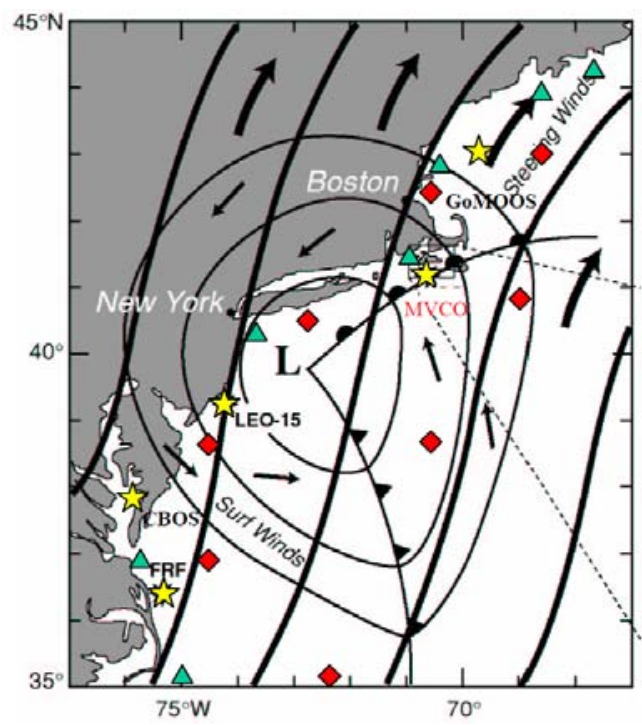

Figura 2.8 Algunos de los observatorios y de los sistemas costeros de observación a lo latgo del litoral del noreste de EEUU.

Este observatorio está formado por un nodo principal submarino (Offshore Node en la Figura 2.9) situado aproximadamente a $2 \mathrm{~km}$ de la costa y a $12 \mathrm{~m}$ de profundidad en el mar, y está conectado con la estación base mediante un cable submarino. El nodo servirá como un punto de conexión para los numerosos instrumentos científicos usados para el control del medio ambiente del ecosistema costero.

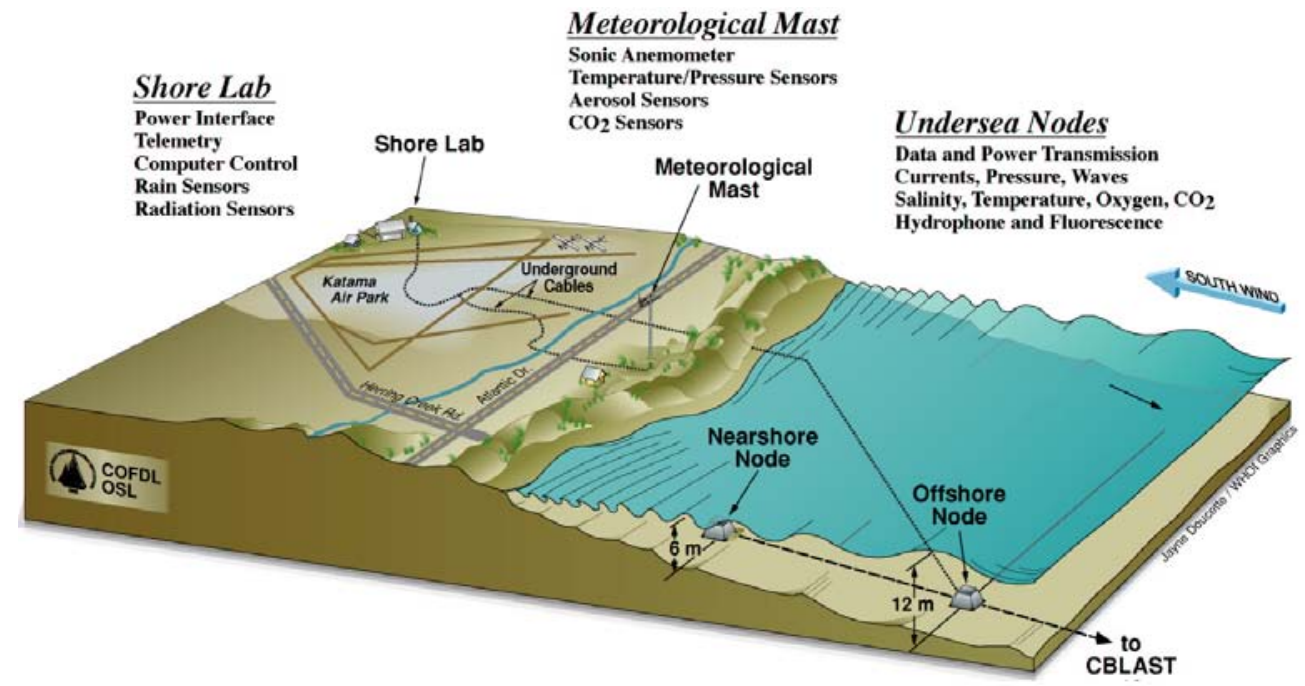

Figura 2.9 Componentes de MVCO.

Un segundo nodo Nearshore Node está instalado cerca de la playa a una profundidad de aproximadamente $6 \mathrm{~m}$. Además de los nodos del fondo del mar, hay un mástil que contiene una estación de sensores meteorológicos para supervisar las condiciones atmosféricas del lugar. 
La estación terrena Shore Lab contiene los sistemas informáticos y las fuentes de alimentación necesarias para controlar los sensores y los datos registrados localmente. Además, el laboratorio incluye un generador de energía de reserva automática para continuar la operación del sistema completo durante interrupciones de energía.

\subsubsection{Observatorio oceanográfico "North-East Pacific Time- series Undersea Networked Experiment".}

Un equipo formado por la Universidad de Washington, el Woods Hole Oceanographic Institute (en adelante WHOI), el MBARI, el JPL (Jet Propulsion Laboratory) y el IPOST (Institute for Pacific Ocean Science and Technology) de Canadá desarrollaron conjuntamente el North-East Pacific Time-series Undersea Networked Experiment (en adelante NEPTUNE), [Barnes et al., 2007]. NEPTUNE es un observatorio oceanográfico regional cableado ubicado en el estrecho de Juan de Fuca (ver Figura 2.10) que abarca aproximadamente unos $3.000 \mathrm{~km}$ y dispone de gran cantidad de instrumentos científicos en el fondo del mar y boyas para la observación de las columnas de agua, vehículos autónomos y operados remotamente. Está formado por 30 nodos distribuidos en el rango abarcado. La mayoría del cableado forma un bucle cerrado en torno a dos estaciones bases emplazadas en Nedonna Beach (Oregon) y Victoria (British Columbia). La zona de estudio de NEPTUNE incluye los principales tipos de límites oceánicos incluyendo la zona de Cascadian.

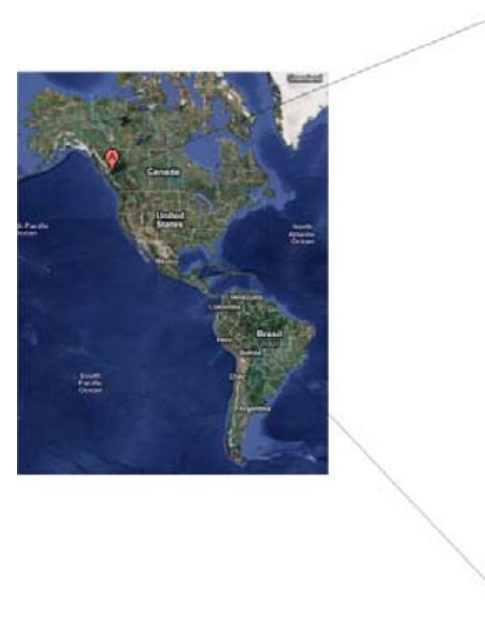

(a)

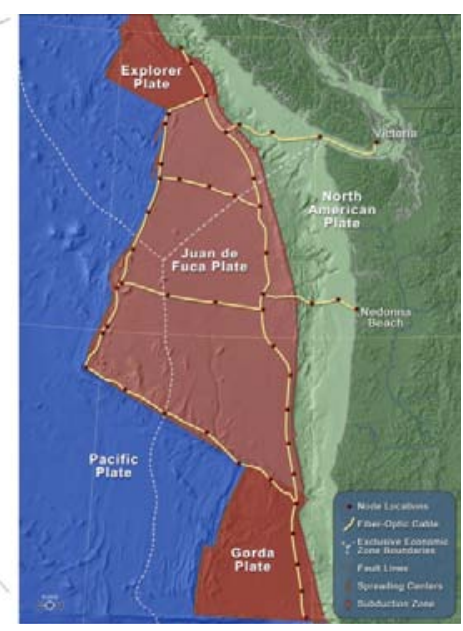

(b)

Figura 2.10 (a) Ubicación geográfica de NEPTUNE. (b) Despliegue de NEPTUNE.

NEPTUNE usa el estándar de comunicaciones de fibra óptica para proporcionar una infraestructura de comunicación y alimentación al sistema. El usuario del sistema puede acceder a cualquiera de los instrumentos a través de Internet ya que cada instrumento está identificado con su dirección IP. 
En 2007 la infraestructura asociada a NEPTUNE fue renombrada por Regional Scale Nodes lo que significaba la integración en la Ocean Observatories Initiative (OOI), [OOI]. E1 nombre NEPTUNE ahora únicamente es usado para actividades de educación y ciencia centradas regionalmente que aprovecharán la alta potencia y el ancho de banda del observatorio cableado regional.

\subsubsection{Conclusiones.}

En relación con los SOCs a nivel internacional, se puede decir a modo de resumen, que existen dos tipos de observatorios, los basados en infraestructuras de comunicaciones cableadas (por ejemplo VENUS [Dewey et al., 2007], LEO-15 [Forrester et al., 1997], MARS [MARS 2009], MVCO [Austin et al., 2002] y NEPTUNE [Barnes et al., 2007]), y los basados en comunicaciones inalámbricas (por ejemplo comunicación acústica y satélite Orbcomm en LBCO [Howarth et al., 2006] y la red de boyas de RCOOS [Fletcher et al., 2009]), siendo las cableadas más notables en EEUU. En general, todos ellos están formados por componentes comunes en sistemas de este tipo. Dichos componentes son los nodos, que incorporan sensores oceanográficos o instrumentación marina ubicados en el mar, y una estación base en la que confluye el sistema completo.

Realizando una comparativa entre los sistemas cableados e inalámbricos, una de las principales ventajas de los primeros frente a un sistema autónomo, es el gran suministro de energía que se puede aportar al sistema junto con un mayor ancho de banda de comunicaciones [Tunnicliffe et al., 2008]. Por el contrario, los sistemas cableados conllevan un elevado coste. Es por ello por lo que surgen las WSNs. El objetivo de los sistemas de monitorización basados en comunicaciones inalámbricas es minimizar los costes de infraestructuras cumpliendo con el objetivo final, monitorizar el medio marino. En ocasiones, donde la profundidad del mar es demasiado elevada aun en zonas costeras, no se considera viable la instalación de un sistema cableado, siendo por tanto las WSNs una buena solución.

Los sistemas presentados en este apartado tienen un objetivo similar al planteado en esta Tesis Doctoral, la monitorización de zonas costeras. La complejidad de las infraestructuras de estos sistemas, en ocasiones, viene impuesta por las características de las zonas que se desean monitorizar. En el caso de estudio de esta Tesis, detallado más adelante, se presenta como zona de estudio una laguna costera de aguas someras. Para monitorizar dicha laguna se ha diseñado un sistema basado en comunicaciones inalámbricas, formado por diferentes dispositivos autónomos y de bajo coste. 


\subsection{Sistemas de observación costeros a nivel nacional.}

Los SOCs en España están en pleno desarrollo tanto tecnológico como logístico encontrándose en un estado mucho más embrionario que los vistos en apartados anteriores. El SOC más desarrollado en este momento pertenece a Puertos del Estado (en adelante PE). Esto se debe a que dicho organismo se encarga de la seguridad portuaria y marítima de la que dependen gran cantidad de empresas nacionales e internacionales. Además de esta institución estatal, existen otras que cuentan con gran cantidad de instrumentación oceanográfica dedicadas principalmente a tareas de control y observación marítima dependiendo de diferentes administraciones. Otras con menor presupuesto están dedicadas a investigación. Todas ellas se recogen en la Tabla 2.2.

También se estudian las iniciativas que han sido recientemente arrancadas como ICTS [Red ICTS; ICTS 2010] y que son SOCs (ver Tabla 2.3).

Tabla 2.2 SOCs a nivel nacional.

\begin{tabular}{llll}
\hline Localización & Acrónimo & \multicolumn{1}{c}{ Observatorio } & Web \\
\hline España & PE & Puertos del Estado & http://www.puertos.es \\
\hline Cataluña & XIOM & $\begin{array}{l}\text { Red de instrumentación oceanográfica } \\
\text { y meteorológica de la Generalitat de } \\
\text { Catalunya }\end{array}$ & http://www.boiescat.org/ \\
\hline $\begin{array}{llll}\text { País Vasco } \\
\text { Cantabria }\end{array}$ & AZTI & $\begin{array}{l}\text { Estaciones océano-meteorológicas de } \\
\text { AZTI }\end{array}$ & $\begin{array}{l}\text { http://www.azti.es/aanderaa } \\
\text { /experiencia.htm }\end{array}$ \\
\hline $\begin{array}{l}\text { Islas } \\
\text { Canarias }\end{array}$ & ACOMAR & $\begin{array}{l}\text { Red de Vigilancia Integral de las Aguas } \\
\text { observación marina }\end{array}$ & http://www.redvigia.es/ \\
\hline $\begin{array}{l}\text { Vilanova i } \\
\text { la Geltrú }\end{array}$ & OBSEA & $\begin{array}{l}\text { Observatorio Submarino Expansible } \\
\text { http://www.rcngc.com/boya }\end{array}$ & http://www.obsea.es/ \\
\hline $\begin{array}{l}\text { Golfo de } \\
\text { Vizcaya }\end{array}$ & AGL & $\begin{array}{l}\text { Oceanografía): Boya oceanográfica } \\
\text { Augusto González de Linares }\end{array}$ & $\begin{array}{l}\text { http://www.boya- } \\
\text { agl.st.ieo.es }\end{array}$ \\
\hline
\end{tabular}

Tabla 2.3 Proyectos de nuevas ICTS.

\begin{tabular}{llll}
\hline Localización & Acrónimo & \multicolumn{1}{c}{ ICTS } & Web \\
\hline Murcia & OOCMur & $\begin{array}{l}\text { Observatorio Oceanográfico } \\
\text { Costero de la Región de Murcia }\end{array}$ & http://www.oocmur.es/oocmur.html \\
\hline $\begin{array}{l}\text { Islas } \\
\text { Baleares }\end{array}$ & SOCIB & $\begin{array}{l}\text { Sistema de Observación Costero } \\
\text { de las Islas Baleares }\end{array}$ & http://oceanbit.org/content/ \\
\hline Asturias & MAREAS & $\begin{array}{l}\text { Sistema de Observación Costero } \\
\text { MAREAS }\end{array}$ & $\begin{array}{l}\text { http://www.redictsmarinas.ieo.es/re } \\
\text { dICTS/ictsRed.html?id=33\&tipo=red }\end{array}$ \\
\hline
\end{tabular}




\subsubsection{Redes de observación para control y observación marítima.}

\subsubsection{Puertos del Estado.}

PE es una institución dependiente del Ministerio de Fomento que tiene la responsabilidad global sobre el sistema portuario dependiente del Estado, [Duarte, 2006; Benjamin et al., 2008]. Comprende un total de 28 Autoridades Portuarias (ver Figura 2.11) y es la encargada de coordinar dicho sistema, así como de implementar la política del gobierno en materia portuaria. Uno de sus papeles fundamentales es el mantenimiento de las redes de observación del medio físico que afecta al sistema portuario. Esta labor es realizada por parte del área del medio físico, y tiene tres ámbitos fundamentales de actividad: redes de observación, sistemas de predicción y bases de datos.

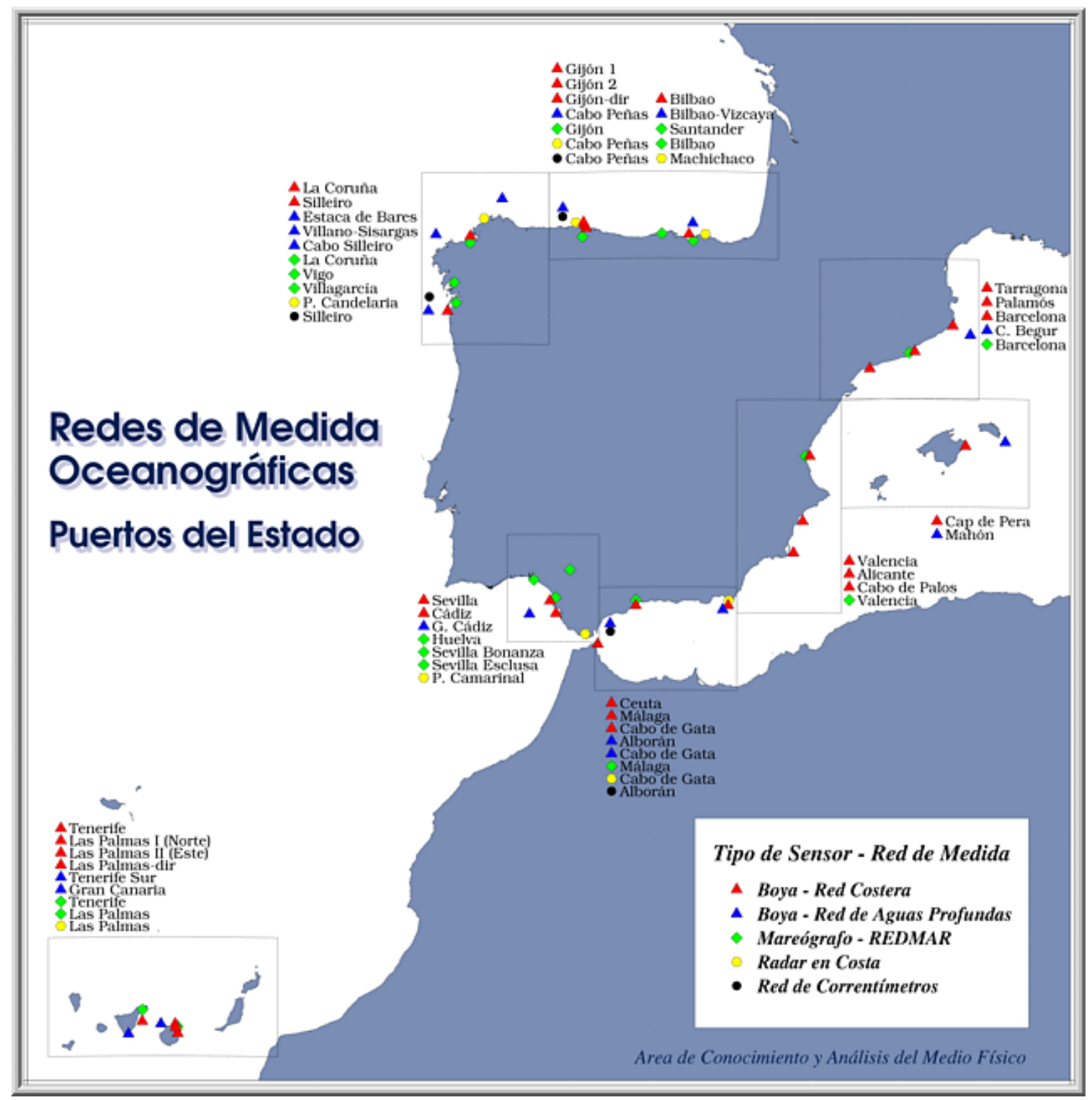

Figura 2.11 Redes de observación de PE. Fuente [PE] 


\subsection{Redes de observación.}

1) La red de aguas profundas está formada por 13 boyas Seawatch y 3 Wavescan como las de la Figura 2.12. Los instrumentos están ubicados a profundidades entre 200 y $800 \mathrm{~m}$ y miden parámetros oceanográficos y meteorológicos. Los datos son transmitidos vía satélite y se envían a la web donde pueden ser visualizados por los usuarios.

2) La red costera de PE proporciona datos de oleaje en tiempo real en aguas poco profundas. Su objetivo es complementar las medidas de la red exterior en lugares de especial interés para las actividades portuarias o la validación de modelos de oleaje. Consta de boyas escalares Waverider y de boyas direccionales Tryaxis (ver Figura 2.13).

3) El objetivo de la red de correntímetros es obtener medidas oceanográficas (corrientes, temperatura y salinidad del mar) que, al igual que en la red costera, complementen y ayuden a interpretar las obtenidas por las boyas de la red exterior. Está formada por cadenas de correntímetros, como el de la Figura 2.14, que se ubican a profundidades predefinidas.

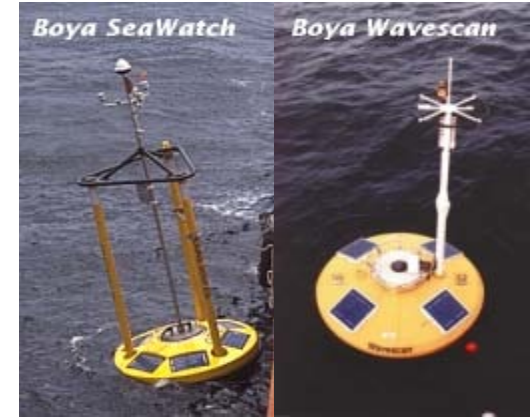

Figura 2.12 Boyas Seawatch y Wavescan.
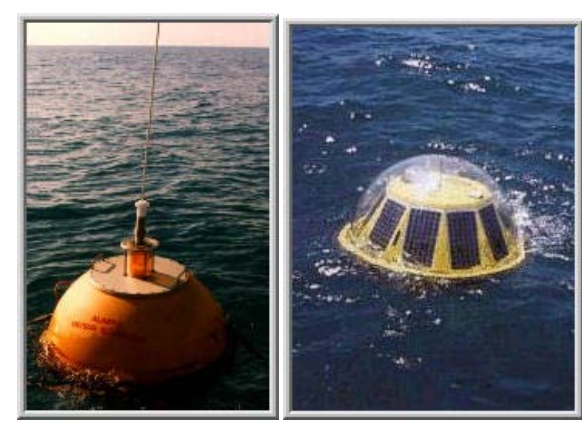

Figura 2.13 Boyas Waverider y Tryaxis.

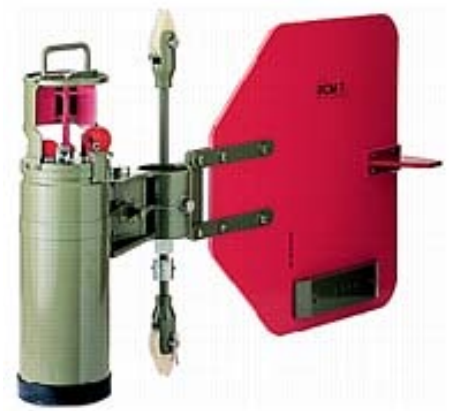

Figura 2.14 Correntímetro de la red de PE.

4) La red de meteorología portuaria REMPOR consta actualmente de 30 estaciones meteorológicas instaladas en 21 Autoridades Portuarias. Todas ellas disponen de sensores de viento, presión, temperatura, humedad relativa y precipitación.

5) La red de mareógrafos REDMAR tiene como objetivo la monitorización del nivel del mar en tiempo real y la generación de series históricas para su posterior explotación. En la actualidad está constituida por 15 mareógrafos acústicos SONAR y 7 mareógrafos de presión AANDERAA.

6) La tecnología radar de alta frecuencia permite la monitorización remota de corrientes y oleaje en un área con rango entre centenas y miles de kilómetros cuadrados.

\subsection{Sistemas de predicción.}

Las aplicaciones de los sistemas de predicción permiten obtener la agitación en el interior del puerto, mientras que las aplicaciones en playas, además del oleaje, generan información relativa a nivel, corrientes en la playa y características de las zonas de rompientes. 


\subsection{Bases de datos.}

El banco de datos de PE almacena todos los datos generados tanto en la red de observación como los datos de los sistemas de predicción. Asimismo incluye varias bases de datos numéricos de retroanálisis siendo éstas accesibles on-line.

\subsubsection{Red de instrumentación oceanográfica y meteorológica de la Generalitat de Catalunya.}

La red de instrumentación oceanográfica y meteorológica de la Generalitat de Catalunya (Xarxa d' Instruments Oceanogräfics i Meteorologics, en adelante XIOM) [XIOM] está compuesta por un conjunto de equipos de medida de las variables costeras más significativas mediante diferentes tipos de boyas Waverider, una estación meteorológica en Deltebre y mareógrafos en L’Ampolla y Carles de la Rápita (ver Figura 2.15). Este organismo cuenta con seis boyas propias situadas en diversos puntos de la costa catalana (Golfo de Rosas, Blanes, Badalona, Llobregat, Vilanova i la Geltrú y Cabo de Tortosa) que proporcionan información sobre el oleaje, periodo de altura y onda, velocidad y dirección de corrientes y altura del nivel del mar. La red es complementaria a la de PE, que dispone de boyas en las bocanas de los Puertos de Barcelona, Tarragona y Palamós, así como boyas exteriores frente a Tarragona y al Cabo de Begur, [Duarte, 2006].

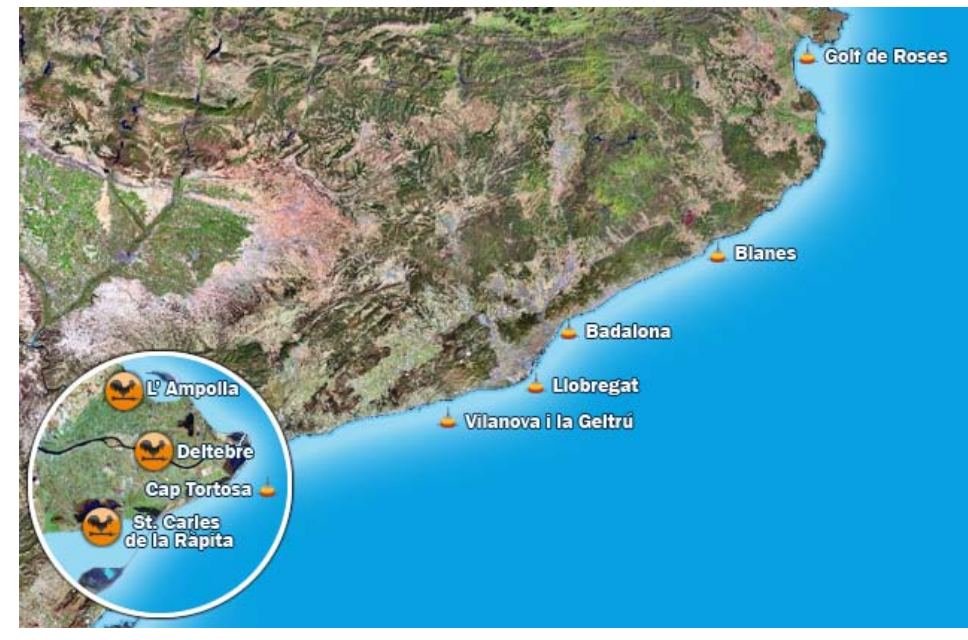

(a)

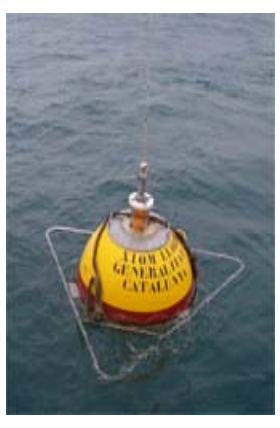

(b)

Figura 2.15 (a) Sistema de boyas del litoral catalán. (b) Boya tipo Waverider.

La XIOM se dedica a la elaboración de un conjunto de datos oceanográficos y al mantenimiento de los instrumentos de medida, y es PE y el laboratorio de ingeniería marítima de la Universidad Politécnica de Cataluña (UPC), los encargados de realizar el análisis de los datos.

\subsubsection{Estaciones océano-meteorológicas de la Comunidad Autónoma del País Vasco.}

Después de la instalación en agosto de 2001 de una estación océano-meteorológica piloto en la desembocadura del puerto de Pasaia, en el año 2003 se creó una extensa red 
océano-meteorológica con la instalación de seis estaciones más en los siguientes puertos de la Comunidad Autónoma del País Vasco (ver Figura 2.16): Bilbao, Armintza, Bermeo, Ondarroa, Getaria y Hondarribia, [Duarte, 2006]. Cada estación registra los siguientes parámetros meteorológicos: viento (dirección, velocidad media y racha máxima), presión atmosférica, temperatura del aire, visibilidad y radiación global y neta.

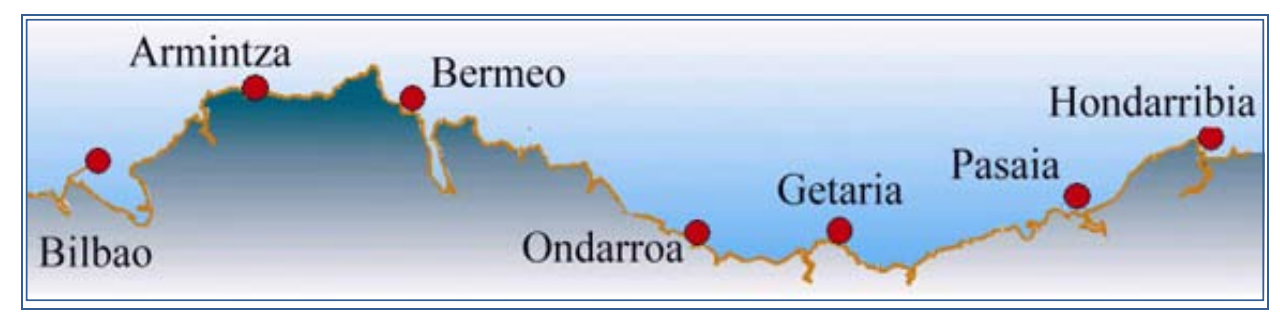

Figura 2.16 Red de estaciones océano-meteorológicas en los puertos del País Vasco.

La información oceanográfica viene dada por un correntímetro de fondo, que mide simultáneamente la velocidad y la dirección de las corrientes en seis capas de la columna de agua. Además, un mareógrafo registra la altura de la marea, la altura significante del oleaje, su periodo y la altura máxima de ola. Finalmente, se adquiere un perfil de temperaturas a través de una cadena de termistores con un sensor cada $5 \mathrm{~m}$ de profundidad (desde la superficie, hasta $25 \mathrm{~m}$ de profundidad).

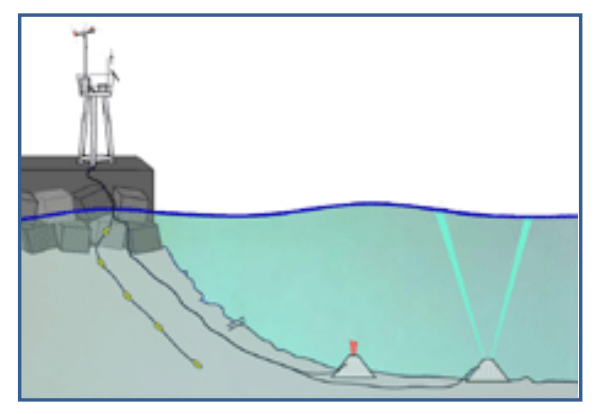

Figura 2.17 Esquema de una estación tipo y la torreta meteorológica.

Toda la información oceanográfica es transmitida por cable a un data-logger principal de la estación meteorológica y, desde ésta, junto a la información meteorológica, se envía vía radio a la unidad de recepción, instalada en una oficina de cada puerto en el que se ubican las estaciones (ver Figura 2.17).

\subsubsection{Red de vigilancia integral de las aguas de la Comunidad de Cantabria.}

La red de VIGilancia Integral de las Aguas (VIGIA) permite el seguimiento en tiempo real de los parámetros de calidad ambiental y situación de las aguas costeras de Cantabria. Dicha red está compuesta por dos boyas costeras (ver Figura 2.18) fondeadas a $28 \mathrm{~m}$ y 32 $\mathrm{m}$ de profundidad y a 1,5 millas de la costa frente a las localidades de Virgen del Mar y Berria. 


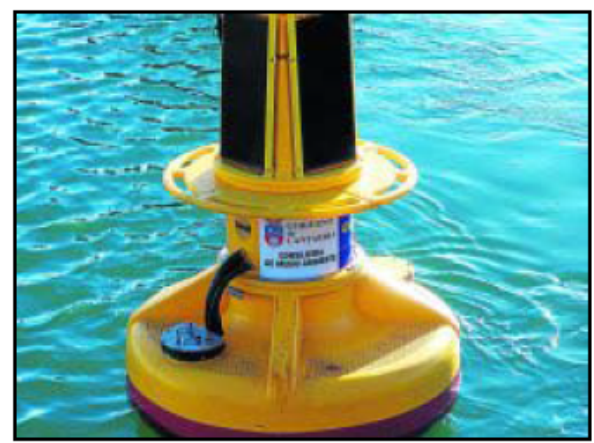

Figura 2.18 Boya tipo WatchKeeper.

Cada boya registra parámetros relacionados con el oleaje (altura de ola, periodo y dirección), con la corriente en cualquier profundidad bajo la boya (magnitud y orientación), así como con datos meteorológicos. Además, por lo que respecta a la calidad ambiental de las aguas, los dispositivos instalados evalúan indicadores como los niveles de bacterias verdes-azuladas, clorofila, concentración de oxígeno, salinidad, $\mathrm{pH}$, turbidez o concentración de nitratos. Además, incluye un sistema de detección de presencia de hidrocarburos en el entorno de las citadas boyas. Este último tiene gran importancia dada la incidencia en los últimos años de accidentes de petroleros.

\subsubsection{Red experimental de alerta, control y observación marina del Gobierno de Canarias.}

La red canaria de Alerta, Control y Observación Marina (ACOMAR) mostrada en la Figura 2.19 [Barrera et al., 2009] es una iniciativa del Instituto Canario de Ciencias Marinas, Gobierno de Canarias, dirigida a aumentar la cantidad y calidad de la observación del medio marino, a fin de entender y predecir los fenómenos que ocurren en él, así como sus repercusiones medioambientales y socioeconómicas.

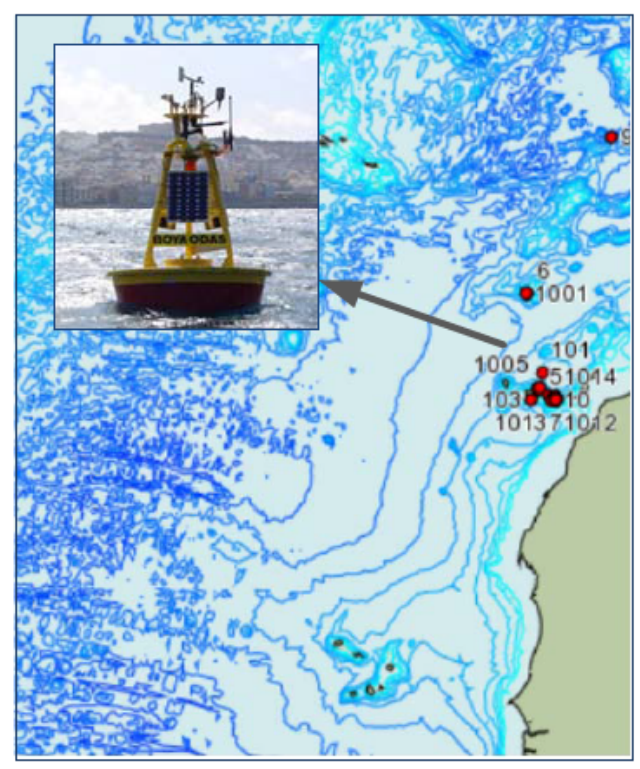

Figura 2.19 Red ACOMAR. 
Se ha intentado integrar la región de Macaronesia así como la costa africana (Azores, Madeira, Cabo Verde y Marruecos) como una zona de estudio común. Esta integración se entiende desde un enfoque instrumental, tratando de aunar y hacer disponible las observaciones in situ de instrumentos fijos y a la deriva, superficiales o de fondo, así como observaciones remotas desde satélite.

Esta red está formada por gran cantidad de boyas:

- Boyas complejas que miden diversos parámetros tanto meteorológicos como oceanográficos.

- Boyas simples cuya principal medida es de un solo parámetro, en este caso hidrocarburos.

- Boyas ODAS (Ocean Data Adquisition System).

\subsubsection{Redes de observación para investigación.}

\subsubsection{Observatorio submarino expansible del CSIC.}

El OBservatorio Submarino ExpAnsible (en adelante OBSEA) [Nogueras et al., 2009] está ubicado a unos $4 \mathrm{~km}$ de distancia y $20 \mathrm{~m}$ de profundidad de la costa de Vilanova i la Geltrú (ver Figura 2.20), en una zona protegida de pesca, e interconectado a la costa mediante un cableado de energía y comunicaciones. La principal ventaja de disponer de un observatorio cableado es la de poder proporcionar energía a los instrumentos científicos y disponer de un enlace de comunicación de banda ancha. De esta manera se puede tener información en tiempo real y se evitan los inconvenientes de los sistemas alimentados con baterías. La solución adoptada es la implementación de una red Ethernet óptica que transmite continuamente los datos de los instrumentos oceanográficos conectados al observatorio.

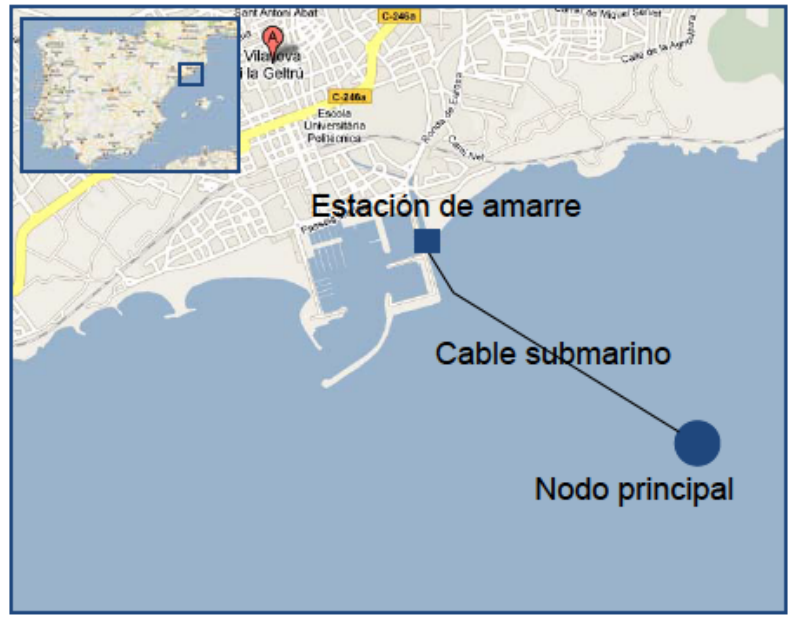

Figura 2.20 Ubicación geográfica y despliegue de OBSEA. 
En cuanto a la arquitectura del sistema, OBSEA ha sido diseñado como un observatorio de prueba para que en un futuro se pueda extender y formar una red de observatorios submarinos que cubra diversos puntos de interés. Cada nodo de esta red proporciona conectividad a múltiples instrumentos (Measure Device en la Figura 2.21) a la vez, permitiendo la extensión de la red hacia nuevas ubicaciones donde se instalarían otros nodos de similares características.

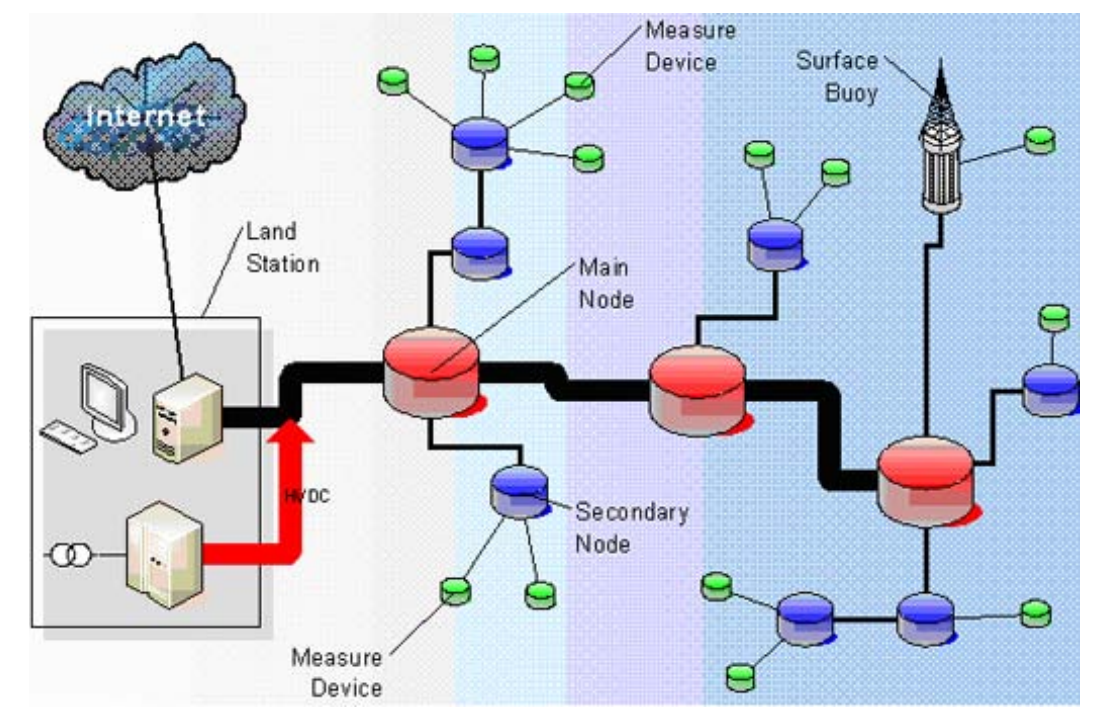

Figura 2.21 Arquitectura de OBSEA.

La estructura física de soporte mostrada en la Figura 2.22 se ha diseñado con tal de mantener los elementos fijos y protegidos de posibles intervenciones externas. A su vez, esta estructura soporta la tracción que puede generar el cable submarino por la fuerza de las corrientes. En la zona central de esta estructura se ubica el cilindro principal que contendrá la electrónica de control del observatorio submarino. Este cilindro se ha diseñado para soportar la presión existente a $300 \mathrm{~m}$ de profundidad, y proporciona una interfaz entre el cable submarino y los diversos instrumentos oceanográficos conectados al observatorio.

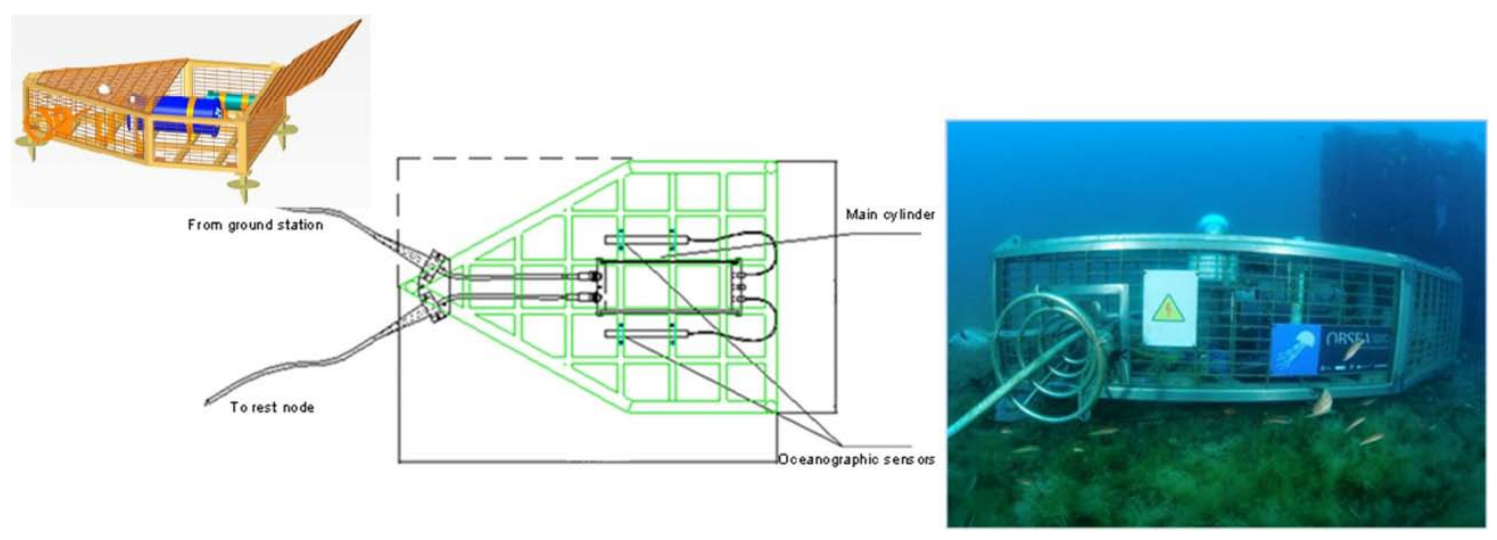

Figura 2.22 Estructura fisica del nodo principal.

En general, en cualquier sistema de observación, tan importante es realizar de forma correcta el despliegue del sistema, como también lo es mantener una buena gestión de la 
información que los nodos sensores van recogiendo. En el OBSEA la transmisión de datos de los instrumentos se realiza mediante el protocolo UDP, la adquisición de datos de los instrumentos se almacenan en archivos de texto y posteriormente en bases de datos SQL. La configuración de equipamientos y usuarios se hace a través de una aplicación interactiva con base de datos LDAP, y la visualización del contenido histórico a través de navegador de Internet descarga de archivos históricos mediante FTP. Además, ofrece la posibilidad de visualizar los datos en tiempo real con aplicaciones a medida del usuario.

\subsubsection{Boya oceanográfica Augusto González de Linares del Instituto Español de Oceanografía.}

La boya océano-meteorológica Augusto González de Linares (en adelante AGL) [Cano et al., 2010] está situada a $40 \mathrm{~km}$ de costa en el Golfo de Vizcaya (ver Figura 2.23), frente a la ciudad de Santander, y es la ubicada a mayor profundidad $(2.850 \mathrm{~m})$ de las que se encuentran actualmente repartidas por las aguas de la Península Ibérica. La boya AGL ofrece en tiempo real información de interés científico e informativo en general de las aguas del mar Cantábrico. Con ella, se analiza la evolución del régimen de brisas costeras y su desarrollo espacial en el medio marino.

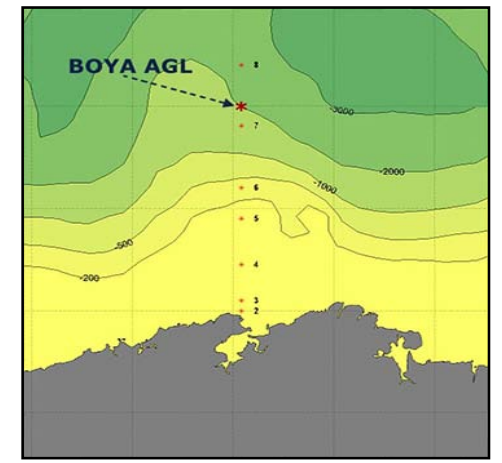

(a)

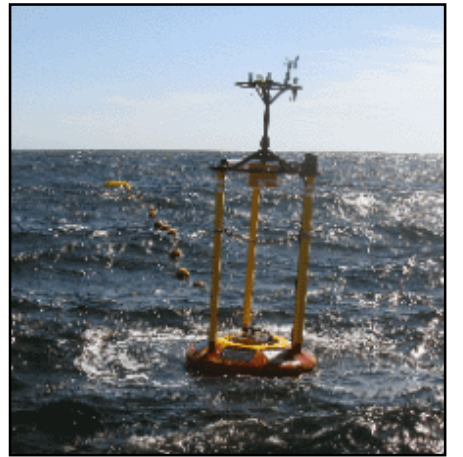

(b)

Figura 2.23 (a) Localización de la Boya AGL. (b) Boya AGL fondeada.

Se trata de una boya de tipo Seawatch, con un diámetro total de 1,7 m, 8,6 m de longitud total y un peso de $710 \mathrm{~kg}$. Está equipada con sensores atmosféricos, hidrológicos, oceanográficos y biogeoquímicos, un GPS que permite monitorizar su posición, una unidad de procesado y almacenamiento y un módem satélite para la transferencia de datos (ver Figura 2.24). En cuanto a la alimentación de la boya, se realiza a través de paneles solares.

Este fondeo complementa otros estudios que realiza el IEO (Instituto Español de Oceanografía) en aguas Atlánticas y Cantábricas basados en muestreos mediante buques oceanográficos desde el año 1991, dentro de los proyectos de estudio de la variabilidad climática tanto en la zona costera (Radiales) como en la oceánica (VACLAN) y la información de satélite. 


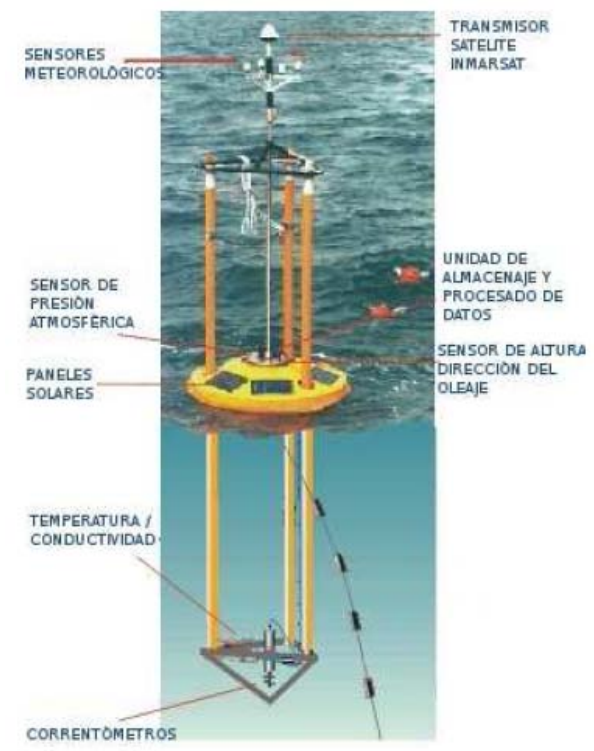

Figura 2.24 Esquema de la boya AGL.

\subsubsection{Otras grandes infraestructuras científico tecnológicas en el ámbito oceanográfico.}

Como se ha visto en los apartados anteriores, en España existe una gran deficiencia de SOCs dedicados a temas de investigación oceanográfica. Para remediar esto, el Gobierno de España ha impulsado una iniciativa consistente en la creación de un conjunto de ICTS en el ámbito de las Ciencias del Mar [ICTS, 2010]. En el presente apartado se describen cada una de estas iniciativas.

\subsubsection{Observatorio oceanográfico costero de la Región de Murcia.}

Dada la relevancia del mar para la Región de Murcia es preciso estudiar los cambios que están experimentando los sistemas costeros marinos. OOCMur nace como respuesta a la creciente necesidad, por un lado, de analizar la capacidad de los ecosistemas marinos para contribuir a la generación de productos y servicios de utilidad para la sociedad y, por otro lado, la necesidad de desarrollar tecnologías de gestión sostenible del medio ambiente marino [OOCMur].

Las principales unidades funcionales previstas para este centro son (1) infraestructura de observación, (2) sistema de gestión de datos, incluyendo modelado y predicción, (3) laboratorios científicos y (4) talleres y laboratorios tecnológicos, incluyendo sistema de telecomunicaciones.

En la Figura 2.25 se muestra la posición orientativa de la red costera de boyas y la red de aguas profundas que se pretende desplegar en un futuro. Como se puede observar, las primeras estarán en la plataforma continental ( $<100 \mathrm{~m}$ de profundidad) y las segundas en el talud continental o la llanura abisal (>200 m de profundidad hasta $2.500 \mathrm{~m}$ ). La red estará formada por:

- Boyas en el Mar Menor. 
- Boyas costeras en San Pedro del Pinatar, Cabo Cope, Cabo de Palos y Cabo Tiñoso (estas dos últimas cableadas dentro de reservas marinas).

- Boyas en altamar repartidas frente al litoral murciano.

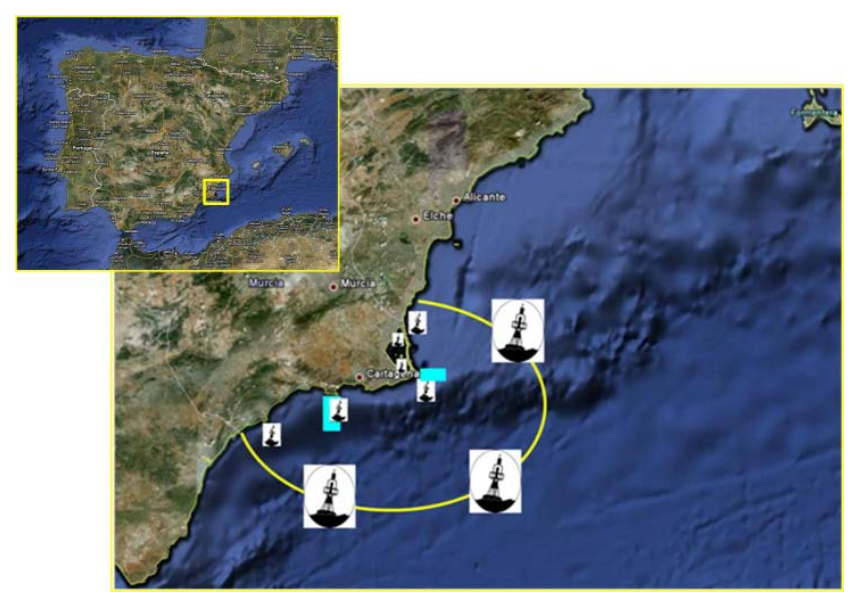

Figura 2.25 Despliegue de la infraestructura de observación de OOCMur.

Esta distribución responde a los objetivos de cada boya:

- Las boyas de aguas profundas estarán instaladas sobre todo en la zona sur debido a que es posible instalarlas a menos de 20 millas en zonas con gran profundidad, mientras que en la zona este es necesario alejarse 50 millas de la costa para alcanzar la misma profundidad. De este modo se tiene en cuenta la reducción de costes en instalación y mantenimiento de boyas.

- Las boyas de aguas costeras estarán instaladas sobre la plataforma continental, cercanas a la costa como zona bien diferenciada de la anterior. Dos se dispondrán en la zona este con una plataforma continental bien definida, y otras dos en la zona sur con una plataforma continental mucho menor. Las del Mar Menor tendrán características especiales de fondeo por su poca profundidad.

- Las boyas de Cabo de Palos y Cabo Tiñoso serán cableadas, conectadas a una instalación terrestre y a un observatorio submarino profundo. Este conjunto de instalaciones responde a la necesidad de estudiar estas reservas marinas y a su situación intermedia entre las demás que les permitiría recibir todos los datos por radio.

\subsubsection{Sistema de observación costero de las Islas Baleares.}

El Sistema de Observación Costero de las Islas Baleares (en adelante SOCIB) es una instalación de investigación y tecnología para oceanografía operacional creada como un Consorcio del Ministerio Español de Educación y Ciencia y el Gobierno de las Islas Baleares, como parte de la implementación de las infraestructuras tecnológicas y científicas de gran escala españolas.

SOCIB se puede definir como un sistema integrado e interdisciplinario de investigación para la observación y predicción de la variabilidad en la zona costera y está constituido principalmente por tres sistemas (ver Figura 2.26): 
1) Un sistema de observación y recopilación de información a diferentes escalas espaciotemporales, que tenga como eje central la adquisición y transmisión de datos en tiempo real y su gestión. Los elementos más relevantes de este sistema son redes de plataformas fijas y móviles, dispositivos de muestreo y de monitorización continua y en tiempo casi real del litoral mediante teledetección.

2) Un sistema de predicción numérica y asimilación de datos en diferentes modelos.

3) Un sistema de gestión de datos y transferencia de resultados, en distintos niveles de procesamiento según las necesidades de los usuarios finales.

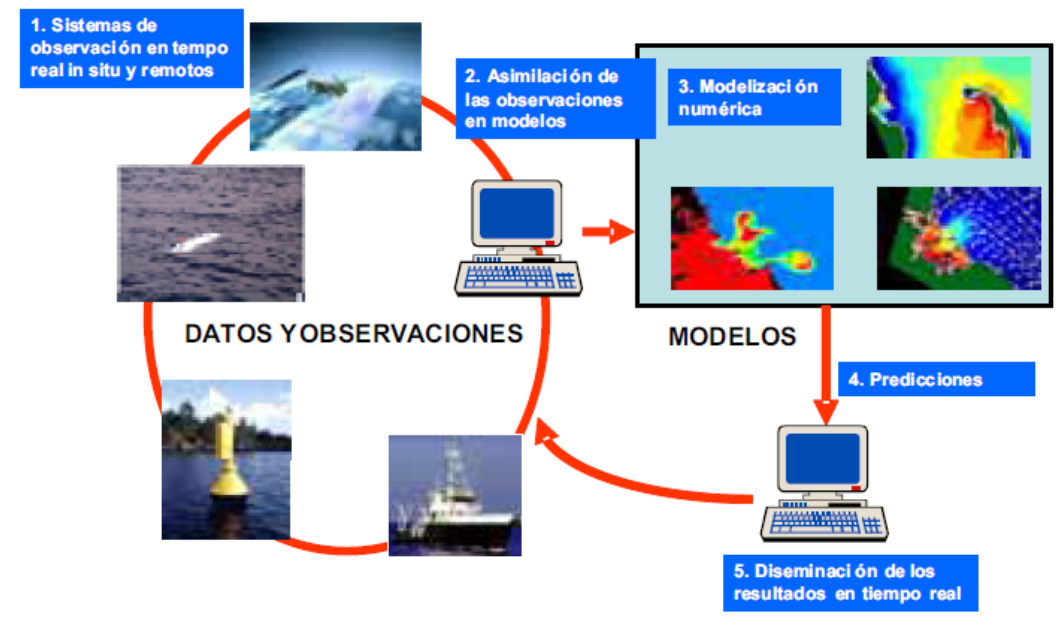

Figura 2.26 Elementos y funcionamiento de SOCIB.

La plataforma permite disponer de un seguimiento en tiempo real del estado del litoral y además, prever su evolución espacial y temporal, así como desarrollar nuevas herramientas tecnológicas que contribuyan a avanzar hacia una verdadera gestión sostenible de la zona costera basada en el conocimiento y los avances científicos.

\subsubsection{Sistema de observación costero "Marine Research Facilities for Environment and Security".}

Marine Research Facilities for Environment and Security (en adelante MAREAS) es una iniciativa conjunta del Ministerio de Educación y Ciencia y del Principado de Asturias para la creación de una ICTS cuyo ámbito de actuación es la observación y el estudio del mar y sus ecosistemas.

Esta ICTS cuenta con dos ventajas estratégicas: (1) los cañones submarinos más abruptos del mundo con profundidades de $4.500 \mathrm{~m}$ a sólo $6 \mathrm{~km}$ de la costa y (2) el área marina protegida submarina "El Cachucho" de gran riqueza biológica.

La ICTS-MAREAS permite mejorar la calidad y frecuencia de las observaciones del océano con la adecuada resolución espacial y temporal, y en consecuencia resolviendo las distintas escalas de variabilidad, e incrementando la capacidad predictiva de los modelos. 


\subsubsection{Conclusiones.}

A nivel nacional, son las redes para control y observación marina las más desarrolladas tanto tecnológicamente como en cantidad de instrumentación marina que incorporan. De los sistemas establecidos orientados a investigación (por ejemplo OBSEA [Nogueras et al., 2009] y AGL [Cano et al., 2010]) se espera su evolución hacia sistemas más complejos y que integren otros sistemas instrumentales. El estado de las tecnologías marinas en España está evolucionando gracias a diversas iniciativas impulsados por diferentes Comunidades Autónomas (por ejemplo OCCMur [OCCMur]), y se espera que en los años venideros se obtengan resultados satisfactorios de tales actuaciones.

Realizando una comparativa entre el nivel de desarrollo tecnológico en los SOCs a nivel nacional e internacional, es en el ámbito internacional donde mayores infraestructuras y nuevas tecnologías se presentan (por ejemplo destacar la agencia japonesa JAMSTEC). En España son tecnologías emergentes que cada vez están siendo más utilizadas.

El objetivo planteado en esta Tesis es diseñar e implementar un sistema de bajo coste y fácil despliegue basado en WSNs, formado por diferentes dispositivos que cooperen entre sí para llevar a cabo un objetivo común, como es la monitorización del medio marino. Tal y como se ha expuesto en la revisión de los sistemas de observación costeros a nivel nacional, no existen sistemas destinados a la monitorización de aguas costeras como el planteado en la presente Tesis Doctoral. Es por ello que se considera una iniciativa de gran interés para futuras infraestructuras que se desarrollen en este ámbito en España. 
Propuesta de una Red de Sensores Inalámbrica para un Sistema de Observación Costero

Esta página se deja en blanco de forma intencionada.

$-30-$ 


\section{Capítulo 3}

\section{Tecnologías aplicadas a los sistemas de observación costeros}

\footnotetext{
xisten diversas causas que dificultan la exploración del medio marino. La observación del medio
marino implica una mayor dificultad que en el medio terrestre ya que el acceso al mar es costoso y, en ocasiones, muy complicado. Por ello, el conocimiento debe estar basado en el desarrollo
} tecnológico de sistemas telemétricos y de plataformas de investigación capaces de moverse sobre la superficie del mar o de soportar las presiones existentes en las profundidades marinas. En este capitulo se analiza la instrumentación oceanográfica existente que permite la monitorización del medio marino diferenciándolo en tres zonas de interés, la superficie del mar, la columna de agua y el fondo marino. 


\subsection{Introducción.}

En un SOC se involucran diversas tecnologías para un objetivo común, la monitorización del entorno marino. Existen desde instrumentos integrados en sistemas de observación in situ hasta equipos remotos cada uno de ellos con un objetivo específico. La información recogida por la instrumentación oceanográfica servirá para realizar predicciones y contrastar estudios realizados con anterioridad. Todas las mediciones en el mar requieren de una plataforma relativamente estable para transportar la instrumentación que se requiere.

La plataforma de observación puede estar en la superficie (buques oceanográficos, redes de boyas de superficie, boyas de deriva y vehículos remolcados) o en el fondo del mar (AUVs, ROVs, gliders y redes de boyas submarinas), en el interior del océano o en el espacio (satélites). La elección de la plataforma depende de su capacidad para obtener, en espacio (cobertura) y tiempo (resolución temporal), la información requerida.

La Figura 3.1 proporciona una representación de la cobertura espacial de diferentes sistemas de monitorización frente a la resolución temporal obtenida en cada uno de ellos [Prandle, 2000a].

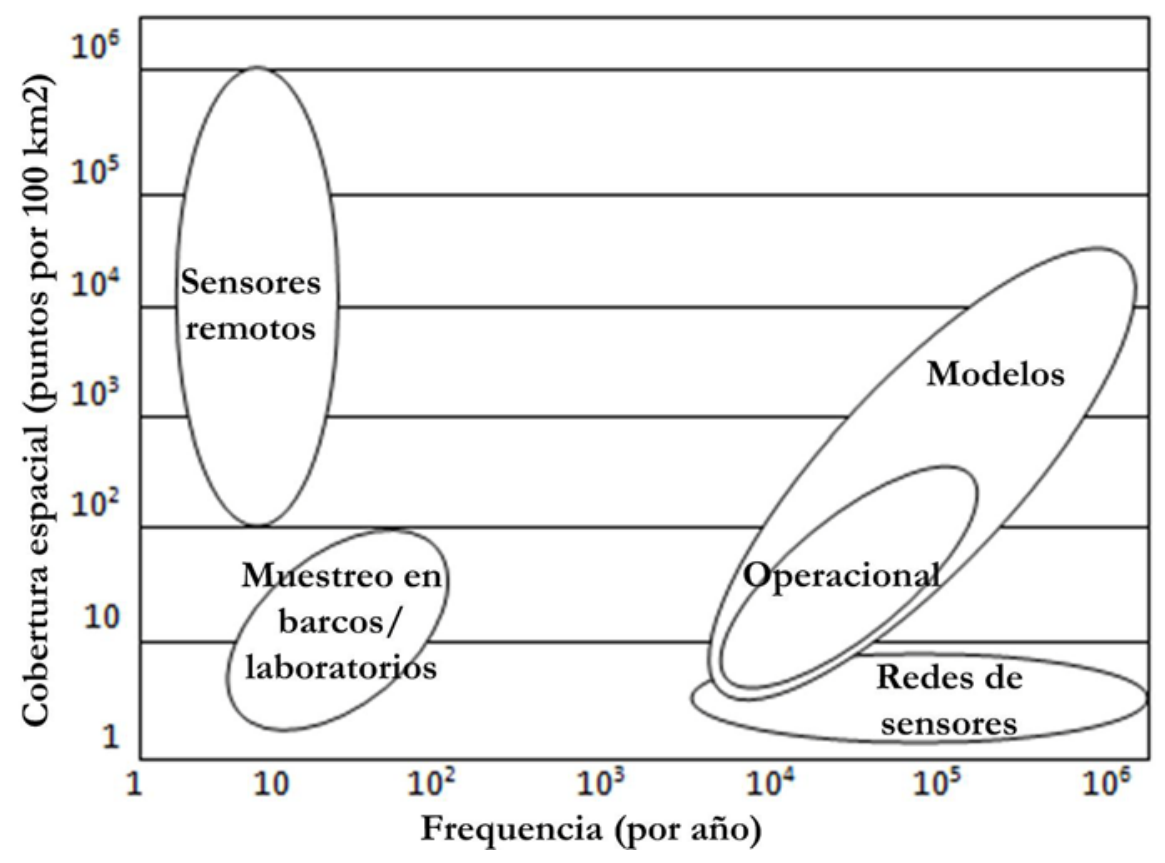

Figura 3.1 Cobertura espacial y temporal de varios sistemas de observación.

Con la teledetección se obtiene una elevada cobertura espacial pero en un determinado intervalo de tiempo. Con el muestreo realizado en las campañas de barcos oceanográficos se obtiene menor cobertura espacial y la resolución temporal se extiende únicamente a la duración de la campaña. Con técnicas como redes de sensores se puede obtener una gran 
resolución temporal comprometiendo en este caso el rango de cobertura espacial. Con la combinación de información recogida por ésta última técnica se puede lograr obtener mayor cobertura espacial aplicando los modelos existentes. Por tanto, lo que se pretende con los sistemas de adquisición y las innovaciones tecnológicas revisados en este capítulo es el incremento de la cobertura y la resolución de los datos experimentales.

Dichos sistemas se encuadran en lo que se conoce como Oceanografía Operacional (en adelante OO). La OO se define como toda actividad que efectúa medidas en los océanos, mares y atmósfera, las disemina e interpreta y todo ello de un modo rutinario con el fin de:

- Suministrar una previsión continua de las futuras condiciones del mar con la mayor antelación posible.

- Suministrar una descripción más precisa del estado actual del mar, incluyendo los recursos vivos.

- Reunir datos climáticos a largo plazo que suministrarán la información necesaria para describir estados pasados, y con la que fabricar series de tiempo que muestren las tendencias y cambios.

En general, el procedimiento que se sigue en la $\mathrm{OO}$ es la transmisión de los datos observados a centros de cálculo, donde se procesan y se integran o asimilan a modelos numéricos de previsión, y finalmente, son empleados en diferentes aplicaciones en función de los requisitos del usuario final (ver Figura 3.2) [Prandle, 2000b]. De este modo, se pueden realizar pronósticos desde horas, días, meses e incluso años y décadas, aunque la resolución espacial y temporal de las predicciones realizadas pueden estar limitados por el límite y condiciones iniciales de resolución.

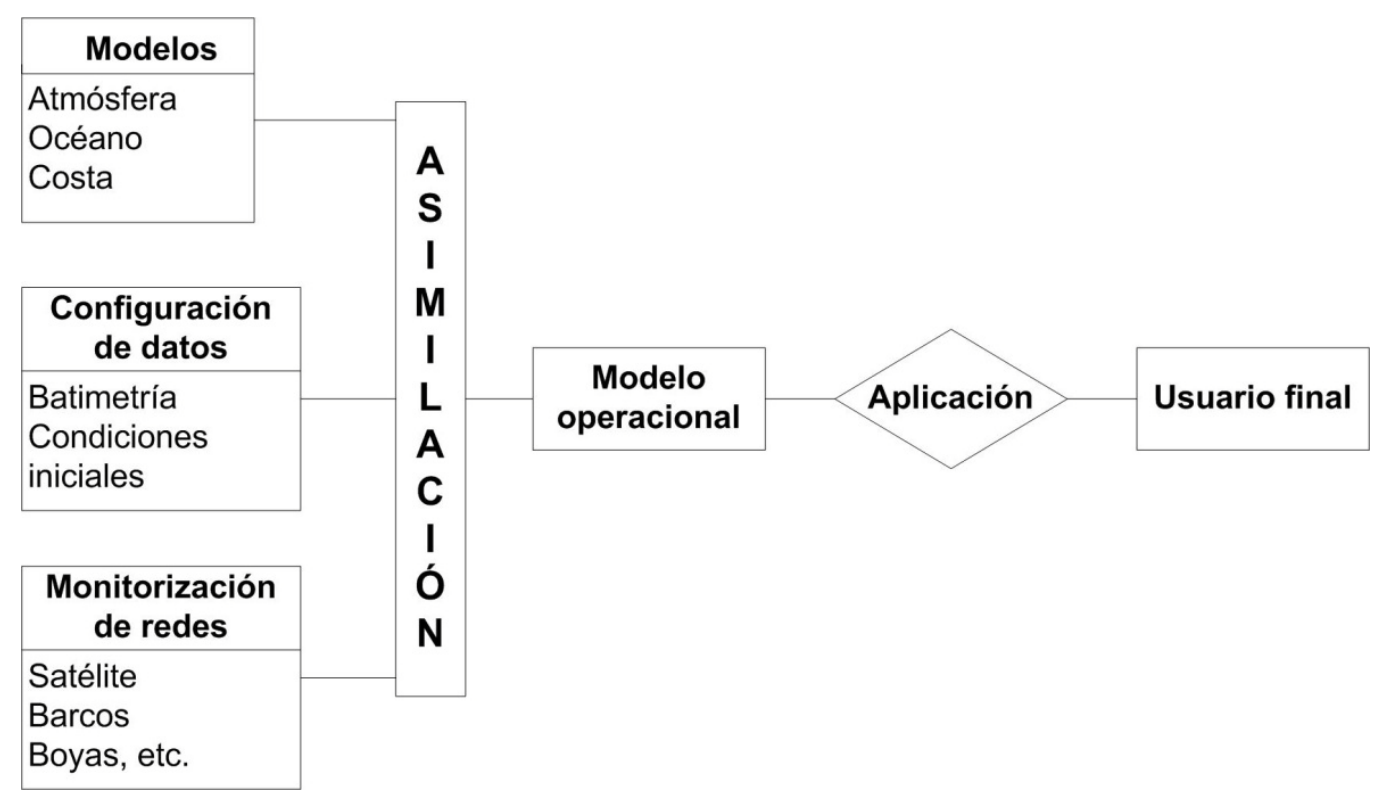

Figura 3.2 Componentes de la oceanografia operacional.

En los siguientes apartados de este capítulo se presenta el impacto de las innovaciones tecnológicas en la investigación del océano diferenciándolo en tres zonas de interés: caracterización de la superficie del mar, a lo largo de la columna de agua y en el fondo marino. 


\subsection{Caracterización de amplias superficies.}

Para caracterizar la superficie del mar se emplean sistemas de teledetección. La teledetección se puede definir como "la ciencia y arte de obtener información acerca de la superficie de la Tierra sin entrar en contacto con ella. Esto se realiza detectando y grabando la energía emitida o reflejada y procesando, analizando y aplicando esa información".

\subsubsection{Sensores aerotrasportados.}

Para la teledetección se emplean sensores activos (aquellos que poseen fuentes internas que generan artificialmente la radiación: el rádar y el líder, este último se trata de un sistema de altimetría láser) y sensores pasivos (aquellos que recogen la radiación electromagnética que procede de la cubierta terrestre: sistemas fotográficos, radiómetros multi e hiperespectrales y espectrómetros de imagen) que pueden ir integrados en los sistemas de teledetección.

Cabe destacar que muchos sensores pasivos tienen sensibilidad multiespectral, es decir, recogen simultáneamente datos de diferentes bandas espectrales. Las mediciones sobre diferentes zonas del espectro electromagnético, aportan una amplia información sobre distintos aspectos del medio ambiente. Por ejemplo, la radiación ultravioleta se utiliza para monitorizar los niveles de ozono en las capas altas de la atmósfera. Las bandas visible e infrarrojas permiten determinar la salud de la cubierta vegetal (cultivos y bosques). Los captadores sensibles a la radiación infrarroja térmica sirven para determinar la temperatura del suelo, de las nubes, y de la superficie de los mares. Algunos ejemplos de sensores multiespectrales son: Coastal Zone Color Scanner Experiment (CZCS) con 6 bandas espectrales, Sea-viewing Wide Field-of-view Sensor (SeaWiFS) con 8 bandas espectrales y MODerate-resolution Imaging Spectroradiometer (MODIS) con 36 bandas espectrales [OceanColor]. Con estos sensores se captan imágenes hiperespectrales obteniendo de esta forma un incremento de la resolución espectral.

\subsubsection{Sistemas de teledetección.}

Estos sensores se pueden instalar en aviones, UAVs, satélites y otros medios de elevación para aportar una visión diferente a la de los sensores terrestres. Tienen la ventaja de obtener una lectura más abarcativa de la realidad, aunque habitualmente, a un coste más elevado.

\subsubsection{Satélites.}

Los satélites se consideran una herramienta clave en el contexto de la oceanografía operacional y en los sistemas de predicción del océano, ya que proporcionan de forma periódica información de la superficie del mar abarcando la superficie global de los océanos. La alta resolución espacial y temporal de este tipo de estos datos representa un 
gran beneficio para aplicaciones como la asimilación en modelos numéricos, la predicción a corto plazo y la monitorización del cambio climático en estudios a largo plazo.

Actualmente se dispone de diferentes conjuntos de datos procedentes de diferentes sistemas satelitales capaces de medir un amplio abanico de variables, tales como:

- Temperatura superficial del mar (Sea Superficial Temperature, en adelante SST).

- El color del océano mediante sensores ópticos que operan en la banda visible del espectro electromagnético.

- El nivel del mar a partir del cual se pueden estimar corrientes superficiales marinas.

- El oleaje a partir de los datos proporcionados por los radares altimétricos.

- Los radares de apertura sintética proporcionan información de la textura de la superficie del mar. Una de las aplicaciones principales de este tipo de datos es la detección de vertidos de hidrocarburos.

- El reciente avance en la teledetección ha consistido en conseguir medidas de la salinidad superficial del mar cuya variable es clave para la correcta monitorización de las corrientes marinas. Durante los últimos años, la ESA (European Space Agency) ha dedicado esfuerzos considerables en este campo bajo la misión SMOS (Soil Moisture and Ocean Salinity) [Font et al., 2010], el primer satélite a nivel mundial de observación de la salinidad

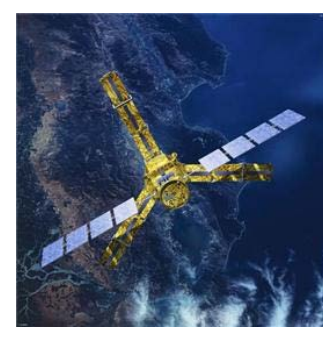

Figura 3.3 Satélite SMOS. (ver Figura 3.3).

\subsubsection{Comparación de diferentes sistemas de teledetección.}

Dependiendo del sistema de transporte elegido se obtendrán diferentes resoluciones espaciales y temporales [Bioing, 2009]. Para el caso particular de imágenes multi e hiperespectrales, es necesario plantear las diferencias con otra fuente de imágenes de amplia cobertura como son los sensores satelitales, para saber cuáles son las posibilidades y limitaciones de ambos sistemas. Las principales diferencias son: la resolución espacial, la resolución espectral, el período de revisita o frecuencia temporal de pasaje del satélite y el coste de la información en términos generales. La resolución espacial, en el caso de los sensores aerotransportados se determina con la altura de vuelo. Este aspecto permite modificar el nivel de detalle cuando un determinado fenómeno o estudio lo requiera. En los sensores satelitales, la resolución espacial de las imágenes es invariable, y el coste de imágenes de muy alta resolución suele ser muy elevado para algunos objetivos que necesitan imágenes actuales.

Otro aspecto importante es el período de revisita. En el caso de los sensores aerotransportados (ya sea en sistemas aerotransportados o en UAVs), es posible llevar a cabo la adquisición de imágenes, o datos, en el momento que sea requerido por los objetivos, siempre que las condiciones meteorológicas lo permitan y que se cuente con el equipamiento adecuado en el sitio de interés. En cambio, los sensores satelitales están limitados a sus órbitas y períodos de revisita (ver Figura 3.4), y de la misma manera son 
afectados por la meteorología. Por tanto, con los sistemas aerotransportados y los UAVs se obtiene un incremento de la resolución espacio-temporal aunque la cobertura temporal queda limitada en los sistemas aerotransportados a unas pocas horas, y en los UAVs estará en función de la autonomía de vuelo del vehículo.

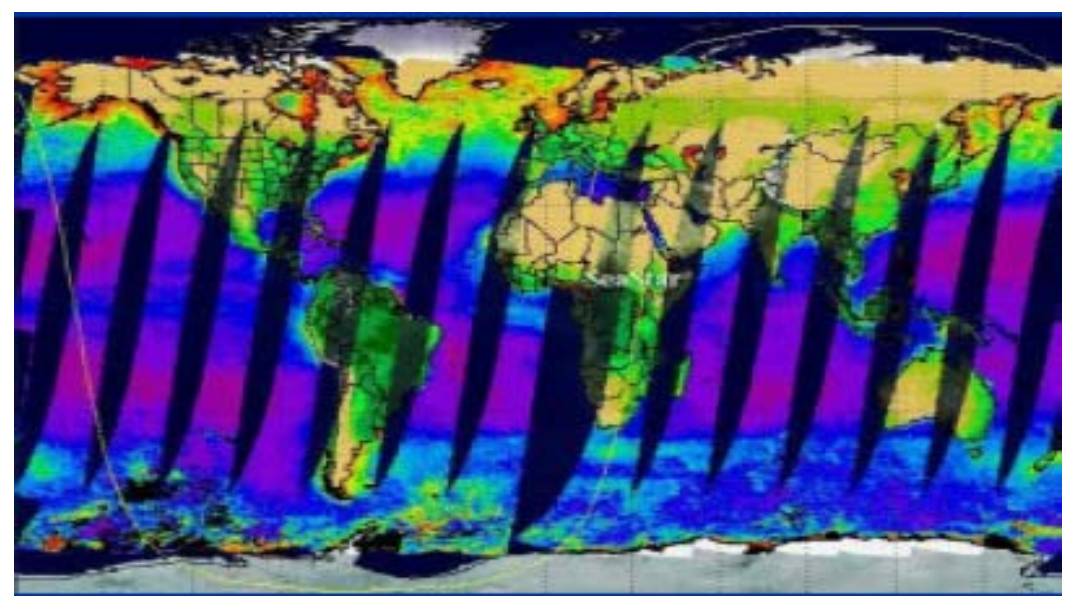

Figura 3.4 Imagen satelital.

En la última década la autonomía de los UAVs ha sido un campo de estudio y esfuerzos por obtener un aumento de la duración máxima de vuelo a la vez que se aumenta la altura de vuelo (ver Figura 3.5), y han sido las células de hidrógeno la última tecnología aplicada para dicho fin.

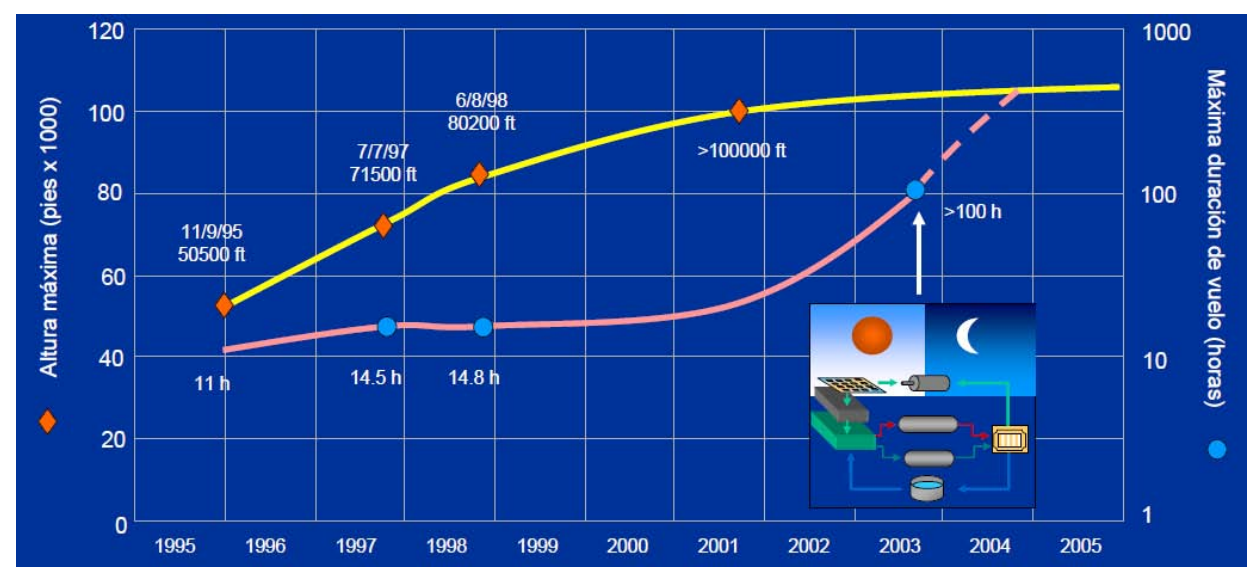

Figura 3.5 Evolución de la autonomía de vuelo en función de la altuta máxima.

\subsubsection{Aplicaciones de los sistemas de teledetección.}

Son diversas las aplicaciones de estos sistemas aerotransportados: clasificación de superficies [Hochberg et al., 2003], clasificación de los fondos a partir de los datos hiperespectrales (ejemplo en Figura 3.6 (a)), SST (ejemplo en Figura 3.6 (b)), detección de mamíferos marinos en tiempo real (ejemplo en Figura 3.6 (c)), y aplicaciones en aguas costeras para monitorizar la distribución de componentes como la clorofila, sedimentos en suspensión y materia orgánica disuelta (ver ejemplos en Figura 3.6 (d), (e) y (f) respectivamente). 


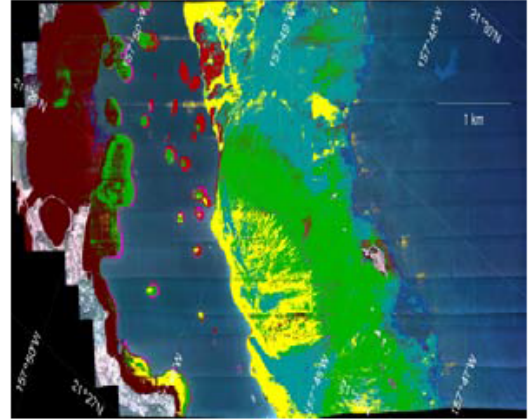

(a)

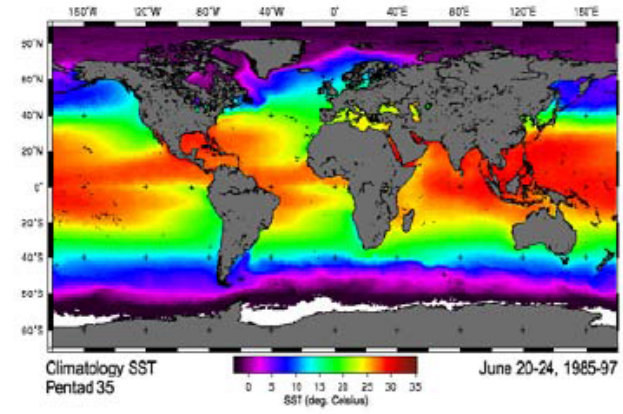

(b)

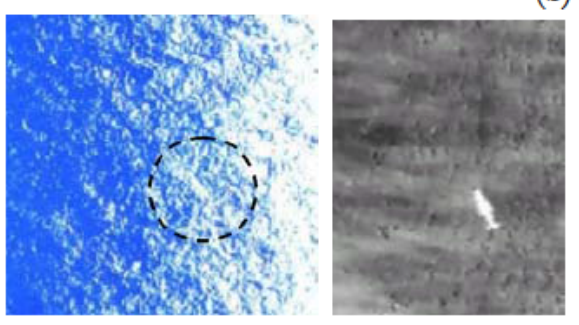

(c)

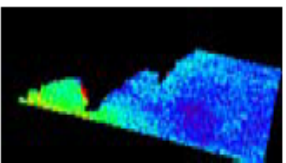

(d)

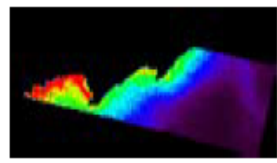

(e)

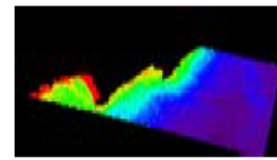

(f)

Figura 3.6 Aplicaciones hiperespectrales. (a) Clasificación de los fondos. (b) SST. (c) Detección de mamíferos marinos. (d)-(f) Distribución de componentes.

\subsubsection{Vehículos remolcados.}

La mayoría de estos vehículos consisten en un cuerpo con forma hidrodinámica sumergido y un cable de arrastre electro-mecánico (ver Figura 3.7). Además del paquete de sensores (comúnmente un CTD (Conductividad, Temperatura y Profundidad)), incluye sensores de presión, inclinación y balanceo que vigilan su comportamiento y controlan su vuelo debajo de la superficie. Los datos se envían al sistema computacional a bordo del barco mediante el cable conductor, a través del cual también se envían instrucciones al cuerpo sumergido a fin de alterar su ángulo de ataque. Los vehículos remolcados se usan para estudiar los procesos oceánicos que requieran alta resolución espacial.

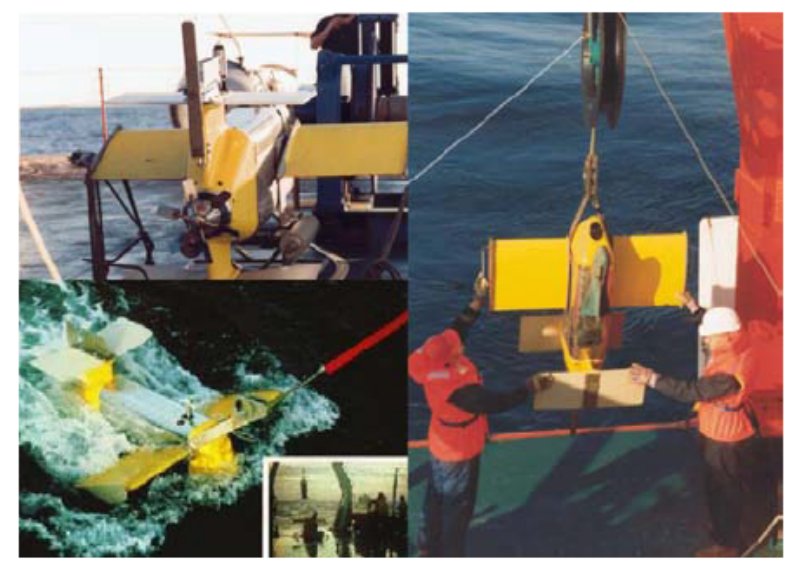

Figura 3.7 Vehículo remolcado durante un despliegue. 


\subsubsection{Boyas.}

Otra de las plataformas con las que se puede caracterizar la superficie del mar son las boyas de superficie. Se distinguen entre boyas fijas (Euleriana) con las que se obtiene resolución temporal alta, y resolución horizontal y vertical bajas puesto que las medidas se realizan en un punto geográfico fijado; y boyas móviles (Lagrangiana) con las que se obtiene una resolución temporal variable, resolución horizontal alta debido a la movilidad de la boya y resolución vertical baja.

Las boyas fijas a su vez pueden formar una red de boyas. Se trata de un conjunto de boyas que establecen una comunicación o bien entre ellas para llevar a cabo un intercambio de información, o directamente con la estación base para el envío de la información recogida por los sensores. Se pueden distinguir tres tipos de redes de boyas en función del tipo de comunicación existente entre los nodos sensores: (1) las redes de boyas cableadas, en las que se establece comunicación mediante un cable de comunicaciones [Barnes et al., 2007], (2) las redes de boyas aéreas, cuya comunicación se realiza de forma inalámbrica vía Radio Frequency (en adelante RF) [Cella et al., 2009], GPRS o la combinación de ambas [Jiang et al., 2009], y (3) las redes de boyas submarinas, cuya comunicación inalámbrica es submarina vía ondas acústicas [Akyildiz et al., 2005]. En la literatura se pueden encontrar infraestructuras que combinan alguna de estas opciones [Yang et al., 2002].

Las boyas móviles se desplazan por la superficie del mar llevadas por la corriente a la vez que se realizan las medidas necesarias. Se utilizan principalmente en regiones alejadas y en las zonas centrales de grandes cuencas oceánicas a las que normalmente no llegan los buques de investigación y donde es difícil y costoso emplazar un anclaje.

Ambos tipos de boyas, fijas y móviles, generalmente pueden incluir instrumentos meteorológicos (anemómetro, veleta, sensores de temperatura del aire, presión atmosférica y radiación solar) y un sistema de comunicaciones (radio, GSM/GPRS, o satélite) junto con la electrónica adecuada e instrumentos oceanográficos (correntímetro, altura y periodo de oleaje, turbidimetro, fluorómetro, mareógrafo, etc.). Los datos recogidos por estos instrumentos se pueden aplicar a realizar validaciones sobre modelos y datos de satélite.

En general, las características de este tipo de boyas se diferencian en características mecánicas, electrónicas y de control remoto.

\subsubsection{Características mecánicas.}

Los elementos básicos de la estructura mecánica de una boya son la cantidad de peso muerto, el cabo que une el anclaje del fondo del mar con sensores oceanográficos hasta la estructura en la superficie, y uno o más elementos flotantes que mantendrán la boya en su posición lo más vertical posible. Además es necesario tener en cuenta temas de seguridad como por ejemplo un compartimento estanco para la electrónica, sellado mediante poliuretano de las antenas, GSM/GPS, etc. 


\subsubsection{Características electrónicas.}

Cuestiones a tener en cuenta en la construcción de la electrónica es dotar a la boyas de la mayor autonomía posible incluyendo incluso sistemas de obtención de energía como pueden ser paneles solares. Suelen tener una parte de lógica inteligente encargada de la gestión de errores internos, lectura, filtrado y emisión de la posición, verificación de la cobertura, etc. La comunicación con la boya debe ser bidireccional de forma que se puedan realizar acciones de configuración sobre el comportamiento de la misma así como enviar la información recogida por los sensores.

\subsubsection{Aplicación de control remoto.}

En cualquier sistema de comunicación inalámbrica existe un programa de control remoto que lleva a cabo el almacenamiento de las posiciones y datos recibidos, bien en ficheros o en bases de datos, incluyendo en ocasiones herramientas de visualización de dichos datos.

\subsection{Caracterización de la columna de agua.}

Para caracterizar la columna de agua existen diferentes plataformas de observación: perfiladores autónomos (McLane Moored Profiler, en adelante MMP; Profiler Autonomous Lagrangian Circulation Explorer, en adelante PALACE; y Autonomous Lagrangian Circulation Explorer, en adelante ALACE), AUVs y gliders. En este apartado se describe cada uno de ellos señalando sus características principales.

\subsubsection{Perfiladores autónomos.}

El MMP [Morrison et al., 2000] es un perfilador autónomo desarrollado a través de una colaboración entre el McLane Research Laboratories, Inc. (MRL), el Advanced Engineering Laboratory y el Department of Physical Oceanography del WHOI. Esta plataforma incluye, además del perfilador autónomo vertical, sensores CTD y correntímetros acústicos como se muestra en la Figura 3.8. La recolección de los datos del MMP sigue el procedimiento planteado por las tareas programadas por el operador y siguiendo una trayectoria a lo largo de un cable de amarre. Los datos son almacenados para una recuperación posterior y análisis por parte de los investigadores.

Los principales componentes del MMP incluyen el controlador, el elemento de flotabilidad, el motor y las ruedas de guía, el conjunto de instrumentos, la estructura interna y la carcasa externa ajustada hidrodinámicamente. La forma y construcción del MMP refleja un balance entre varios principios de diseño: un arrastre hidrodinámico bajo para que el vehículo sea capaz de soportar despliegues a millones de metros, y la combinación del movimiento vertical y corrientes horizontales requieren un bajo arrastre sobre varias posibilidades de asaltos. 


\section{SKETCH OF THE MOORING CONFIGURATIONS}

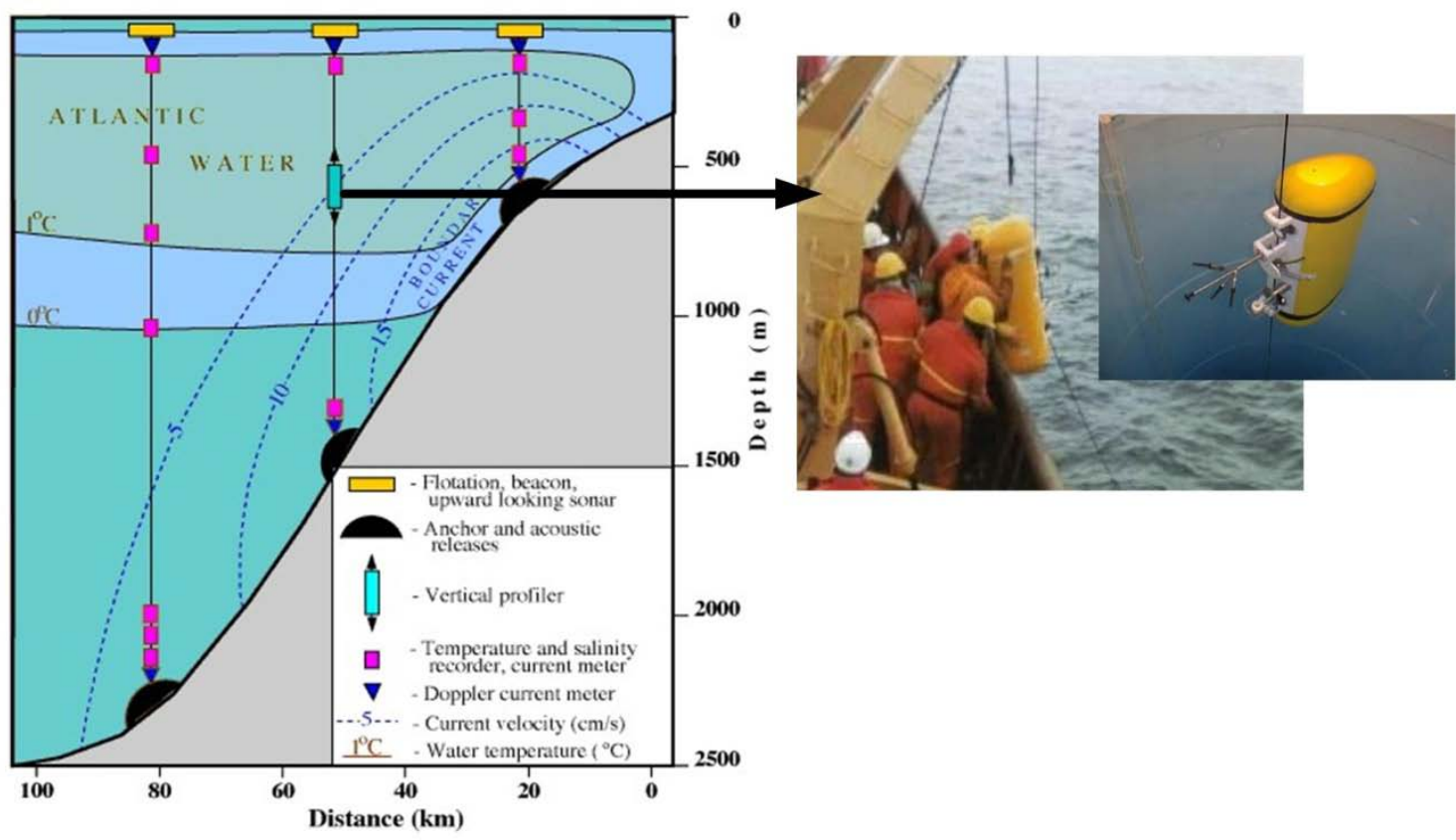

Figura 3.8 Perfilador autónomo MMP.

El perfilador autónomo PALACE [Danchenkov y Riser, 2000], mostrado en la Figura 3.9, tiene como objetivo monitorizar las corrientes en el mar y analizar la estructura de la columna de agua. Estos instrumentos fueron construidos y desarrollados por WEBB Corporation and Scripps Institution of Oceanography en 1991 [Davis et al., 1992].
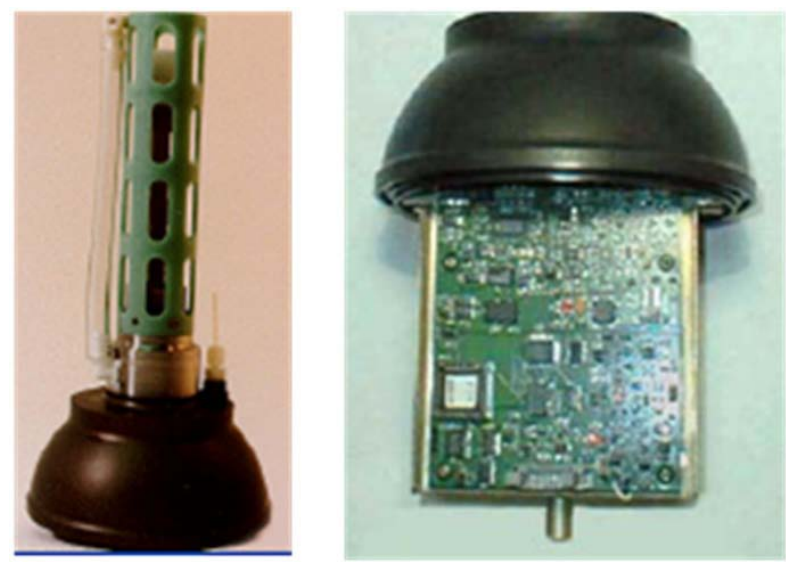

Figura 3.9 Perfilador autónomo PALACE.

Algunas de las características básicas de PALACE son las siguientes: profundidad máxima de operación a $2.000 \mathrm{~m}, 5$ años de funcionamiento, 75 ciclos de superficie, $23 \mathrm{~kg}$ de peso, incorpora sensores de temperatura y conductividad de SeaBird que permiten obtener perfiles de temperatura y salinidad, además de información de corrientes profundas, y tiene una periodicidad de 7 días.

ALACE [Davis et al., 1992] es un flotador subsuperficial. El diseño de este tipo de flotadores se realiza de tal manera que para una profundidad dada, tengan flotabilidad neutra. Estos flotadores permanecen hundidos durante el tiempo necesario y vuelven a la 
superficie para transmitir sus datos vía satélite para luego regresar a su profundidad asignada. Por lo tanto, estos flotadores se pueden programar para estudiar cualquier profundidad pudiendo también realizar medidas de la columna de agua durante su ascenso a la superficie (ver Figura 3.10).

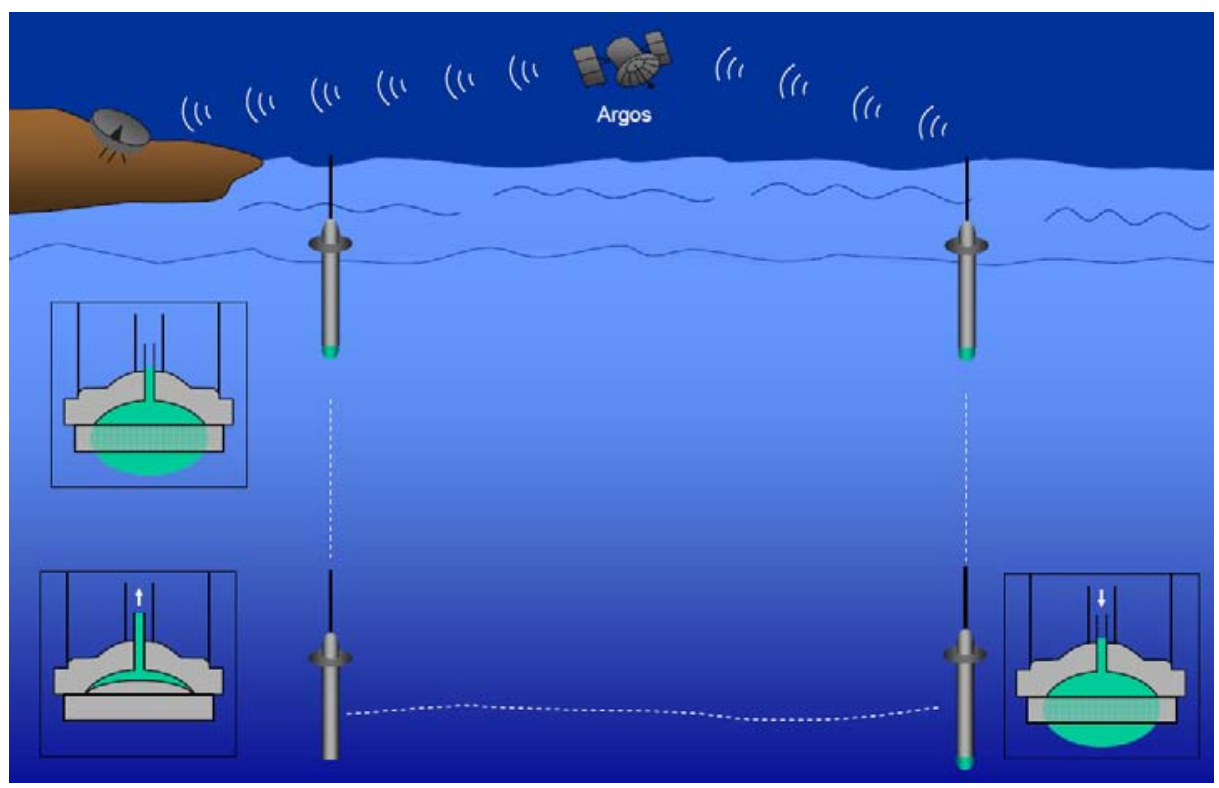

Figura 3.10 Perfilador autónomo ALACE.

De los principales componentes de ALACE se destacan tres subsistemas: un sistema hidráulico para ajustar la flotabilidad, un microcontrolador para programar y controlar el funcionamiento del perfilador, y el transmisor Argo y antena de comunicaciones.

\subsubsection{Vehículos autónomos submarinos.}

En los últimos tiempos se han realizado grandes avances en robótica e informática que, entre otras cosas, han impulsado la evolución de los vehículos submarinos no tripulados hasta niveles cada vez mayores de sofisticación [Conforto, 2010]. Los primeros vehículos de este tipo, cuyo desarrollo se inició en los años 60, fueron los ROVs que son controlados por operadores humanos a través de un cable que une al vehículo con su plataforma de control.

Una evolución del ROV ha sido el AUV en el que el control pasa a tomarlo un ordenador instalado en el propio vehículo, lo cual le permite operar de forma independiente (ver Figura 3.11). De esta forma, un AUV es capaz de tomar decisiones en función de cambios del medio o de los distintos eventos que sus sensores detecten y su software interprete. Sus aplicaciones son similares a las de los ROVs, con las ventajas añadidas de poder actuar de forma encubierta y de contar con suficiente alcance y autonomía para operar alejados de su plataforma de control. 


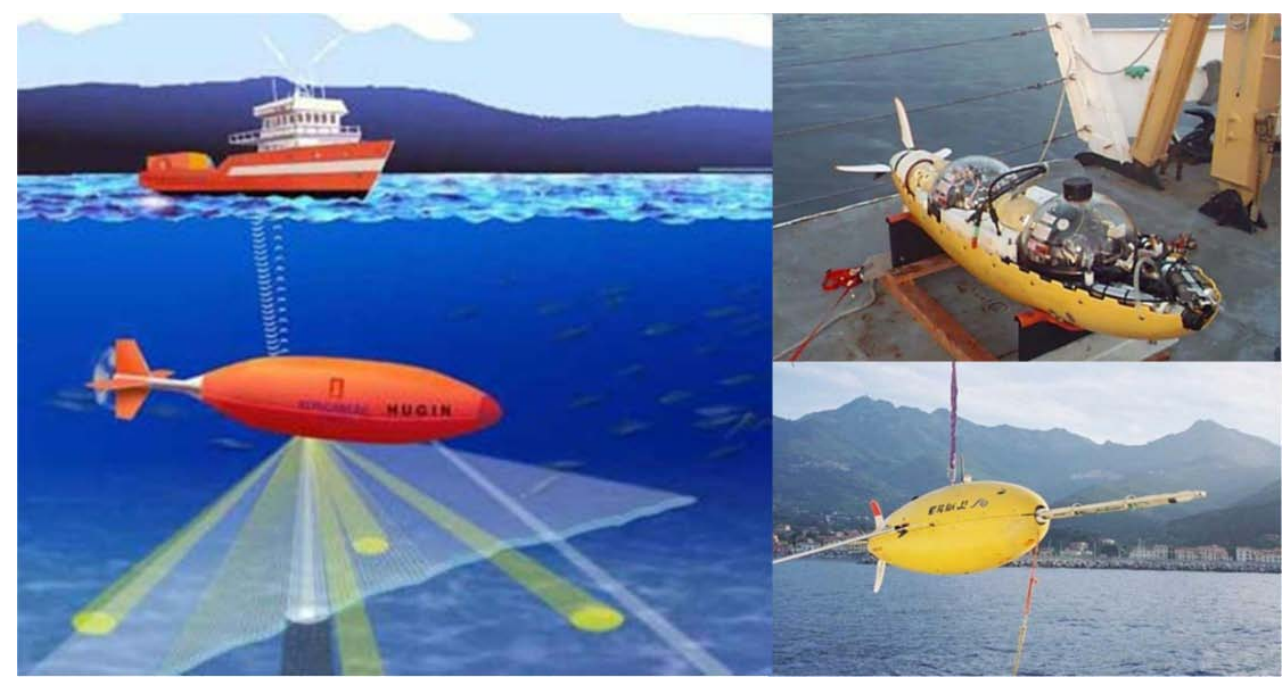

Figura 3.11 $A U V$.

\subsubsection{Características de un AUV.}

Los elementos y el diseño de un AUV son básicamente los mismos de un submarino convencional. Un AUV típico tiene un casco de forma cilíndrica o ahusada y está impulsado por baterías eléctricas, o bien por células de combustible que accionan una hélice situada a popa. El control se consigue a través de la propia hélice, de planos de deriva y profundidad y de hidrorreactores. Naturalmente, incorporan uno o varios sistemas de navegación (inercial, giroscópica, etc.) y control, así como módems acústicos para comunicaciones submarinas.

Las dimensiones de un AUV van desde $1,5 \mathrm{~m}$ a $7 \mathrm{~m}$, siendo los mayores normalmente aquellos diseñados para operar a mayor profundidad. La velocidad máxima en inmersión ronda los 4 u 8 nudos, según el modelo.

La instrumentación que puede montar el vehículo la integra un amplio espectro de sensores y dispositivos: sónares (batimétricos, de barrido lateral, de apertura sintética, etc.), sensores CTD, ecosondas, videocámaras, etc. Normalmente los AUVs tienen un diseño modular para que pueda instalarse un tipo u otro de sensores, dependiendo de la misión, proporcionando así una gran versatilidad de uso.

Se pueden destacar varias innovaciones tecnológicas en este tipo de plataformas oceanográficas como pueden ser los sistemas de navegación y posicionamiento y sistemas de instrumentación. En cuanto a los sistemas de navegación y posicionamiento, cuando el vehículo está en superficie puede utilizar los sistemas de comunicación por RF y determinar su posición mediante GPS. Una vez sumergido, la navegación se realiza mediante un sistema inercial, aunque el vehículo cuenta también con sistemas precisos de posicionamiento acústico submarino de tipo USBL (Ultra Short Base Line) y LBL (Long Base Line). Referente a los sistemas de instrumentación se pueden incluir sonar de barrido frontal [Sonatech], unidades de navegación inercial [Seanav], sistemas de inteligencia artificial que ofrecen generación de mapas concurrentes, perfiladores doppler, sensores químicos in situ basados en espectrometría de masas para la detección de compuestos 
orgánicos volátiles y gases disueltos, sistemas de detección y visualización de partículas y organismos planctónicos.

\subsubsection{Planeadores submarinos, gliders.}

Los gliders (ver Figura 3.12) son un tipo de AUV que mediante pequeños cambios de su flotabilidad y utilizando unas alas, permite convertir el movimiento horizontal en vertical, obteniendo así un sistema de propulsión de muy bajo consumo. Están diseñados para observar el interior de amplias zonas oceánicas a un coste mucho menor que los buques oceanográficos y anclajes.

La localización del glider se lleva a cabo mediante GPS cuando éste está en superficie, donde también se realiza la transmisión de datos entre el glider y el laboratorio. Las comunicaciones con el dispositivo son bidireccionales, y se pueden llevar a cabo mediante un sistema de radio o mediante telefonía vía satélite. Esta segunda opción permite modificar desde cualquier parte del mundo la misión que el dispositivo lleva a cabo para adaptar la estrategia de muestreo como respuesta a los datos adquiridos en tiempo real.

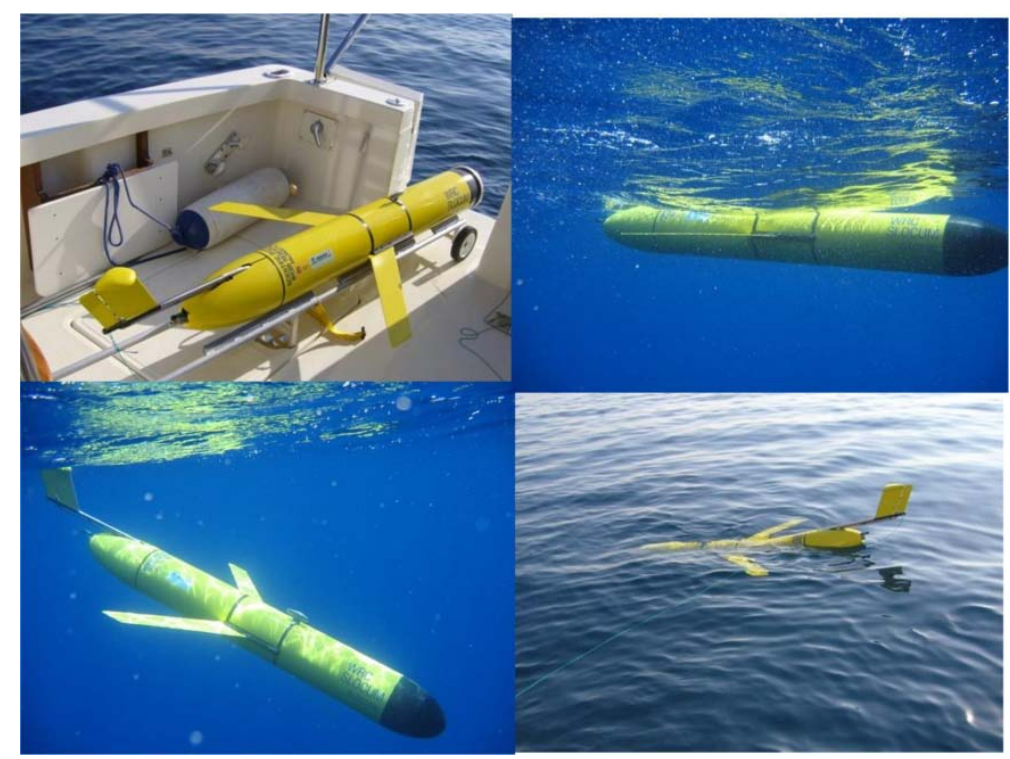

Figura 3.12 Glider.

En general, la instrumentación que se puede integrar en un glider está limitada por el consumo eléctrico, la resistencia hidrodinámica que pueda generar y el coste de ésta. Actualmente, los gliders transportan sensores CTD de precisión comparable a los utilizados en buques oceanográficos. La inclusión de sensores que midan propiedades ópticas del medio y del oxígeno disuelto está todavía en desarrollo. La autonomía de estas plataformas de observación alcanza los dos meses de operación sin intervención humana. 


\subsection{Caracterización del fondo marino.}

Finalmente, para monitorizar el fondo marino se emplean sistemas de observación que se pueden clasificar en dos grupos: (1) sistemas de observación de percepción remota, y (2) sistemas de observación mediante instrumentación in situ.

En el primer grupo se engloba a los buques de investigación equipados con instrumentación y a los AUVs. En el segundo incluye observatorios submarinos acústicos o cableados basados en redes de sensores como los analizados en el Capítulo 4.

\subsubsection{Sistemas de observación de percepción remota.}

En la Figura 3.13 se recogen diferentes tipos de instrumentación que intervienen en la observación del fondo marino de forma remota: barcos de investigación, sonar o ecosondas para hallar la profundidad a la que se encuentra, hidrófonos para la detección de seísmos [Shariat et al., 2008], batimetrías que permiten el estudio de las capas del fondo marino y vehículos remolcados.

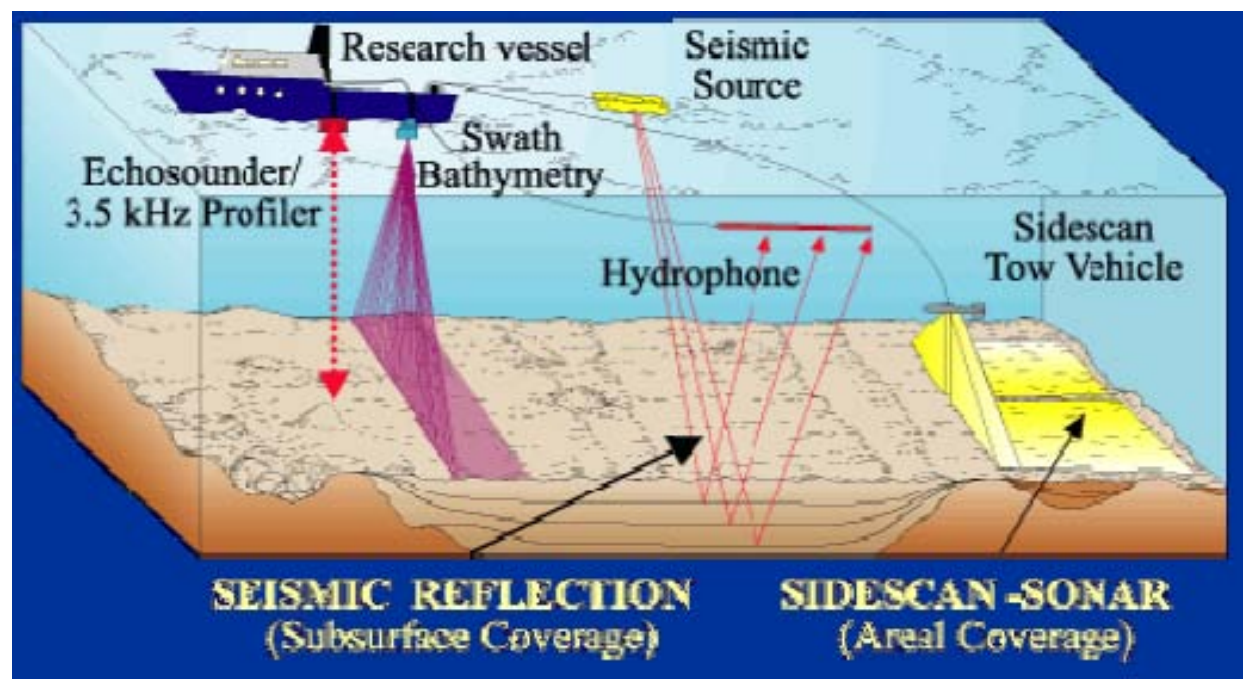

Figura 3.13 Instrumentación para percepción remota.

\subsubsection{Sistemas de observación mediante instrumentación in situ.}

Estos sistemas ya fueron analizados en el capítulo anterior pero cabe destacar algunos retos tecnológicos que implica llevar a cabo un despliegue de tal envergadura [Akyildiz et al., 2005]:

- Requieren una instalación compleja por el medio en el que se encuentran, el acceso al fondo de mar requiere de instrumentación precisa y especializada.

- Las comunicaciones en el mar pueden ser o bien cableadas, si la profundidad lo permite, o bien con una comunicación inalámbrica mediante ondas acústicas. En cualquier caso, implica un buen estudio previo al despliegue para asegurar una comunicación fiable. 
- Al estar en el fondo del mar, si se trata de sistemas inalámbricos requieren una cierta autonomía mediante sistemas de alimentación específicos.

- La recuperación de los equipos es costosa y complicada.

\subsection{Conclusiones.}

Existe instrumentación oceanográfica muy variada en función de los parámetros oceanográficos que se deseen monitorizar. En la capa superficial se estudian parámetros atmosféricos que están directamente relacionados con el comportamiento del mar, además de variables oceanográficas como el oleaje y la temperatura del mar. Para ello se emplean sensores aéreos transportados, sistemas de teledetección, vehículos remolcados y boyas de superficie. En cuanto a la columna de agua, en la que se analizan los cambios de los parámetros a diferentes profundidades, se emplean perfiladores autónomos, AUVs o gliders. Y finalmente, para monitorizar el fondo del mar existen instrumentos de percepción remota o in situ que permiten estudiar las capas del fondo marino así como detectar pequeños seísmos. Todos estos sistemas son muy deterministas ya que están orientados a monitorizar una zona en concreto del medio marino.

Para el caso que nos ocupa en esta Tesis Doctoral, se presenta una boya multitarea capaz de incorporar sensores para monitorizar parámetros ambientales, de la superficie del mar, de la columna de agua y del fondo marino para aguas someras. En el diseño de la boya que será presentada más adelante, se han tenido en cuenta características mecánicas, electrónicas y de control remoto como las detallas en el apartado 3.2.4 del presente capítulo. El sistema completo está formado por un conjunto de boyas fijas interconectadas entre sí mediante comunicación inalámbrica aérea y que forman una WSN. Con esta solución se obtiene una elevada resolución temporal, si bien la resolución espacial estará limitada a la zona de despliegue. 
Propuesta de una Red de Sensores Inalámbrica para un Sistema de Observación Costero

Esta página se deja en blanco de forma intencionada.

$-46-$ 


\section{Capítulo 4}

\section{Redes de sensores inalámbricas aéreas para observación oceanográfica}

\section{T}

as redes de sensores inalámbricas se presentan como una solución alternativa e innovadora para la observación oceanográfica. Éstas permiten obtener una mayor resolución espacio-temporal de la información recogida a través de un despliegue con mayor densidad y menor coste. El objetivo es que diferentes nodos sensores formen una red, implementando diferentes topologias tanto físicas como lógicas, para el intercambio de información de forma inalámbrica, y sea un único nodo el encargado de transmitir dicha información hasta la estación base mediante la conexión de largo alcance requerida en cada situación. 


\subsection{Introducción.}

En este capítulo se dedica especial atención a los aspectos generales de las WSNs para la observación oceanográfica. Se plantea la importancia de las WSNs aplicadas a los SOCs como medio de solventar diversos problemas que existen en la tecnología aplicada en dichos sistemas en la actualidad. Se hace la distinción entre implantar una WSN terrestre y marina. Dentro del campo de las WSN marinas, se hace una breve comparación ente las UW-ASNs y A-WSNs analizando las ventajas e inconvenientes de cada una de ellas siendo estas últimas objetivo de las posteriores secciones. Tras proporcionar una descripción de los elementos que conforman una A-WSN para monitorización oceanográfica, se expone una perspectiva global de los sistemas desarrollados en la última década y basados en el empleo de estas redes. El estudio realizado se ha llevado a cabo a partir de los despliegues más significativos a nivel mundial que serán detallados más adelante.

Para cada uno de ellos se ha extraído la información más relevante y se ha realizado un estudio comparativo de las diferentes soluciones. Como resultado de dicho estudio se han identificado y resumido los principales elementos utilizados (infraestructura hardware/software) a la hora de implementar los diferentes sistemas de monitorización y las principales características de los mismos (magnitudes muestreadas, características del despliegue, harvesting systems, etc.).

\subsection{La importancia de las WSNs aplicadas a los SOCs.}

La innovación tecnológica, y en concreto, el desarrollo de nuevos sensores y plataformas de adquisición de datos en tiempo real es uno de los aspectos característicos de los SOCs. Estos desarrollos están encaminados, por un lado, a la progresiva mejora en la información obtenida (nuevas variables y mayor rango de escalas espacio-temporales analizadas) y, por otro lado, la transmisión en tiempo real de la información. En este sentido, han ido apareciendo instrumentos oceanográficos que incorporan sistemas de transmisión de datos basados en GSM o GPRS y que permiten cubrir áreas extensas. Estos instrumentos presentan varios inconvenientes. En primer lugar, cuando es necesario desplegar una gran cantidad de instrumentos, como es el caso de los observatorios oceanográficos costeros, aumentan los costes de explotación debido a la necesidad de contratar una línea de transmisión de datos por instrumento. Este problema se agrava si el tráfico de información es muy elevado. Por otro lado, en algunas ocasiones, en la zona de ubicación de los instrumentos no se dispone de acceso a la red comercial de transmisión de datos, o su acceso es problemático según las horas del día y el estado de ocupación de la red. Además, estos dispositivos tienen mayores requerimientos energéticos, ya que el 
consumo durante la transmisión de datos a través de dichas tecnologías es muy elevado, lo que reduce considerablemente su autonomía.

En relación con las WSNs, se están utilizando diferentes tecnologías para pequeñas potencias de transmisión y elevada autonomía de los nodos sensores. Comunicaciones acústicas [Akyildiz et al., 2005] entre los diferentes nodos de la red para cubrir áreas no muy extensas, y señales de radio de distinta frecuencia (173 MHz [Fitz et al., 2005], $433 \mathrm{MHz}$ [Seders et al., 2007], $900 \mathrm{MHz}$ [Consi et al., 2008], 2,4 GHz [O’Flynn et al., 2007]) que se utilizan cuando se puede acceder a la superficie del agua y que permiten coberturas en el rango de $100 \mathrm{~m} \mathrm{-} 2 \mathrm{~km}$. Luego, las WSNs tanto aéreas como submarinas, son una tecnología emergente con un prometedor futuro dentro del campo de la observación oceanográfica costera y que presentan numerosas ventajas frente a las soluciones basadas en instrumentos con conectividad GSM/GPRS:

- Los nodos de las WSNs presentan un bajo consumo de energía y suelen ser dispositivos de bajo coste.

- Utilizando diferentes topologías y mediante un protocolo multi-hop entre nodos, los datos pueden transmitirse desde un nodo Sensor hasta un nodo Sumidero localizado a varias millas.

Un área extensa se puede cubrir mediante subredes de topología adecuada y asociándoles a cada una de ellas un único nodo con conexión GSM/GPRS. De este modo disminuyen drásticamente los costes de explotación debidos a las líneas de transmisión de datos.

\subsection{WSNs terrestres frente a WSNs marinas.}

El diseño, implementación y despliegue de una WSN para aplicaciones oceanográficas ofrece nuevos retos frente al caso terrestre ya que el impacto del medio marino sobre la red de sensores limita y condiciona su desarrollo. Algunas de las diferencias más destacadas son las siguientes:

- El medio marino representa un entorno agresivo que exige mayores niveles de protección de los dispositivos.

- Es necesario prever el movimiento de los nodos como consecuencia de mareas, olas, embarcaciones, etc.

- El consumo de energía es elevado dado que, generalmente, los sensores tienen mayores requerimientos energéticos, es necesario cubrir distancias mayores que en el ámbito agronómico, se produce mayor atenuación de las señales de comunicaciones por reflexiones en el mar, y además, al contrario que en las WSNs terrestres, el 
movimiento de los nodos debido al oleaje puede originar una menor calidad de la conexión con las consiguientes reconexiones necesarias.

- El precio de la instrumentación de sensorización es generalmente mayor que en el caso de una WSN terrestre.

- Existen problemas añadidos en el despliegue y el acceso a los motes, la necesidad de mecanismos de flotabilidad y fijación, y los posibles actos de vandalismo entre otros.

A pesar de estas desventajas, es posible encontrar en la literatura distintos casos de estudio de monitorización de ecosistemas marinos utilizando WSNs [Cella et al., 2009; Freitas et al., 2009; Guo et al., 2008; Jiang et al., 2009; Tatesonet al., 2005; Voigt et al., 2007; Yang et al., 2009; Seders et al., 2007; O’Flynn et al., 2007; Ruberg et al., 2007]. Estas soluciones tienen en común el hecho de estar diseñadas e implementadas mayoritariamente ad-hoc (boyas, electrónica y software) siendo normalmente los sensores oceanográficos y algunos otros componentes los únicos elementos adquiridos a terceros.

\subsection{Redes de sensores inalámbricas submarinas vs. aéreas.}

Es posible distinguir en la literatura científica dos grandes categorías de redes de sensores inalámbricas marinas dependiendo del medio de transmisión de datos que utilicen: WSNs basadas en comunicaciones submarinas, UW-ASNs, y las basadas en comunicaciones aéreas vía radio, A-WSNs.

Una UW-ASN [Akyildiz et al., 2005] consiste en un número variable de sensores y vehículos que son desplegados para realizar tareas de monitorización sobre un área dada. En condiciones submarinas, las ondas de RF se atenúan muy rápidamente y no son de utilidad. En dichas condiciones, las ondas de radio sólo se propagarían a muy bajas frecuencias (30-300 Hz) lo que supondría disponer de antenas especiales y un suministro de potencia mucho más elevado.

Algunos problemas que presentan este tipo de UW-ASNs son [Akyildiz et al., 2005]: ancho de banda limitado, los retardos de propagación son cinco órdenes de magnitud mayores que en canales terrestres RF y mayor velocidad de error de bit y pérdidas temporales de la conectividad. Por tanto, las UW-ASNs se adoptan como solución únicamente para hacer viable la monitorización oceanográfica a grandes profundidades, que involucren por ejemplo el uso de AUVs equipados con sensores submarinos.

Las A-WSNs [Xia et al., 2007] están formadas por un conjunto de nodos con escasas necesidades energéticas, que además se comunican entre sí mediante módulos de radio de bajo consumo. Además, pueden contar con un nodo que dispone de mayores recursos 
energéticos y que actúa como coordinador de la red. Éstos se comunican con una estación remota por medio de conexiones de mayor alcance (por ejemplo vía satélite o GPRS). No hay que confundir este tipo de redes con aquellas en las que cada nodo tiene elevados recursos energéticos y que se comunica directamente con la estación base.

Las A-WSNs no presentan los problemas de conectividad mencionados anteriormente en relación con las UW-ASNs (atenuación de las ondas RF, ancho de banda limitado y propagación a muy bajas frecuencias), sin embargo presentan otros problemas, como por ejemplo la necesidad de transmitir mediante cables la información procedente de los sensores submarinos hasta las boyas en superficie. En el caso de que estos sensores se encuentren situados a elevadas profundidades los problemas que surgen pueden ser también importantes. Se puede decir por tanto que no hay una solución ideal y que dependiendo del caso será más adecuado utilizar una u otra tecnología.

El caso de estudio tratado en esta Tesis Doctoral tiene como objetivo la monitorización de una laguna costera somera, el Mar Menor. Como se explicó en este apartado, las UWASNs se adoptan como única solución ante la monitorización de zonas con grandes profundidades, siendo las A-WSNs utilizadas para el resto de situaciones, como es el caso que nos ocupa. Además, teniendo en cuenta la experiencia adquirida en el grupo de trabajo de WSNs del DSIE en trabajos anteriores en el ámbito de las A-WSNs en agricultura de precisión [López, 2011], la elección de la tecnología empleada de las presentadas en este capítulo se centra en el despliegue de una A-WSN, cuyas características serán detalladas en capítulos posteriores. Por ello, a continuación únicamente se describen las A-WSNs para monitorización oceanográfica, descartando por tanto las UW-ASNs.

\subsection{A-WSNs para monitorización oceanográfica.}

En esta sección se detallan los distintos componentes que integran una red A-WSN y los recursos necesarios para un despliegue oceanográfico.

\subsubsection{Arquitectura del nodo sensor.}

En la Figura 4.1 se detalla los elementos habituales utilizados en el diseño e implementación de un nodo Sensor (mote). Como puede observarse, es habitual la consideración de un elemento de flotación tipo boya con el propósito de mantener parte del nodo fuera del agua. Esta parte exterior incluye siempre una antena para transmisión por RF, opcionalmente un harvesting system (panel solar, generador eólico, etc.) como complemento al sistema de alimentación y, en algunos casos, uno o más sensores exteriores para monitorizar fundamentalmente valores meteorológicos (velocidad del viento, temperatura y humedad del ambiente, etc.). La parte sumergida del nodo está compuesta 
por uno o más sensores, que pueden estar dispuestos a diferentes profundidades, y por último, un sistema de fijación o anclaje de la boya al fondo para evitar los desplazamientos (por corrientes marinas, vientos, olas, etc.).

La electrónica del mote incluye: un módulo dedicado a las transmisiones por RF, un sistema de regulación de alimentación y de gestión de fuentes energéticas, un conjunto de interfaces para el acceso a los sensores, un módulo para la amplificación, conversión (analógico a digital) y multiplexación de los valores leídos desde los sensores (de superficie y submarinos), una memoria permanente de lectura/escritura tipo FLASH, un reloj que haga las veces de temporizador y, por último, la CPU (microprocesador) que centraliza todo el proceso e implementa la funcionalidad definida por el usuario para la monitorización.

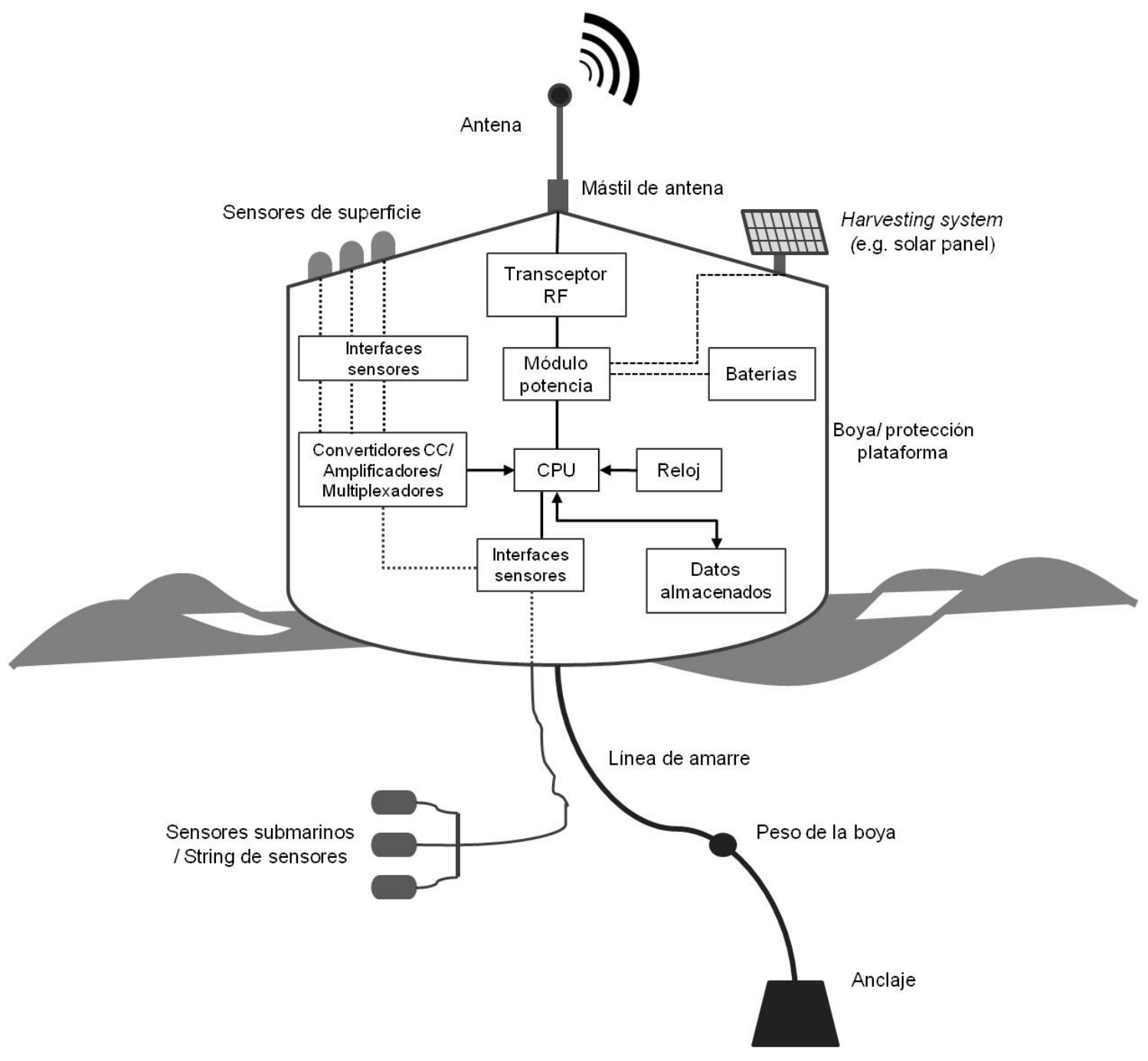

Figura 4.1. Esquema general de un nodo sensor para oceanografia. 


\subsubsection{Arquitectura general de una A-WSN.}

La Figura 4.2 muestra una arquitectura general de una A-WSN para monitorización oceanográfica. En ella pueden apreciarse dos mecanismos habituales de comunicación: punto a punto vs. multihop. En algunas situaciones, suele existir algún nodo próximo a la estación base y comunicarse con la ésta vía RF para el intercambio de información. En otras ocasiones, en las que la distancia entre los nodos y la estación base es muy grande, se pueden utilizar nodos intermedios o bien una comunicación de largo alcance.

En términos generales, las diferencias entre un despliegue y otro vendrán dadas fundamentalmente por decisiones sobre:

- La topología de la red.

- Las dimensiones del área que se va a monitorizar.

- Los mecanismos/protocolos de comunicación utilizados y las frecuencias de radio escogidas.

- La cantidad de nodos utilizados en el despliegue.

- Las facilidades de acceso a los nodos para reparación o repliegue (mantenimiento).

- Los sistemas de flotabilidad y anclaje utilizados.

- Los tipos de sensores oceanográficos considerados.

- Las herramientas para la monitorización de la red desarrolladas para visualizar en tiempo real los datos recogidos.

- La electrónica para llevar a cabo de forma autónoma el muestreo de los parámetros requeridos y el envío de información de forma inalámbrica a un servidor de datos.

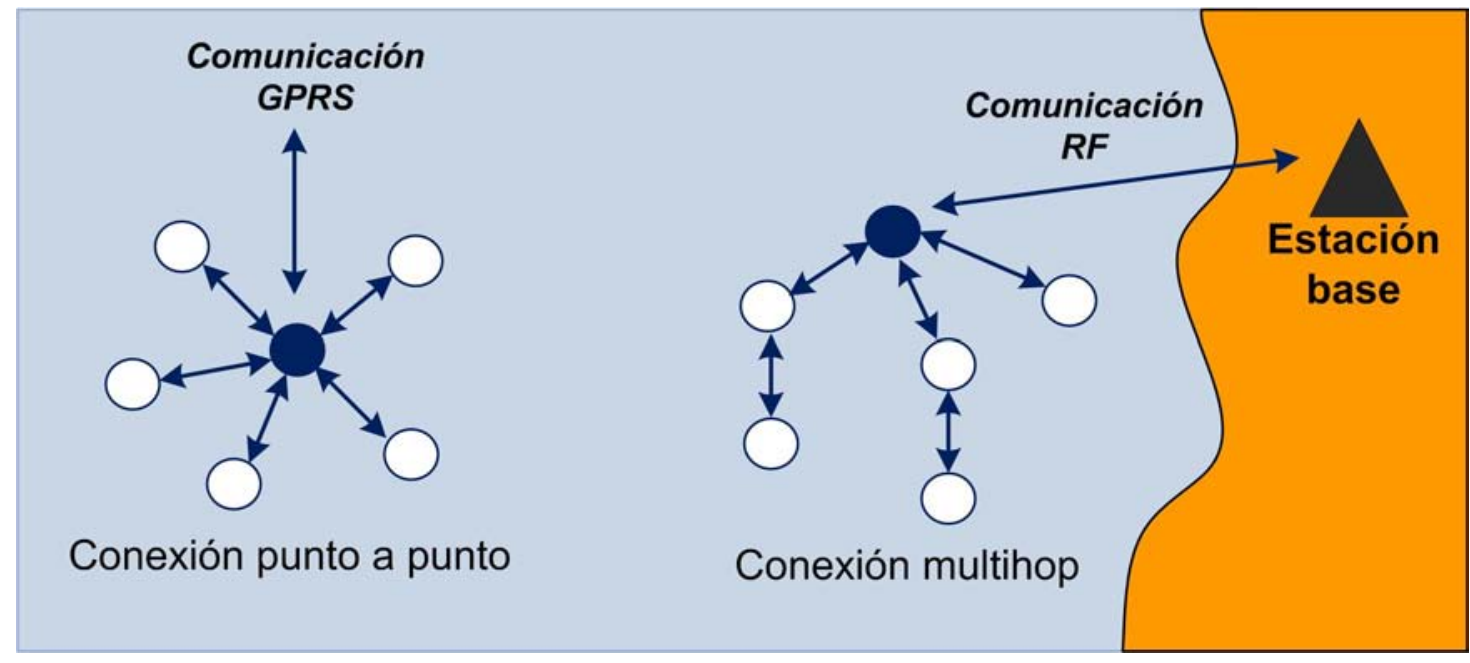

Figura 4.2 Estructura general de una A-WSN para monitorización oceanográfica.

En general, los elementos que integran una A-WSN son comunes independientemente del ámbito de aplicación (nodos inalámbricos, un protocolo de comunicaciones y una 
aplicación de monitorización). Aún así, suelen existir diferencias dependiendo del ámbito de despliegue. Una de estas diferencias más obvias, como se detalla más adelante, es el tipo de sensores que se van a utilizar que serán muy específicos del medio que se va a monitorizar y del propósito que se persigue.

\subsubsection{Comunicaciones inalámbricas.}

La topología física de la red y la densidad son completamente dependientes de la aplicación [Li y Yang, 2006]. Antes de llevar a cabo el despliegue de una A-WSN es necesario analizar el medio en el cual será instalada. Esto implica elegir el número de nodos adecuado y su posición dentro del área de monitorización. Los despliegues más densos mejoran la precisión de los datos y proporcionan una mayor conectividad en la red. Sin embargo, al mismo tiempo una infraestructura más densa puede afectar negativamente a la funcionalidad de la red (colisiones, interferencias, etc.) [Zeng et al., 2010]. De este modo, la densidad de la red, la topología física y el tipo de comunicación determina la elección de la topología lógica.

Cada topología tiene características propias que hacen que sean ventajosas o no sobre otras en términos de atributos de funcionamiento de la red como tolerancia a fallos y conectividad. Por ese motivo, dependiendo del conjunto de requisitos de funcionamiento de la red es posible que sea necesario descartar unas topologías frente a otras. De entre las topologías más habituales para la interconexión de nodos en una red, las topologías lógicas más utilizadas para A-WSNs son Tree, Chain, Partially Connected and Star (ésta última marcada como 'Conexión Punto a Punto' en la Figura 4.2). Es importante reseñar que después del despliegue, la topología física puede cambiar debido a variaciones en la posición de los nodos sensores, problemas en el alcance para establecer la comunicación entre nodos (debido al ruido, obstáculos en movimiento, etc.), energía disponible, mal funcionamiento y detalles de tarea [Kim et al., 2009].

Para la comunicación inalámbrica el nodo sensor incorpora un módulo de radio RF siendo un requisito para su elección el alcance del despliegue en cuestión. En el entorno agronómico, en el que las distancias a cubrir no suelen superar los 300 ó $400 \mathrm{~m}$, con dicho módulo de radio sería suficiente para dar cobertura a la zona de monitorización. En cambio, en el ámbito oceanográfico, ya que las distancias a cubrir son mayores, se suele integrar además un módulo amplificador para transceptores RF, denominados también range extenders, con el objetivo de incrementar el alcance del enlace, proporcionando así una amplificación que mejora tanto la potencia de salida como el Low Noise Amplifier (en adelante LNA). Otra opción, cuando la distancia no es posible cubrirla con este tipo de dispositivos, es incluir un módulo GSM/GPRS que permita realizar conexiones de muy largo alcance en aquellos lugares en los que haya cobertura GPRS.

Para la comunicación entre los nodos sensores es posible, o bien desarrollar protocolos de comunicaciones sobre la capa de enlace de datos a partir de diferentes mecanismos de acceso al medio (tales como TDMA, FDMA y CSMA), o bien soportados sobre diferentes estándares y tecnologías de comunicación inalámbrica (ver Tabla 4.1). 
Capítulo 4. Redes de sensores inalámbricas aéreas para observación oceanográfica

Tabla 4.1 Tecnologías de comunicación inalámbrica.

\begin{tabular}{ccl}
\hline Tecnología & Estándar & \multicolumn{1}{c}{ Descripción } \\
\hline WiFi & IEEE 802.11n & $\begin{array}{l}\text { Sistema de envío de datos de forma inalámbrica sobre } \\
\text { redes computacionales }\end{array}$ \\
\hline WiMAX & IEEE 802.16 & Norma de transmisión de datos usando ondas de radio \\
\hline Bluetooth & IEEE 802.15.1 & $\begin{array}{l}\text { Especificación industrial para Wireless Personal Area } \\
\text { transmisión de voz y datos entre diferentes dispositivos } \\
\text { mediante un enlace por radiofrecuencia segura y } \\
\text { globalmente libre (2,4 GHz) }\end{array}$ \\
\hline GSM & IEEE 802.15.4 & $\begin{array}{l}\text { Sistema estándar para la comunicación mediante teléfonos } \\
\text { móviles que incorporan tecnología digital }\end{array}$ \\
\hline GPRS & $\begin{array}{l}\text { Extándar que define el nivel físico y el control de acceso al } \\
\text { medio de WPANs con tasas bajas de transmisión de datos }\end{array}$ \\
\hline ZigBee & IEEE 802.15.4 la transmisión de datos no conmutada \\
& $\begin{array}{l}\text { Especificación de un conjunto de protocolos de alto nivel } \\
\text { de comunicación inalámbrica para su utilización con radios } \\
\text { digitales de bajo consumo, basada en el estándar IEEE } \\
\text { 802.15.4 de WPANs }\end{array}$ \\
\hline
\end{tabular}

La elección de una u otra tecnología dependerá de los requisitos de la A-WSN que se pretenda realizar, principalmente de la cantidad de información que se debe enviar así como de si requiere el envío de imágenes en tiempo real. Otro de los requisitos a tener en cuenta son las distancias máximas a cubrir en un enlace de comunicaciones pues determina la elección de la antena RF. Existen varios tipos de antenas (omnidireccionales, sectoriales, etc.) que se eligen atendiendo a características como el diagrama de radiación, el ancho de banda necesario, la directividad, la ganancia, la eficiencia, la anchura de haz y la polarización deseada. En el caso de los nodos sensores resulta más eficaz la comunicación con antenas omnidireccionales de forma que la potencia radiada sea igual en todas direcciones. Esto es necesario puesto que, debido al movimiento del mar, el nodo sensor puede sufrir desplazamientos rotacionales, verticales u horizontales modificando la posición inicial de la boya. El inconveniente de este tipo de antenas es que, al estar más dispersa la potencia radiada se obtiene un menor alcance que con antenas directivas. Las antenas directivas requieren un alineamiento adecuado canalizando la potencia en una dirección, consiguiendo de esta forma un mayor alcance en dicha dirección y evitando así, en algunos casos, interferir con otros servicios. Un factor importante que se debe tener en cuenta es la altura de la antena sobre el elemento de flotación que sostiene el nodo ya que, en grandes distancias, la línea de visión no es suficiente para la propagación debido a la atenuación, por tanto se requiere línea de visión RF. El alcance entre nodos está condicionado por dicha altura según la Zona de Fresnel la cual nos indica que para obtener una buena línea de visión RF, el radio de la Zona de Fresnel debe ser menor que la altura de las antenas conjunta [Carr, 2001]. 


\subsubsection{Sensores oceanográficos.}

Para la monitorización de parámetros oceanográficos (físicos, químicos y biológicos) existen numerosos tipos de sensores. Para la elección adecuada de un sensor hay que tener en cuenta los requisitos definidos por el usuario y aquellos impuestos por las características de la zona de despliegue. Entre ellos se pueden destacar el rango de medida del parámetro a medir, el lugar en el que se pretende desplegar el sensor, la sensibilidad y la linealidad. Otras características a tener en cuenta son exactitud, precisión, resolución, velocidad de muestreo, consumo y tiempo de despliegue. Los parámetros más habituales de medida de un entorno marino y sus unidades de medida se muestran en la Tabla 4.2. Además, dependiendo del sensor utilizado habrá que tener en cuenta la posición del mismo dentro del nodo así como la profundidad a la que se va a desplegar dentro del agua. Por ejemplo, para obtener el perfil de temperatura de una columna de agua será necesario ubicar varios sensores de temperatura a diferentes profundidades en una misma vertical.

Tabla 4.2 Sensores oceanográficos habituales.

\begin{tabular}{|c|c|}
\hline Parámetros medidos & Unidades \\
\hline Temperatura & ${ }^{\circ} \mathrm{C},{ }^{\circ} \mathrm{F}$ \\
\hline Presión & mbar \\
\hline Salinidad (Conductividad) & $\mathrm{g} / \mathrm{l}$ \\
\hline Velocidad del agua & $\mathrm{m} / \mathrm{s}$ \\
\hline \multirow{4}{*}{ Turbidez } & FTU (Formazin Turbidity Unit) \\
\hline & NTU (Nephelometric Turbidity Units) \\
\hline & JTU (Jackson Turbidity Unit) \\
\hline & $\mathrm{mg} / \mathrm{I} \mathrm{SiO}_{2}$ \\
\hline Clorofila & $\mu \mathrm{g} / \mathrm{l}$ \\
\hline Oxígeno disuelto & $\mathrm{mg} / \mathrm{l}$ \\
\hline Nitratos & $\mathrm{mg} / \mathrm{l}$ \\
\hline$p H$ & pKa \\
\hline \multirow{2}{*}{ Oleaje } & Altura: metros \\
\hline & Dirección: grados \\
\hline Phycocyanin (en algas) & Unidades relativas de fluorescencia \\
\hline Amoníaco & $\mathrm{mg} / \mathrm{l}-\mathrm{N}$ \\
\hline Cloruro & $\mathrm{mg} / \mathrm{l}$ \\
\hline Rodamina & $\mu \mathrm{g} / \mathrm{l}$ \\
\hline Hidrocarburos & ppm \\
\hline
\end{tabular}

Por otro lado, el nodo sensor puede ir dotado de sensores de superficie (ver Tabla 4.3) que suelen ser de utilidad para conocer parámetros de la superficie del agua o del aire. Por ejemplo, ante condiciones atmosféricas adversas el nodo Sensor puede tomar la decisión de 
aumentar su frecuencia de muestreo para obtener una monitorización más precisa del entorno.

Tabla 4.3 Sensores de superficie.

\begin{tabular}{cc}
\hline Parámetros medidos & Unidades \\
\hline Temperatura del aire & ${ }^{\circ} \mathrm{C},{ }^{\circ} \mathrm{F}$ \\
\hline Velocidad del viento & $\mathrm{m} / \mathrm{s}$ \\
\hline Dirección del viento & grados \\
\hline Precipitaciones & $\mathrm{mm}$, inch \\
\hline Presión atmosférica & $\mathrm{mbar}$ \\
\hline Humedad relativa & $\% \mathrm{RH}$ \\
\hline Radiación Solar & $\mathrm{W} / \mathrm{m}^{2}$ \\
\hline Salinidad de superficie & $\mathrm{ppt}$ \\
\hline Conductividad de superficie & $\mathrm{S} / \mathrm{m}$ \\
\hline
\end{tabular}

\subsubsection{Implementación hardware y software del nodo.}

Algunas implementaciones del nodo Sensor reutilizan soluciones comerciales (MicaZ®,

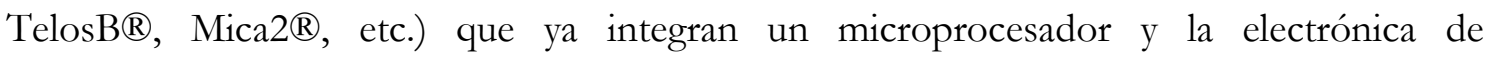
comunicaciones (módulos de radio y antenas). Estos motes suelen tener asociado un conjunto de herramientas de desarrollo software (sistema operativo, lenguajes de programación y componentes reutilizables) junto con soporte técnico del proveedor. Cuando las características de estos motes comerciales no son suficientes o adecuadas, es habitual el desarrollo ah-doc de los nodos sensores utilizando para ello los componentes electrónicos indicados en la Figura 4.1.

El principal componente es un microcontrolador de baja potencia que representa el núcleo de la plataforma y está encargado de gestionar el comportamiento del nodo. Este microprocesador debe tener una serie de características que le hagan adecuado para AWSNs: su arquitectura, combinada con algunos modos de baja potencia, tiene que ser optimizada para lograr una elevada duración de las baterías en aplicaciones de medidas portátiles. Por otro lado, es necesario que incluya varias interfaces de comunicaciones universales síncronas/asíncronas (tales como UART, $\mathrm{I}^{2} \mathrm{C}$, SPI, etc.) para poder integrar sensores con distintos tipos de señales eléctricas.

El tiempo de vida de la red depende de la autonomía de los nodos sensores. La alimentación suele proporcionarse mediante baterías que pueden ser complementadas con sistemas de recolección de energía (por ejemplo paneles solares o generadores eólicos) para aumentar la vida útil del nodo sensor. En ocasiones, es necesario realizar una adaptación de tensiones entre la alimentación del nodo y el resto de componentes mediante convertidores CC/CC. 
La inclusión de una memoria permanente de lectura/escritura tipo FLASH dota al mote de mayor robustez, pues permite el almacenamiento de datos y la comunicación posterior cuando las condiciones lo permitan, evitando así la pérdida de información.

Otro componente a tener en cuenta es un reloj en tiempo real (Real Time Clock, en adelante RTC) de bajo consumo. La disponibilidad de un reloj permite que cuando se realiza la lectura de un sensor, ésta pueda almacenarse junto con el instante en el que se leyó. Posteriormente, podrá enviarse dicha información al servidor de datos que será importante a la hora de realizar el análisis de los datos obtenidos.

\subsubsection{Aplicación de monitorización.}

La información recogida por los nodos Sensores tiene que ser transmitida hasta una estación base que incluya un sistema de almacenamiento masivo de datos y que será de utilidad para realizar los estudios necesarios de acuerdo con los modelos teóricos oceanográficos existentes. La integración de herramientas de monitorización permite mantener en todo momento la comunicación con la red de sensores desplegada, y el acceso vía Internet a los datos almacenados. Dichas herramientas suelen mostrar información relativa fundamentalmente al número de nodos desplegados, los parámetros analizados, la ubicación geográfica de cada nodo, los datos más recientes recogidos por los nodos sensores, y la visualización de un histórico de datos. Un ejemplo de aplicación de monitorización es la mostrada en la Figura 4.3, donde pueden apreciarse los elementos habitualmente integrados: (1) un área de datos (parte izquierda) donde se representan estadísticas de datos relativos a un determinado subconjunto de la WSN y de un espacio temporal seleccionado por el usuario y (2), una representación bidimensional del despliegue realizado (parte derecha) junto con utilidades para visualizar los últimos datos recogidos por los sensores seleccionados en dicha área gráfica (en el ejemplo se ha utilizado Google Maps ${ }^{\circledR}$ y las APIs necesarias para integrar los puntos de interés).

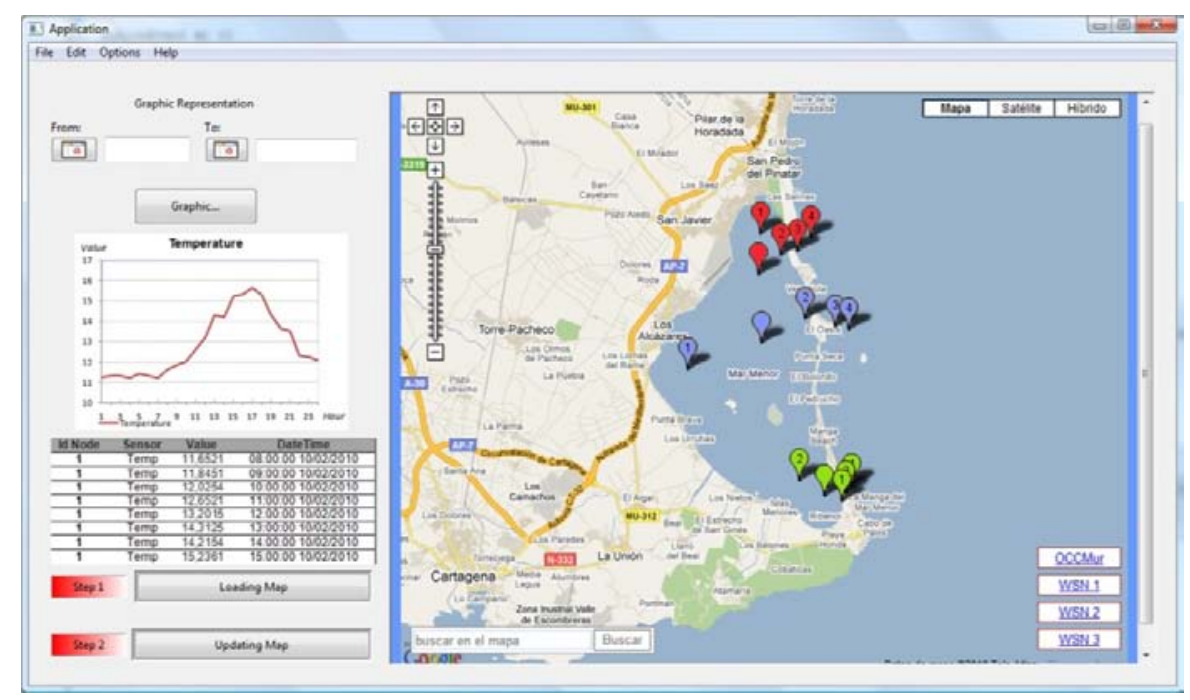

Figura 4.3 Ejemplo de aplicación de usuatio de una A-WSN oceanográfica. 


\subsection{Discusión de los casos de estudio de A-WSNs analizados.}

En este apartado se describen los diferentes casos de estudios encontrados en la literatura de A-WSNs. En la Figura 4.4 puede observarse que los despliegues se distribuyen entre Norte América, Europa, China y Australia, lo cual es representativo del interés mundial en avances en este campo. En once de los doce estudios participan universidades y en la mitad de ellos intervienen centros de estudios marinos especializados.

La totalidad de los despliegues realizados estaban destinados a la monitorización de aguas costeras siendo los parámetros de mayor interés las mediciones de temperatura, $\mathrm{pH}$, turbidez y oxígeno disuelto. Las topologías más habituales eran Star (point to point) y Partially Connected. La banda más utilizada de radio es la de 2,4 GHz ISM. Por último, destacar que once de los doce sistemas estaban basados en el uso de baterías considerando en seis de los doce la inclusión de paneles solares.

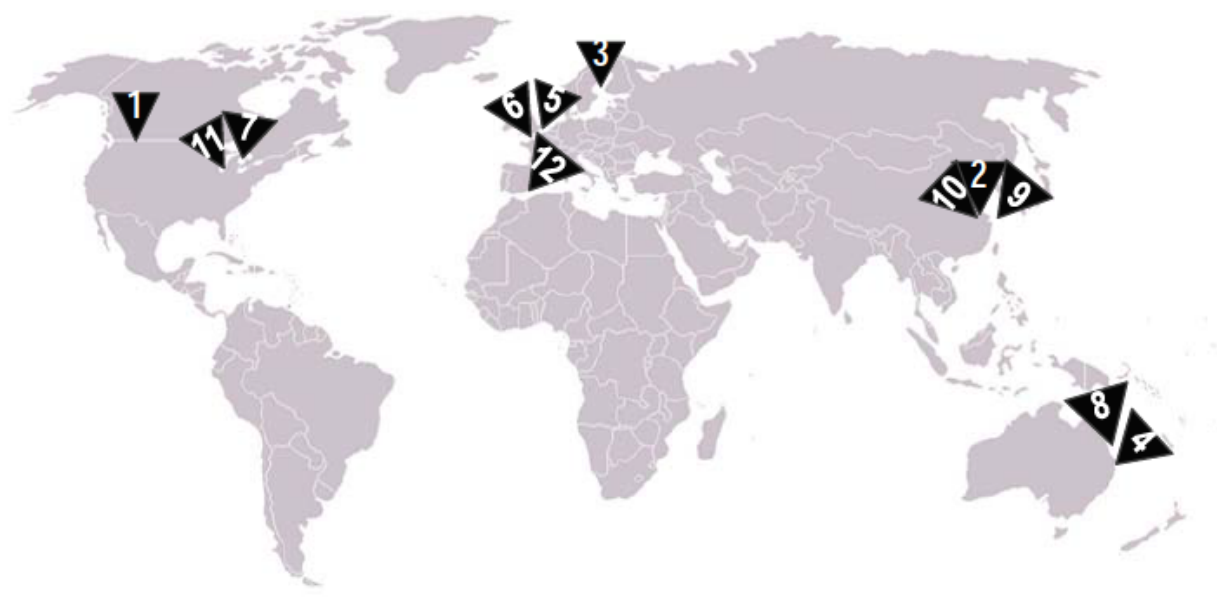

Figura 4.4 Mapamundi con ubicación de los despliegues estudiados.

El acceso y la preservación de los elementos de una A-WSN para oceanografía conlleva una serie de dificultades añadidas a las que se pueden dar en el medio terrestre. Es por ello que se hace imprescindible definir una estrategia de mantenimiento del sistema que minimice los costes asociados y que preserve la funcionalidad para la que fue concebida.

El mantenimiento de una red una vez desplegada tiene que ver fundamentalmente con tres aspectos bien diferenciados: (1) el mantenimiento de los elementos de sensorización y comunicaciones (antenas) por pérdida de funcionalidad o deterioro (biofouling, calibración, orientación, etc.); (2) el mantenimiento del sistema energético (baterías, paneles solares, etc.); y (3) el mantenimiento de la infraestructura y topología de la red (por ejemplo degradación del funcionamiento, sincronización de relojes, actos de vandalismo, etc.). A continuación se detallan estos aspectos a partir de los resultados del estudio:

1) Cuando se realizan observaciones en un largo periodo de tiempo, los sensores son susceptibles al biofouling. Por ello, es necesario dedicar una especial atención a la calidad de los instrumentos utilizados ya que, a corto plazo, el efecto del biofouling 
puede ser considerable (en ocasiones la calidad de las medidas pueden ser perturbadas en menos de una semana). Hay muchas técnicas que han sido estudiadas para prevenir el biofouling en materiales [Delauney et al., 2009]. La protección contra el biofouling para sensores oceanográficos deberían tener en cuenta aspectos como:

a. No debe afectar a las mediciones ni al entorno.

b. No deben consumir demasiada energía para preservar el funcionamiento del sistema de monitorización autónomo.

c. Debe ser fiable incluso en condiciones agresivas.

El tratamiento de superficies basado en pinturas antifouling principalmente se usa para proteger la carcasa de los sensores. El uso de radiación ultravioleta es una alternativa muy interesante y no invasiva para el medio marino, pero con la tecnología actual no es viable dado el elevado consumo de energía que conlleva. Otro modo de protección es utilizar cobre para recubrir los elementos más sensibles del sensor aunque el coste es también elevado. En suma, es un factor muy importante que se debe tener en cuenta por parte de los diseñadores de los nodos Sensores. La calibración de los elementos sensores suele realizarse necesariamente con instrumentación no portable, lo que obliga a acceder al nodo para obtener el sensor y calibrarlo en el laboratorio. Las operaciones de mantenimiento relativas a reubicación del nodo sensor pueden realizarse sin necesidad de extraer el nodo Sensor de la red.

2) Para el sistema de alimentación del nodo, y dependiendo de los elementos utilizados, será necesario un mantenimiento a corto, medio o largo plazo. El uso de baterías limita la funcionalidad, en condiciones normales, a algunas semanas o incluso meses. Por ello, es necesario considerar el uso de energías renovables como la solar, la eólica, la undimotriz (olas) o mareomotriz para reducir considerablemente la necesidad de mantener el sistema. De todos ellos, la solar es la más utilizada por la disponibilidad prácticamente constante de radiación lumínica así como por la experiencia acumulada en la integración de paneles solares como complemento energético en los despliegues de A-WSNs [Wang et al., 2007].

3) Con respecto de la topología e infraestructura de la red, uno de los principales retos para A-WSNs es disponer de una red que funcione sin sacrificar los requisitos de rendimiento, cobertura de sensorización y conectividad definidos originalmente [Zeng et al., 2010]. En el caso oceanográfico las posibilidades de alteraciones en la topología física original se ven incrementadas por ser el mar un medio en continuo movimiento (olas, mareas, etc.). Son por ello de interés el uso de técnicas que permitan monitorizar la situación de la red y las posibles variaciones con respecto a su despliegue inicial (el ideal) [Knight et al., 2008]. Al mismo tiempo, se han invertido grandes esfuerzos en el diseño de métodos de envíos de mensajes de forma eficiente [Qiu et al., 2009]. Teóricamente, los sistemas point-to-point son los más fiables ya que sólo hay un único punto de fallo en la topología (el Coordiandor o host). Además, es posible mejorar la robustez del sistema añadiendo hosts adicionales. Sin embargo, las limitaciones en el alcance de la señal pueden obligar a considerar otras topologías que ofrezcan una 
cobertura más amplia al tiempo que minimicen los riesgos de caída de la red por fallo de un único nodo [Kim et al., 2009].

En todos los casos estudiados, se ha identificado como de vital importancia el diseño del elemento flotador (boya). Por un lado, es importante realizar un análisis de los elementos y pesos que configuran el nodo, ya que determinado peso a distancias considerables de la línea de flotación de la boya provocan inestabilidades representadas por oscilaciones con amortiguamientos lentos que pueden provocar el vuelco de la misma. Por otro lado, elementos como la batería y la electrónica cerca de la línea de flotación, requieren mayor esfuerzo a la hora de aislar adecuadamente el recinto que los contiene. No hay que olvidar el efecto Fresnel que conlleva elevar en lo posible la antena de comunicaciones para mejorar en lo posible la robustez y calidad en las comunicaciones del nodo. Se han identificado diversas implementaciones de boyas atendiendo a la ubicación de los componentes (electrónica, radio, baterías, sensores) y al sistema de anclaje. La Figura 4.5 muestra las situaciones más representativas extraídas del estudio, que pueden variar considerando la ubicación de los sensores.

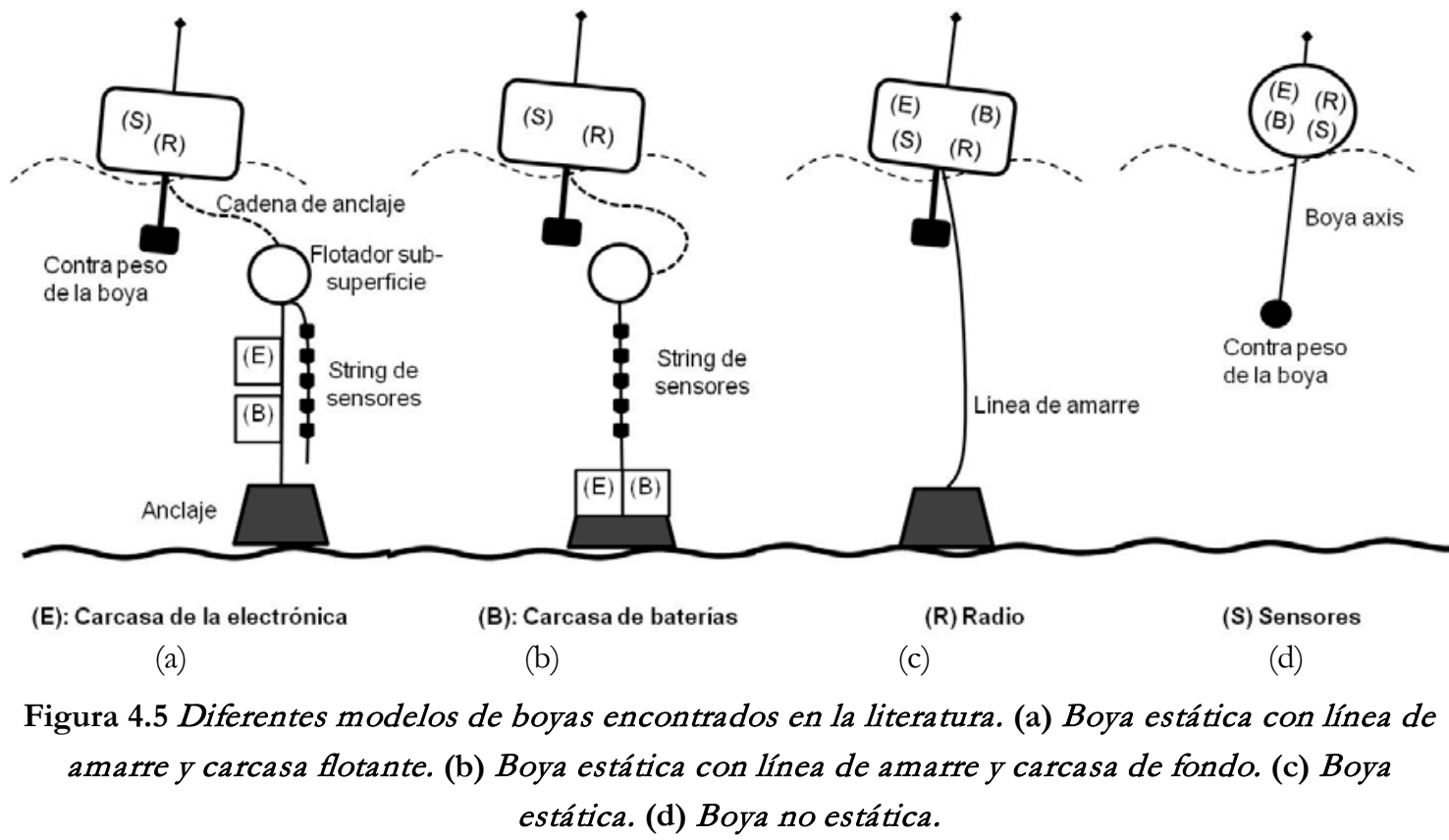

En las Tabla 4.4 y Tabla 4.5 se recogen los principales aspectos organizacionales de los casos de estudio analizados, y los detalles técnicos de cada unos de ellos, respectivamente. 


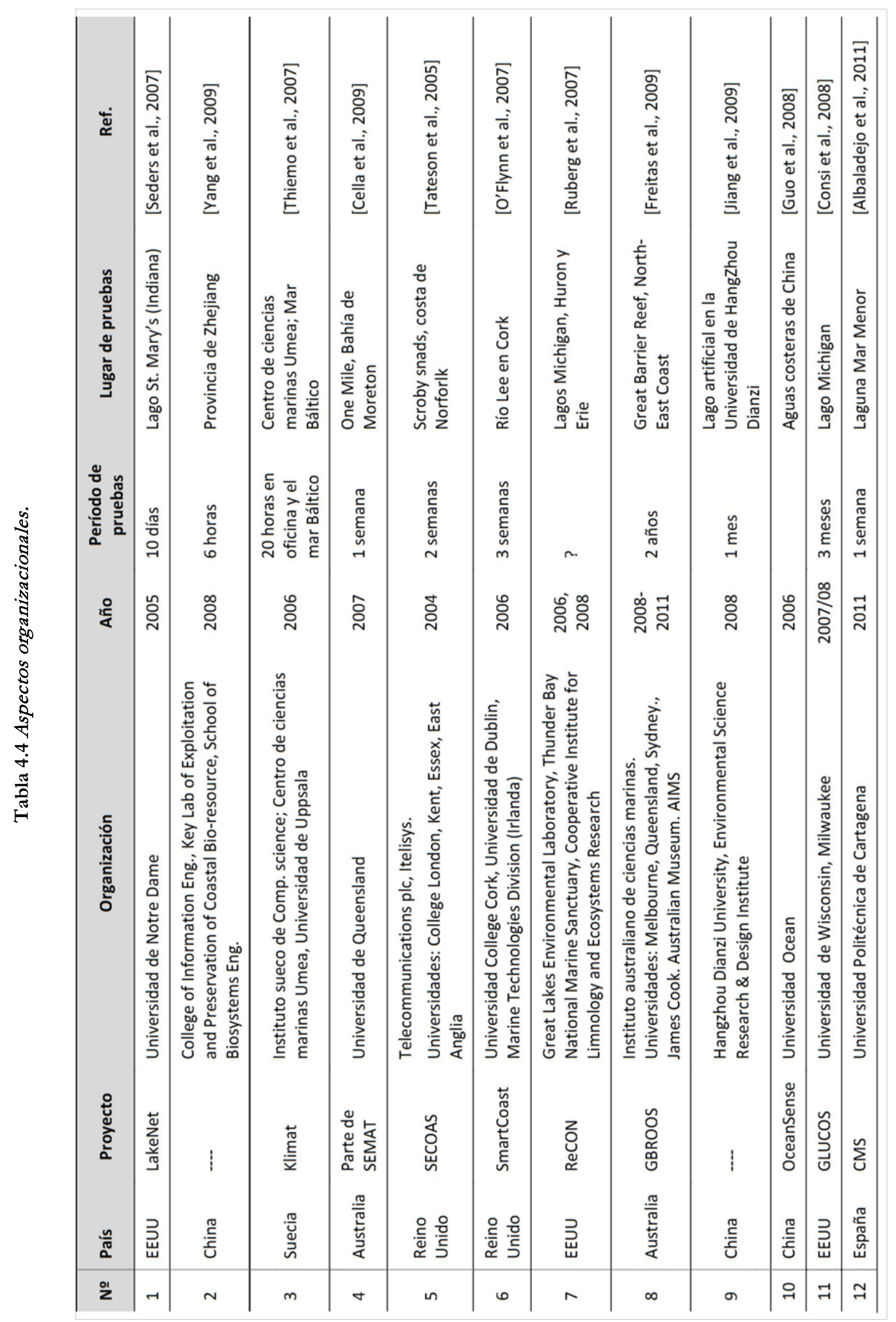




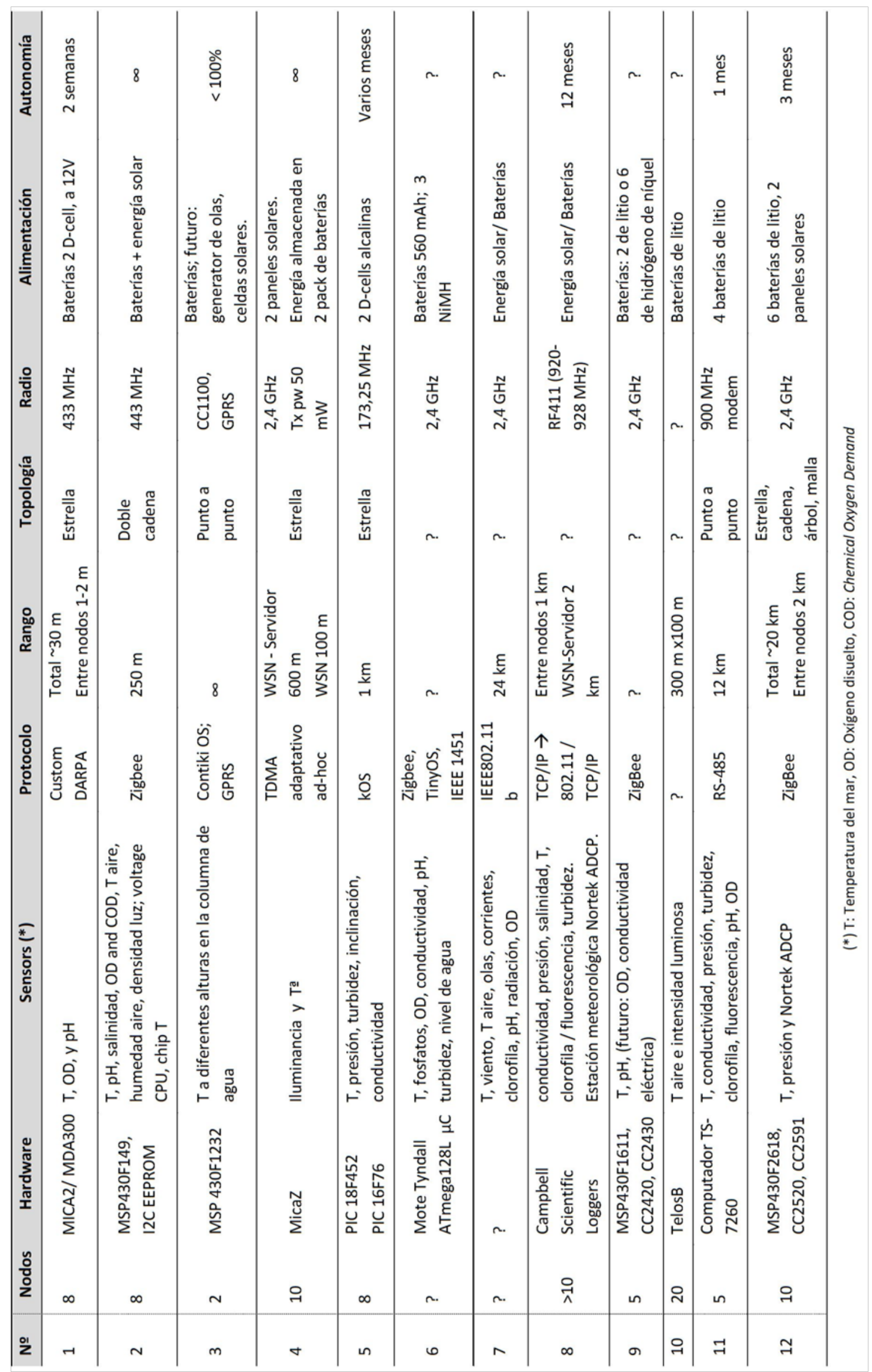


En resumen del alcance de los proyectos presentados en las tablas anteriores, desde el punto de vista del despliegue, los datos recogidos y su continuidad en el tiempo, la mayor parte de las A-WSNs estudiadas cubren zonas marinas relativamente poco extensas de unos pocos kilómetros (no más de 20) siendo la distancia entre nodos del orden de 100-250 m. En cuanto a la resolución temporal en la mayoría de los casos estudiados se muestreaban los datos con períodos de entre 5 y $10 \mathrm{~min}$. Estos datos revelan una mayor resolución espacio-temporal que la conseguida con las redes de boyas utilizadas en los observatorios oceanográficos costeros. En éstos, la resolución espacial es del orden de kilómetros desde el punto de vista espacial y la resolución temporal de horas o días. No obstante, en los observatorios costeros el área cubierta suele ser mucho mayor, pudiendo llegar a los centenares de kilómetros.

Por último, habría que destacar que la práctica totalidad de los despliegues realizados fueron para un intervalo corto de tiempo abarcando a lo sumo unas tres semanas, exceptuando el caso de estudio número 11 de las Tabla 4.4 y Tabla 4.5 (GLUCOS Project) que abarcaba semestres completos para la monitorización. Este dato revela que la mayor parte de los despliegues realizados tienen un carácter puramente experimental y que todavía queda mucho por hacer para tener instalaciones con un carácter más permanente.

\subsection{Conclusiones.}

Se han presentado dos alternativas de redes inalámbricas para la monitorización del medio marino en función de las características de la zona a monitorizar, las UW-ASNs y las A-WSNs. Se puede concluir que las UW-ASNs se utilizan únicamente cuando se requieren monitorizaciones a grandes profundidades, siendo las A-WSNs empleadas para el resto de situaciones. Puesto que el caso de estudio de esta Tesis se centra en una laguna costera de aguas someras, el sistema diseñado e implementado se basa en A-WSNs.

Las A-WSNs representan una alternativa importante para la monitorización de sistemas oceanográficos frente a los complejos sistemas de observación costera existentes en la literatura y presentados en el capítulo 2 del presente documento. Algunas de las ventajas de los sistemas presentados son la mayor resolución espacial y temporal de los parámetros monitorizados, y además, el despliegue de una red de este tipo requiere una inversión menor tanto en coste como en tiempo, frente a soluciones clásicas como las utilizadas en los observatorios oceanográficos en los que se utilizan recursos con mayores prestaciones (boyas de aguas profundas, AUVs, gliders o boyas lagrangianas).

Tal y como se detalló en el apartado 4.3, el medio marino presenta nuevas peculiaridades frente al caso terrestre. El acceso a los nodos desplegados en el medio marino implica costes adicionales al sistema, por lo que es necesario diseñar un sistema lo más autónomo posible y que requiera muy poco mantenimiento. Estas características han sido tenidas en cuenta en la implementación y puesta en marcha de la A-WSN marina presentada en esta Tesis. Junto con esto, cobra una gran importancia la estructura mecánica de la boya que soportará los sensores y la electrónica necesaria para la gestión del sistema. En el apartado 4.6 se han presentado doce casos de estudio de los que se han extraído diferentes modelos de boyas. Todas ellas 
tienen en común cuatro partes: (1) un sistema de flotación que soportará, entre otras cosas, la antena de comunicaciones vía radio, los sensores ambientales y oceanográficos, (2) la carcasa con la (3) electrónica del nodo, (4) y el sistema de alimentación. La disposición de las distintas partes, la robustez y las características de la boya son diseñadas ad-hoc a las necesidades de la zona de despliegue.

Del estudio que se ha realizado en esta Tesis se puede concluir que la solución a la que se llega es ad-hoc puesto que depende de diversos factores que condicionan su diseño. Entre ellos podemos destacar: las características del medio marino (aguas profundas frente a aguas someras, lagunas costeras, condiciones climatológicas adversas, etc.), el alcance temporal del despliegue (monitorización durante un periodo de semanas o meses hasta instalaciones permanentes), el alcance espacial del despliegue (áreas extensas con poca resolución espacial frente a otras más reducidas con mayor resolución espacial), la resolución temporal de los datos recogidos (frecuencias de muestreo desde minutos u horas, hasta días o semanas).

Toda esta casuística de posibilidades lleva a adoptar soluciones de diseño particulares en las que se hace necesario minimizar los costes de despliegue y de mantenimiento de la red. Los principales retos identificados a partir de la información recopilada en los casos de estudio catalogados son los siguientes:

- Disponer de un suministro de energía que cubra las necesidades del despliegue.

- Garantizar unos niveles de aislamiento de los componentes y unas medidas anticorrosión. Es de particular importancia realizar un diseño que minimice el número de conectores utilizados ya que son especialmente sensibles a la corrosión del medio marino.

- Realizar un diseño de boyas que facilite el acceso a los componentes del mote para su mantenimiento y retirada posterior. Esto viene determinado fundamentalmente por la reposición de los sistemas de alimentación, la sustitución o calibrado de los sensores utilizados y por el repliegue del sistema tras finalizar la tarea de monitorización.

- Integrar un sistema de comunicaciones (antenas y módulos de radio) fiable que garantice en condiciones meteorológicas adversas la comunicación entre los nodos sensores.

- Minimizar el impacto de las redes desplegadas en los entornos monitorizados. La presencia de boyas flotantes en la superficie representa un problema potencial en áreas en las que por ejemplo el tránsito de embarcaciones es frecuente.

El estudio realizado pone de manifiesto la madurez de la tecnología para poder abordar con éxito estos retos.

Los estudios llevados a cabo en este capítulo han sido publicados en una revista internacional listada en el ISI [Albaladejo et al., 2010a]. 
Propuesta de una Red de Sensores Inalámbrica para un Sistema de Observación Costero

Esta página se deja en blanco de forma intencionada.

$-68-$ 


\section{Capítulo 5}

\section{Propuesta de una arquitectura de red de sensores inalámbrica aérea}

I a exploración del medio marino, en concreto las zonas costeras, constituye un objetivo prioritario acontecen. Las WSNs, como se explicó en el capitulo 4, son sistemas formados por dispositivos autónomos, de fácil despliegue, bajo coste y ligeros, que se comunican de forma inalámbrica entre ellos con el fin de llevar a cabo la monitorización de parámetros oceanográficos, de una forma sencilla y eficaz:

En este capitulo, se expone la necesidad general de emplear un sistema de este tipo para la observación de las aguas costeras. Se describe un sistema basado en redes de sensores detallando las características de los elementos que la forman y la funcionalidad de los mismos, asi como las tecnologías de comunicación inalámbricas existentes en el mercado, seleccionando la que más se adecúa a estos sistemas. Por último, se proponen dos alternativas para la implementación del sistema de monitorización que gestiona la información, una basada en servidores remotos, y una segunda opción, haciendo uso del paradigma "Cloud Computing". 


\subsection{Introducción.}

Las zonas costeras son cada vez más transitadas debido al tráfico marítimo y a la actividad pesquera que se desempeña en este medio. Además, la contaminación de las aguas (debida a desembocaduras de ramblas, barcos, actividad humana, accidentes petrolíferos, etc.), y las alteraciones físicas por obras marítimas pueden ser problemas derivados de la gran actividad en aguas costeras. La obtención de información de este tipo de problemas, con la suficiente resolución espacial y temporal para su correcto seguimiento, es un objetivo vital para adoptar soluciones y disminuir daños mayores en el ecosistema marino.

Hoy en día, existen sistemas como los explicados en el capítulo 2, encargados de monitorizar zonas costeras mediante gran cantidad de instrumentación, con altas prestaciones cuyo coste se dispara en despliegues de numerosos puntos de vigilancia, consiguiéndose la resolución espacial necesaria mediante la utilización de modelos predictivos. Esta solución es adecuada, aunque costosa, en situaciones de vigilancia continua. Sin embargo, en situaciones de emergencia, donde es necesario la movilización de numerosos recursos humanos y materiales en breves períodos temporales, y en donde, por ejemplo, las sustancias nocivas emitidas pueden esparcirse en el mar, se hacen necesarios sistemas que proporcionen información de lo que realmente está sucediendo en el medio, con mayor resolución espacial y temporal que los basados en modelos predictivos.

En conclusión, es de gran interés monitorizar estas zonas mediante sistemas adecuados a las características del medio marino y su entorno, flexibles, ligeros, de bajo coste, autónomos y que requieran poco mantenimiento.

Los sistemas de monitorización costera basados en A-WSNs son muy adecuados para monitorizar y controlar el estado de las aguas. Los casos de estudios reales encontrados en la literatura han sido recogidos en las Tablas 4.4 y 4.5 en el capítulo 4. Son numerosas las ventajas de este tipo de sistemas inalámbricos. Permiten la monitorización de parámetros oceanográficos, mediante sensores de bajo coste y de forma inalámbrica, desplegando redes de sensores lo suficientemente tupidas para poder abarcar la zona completa de monitorización. La toma de muestras se realiza sin presencia física y con la frecuencia de muestreo deseada.

Los nodos o motes que forman una A-WSN se ubican en puntos estratégicos en los que se desean monitorizar parámetros oceanográficos (temperatura, presión, nitratos, clorofila, turbidez, etc.). Estos dispositivos se comunican de forma inalámbrica y hacen llegar la información de los sensores, a través de un nodo Coordinador, hasta un servidor de datos. En función de la disposición de los nodos Sensores, es posible agruparlos formando diferentes topologías siendo el núcleo de cada una el nodo Coordinador. Éste es 
el encargado de transmitir la información de la red hasta un servidor de datos en el que se ejecuta un sistema de monitorización, mediante el cual, el usuario puede visualizar la información de la red (los datos de los sensores o información relativa al despliegue) en una aplicación local a través de Internet.

Hasta ahora, para conocer el estado del mar, el usuario tenía que acceder hasta la zona que se deseaba monitorizar, ubicar el sensor/registrador, al tiempo volver a recoger el sensor, volcar los datos y analizarlos. Con el sistema de redes de sensores propuesto, no solo el usuario podrá estar informado de dichos valores en tiempo real, sino que además podrá consultarlos desde cualquier lugar a través de la nube, analizar su evolución y contrastarlos con los modelos teóricos adecuados. Otras soluciones plantean alternativas de sistemas cableados. Si bien se elimina el problema de la autonomía de los nodos, son sistemas de elevado coste y que requieren grandes infraestructuras.

El acceso al mar implica un coste elevado respecto a un despliegue terrestre, y es por ello que se deben tener en cuenta factores que minimicen dichos costes [Albaladejo et al., 2010a]. En definitiva, se debe realizar un diseño tal que minimice los costes de despliegue, mantenimiento y repliegue de la red. Estos sistemas deben estar formados por elementos lo más ligeros posible facilitando así la instalación de los mismos. El sistema de flotación del nodo debe ser robusto y estar formado por materiales no contaminantes y resistentes a las condiciones marinas y ambientales. Con ello se garantiza la durabilidad de la estructura y un mínimo mantenimiento. Minimizando el mantenimiento del sistema y maximizando la vida útil de la red (autonomía de los nodos), se limitará el acceso al sistema, disminuyendo así su coste de mantenimiento. Además, en las A-WSNs, los nodos se dotan de un sistema de captación de energía que permiten recargar las baterías que éstos incluyen, mediante energías renovables como la solar o la eólica. De esta forma, se obtiene una solución autónoma que elimina el problema de la compleja y costosa infraestructura de los sistemas cableados.

Queda así justificada la aplicación de un sistema basado en A-WSNs para la monitorización de zonas costeras. A continuación se propone una arquitectura para llevar a cabo la implementación de un sistema de este tipo. Se realiza una descripción general del mismo, analizando las tecnologías de comunicación inalámbricas disponibles, describiendo la funcionalidad de los nodos que forman la red, y finalizando con la descripción del sistema de monitorización. 


\subsection{Propuesta de una arquitectura para una A-WSN en observación costera.}

Según la necesidad de un sistema con las características expuestas en la Introducción, se define una arquitectura de un sistema basado en A-WSNs. En este apartado se realiza una descripción general de los sistemas de monitorización marinos basados en redes de sensores, las tecnologías de comunicación inalámbricas actualmente existentes en el mercado y la utilizada entre los dispositivos que componen la red, las características funcionales de los nodos, y el sistema de monitorización, introduciendo el reciente concepto de "Cloud Computing".

\subsubsection{Descripción general de la arquitectura.}

Las A-WSNs han sido aplicadas a diferentes campos demostrando su eficiencia. Así, se pueden encontrar aplicaciones de las A-WSNs en hospitales [Hande et al., 2006], entornos hostiles [Song et al., 2008], aplicaciones de control remoto [Xia et al., 2007] y seguimiento de objetos [Wang et al., 2007], entre otras. Otro ejemplo de aplicación de las A-WSNs está en el ámbito de la agricultura de precisión. En el DSIE de la UPCT se está trabajando en A-WSNs desde el año 2006. Los resultados de estos años de trabajo se han reflejado en la Tesis Doctoral de D. Juan Antonio López Riquelme [López, 2011]. Dicha Tesis describe el diseño y la implementación de una arquitectura hardware, basada en A-WSNs, que permite estimar, evaluar y entender las variaciones existentes en los cultivos, con objeto de determinar con mayor exactitud las necesidades de fertilizantes y riego, las fases de desarrollo y maduración de los productos, así como los puntos óptimos de siembra y recolección, que son los principales objetivos de la agricultura de precisión.

Ante la necesidad de diseñar un sistema para la monitorización de ciertas zonas de la laguna costera del Mar Menor, y con la experiencia adquirida en A-WSNs, se decidió realizar una transferencia de la tecnología desarrollada desde el ámbito agrícola al ámbito marino. Uno de los objetivos de la presente Tesis es estudiar la viabilidad de emplear dichas soluciones utilizadas en la monitorización agrícola, en el campo oceanográfico haciendo las correcciones adecuadas.

El sistema propuesto se puede ver desde dos puntos de vista: como una solución puntual a problemas que surgen inesperadamente, como por ejemplo, la necesidad de monitorizar una zona contaminada debido a vertidos tóxicos al mar; o bien, como un sistema de monitorización a largo plazo de las zonas costeras. En ambos casos, se trata de un sistema flexible, de bajo coste y autónomo, capaz de monitorizar zonas de interés. Esto 
se consigue desplegando los dispositivos adecuados en situaciones estratégicas de tal forma que cubran el área completa de monitorización.

Una A-WSN puede estar formada por diferentes tipos de nodos o motes (nodos Sensor, Router y Coordinador) que se comunican de forma inalámbrica. En la Figura 5.1 se presenta un esquema de la arquitectura propuesta para una A-WSN en observación oceanográfica. En los puntos que se desee llevar a cabo la monitorización de parámetros oceanográficos, se dispondrán diferentes nodos o boyas pudiendo a su vez formar diferentes topologías. La comunicación entre las boyas de cada A-WSN se realiza de forma inalámbrica mediante una tecnología de comunicación inalámbrica que soporte el uso de radios digitales de bajo consumo. Además, en función de la distancia entre el despliegue de boyas y la estación base situada en tierra, se pueden utilizar diferentes tecnologías de comunicación. En las boyas más cercanas a la costa, el nodo Coordinador comunica vía RF con un nodo Sumidero conectado a la estación base. Para zonas lo suficientemente alejadas como para no tener cobertura RF entre el nodo Coordinador de la red y la estación base, se puede emplear una comunicación GPRS o satélite para el envío de información.

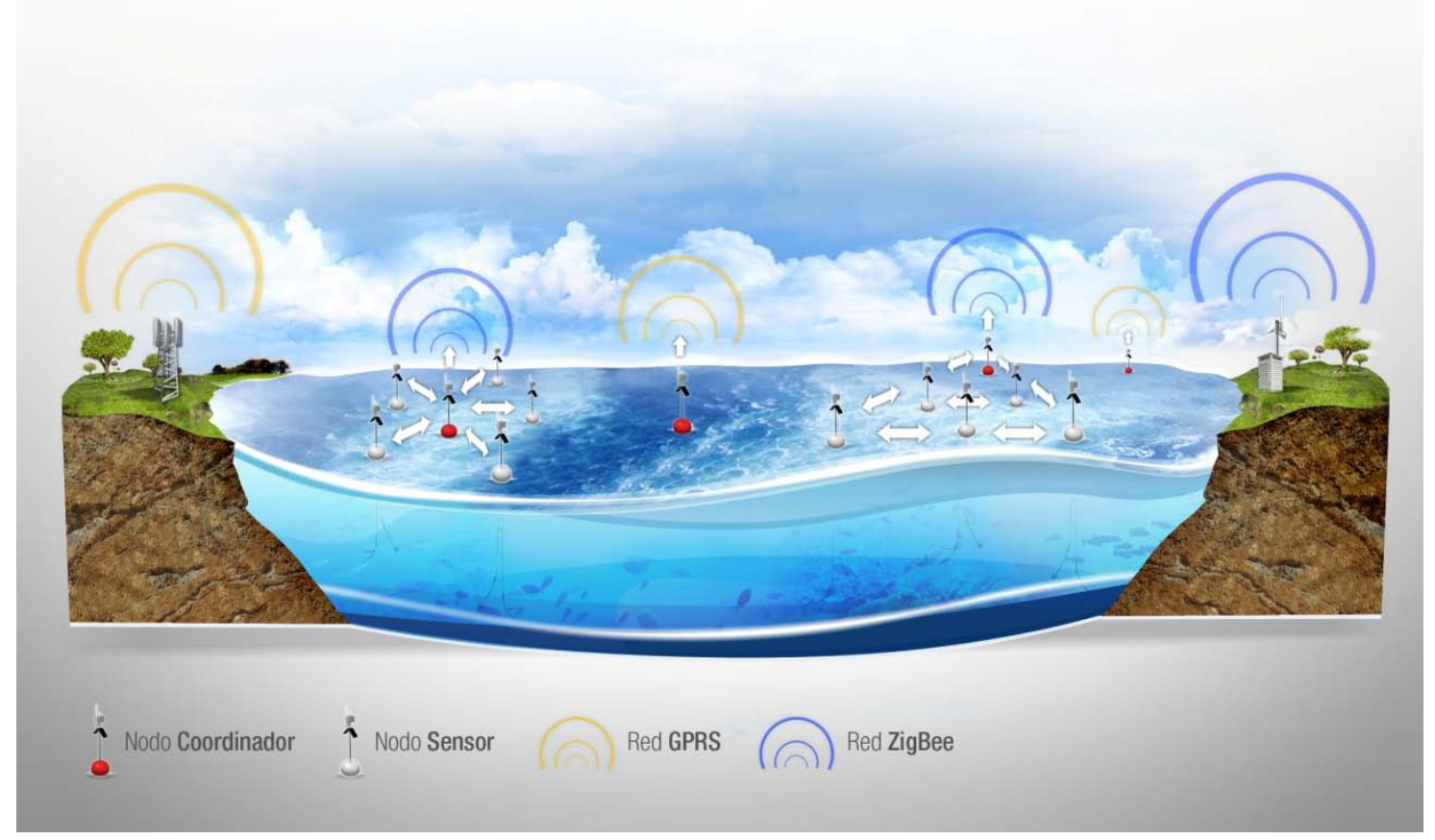

Figura 5.1 Arquitectura propuesta para una A-WSN en observación oceanográfica.

Los nodos Sensores toman datos de sus sensores, los envían inalámbricamente hasta un nodo Router que encamina los mensajes hasta el Coordinador de la red, o directamente al Coordinador, dependiendo de la topología de red implementada. El nodo Coordinador transmite los mensajes recibidos de los nodos de la red hasta el sistema de monitorización. Dicho sistema, unas veces está formado por un nodo Sumidero conectado a un servidor de datos, cuya comunicación con la red se hace a través del Sumidero vía RF, y otras 
únicamente por dicho servidor, en cuyo caso, la comunicación del nodo Coordinador con el servidor remoto se realiza a través de una conexión GSM/GPRS o comunicación satélite. En el servidor de datos se almacena y gestiona la información recibida y se muestra al usuario final que podrá acceder a ella a través de la nube.

\subsubsection{Tecnologías de comunicación aérea inalámbrica.}

Hasta ahora, la forma más habitual de intercambiar información entre dos puntos ha sido mediante comunicaciones cableadas. No todo son ventajas en dicha tecnología, y es debido precisamente a los inconvenientes que esta presenta (geográficos, económicos y de comodidad), por lo que las comunicaciones inalámbricas están en continuo crecimiento.

Para la transmisión de información de forma inalámbrica se suelen usar las bandas de infrarrojo, con las que se pueden alcanzar tasas de transferencia de hasta 4 Mbps a pequeñas distancias, con el transmisor y receptor en línea de visión directa; y RF, que poseen altas tasas de transferencia, permitiendo una comunicación entre dos puntos muy alejados y sin línea directa de visión.

La banda ISM, dentro del espectro de RF, es de propósito general por lo que puede ser usada sin necesidad de licencias respetando ciertos límites de potencia emitida. Los sistemas diseñados para trabajar en la banda ISM se caracterizan por un bajo consumo y, en principio, tasas de transmisión no muy altas, aunque se está trabajando para alcanzar mayores velocidades.

Para el trabajo presentado en esta Tesis Doctoral, se tratarán dispositivos que trabajen en la banda libre de los 2,4 GHz ya que, a esta frecuencia, trabajan un gran número de tecnologías, como por ejemplo, Wi-Fi, WiMAX, Bluetooth y ZigBee, las cuales se describen brevemente a continuación.

WiFi es un sistema de envío de datos de forma inalámbrica sobre redes computacionales, que permite formar redes inalámbricas equiparables en prestaciones a Ethernet; WiMAX (Worldwide Interoperability for Microwave Access) es una norma de transmisión de datos usando ondas de radio; Bluetooth es una especificación industrial para WPANs que posibilita la transmisión de vOz y datos entre diferentes dispositivos mediante un enlace por radiofrecuencia segura y globalmente libre; y finalmente ZigBee, es el nombre de la especificación de un conjunto de protocolos de alto nivel de comunicación inalámbrica para su utilización con radios digitales de bajo consumo, basada en el estándar IEEE 802.15.4, que define el nivel físico y el control de acceso al medio de WPANs. La Tabla 5.1 recoge las principales características de las tecnologías de comunicación inalámbricas citadas en este apartado. 


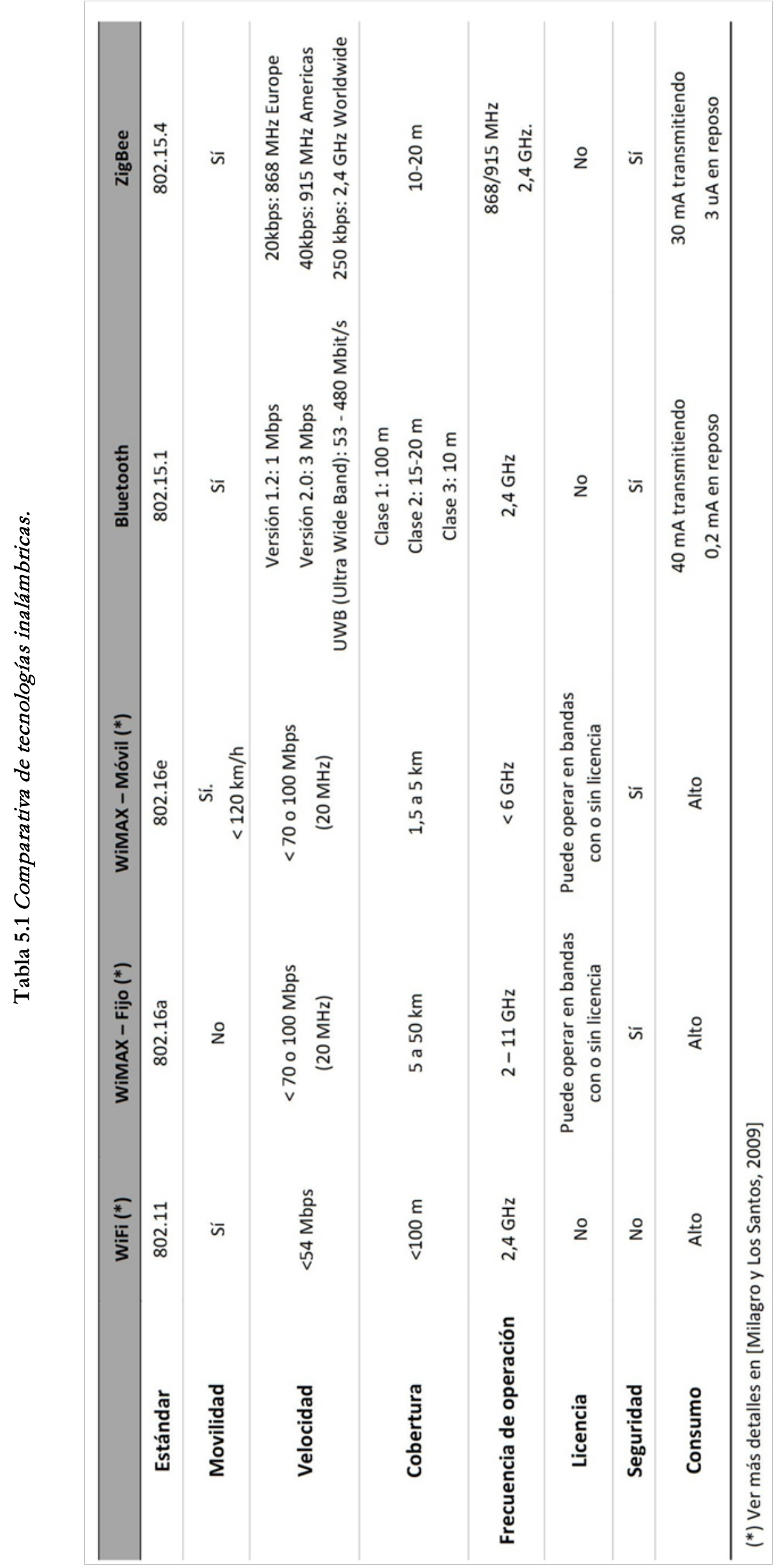

$-73-$ 
Teniendo en cuenta las especificaciones de una A-WSN [Akyildiz et al., 2002], ZigBee es la mejor alternativa ya que ofrece una baja tasa de transferencia de información y permite su utilización con radios digitales de bajo consumo. En cuanto al alcance obtenido con ZigBee, depende fuertemente de las características del hardware utilizado y de las características del entorno de transmisión. Por tanto, en esta Tesis se estudia la viabilidad de ZigBee en entornos marinos. Por otro lado, la tecnología inalámbrica WiMAX parece ser una tecnología prometedora, pero hoy en día, no existen sistemas de desarrollo que permitan realizar aplicaciones a medida como es la planteada en esta Tesis Doctoral.

En ocasiones, y al margen de las A-WSNs, es necesario comunicar nodos aislados directamente con el sistema de monitorización. En estos casos, sería necesario establecer una conexión vía GSM o GPRS. GSM (Global System for Mobile) es un sistema estándar para la comunicación mediante teléfonos móviles que incorporan tecnología digital y GPRS (General Packet Radio Service) es una extensión GSM para la transmisión de datos no conmutada (o por paquetes).

Analizando los resultados expuestos en la Tabla 5.2, entre GSM y GPRS, se puede concluir que, puesto que el objetivo perseguido es realizar la transmisión únicamente de datos, el servicio adecuado para tal fin es GPRS.

Tabla 5.2 Comparativa de las tecnologías inalámbricas GSM y GPRS.

\begin{tabular}{ccc}
\hline & GSM & GPRS \\
\hline Transmisión de información & $\begin{array}{c}\text { Conmutación de circuitos } \\
\text { transmisión de voz }\end{array}$ & $\begin{array}{c}\text { Conmutación de paquetes - } \\
\text { transmisión de datos }\end{array}$ \\
\hline $\begin{array}{c}\text { Velocidad de transferencia } \\
\text { Tiempo de establecimiento } \\
\text { de conexión }\end{array}$ & $9,6 \mathrm{Kbps}$ & $40-115 \mathrm{Kbps}$ \\
\hline Tarificación & 15 a $30 \mathrm{~s}$ & $<1 \mathrm{~s}$ \\
\hline
\end{tabular}

\subsubsection{ZigBee/IEEE 802.15.4.}

\subsubsection{Descripción.}

ZigBee es el nombre de la especificación de un conjunto de protocolos de alto nivel de comunicación inalámbrica para su utilización con radios digitales de bajo consumo [Gislason, 2008], basada en el estándar IEEE 802.15.4 [IEEE 802.15.4, 2006] de redes WPANs. Su objetivo son las aplicaciones que requieren comunicaciones seguras con baja tasa de envío de datos y maximización de la vida útil de sus baterías. Trata de proponer una red comunicación de dispositivos con un tamaño de paquete pequeño, en contraposición a otras tecnologías como Bluetooth o WIFI, que tratan volúmenes de información superiores y por supuesto se sitúan entre las tecnologías más complejas. 
A diferencia de otras tecnologías, ZigBee está especialmente diseñada para grandes redes de sensores, con las características inherentes a ellas: fiabilidad, larga duración de las baterías de los dispositivos, bajo coste, tamaño pequeño y complejidad reducida, sin requerimientos de calidad de servicio importantes, etc. El objetivo es ofrecer un estándar abierto, eficiente, de poco consumo e inalámbrico para la monitorización y control de dispositivos.

Es un protocolo de comunicación multi-hop, es decir, que se puede establecer comunicación entre dos nodos aún cuando estos se encuentren fuera del rango de transmisión, siempre y cuando existan otros nodos intermedios que los interconecten, incrementándose de esta manera el área de cobertura de la red.

\subsubsection{Características de ZigBee.}

ZigBee utiliza la banda ISM para usos industriales, científicos y médicos; en concreto, $868 \mathrm{MHz}$ en Europa, $915 \mathrm{MHz}$ en Estados Unidos y 2,4 GHz en todo el mundo (ver Tabla 5.3). Sin embargo, a la hora de diseñar dispositivos, las empresas optan, prácticamente siempre, por la banda de 2,4 GHz, por ser libre a nivel mundial. El desarrollo de la tecnología se centra en la sencillez y el bajo coste más que otras redes inalámbricas semejantes de la familia WPAN, como por ejemplo Bluetooth.

Tabla 5.3 Características de radio ZigBee.

\begin{tabular}{ccccccc}
\hline Frecuencia & Banda & Cobertura & Datos & Canales & $\begin{array}{c}\text { Sensibilidad de } \\
\text { recepción }\end{array}$ & Modulación \\
\hline $2,4 \mathrm{GHz}$ & ISM & Mundial & $250 \mathrm{kbps}$ & 16 & $-85 \mathrm{dBm}$ & O-QPSK \\
\hline $888 \mathrm{MHz}$ & & Europa & $20 \mathrm{kbps}$ & 1 & $-92 \mathrm{dBm}$ & BPSK \\
\hline $915 \mathrm{MHz}$ & ISM & América & $40 \mathrm{kbps}$ & 10 & $-92 \mathrm{dBm}$ & BPSK \\
\hline
\end{tabular}

A pesar de coexistir en la misma frecuencia con otro tipo de redes como WiFi o Bluetooth su desempeño no se ve afectado, esto es debido a su baja tasa de transmisión y, a características propias del estándar IEEE 802.15.4.

Cada red ZigBee tiene un identificador de red único, lo que permite que coexistan varias redes en un mismo canal de comunicación sin ningún problema. Teóricamente pueden existir hasta 16.000 redes diferentes en un mismo canal y cada red puede estar constituida por hasta 65.000 nodos, obviamente estos límites se ven truncados por algunas restricciones físicas como por ejemplo la memoria disponible y el ancho de banda.

\subsubsection{Tipos de dispositivos en una red ZigBee.}

Se definen tres tipos distintos de dispositivos ZigBee según su papel en la red: 
- Coordinador ZigBee (ZigBee Coordinator, en adelante ZC). Es el tipo de dispositivo más completo y únicamente debe existir uno por red. Sus funciones son las de encargarse de controlar la red y los caminos que deben seguir los dispositivos para conectarse entre ellos. En definitiva, el ZC es el encargado de gestionar la red.

- Router ZigBee (ZigBee Router, en adelante ZR). Interconecta dispositivos separados en la topología de la red, además de ofrecer un nivel de aplicación para la ejecución de código de usuario.

- Dispositivo final ZigBee (ZigBee End Device, en adelante ZED). Posee la funcionalidad necesaria para comunicarse con su nodo padre (ZC o ZR), pero no puede transmitir información destinada a otros dispositivos. Este tipo de nodo puede estar en modo POWER_SAVING la mayor parte del tiempo, aumentando la vida media de sus baterías.

Basándose en la funcionalidad de los dispositivos, se plantea una segunda clasificación. Se define como dispositivo de funcionalidad completa (Full Functionality Device, FFD) o nodo activo, aquel nodo que es capaz de recibir mensajes en formato 802.15.4. Gracias a la memoria adicional y a la capacidad de cómputo, puede funcionar como ZC o ZR, o puede ser usado en dispositivos de red que actúen de interfaz con los usuarios. Por otro lado, un dispositivo de funcionalidad reducida (Reduced Functionality Device, RFD) o nodo pasivo, tiene capacidad y funcionalidad limitadas con el objetivo de conseguir un bajo coste y una gran simplicidad. Básicamente, son los sensores/actuadores de la red.

\subsubsection{Topologías ZigBee.}

ZigBee permite tres topologías de red: en estrella ('Star'), en árbol ('Tree'), y mallada ('Mesh), las cuales pueden observarse en la Figura 5.2.

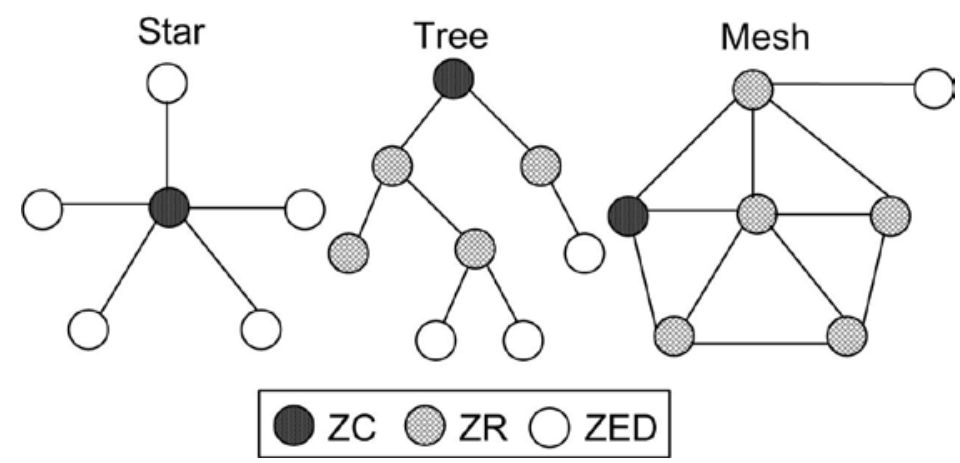

Figura 5.2 Topologías de red.

En la topología en estrella, el coordinador se sitúa en el centro. En la topología en árbol, el coordinador será la raíz del árbol. Y en la topología de malla, al menos uno de los nodos tendrá más de dos conexiones. Además, esta última, permite que, si en un momento dado, un nodo de la ruta establecida falla y se cae, pueda seguir la comunicación entre 
todos los demás nodos debido a que se rehacen todas las rutas. La gestión de las rutas es tarea del coordinador. En las tres topologías hay un único nodo que asume el papel de ZC, y es el encargado de centralizar la adquisición y las rutas de comunicación entre el resto de dispositivos ZEDs y ZRs.

\subsubsection{Estrategias de conexión de los dispositivos en una red ZigBee.}

Las redes ZigBee han sido diseñadas para conservar la potencia en los nodos ZEDs. De esta forma se consigue el bajo consumo de potencia. La estrategia consiste en que, durante mucho tiempo, un dispositivo ZED está en modo dormido, de tal forma que solo se despierta por una fracción de segundo para confirmar que está vivo en la red de dispositivos de la que forma parte. Esta transición del modo dormido al modo despierto (modo en el que realmente transmite), dura unos $15 \mathrm{~ms}$.

En las redes Zigbee, se pueden usar dos tipos de entornos o sistemas:

1) Con balizas. Se trata de un mecanismo de control del consumo de potencia en la red. Permite a todos los dispositivos saber cuándo pueden transmitir. Las balizas que dan nombre a este tipo de entornos, se usan para poder sincronizar todos los dispositivos que conforman la red, identificando la red, y describiendo la estructura de la supertrama. Los intervalos de las balizas son asignados por el coordinador de red y pueden variar desde los $15 \mathrm{~ms}$ hasta los $4 \mathrm{~min}$.

Este modo es más recomendable cuando el coordinador de red trabaja con una batería. Los dispositivos que conforman la red, escuchan a dicho coordinador durante el balizamiento (envío de mensajes a todos los dispositivos -broadcast- , entre 0,015 y 252 s). Un dispositivo que quiera intervenir, lo primero que tendrá que hacer es registrarse para el coordinador, y es entonces cuando mira si hay mensajes para él. En el caso de que no haya mensajes, este dispositivo vuelve a dormir, y se despierta de acuerdo a un horario que ha establecido previamente el coordinador. En cuanto el coordinador termina el balizamiento, vuelve a dormirse.

2) Sin balizas: Se usa el acceso múltiple al sistema Zigbee en una red punto a punto cercano. En este tipo, cada dispositivo es autónomo, pudiendo iniciar una conversación, en la cual los otros pueden interferir. A veces, puede ocurrir que el dispositivo destino puede no oír la petición, o que el canal esté ocupado.

Este sistema se usa típicamente en los sistemas de seguridad, en los cuales sus dispositivos (sensores, detectores de movimiento o de rotura de cristales), duermen prácticamente todo el tiempo (el 99,99\%). Para que se les tenga en cuenta, estos elementos se despiertan de forma regular para anunciar que siguen en la red. Cuando se produce un evento, el sensor despierta instantáneamente y transmite la alarma correspondiente. Es en ese momento cuando el Coordinador de red recibe el mensaje 
enviado por el sensor, y activa la alarma correspondiente. En este caso, el Coordinador de red se alimenta de la red principal durante todo el tiempo.

\subsubsection{Arquitectura de red.}

ZigBee es una pila de protocolos, que de manera similar al modelo OSI (Open System Interconnection) está constituida por diferentes capas, las cuales son independientes una de la otra. En la Figura 5.3 se muestran las diferentes capas que conforman la pila de protocolos para ZigBee.

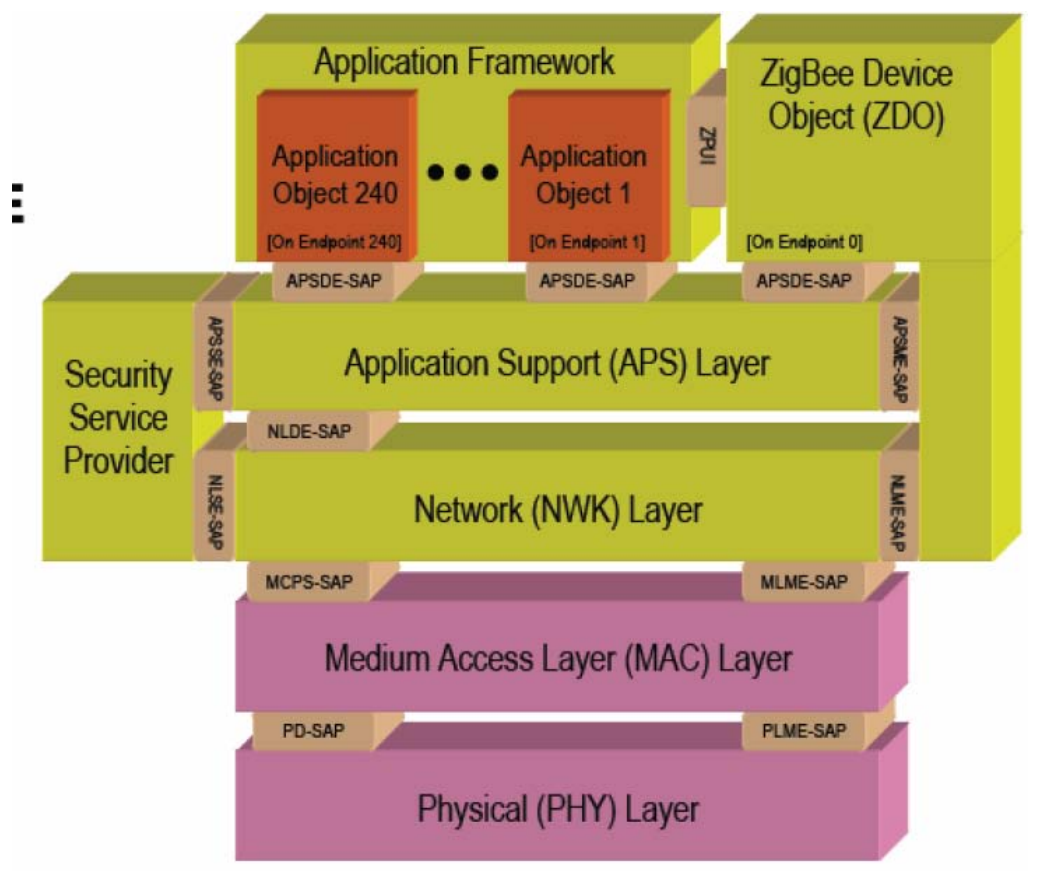

Figura 5.3 Pila de arquitectura ZigBee.

La pila de arquitectura ZigBee consta de varios componentes en capas: la capa de control de acceso al medio (Medium Access Control, en adelante MAC), la capa física (PHYsical, en adelante PHY) y la capa de red Zigbee (NetWorK, en adelante NWK). La capa de aplicación de ZigBee se subdivide en la subcapa de aplicación (APplication Support, en adelante APS), la capa Zigbee Device Objects (en adelante ZDO), y los objetos de aplicación definidos por cada uno de los fabricantes.

La subcapa de soporte APS proporciona un interfaz entre la capa de NWK y la capa de aplicación, a través de un conjunto de servicios que se utilizan junto a los ZDO y otros objetos que hayan sido definidos por los fabricantes.

La capa de más bajo nivel es la capa PHY, que en conjunto con la capa MAC, brindan los servicios de transmisión de datos por el aire, punto a punto. Estas dos capas están descritas en el estándar IEEE 802.15.3-2003 [IEEE 802.15.3, 2003]. 
La capa NWK tiene como objetivo principal permitir el correcto uso del subnivel MAC y ofrecer una interfaz adecuada para su uso por parte de la capa de aplicación. En esta capa se brindan los métodos necesarios para: iniciar la red, unirse a la red, enrutar paquetes dirigidos a otros nodos en la red, proporcionar los medios para garantizar la entrega del paquete al destinatario final, filtrar paquetes recibidos, cifrarlos y autentificarlos.

La siguiente capa, APS, es la responsable de mantener el rol que el nodo juega en la red, filtrar paquetes a nivel de aplicación, mantener la relación de grupos y dispositivos con los que la aplicación interactúa y simplificar el envío de datos a los diferentes nodos de la red. Las capas NWK y APS son definidas por la ZigBee Alliance.

En el nivel conceptual más alto se encuentran los ZDO que se encargan de definir el papel del dispositivo en la red, si el nodo actuará como ZC, ZR o ZED, la subcapa APS y los objetos de aplicación definidos por cada uno de los fabricantes.

\subsubsection{Descripción funcional de los diferentes componentes.}

La arquitectura propuesta, como se detalla en el apartado 5.2.1, está formada por nodos Sensores, Routers y Coordinadores. La red se comunica con el sistema de monitorización a través de un nodo Sumidero conectado al servidor de datos o directamente a este servidor prescindiendo de dicho Sumidero. En este apartado se describe el comportamiento funcional de cada nodo del sistema y los elementos que son necesarios para su implementación. En cuanto al sistema de monitorización, existen dos alternativas para su implementación que serán analizadas en este apartado: un sistema basado en servidores remotos o haciendo uso del paradigma "Cloud Computing".

El núcleo principal de los motes, tanto en los nodos Sensor, Router, Coordinador como Sumidero, está formado por un microcontrolador de baja potencia que centraliza todo el proceso. Además de éste, hay otros elementos comunes en los diferentes tipos de nodos como se puede observar en las Figura 5.4, Figura 5.5, Figura 5.6 y Figura 5.7. Se incluyen uno o varios módulos de radio dedicados a las comunicaciones inalámbricas, un sistema de regulación de alimentación y de gestión de fuentes energéticas, una memoria permanente de lectura/escritura tipo FLASH para almacenar la información de los sensores, y por último, un RTC que haga las veces de temporizador y permita conocer el instante en el que se produjo el muestreo del sensor. En ocasiones, será útil incorporar un módulo GPS para conocer la localización del nodo y poder detectar desplazamientos de los mismos, ya sean debidos a problemas en el sistema de anclaje, actos de vandalismo, o incluso en boyas de deriva desplazadas por la propia corriente del mar. 


\subsubsection{Nodos Sensores.}

Los nodos Sensores, además de los elementos comunes, deben incluir la electrónica necesaria para realizar el muestreo de los sensores y, si las características del despliegue lo requieren, un módulo de comunicaciones GPRS o satélite, tal y como se muestra en la Figura 5.4. La comunicación inalámbrica puede ser proporcionada o bien mediante módulos RF entre los nodos de la red de sensores, o mediante una comunicación GPRS o satélite para nodos que monitoricen zonas aisladas. En el siguiente capítulo se describe con más detalle esta situación.

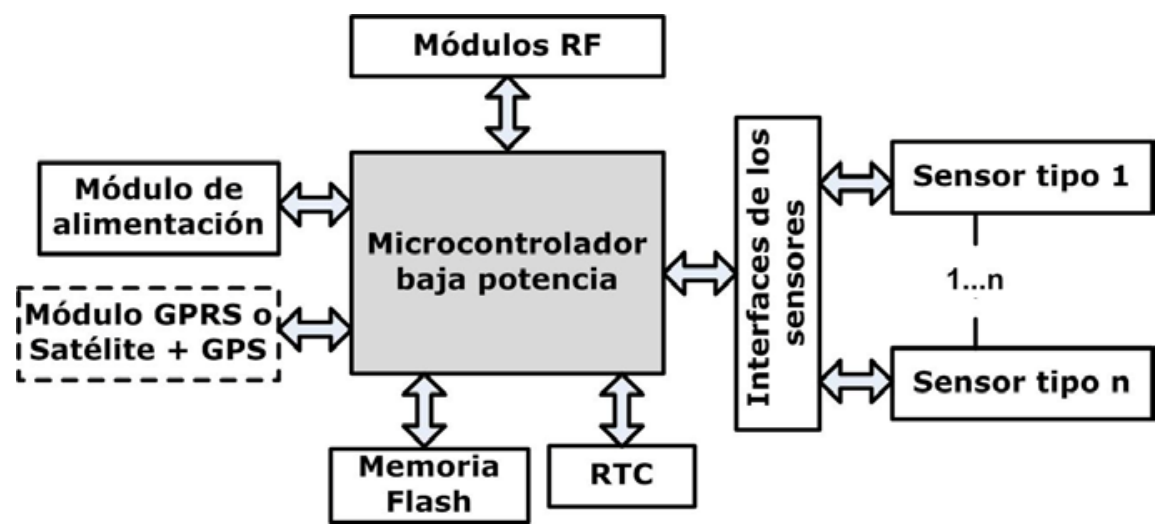

Figura 5.4 Diagrama de bloques de un nodo Sensor genérico.

\subsubsection{Nodos Routers.}

La implementación de un nodo Router se simplifica (ver Figura 5.5) puesto que su única misión es encaminar los mensajes recibidos hasta su destino final. En este caso, el mote incluye uno o varios módulos RF (dependiendo del alcance que se desee lograr) que permita realizar dicho envío de información, un sistema de alimentación para dotar de autonomía al nodo, una memoria FLASH para el almacenamiento de datos y un RTC. En definitiva, los elementos que se han definido como comunes a todos los nodos. En este tipo de nodos no tiene sentido incluir un módulo GPS puesto que a priori se conoce su ubicación, y en caso de que el nodo vaya a la deriva, éste perdería conectividad con la AWSN siendo imposible comunicar con el sistema para alertar de su nueva posición geográfica.

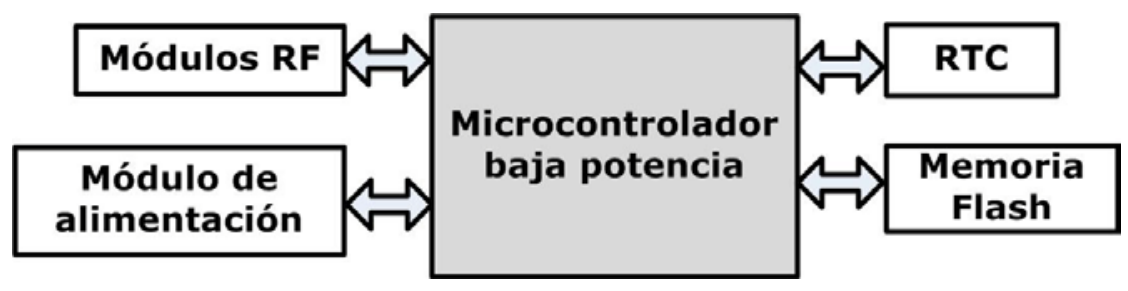

Figura 5.5 Diagrama de bloques de un nodo Router genérico. 


\subsubsection{Nodo Coordinador.}

El rol del nodo Coordinador consiste en transmitir la información que recibe vía RF de la A-WSN hasta el sistema de monitorización. Se contemplan dos alternativas, (1) que el coordinador realice el envío mediante una comunicación GPRS o satélite al servidor de datos, (2) o que realice el envío vía RF al nodo Sumidero conectado a un PC vía RS232. Teniendo en cuenta las dos opciones planteadas, la electrónica necesaria para implementar un nodo Coordinador (ver Figura 5.6) debe incluir, junto con los elementos comunes definidos al inicio de este apartado, para la primera opción (1) uno o varios módulos RF para la recepción de datos de la red y un módulo de comunicaciones GPRS o satélite para enviarlos al servidor remoto, y en la segunda opción (2) únicamente los módulos RF que permitirán la comunicación con la red y el nodo Sumidero.

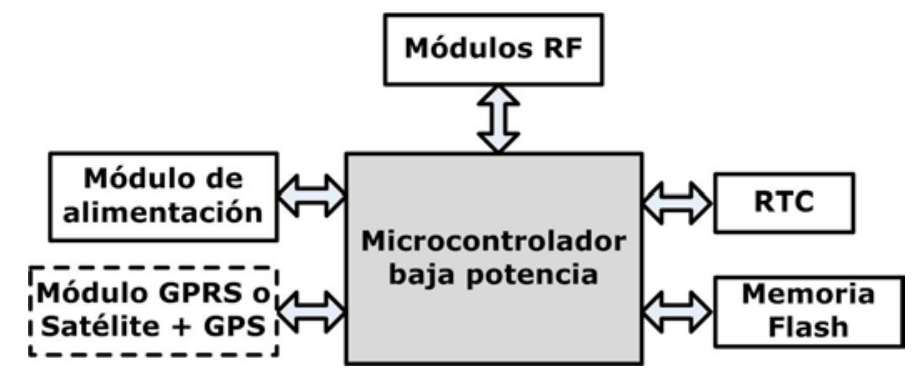

Figura 5.6 Diagrama de bloques de un nodo Coordinador genérico.

En el caso de dotar a este tipo de nodos con un módulo GPRS o satélite, se puede incluir también la opción de GPS con el mismo objetivo que en el caso del nodo Sensor aislado.

\subsubsection{Nodo Sumidero.}

Para escenarios cuya situación sea la segunda opción, en la que la comunicación entre la red de sensores y el sistema de monitorización se realiza a través de un nodo Sumidero, la electrónica del mote debe incluir los elementos mostrados en el diagrama de bloques de la Figura 5.7. En este caso, la alimentación del nodo se suministra a través de la red eléctrica de forma que esté activo en todo momento para la recepción o envío de mensajes. Además, incluye los módulos RF para la comunicación inalámbrica con el nodo Coordinador, un RTC, la memoria FLASH y un interfaz estándar RS232 para la conexión al PC.

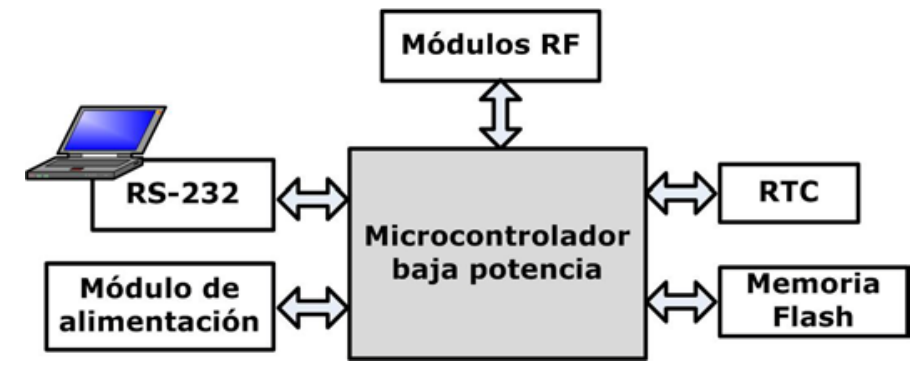

Figura 5.7 Diagrama de bloques de un nodo Sumidero genérico. 


\subsubsection{Sistema de monitorización.}

Una vez que los datos procedentes de la red de sensores se envían al sistema de monitorización, se almacenan y se procesan para la visualización y tratamiento de los mismos. El sistema de monitorización debe mostrar toda la información relativa a la red y permitir la interacción del usuario con la red. En este apartado se contemplan dos alternativas para la implementación de este sistema: mediante servidores remotos y haciendo uso del "Cloud Computing".

\section{1) Basado en servidores remotos.}

El concepto clave de un sistema de monitorización basado en servidores remotos consiste en que, para cada WSN, existe un servidor de datos en el que reside el sistema de monitorización. La funcionalidad general de este sistema se puede explicar describiendo el diagrama de Casos de Uso mostrado en la Figura 5.8.

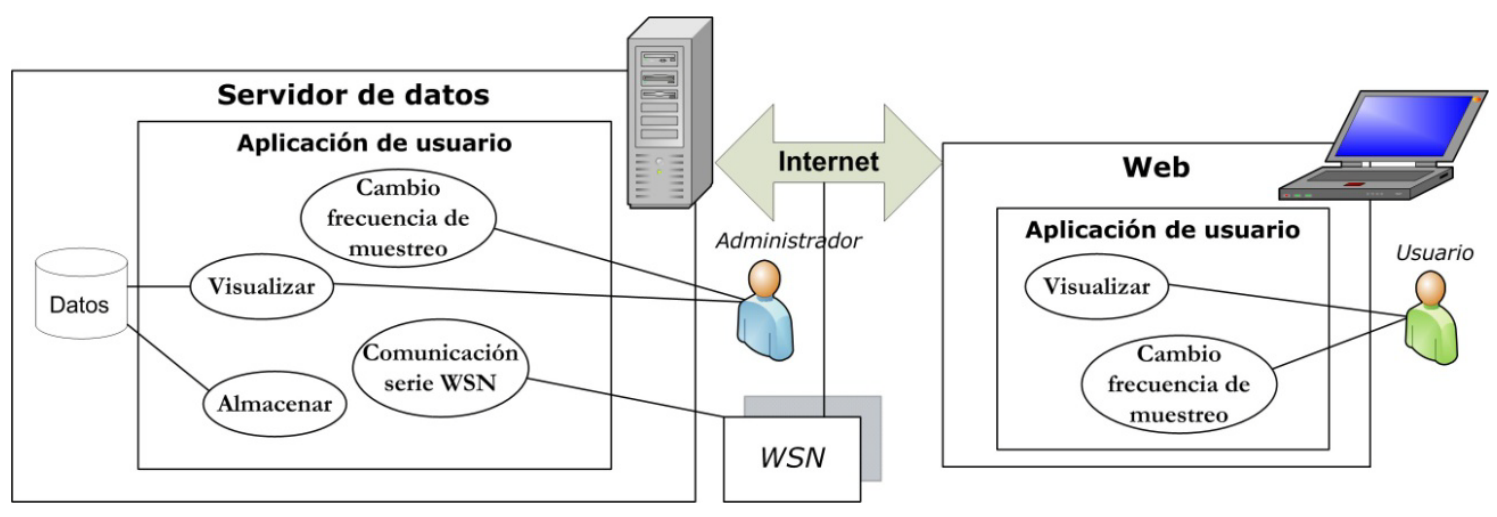

Figura 5.8 Diagrama de casos de uso del sistema de monitorización.

Se distinguen diferentes límites en el sistema, un 'Servidor de datos' donde reside el sistema de monitorización, formado por los datos almacenados y la aplicación que los gestiona ('Aplicación de usuario'), y una aplicación Web a través de la cual, cualquier usuario podrá acceder a la aplicación de monitorización vía Internet.

El sistema 'Aplicación de usuario' de 'Servidor de datos' incluye 4 casos de uso. 'Visualizar' permite la visualización de la información relativa a la red de sensores (datos de los sensores, topología de red, nodos activos e inactivos, posición geográfica, evolución de los datos, calidad de la comunicación inalámbrica, etc). 'Comunicación serie WSN' hace referencia a la comunicación de la WSN con el sistema de monitorización mediante el nodo Sumidero vía RS232, en el caso que lo incluya. A través de este puerto se realiza la recepción de mensajes por parte de la red (mensajes de datos y de estado de la red), y se envían mensajes a la red procedentes de la aplicación de usuario (por ejemplo, 'Cambio frecuencia de muestreo' en Figura 5.8) dirigida por el Administrador (desde el propio servidor de datos) o por el Usuario (desde una localización Web remota). Además se realizan operaciones sobre el 
archivo de datos o base de datos para almacenar la información recibida de la red de sensores.

La aplicación de usuario del sistema de monitorización de una A-WSN debe recoger toda la información que caracterice al despliegue de la red, como por ejemplo, la vista principal del despliegue indicando la posición geográfica de cada nodo utilizando el API de Google Maps, los últimos datos recogidos por los nodos sensores desplegados, los nodos activos/inactivos, la representación gráfica de los datos en una fecha seleccionada, modificación del periodo de muestreo de un nodo desde la aplicación de usuario durante el funcionamiento del sistema.

\section{2) Basado en el paradigma "Cloud Computing".}

La segunda alternativa para la implementación del sistema de monitorización, surge con la reciente aparición del paradigma "Could Computing” [Jeffery y Neidecker, 2010]. Se trata de un nuevo modelo de prestación de servicios de negocio y tecnología, que permite al usuario acceder a un catálogo de servicios estandarizados y responder a sus necesidades, de forma flexible y adaptativa. Este paradigma es aplicable a la gestión de los sistemas de monitorización en redes de sensores para la implementación de los servidores remotos. Puesto que la recolección de datos se hace de forma automática, desasistida y centralizada en un servidor de datos, se puede considerar en vez de éste, un centro de supercomputación que contendrá tantas máquinas virtuales como sean necesarias para gestionar los correspondientes sistemas de monitorización.

La utilización masiva de sistemas de monitorización hace necesaria la optimización de los recursos computacionales. Las soluciones tradicionales se basan en la utilización de un ordenador por sistema de monitorización. En el caso de que se implanten una gran cantidad de sistemas, en diferentes emplazamientos y dependientes de distintos clientes (administraciones, empresas, organismos gestores de los parques industriales, etc), el resultado es la generación de un parque se servidores inconexo, en el que cada cliente se mantiene su propio servidor de datos.

La centralización de los sistemas de monitorización en un supercomputador, que ofrezca servicios de hosting mediante la creación y mantenimiento de máquinas virtuales, permite que los usuarios finales se liberen de la adquisición y mantenimiento de este tipo de infraestructuras mediante la externalización del servicio. De este modo, se reducen los costes de explotación del sistema, no siendo necesario adquirir ni mantener los correspondientes servidores remotos. El acceso de los usuarios finales a la información se lleva a cabo haciendo uso de Internet y mediante la utilización de dispositivos móviles (tablets, smartphones, etc). 


\subsection{Conclusiones.}

Una de las soluciones más novedosas y económicas para la monitorización de diversos ambientes consiste en la utilización de A-WNSs. En trabajos previos a esta Tesis se llevaron a cabo despliegues en el ámbito de la agricultura de precisión desarrollados en el seno del grupo de investigación DSIE, y fueron los buenos resultados obtenidos los que hicieron posible la migración al medio marino. Dichos resultados están avalados por numerosas publicaciones en revistas ISI [López et al., 2009a; López et al., 2009b, López et al., 2011a] y congresos nacionales e internacionales.

En este capítulo, se ha dado una visión general de nodos que pueden formar una AWSN. A modo de resumen, una red de este tipo puede integrar nodos Sensores que medirán parámetros del medio marino o parámetros ambientales, nodos Routers para encaminar la información, nodos Coordinadores que gestionan el comportamiento de la red, incluso nodos Sumideros conectados al sistema de monitorización. Los nodos Sensores, además pueden agruparse formando diferentes topologías.

En cuanto a las tecnologías de comunicación inalámbrica que se pueden utilizar en un sistema basado en A-WSNs, se han presentado WiFi, WiMAX, Bluetooth y ZigBee para la comunicación entre los nodos de la red de sensores, y GPRS y GSM cuando se requieren conexiones de mayor alcance. Para la comunicación en la red de sensores, ZigBee fue la seleccionada ya que se trata de una especificación diseñada para su utilización con radios digitales de bajo consumo, premisa de las WSNs. Y para despliegues o nodos alejados de la estación base, GPRS será la tecnología utilizada. Por último, referente a las tecnologías de comunicación, se han detallado las características y arquitectura del protocolo de comunicaciones ZigBee, analizando los diferentes tipos de dispositivos que utiliza, las topologías de red y las estrategias de conexión empleadas en la red. En la puesta en marcha de la A-WSN presentada en esta Tesis, se ha trabajado sobre este estándar para llevar a cabo una implementación óptima de una red WSN basada en ZigBee. Además, se ha diseñado un nodo que incluye la tecnología GPRS para la monitorización de zonas aisladas, como se detalla en el capítulo 6.

Una vez establecido el uso de ZigBee en una A-WSN y de una conexión GPRS en el caso de grandes distancias, se han descrito de forma conceptual los requerimientos hardware que deberán tener los posibles componentes de la red. Se presentan como un sistema robusto y capaz de monitorizar, de forma autónoma y relativamente sencilla, el comportamiento del mar en las zonas costeras. Estos diseños conceptuales han sido desarrollados en esta Tesis tal y como se describe en el siguiente capítulo. 
Finalmente, tan importante como el diseño e implementación de los nodos que forman la red, es la implementación del sistema de monitorización en el que se almacena y procesa la información, facilitándola a los usuarios finales. Se han presentado dos alternativas. Una basada en servidores remotos, que será la llevada a cabo en esta Tesis Doctoral, y otra basada en el paradigma "Cloud Computing", cuya implementación se llevará a cabo en trabajos futuros. 
Propuesta de una Red de Sensores Inalámbrica para un Sistema de Observación Costero

Esta página se deja en blanco de forma intencionada. 


\section{Capítulo 6}

\section{Implementación de la arquitectura de red propuesta}

\footnotetext{
W este capitulo, se presenta la implementación real de los nodos que componen la red, tanto a
} que dota de funcionalidad al mismo) teniendo en cuenta las dificultades impuestas por el medio marino, un protocolo de comunicaciones para el intercambio de mensajes a nivel de aplicación entre los nodos de la red ZigBee y el sistema de monitorización, una aplicación gráfica que muestra al usuario los datos procesados, y finalmente, las pruebas realizadas en el laboratorio y pruebas de campo para la validación de todos estos elementos. 


\subsection{Introducción.}

En una red de sensores basada en el estándar ZigBee se distinguen nodos Sensores o ZED, ZR y ZC. Es posible que, dependiendo de las características de la zona de monitorización, existan puntos de interés demasiado alejados del resto con respecto al alcance de la A-WSN. Para escenarios con esta peculiaridad, se plantean dos alternativas con el objetivo de dar cobertura a dichos nodos aislados: (1) instalar nodos Routers entre el nodo puntual y el resto de nodos de la red de sensores, o (2) dotar a este nodo de la electrónica adecuada para que, de forma autónoma, realice el muestreo de los sensores y envíe la información directamente al servidor de datos. En esta segunda opción, la tecnología de comunicación inalámbrica del nodo no estaría basada en ZigBee, sino en una comunicación GPRS.

La primera alternativa puede llegar a ser considerablemente costosa puesto que, para grandes distancias (siempre en relación al alcance de la red, del que se hablará más adelante), se requiere la instalación de varios nodos Routers cuyo coste habría que evaluar frente a una segunda opción. La segunda alternativa debe incluir un módulo que permita la conexión a través de la red de datos. Esta conexión implica un consumo bastante elevado que hay que tener en consideración a la hora de diseñar el sistema de recolección de energía.

Por tanto, los nodos que intervienen en un despliegue para la monitorización de zonas costeras se pueden clasificar en: nodos ZigBee, entre los que se incluyen los nodos Sensores o ZED, ZR, ZC, y los nodos aislados, denominados nodos GPRS.

En el capítulo 5, se presentó de forma conceptual el hardware necesario para implementar diferentes tipos de nodos que pueden integrar una A-WSN. En este capítulo, se realiza una descripción detallada de los diseños hardware finalmente desarrollados, así como el software implementado para cada uno de ellos. Además, se presenta la estructura mecánica de la boya diseñada en esta Tesis Doctoral, ya que la electrónica debe ir embarcada en una estructura lo suficientemente robusta como para soportar las condiciones impuestas por el medio marino.

\subsection{Implementación real de los nodos.}

Para la implementación de los nodos que forman la red, se ha tenido en cuenta la descripción realizada en el capítulo 5, en el que se especifican los componentes habituales y necesarios según la funcionalidad de cada nodo. 
En este apartado, se realiza una descripción detallada del hardware desarrollado y de las herramientas de desarrollo empleadas en los dos grupos de nodos definidos en la Introducción: nodos ZigBee y nodos GPRS.

\subsubsection{Nodos ZigBee.}

La electrónica de los diferentes tipos de nodos ZigBee que forman una red de sensores (nodos ZED, ZR o ZC), aun teniendo distintas funcionalidades, tienen componentes hardware similares. Estos componentes son: el microcontrolador, el módulo de potencia, la memoria FLASH, el RTC y los módulos RF. Por ello, y teniendo en cuenta dichas similitudes, se ha realizado un diseño genérico teniendo como requisitos la utilización de mínimos componentes, con un mínimo coste y consumo. De esta forma, un único dispositivo, en función del programa software con el que se programe, tendrá un rol diferente en la red. Además, incluirá unos conectores de expansión que permiten la conexión de diferentes placas de interfaz, dependiendo de los requisitos de cada trabajo.

\subsubsection{Herramientas de desarrollo empleadas.}

El trabajo previo a la implementación de los nodos ZigBee, ha sido realizado con el kit de desarrollo CC2520DK (ver Figura 6.1) [swru138] de Texas Instruments (en adelante TI). El módulo CC2520 es la segunda generación de transceptores RF ZigBee/IEEE 802.15.4 en la banda ISM 2,4 GHz sin licencia. Este kit incluye el hardware y el software necesario para testear el funcionamiento del módulo, y ofrece una plataforma completa para el desarrollo de prototipos de sistemas RF.

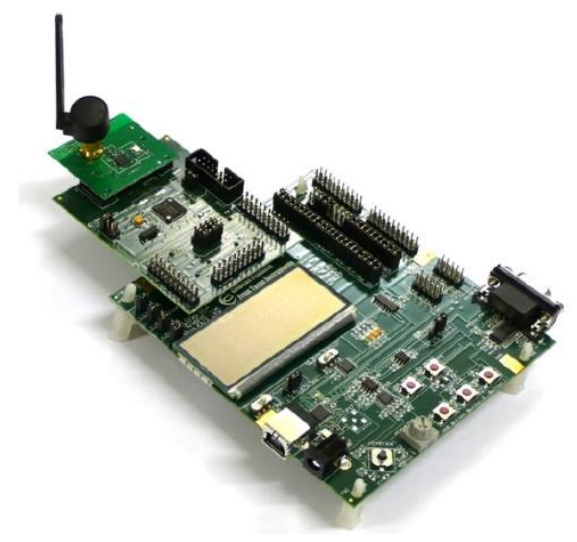

Figura 6.1 CC2520DK Fuente [TI]

Tras analizar y evaluar las características de estos equipos y comprender el funcionamiento de la implementación de ZigBee proporcionada por TI, se decidió llevar a cabo el desarrollo de un sistema propio para la implementación de redes de sensores inalámbricas. Los dispositivos hardware desarrollados están basados en el módulo de radio CC2520 y el microcontrolador MSP430F2618 utilizados en el kit presentado, junto con un 
módulo amplificador CC2591 que permite obtener mayores alcances en la comunicación inalámbrica.

\subsubsection{Características del nodo ZigBee diseñado.}

El nodo diseñado se denomina MultiEnviromental Wireless Node (en adelante MEWiN). Dicho diseño está basado en una estructura modular compuesta por diferentes placas electrónicas. Una placa principal multipropósito denominada MEWiN Main-Board, que incluye los componentes comunes, de forma que se puede utilizar en diferentes aplicaciones de investigación de redes de sensores llevados a cabo en diversos ámbitos, como por ejemplo agricultura, medioambiente y oceanografía. Y conectado a ésta, diferentes placas de interfaz diseñadas ad-hoc para las características del trabajo en cuestión. MEWiN Sea-Board es la placa de interfaz diseñada para el trabajo realizado en esta Tesis Doctoral. La combinación de la placa principal con las placas de interfaz necesarias, y programadas con el software adecuado, dan como resultado cualquiera de los nodos de una A-WSN expuestos en el capítulo 5.

A continuación se describen a nivel de diagrama de bloques las placas MEWiN MainBoard y MEWiN Sea-Board.

\subsection{Arquitectura de MEWiN Main-Board.}

El diagrama de bloques de la Figura 6.2 muestra los componentes que incluye MEWiN Main-Board.

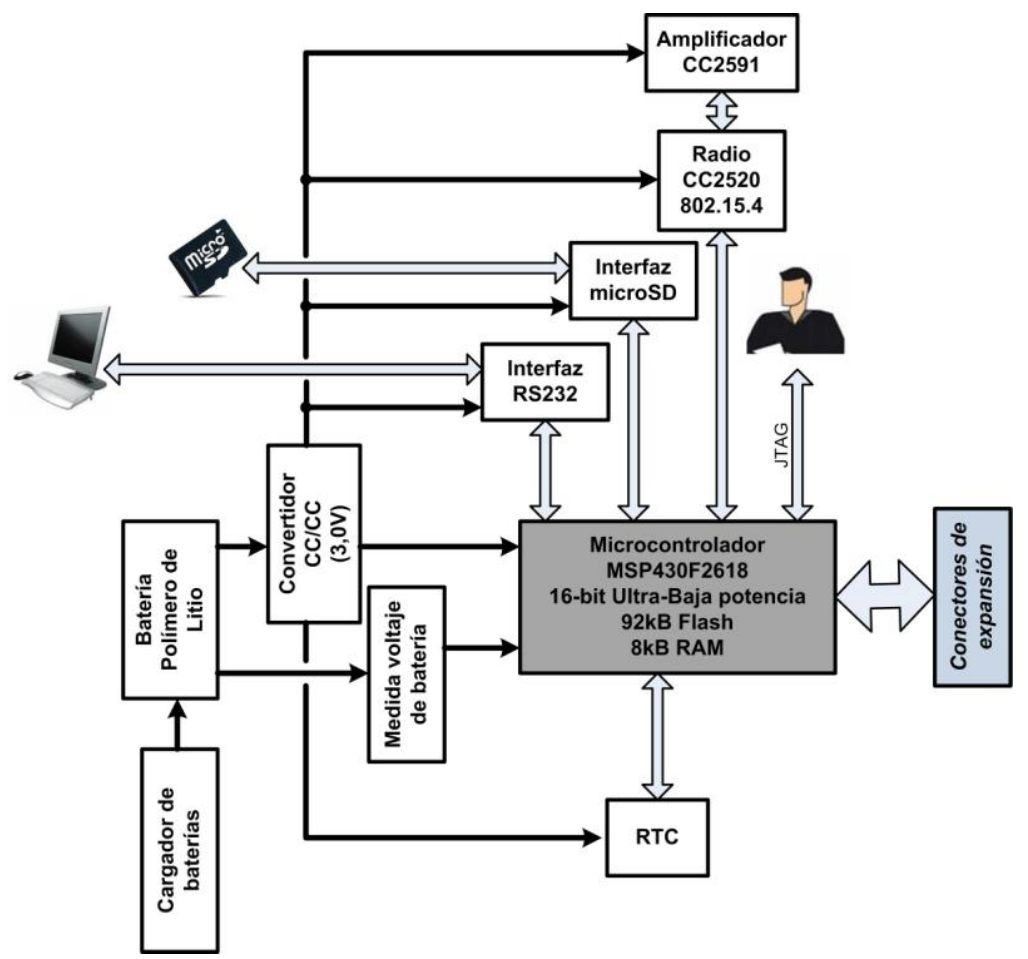

Figura 6.2 Diagrama de bloques MEWiN Main-Board. 
El núcleo de la plataforma es el microcontrolador de baja potencia MSP430F2618 de TI, encargado de gestionar el comportamiento del nodo. La comunicación inalámbrica, mediante el protocolo ZigBee, es proporcionada por el módulo de radio CC2520 que en combinación con el dispositivo CC2591 permiten incrementar el alcance del enlace proporcionando una amplificación de potencia para mejorar la potencia de salida y el LNA, y de esta forma mejorar la sensibilidad en el receptor.

La alimentación del nodo se proporciona mediante baterías de polímero de litio de $5.000 \mathrm{~mA} \mathrm{~h}$, con una tensión nominal de 3,7 V. Esta batería, cuya tensión máxima de carga es de $4,2 \mathrm{~V}$, cuenta con un circuito de protección que impide que se descargue por debajo de los 3,25 V. La tensión de la batería es regulada a un valor fijo y constante de $3 \mathrm{~V}$ que serán los usados para alimentar cada una de las partes del mote.

Además del interfaz microSD, que permite el almacenamiento de datos evitando la pérdida de los mismos aunque se pierda la conectividad, se ha incluido un RTC permitiendo así adjuntar la hora en la que se ha producido la toma de una muestra junto con el valor de la muestra. La combinación de estos dos componentes es esencial para evitar la pérdida de información y conocer la hora exacta en la que se produjeron ciertos eventos.

En la Figura 6.3 se muestra la placa MEWiN Main-Board implementada en la que se resaltan los componentes detallados en este apartado.

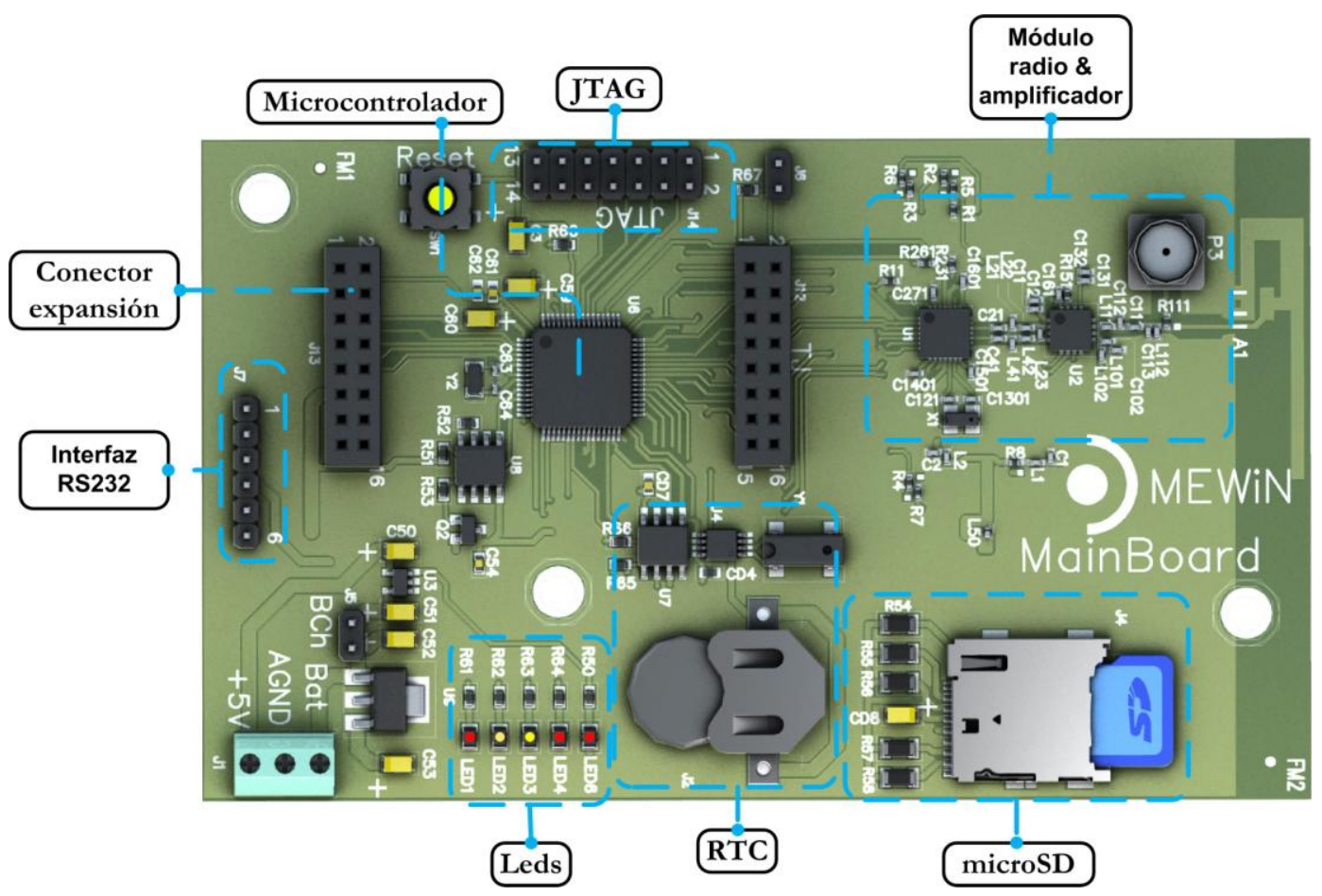

Figura 6.3 MEWiN Main-Board. 
El micro dispone de dos UARTs, UART0 y UART1. Los pines que dan acceso a ambas han sido externalizados con diferentes objetivos. La UART0 permite, o bien conectar el mote a un ordenador para depuración, o como nodo Sumidero. Y la UART1, se ha pensado para la conexión de un sensor con interfaz de conexión RS232. Incluye también un conector JTAG que permite al usuario realizar la programación de las placas con el software adecuado. Se han incluido 4 LEDs que permiten saber el estado de la aplicación que se está ejecutando.

Los conectores de expansión indicados en la Figura 6.3 permiten el acceso a los diferentes pines del microcontrolador.

La Tabla 6.1 especifica los pines del microcontrolador externalizados y la conexión realizada a los conectores de expansión.

Tabla 6.1 Conexiones con el microcontrolador.

\begin{tabular}{|c|c|c|}
\hline Conector - Pin & $\begin{array}{c}\text { Pin del } \\
\text { microcontrolador }\end{array}$ & Descripción \\
\hline $\mathrm{J} 12-1$ & P1.1/DIO0 & Pin I/O digital de propósito general \\
\hline $\mathrm{J} 12-2$ & $\mathrm{P} 1.2 / \mathrm{DIO} 1$ & Pin I/O digital de propósito general \\
\hline $\mathrm{J} 12-3$ & $\mathrm{P} 1.7 / \mathrm{DIO} 2$ & Pin I/O digital de propósito general \\
\hline $\mathrm{J} 12-4$ & P4.7/DIO3 & Pin I/O digital de propósito general \\
\hline $\mathrm{J} 12-5$ & P3.6/UART1_TX & \multirow{4}{*}{ Pines para la utilización de la UART1 } \\
\hline $\mathrm{J} 12-6$ & P2.5/UART1_CTS & \\
\hline $\mathrm{J} 12-7$ & P3.7/UART1_RX & \\
\hline $\mathrm{J} 12-8$ & P4.6/UART1_RTS & \\
\hline $\mathrm{J} 12-9$ & GND & Ground \\
\hline $\mathrm{J} 12-10$ & $+3.0 \mathrm{~V}$ & Tensión regulada \\
\hline $\mathrm{J} 12-11$ & P5.4/DIR_OUT & Control del interfaz SDI-12 \\
\hline $\mathrm{J} 12-12$ & $\mathrm{P} 4.4 / \mathrm{DIO} 4$ & Pin I/O digital de propósito general \\
\hline $\mathrm{J} 12-13$ & P2.1/GPIO0_S & \multirow{4}{*}{ Pines de control del módulo de radio secundario } \\
\hline $\mathrm{J} 12-14$ & P5.6/RESET_S & \\
\hline $\mathrm{J} 12-15$ & P2.4/GPIO2_S & \\
\hline $\mathrm{J} 12-16$ & P2.2/GPIO1_S & \\
\hline $\mathrm{J} 13-1$ & VREF+ & Referencia de tensión \\
\hline
\end{tabular}


Capítulo 6. Implementación de la arquitectura de red propuesta

\begin{tabular}{|c|c|c|}
\hline$J 13-2$ & $+3.0 \mathrm{~V}$ & Tensión regulada \\
\hline$J 13-3$ & $\mathrm{P} 6.0 / \mathrm{AO}$ & $\begin{array}{l}\text { Pin I/O digital de propósito general. Entrada analógica AO - ADC } 12 \\
\text { bits }\end{array}$ \\
\hline$J 13-4$ & P6.1/A1 & $\begin{array}{l}\text { Pin I/O digital de propósito general. Entrada analógica A1 - ADC } 12 \\
\text { bits }\end{array}$ \\
\hline $\mathrm{J} 13-5$ & P6.2/A2 & $\begin{array}{l}\text { Pin I/O digital de propósito general. Entrada analógica A2 - ADC } 12 \\
\text { bits }\end{array}$ \\
\hline$J 13-6$ & P6.3/A3 & $\begin{array}{l}\text { Pin I/O digital de propósito general. Entrada analógica A3 - ADC } 12 \\
\text { bits }\end{array}$ \\
\hline $\mathrm{J} 13-7$ & P6.4/A4 & $\begin{array}{l}\text { Pin I/O digital de propósito general. Entrada analógica A4 - ADC } 12 \\
\text { bits }\end{array}$ \\
\hline$J 13-8$ & P6.5/A5/DAC1 & $\begin{array}{l}\text { Pin I/O digital de propósito general. Entrada analógica A5 - ADC } 12 \\
\text { bits. Salida DAC } 12.1\end{array}$ \\
\hline $\mathrm{J} 13-9$ & P6.6/A6/DACO & $\begin{array}{l}\text { Pin I/O digital de propósito general. Entrada analógica A6 - ADC } 12 \\
\text { bits. Salida DAC } 12.0\end{array}$ \\
\hline$J 13-10$ & P6.7/A7 & $\begin{array}{l}\text { Pin I/O digital de propósito general. Entrada analógica A7 - ADC } 12 \\
\text { bits. Salida DAC } 12.1\end{array}$ \\
\hline J13- 11 & VCC & Tensión de batería \\
\hline $\mathrm{J} 13-12$ & P2.0/VREG_EN_S & Pin de control del módulo de radio secundario \\
\hline$J 13-13$ & P3.0/SPI_CS_S & \multirow{4}{*}{ Pines de control del módulo de radio secundario. Bus SPI } \\
\hline J13- 14 & P3.1/SPI_SI_S & \\
\hline$J 13-15$ & P3.2/SPI_SO_S & \\
\hline $\mathrm{J} 13-16$ & P3.3/SPI_CLK_S & \\
\hline
\end{tabular}

\subsection{Arquitectura de MEWiN Sea-Board.}

En cuanto a MEWiN Sea-Board (ver Figura 6.4), en esta versión del nodo Sensor se pueden incorporar sensores con diferentes tipos de interfaz de conexión: un sensor con interfaz de conexión RS232, un sensor con interfaz de conexión 4-20 mA a 2 hilos, y otro sensor con interfaz de conexión $4-20 \mathrm{~mA}$ a 3 hilos. En la Figura 6.4 se muestran los tres sensores con diferentes interfaces que se han utilizado (SBE 39 con RS232, SENSOTEC LMK 807 con interfaz 4-20 mA a 2 hilos, y YOUNG 61302L con interfaz 4-20 mA a 3 hilos).

En el nodo Sensor, además de los parámetros medidos por los sensores y el valor de la tensión de batería proporcionado por el interfaz de medida en MEWiN Main-Board, se realiza la monitorización de la temperatura del interior de la caja que incluye la electrónica. Por último, se contempla un cargador de baterías mediante energía solar y un convertidor 
que proporciona los $12 \mathrm{~V}$ necesarios para los sensores externos conectados mediante la interfaz RS232 y 4-20 mA, y que será habilitado desde el microcontrolador en función de las necesidades, minimizando así el consumo del dispositivo.

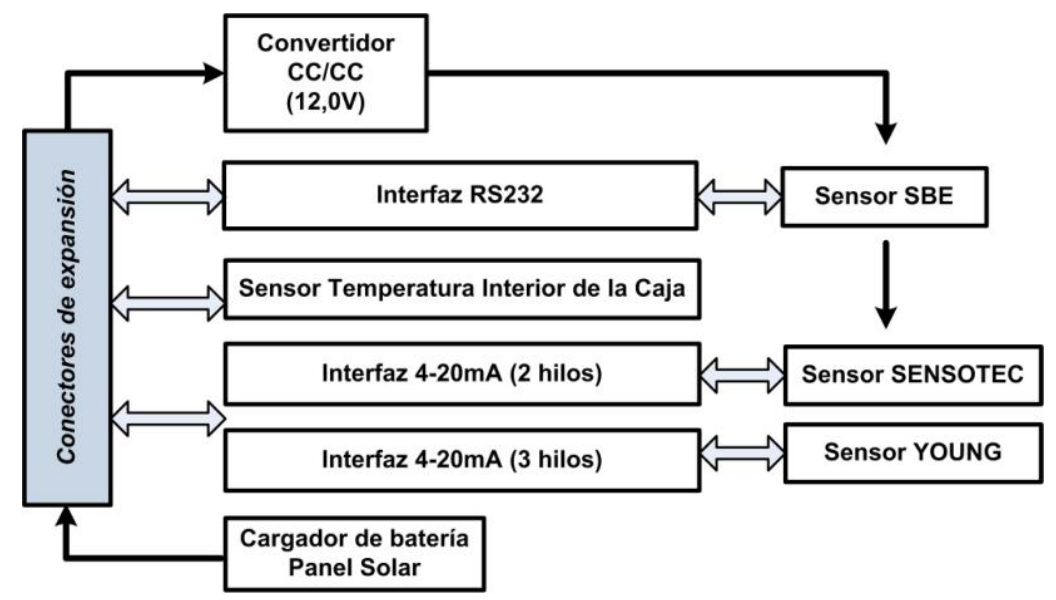

Figura 6.4 Diagrama de bloques MEWiN Sea-Board.

En la Figura 6.5 se muestra la placa MEWiN Sea-Board implementada en la que se resaltan los componentes detallados en este apartado.

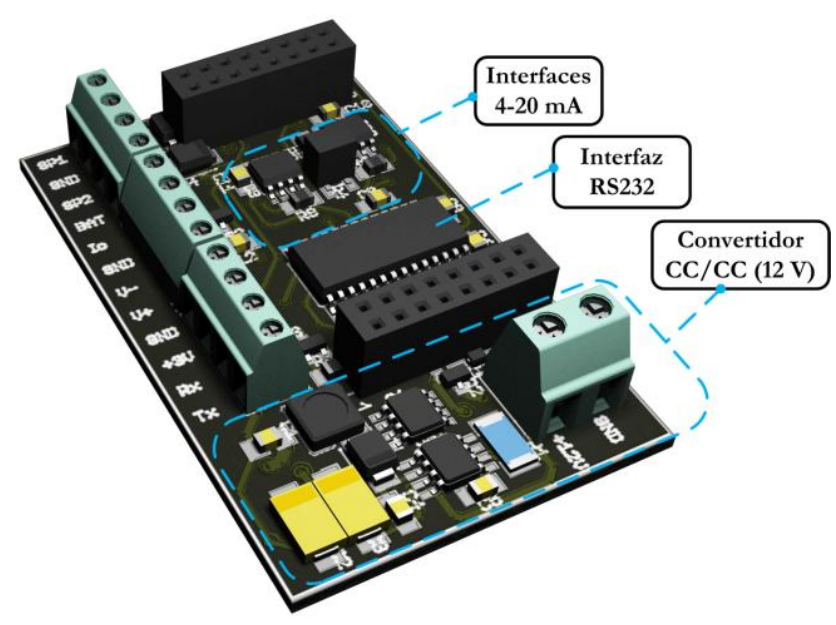

Figura 6.5 MEWiN Sea-Board.

En la Tabla 6.2 se especifican los pines del conector de expansión que se utilizan en MEWiN SeaBoard.

Tabla 6.2 Pines del conector de expansión.

\begin{tabular}{c|c}
\hline Conector - Pin & Descripción \\
$\mathrm{J} 18-\mathrm{P} 4.7$ & Configuración del pin de habilitación de la fuente como salida \\
\hline $\mathrm{J} 18-\mathrm{P} 2.4$ & Habilitación interfaces 4-20 mA \\
\hline $\mathrm{J} 19-\mathrm{P} 6.0$ & Habilitación de la UART1 \\
\hline $\mathrm{J} 19-\mathrm{P} 6.1$ & Lectura ADC del sensor de presión marina \\
\hline $\mathrm{J} 19-\mathrm{P} 6.3$ & Lectura ADC del sensor de temperatura en la caja \\
\hline $\mathrm{J} 19-\mathrm{P} 6.5$ & Lectura ADC del sensor de presión atmosférica \\
\hline
\end{tabular}


Las diferentes placas de interfaz que se desarrollen, al igual que MEWiN SeaBoard, serán conectadas a la placa principal MEWiN MainBoard a través de los conectores de expansión que ésta incluye, tal y como se puede observar en la Figura 6.6.

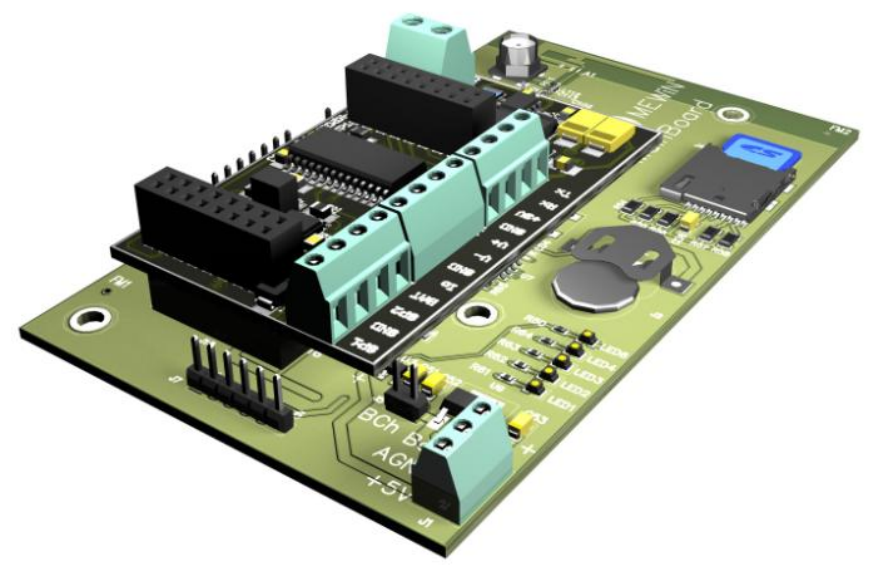

Figura 6.6 MEWiN Main\&Sea Board.

\subsubsection{Nodo GPRS.}

En el trabajo previo al desarrollo del nodo GPRS, teniendo en cuenta la funcionalidad que éste requiere, se utilizó un kit de desarrollo de Telit Communications [Telit] descrito a continuación. Una vez evaluado este equipo, se procedió al diseño ad-hoc del nodo.

En este apartado, tras presentar las herramientas de desarrollo empleadas, se muestra el diseño realizado mediante un diagrama de bloques hardware e imágenes reales de la implementación del nodo.

\subsubsection{Herramientas de desarrollo empleadas.}

El sistema de desarrollo utilizado para la implementación del nodo GPRS es Starter-Kit STK-AARLOGIC-C01 [RoundSolutions]. Incluye un módulo GE863-GPS, que incorpora los servicios de GSM/GPRS y GPS (ver Figura 6.7). Combina un modem GSM/GPRS cuatribanda con un receptor de 20 canales y alta sensibilidad en recepción $(-159 \mathrm{dBm})$.

El módulo GE863-GPS utilizado incluye un intérprete de Python [Phyton], que permite el manejo del equipo internamente desde una aplicación escrita en dicho lenguaje. Para ello, estas versiones programables implementan una memoria adicional de $3 \mathrm{MB}$ de memoria no volátil y 1,5 MB de RAM. La comunicación con este módulo se realiza mediante comandos AT. 


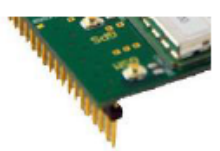

Figura 6.7 Módulo Telit - Starter-Kit STK-AARLOGIC-C01. Fuente [RoundSolutions]

La placa de desarrollo de este kit, mostrada en la Figura 6.7, ofrece diferentes puertos serie para la conexión de diversos instrumentos con unos requisitos específicos. En uno de estos puertos se ha conectado el sensor oceanográfico, cuya gestión se lleva a cabo desde la aplicación cargada en el módulo Telit. Además, la característica GPRS que ofrece este módulo permite a un usuario contactar con un dispositivo y establecer con él un flujo de datos sobre las redes GPRS e Internet. Haciendo uso de esta utilidad, se establece la comunicación entre el nodo Sensor y el servidor de datos para enviarle la información recogida por el sensor. Una última característica a destacar es el servicio GPS incluido en el módulo. Éste será utilizado para verificar la correcta posición geográfica del nodo, y de esta forma poder controlar desplazamientos del mismo debido, por ejemplo, a roturas en el sistema de anclaje.

Una vez analizado el funcionamiento del módulo Telit con la placa del kit de desarrollo utilizado, se ha diseñado y fabricado el hardware adecuado a las necesidades del nodo GPRS.

\subsubsection{Características del nodo GPRS diseñado.}

El nodo GPRS opera de forma autónoma e independiente de la red de sensores. El objetivo de este nodo es monitorizar puntos estratégicos y aislados, procesar la información que recoge de los sensores, y establecer una conexión con el servidor de datos a través de una comunicación GPRS para el envío de información.

El módulo de comunicaciones utilizado tiene la peculiaridad de incluir en un mismo dispositivo conectividad a la red de telefonía móvil GSM con comunicaciones de datos GPRS de clase 10, un receptor GPS tipo SIRF-III de 20 canales, una pila software TCP/IP, un cliente FTP y SMTP, un intérprete embebido de lenguaje Phyton, y memoria flash no volátil donde almacenar aplicaciones propias.

La característica de transmisión de datos utilizando la red GPRS, y la inclusión de una pila de protocolo TCP/IP que ofrece este módulo, permiten establecer de forma periódica una conexión entre el nodo Sensor y un servidor de datos donde almacenar y tratar la información recogida por los sensores. El uso del protocolo de comunicaciones de red 
estándar TCP/IP permite que este servidor esté ubicado en cualquier lugar del mundo a cualquier distancia del nodo Sensor, siempre que tenga una conexión permanente a la red global de Internet. Incluso sería posible la conexión con varios servidores. Del mismo modo, el uso de un protocolo de transferencia de archivos estándar como es FTP, elimina la necesidad de la instalación de un software específico y propietario en el lado del servidor. En cuanto a la compatibilidad con redes GSM, el dispositivo es de tipo quad-band (850/900/1800/1900 MHz), con lo que está garantizada su utilización con la mayoría de operadores GSM a lo largo del mundo. El intérprete Phyton incluido facilita el desarrollo del software embebido y proporciona gran flexibilidad a la hora de añadir nuevas funcionalidades o incluir soporte para sensores de otros fabricantes.

\subsubsection{Arquitectura del nodo GPRS.}

El núcleo del nodo GPRS desarrollado es el módulo de comunicaciones inteligente GE863-GPS, tal y como se muestra el diagrama de bloques de la Figura 6.8. A través de éste, se gestiona la conexión con el servidor de datos para el envío de información. La antena incluida en el diseño es la proporcionada en el kit de desarrollo (GSM-GPS GNR600). La conexión entre el sensor y el módulo se realiza a través de un interfaz serie estándar RS232. La alimentación del sistema se proporciona mediante una batería de iones de litio, la cual es recargada a partir de células solares mediante un circuito de control de carga.

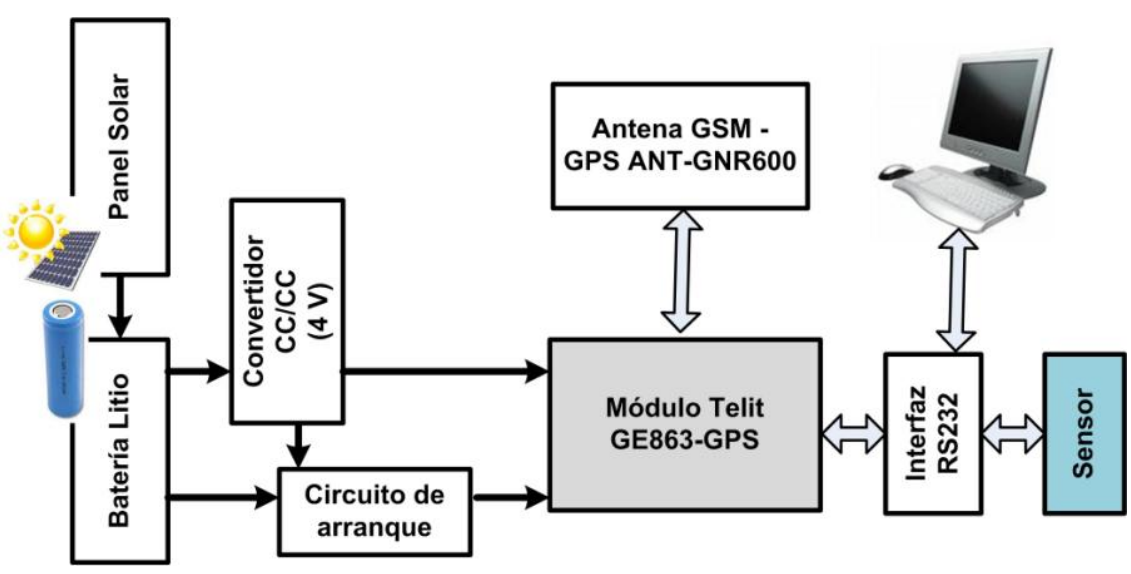

Figura 6.8 Diagrama de bloques del nodo GPRS.

La instrumentación utilizable con este sistema, sólo tiene como requisitos el disponer de un interfaz de comunicaciones digital estándar RS232 con velocidades comprendidas entre los 300 y 115200 bps, un protocolo de comunicación mediante comandos, y la capacidad de pasar a un estado de bajo consumo de energía entre muestreos.

En la Figura 6.9 se muestra la placa desarrollada en la que se destacan los componentes detallados en este apartado. 

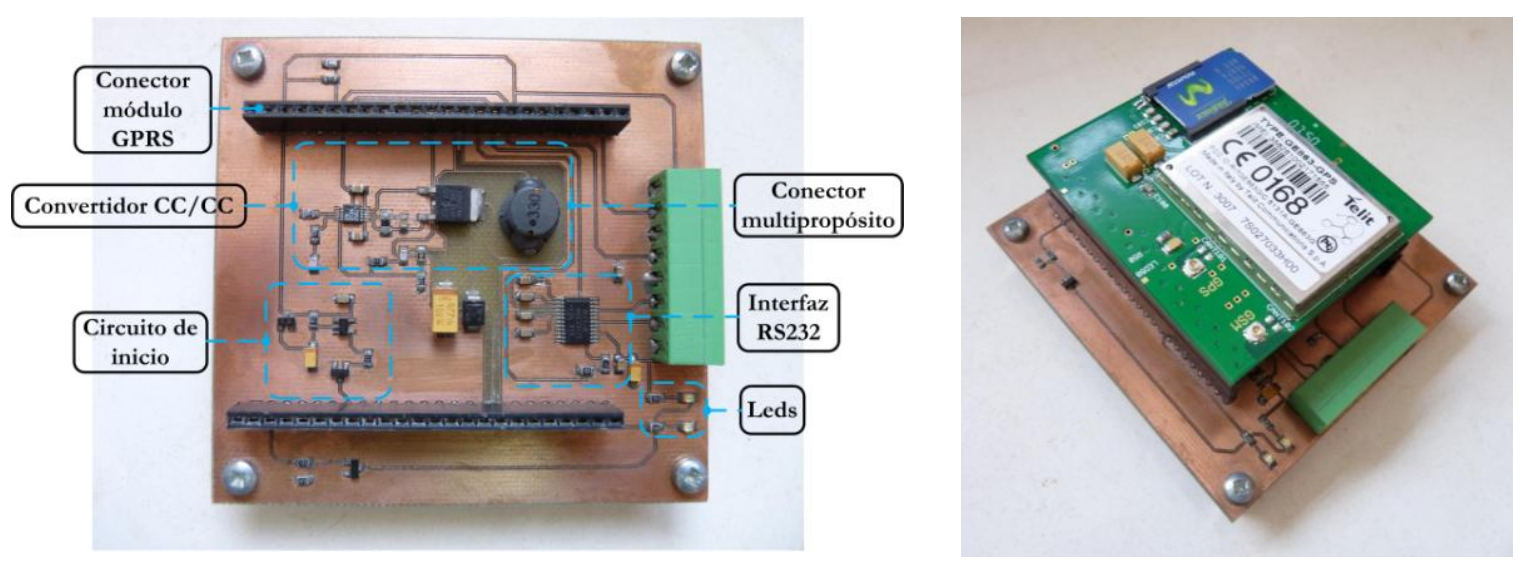

Figura 6.9 Nodo GPRS.

El conector multipropósito permite la conexión tanto del sensor oceanográfico como de la batería, y su fácil sustitución en tareas de mantenimiento. Finalmente, se ha incluido la circuitería de retardo y supervisión necesaria para producir un arranque correcto según especificaciones proporcionadas por el fabricante del módulo de comunicaciones GSM.

\subsection{Software de los nodos.}

El software que dota de funcionalidad a los nodos ha sido desarrollado en diferentes plataformas. Para el desarrollo de aplicaciones de los nodos ZigBee se ha utilizado el software IAR de TI [IAR], y para el nodo GPRS, se ha hecho uso del paquete de Python TelitPy1.5.2+_v4.1.

A continuación, se describen tanto los entornos de desarrollo software empleados para la implementación de las aplicaciones de los nodos ZigBee y GPRS, como el flujo de dichas aplicaciones. Se detallan las características de dichos programas y las opciones que éstos incluyen, junto con las modificaciones realizadas para adecuar el software a los requisitos de este trabajo.

\subsubsection{Software de un nodo ZigBee.}

En este apartado, se detallan las características del entorno de trabajo IAR que ha sido utilizado en el desarrollo de aplicaciones en lenguaje C para los nodos ZigBee, la evaluación de las diferentes alternativas que TI ofrece para la comunicación inalámbrica entre los nodos de una A-WSN (BasicRF, SimpliciTI, TIMAC y Z-Stack), las aportaciones y modificaciones realizadas sobre el software elegido, y por último, el funcionamiento de las aplicaciones mediante diagramas de flujo. 


\subsubsection{IAR Embedded Workbench para MSP430.}

IAR Embedded Workbench para MSP430 es un Entorno de Desarrollo Integrado (IDE) para el desarrollo y depuración de aplicaciones embebidas para microcontroladores MSP430. Esta herramienta permite la complicación de código (escrito en lenguaje de programación C) para posteriormente cargarlo en el microprocesador del mote. IAR ofrece una versión gratuita de este producto que limita el código compilado a 4 Kbytes. El DSIE dispone de la versión completa del software, por lo que no se ha tenido ningún límite más allá del propio espacio de memoria que ofrece el microprocesador MSP430.

Como cualquier otro entorno de desarrollo, LAR Embedded Workbench está compuesto principalmente por tres partes: una de ellas dedicada a escribir el código fuente, otra incluye el espacio de trabajo, y por último, la zona de depuración (ver Figura 6.10).

Para una descripción detallada del funcionamiento de este entorno de desarrollo, se recomienda consultar el documento referenciado en [IAR IDE].

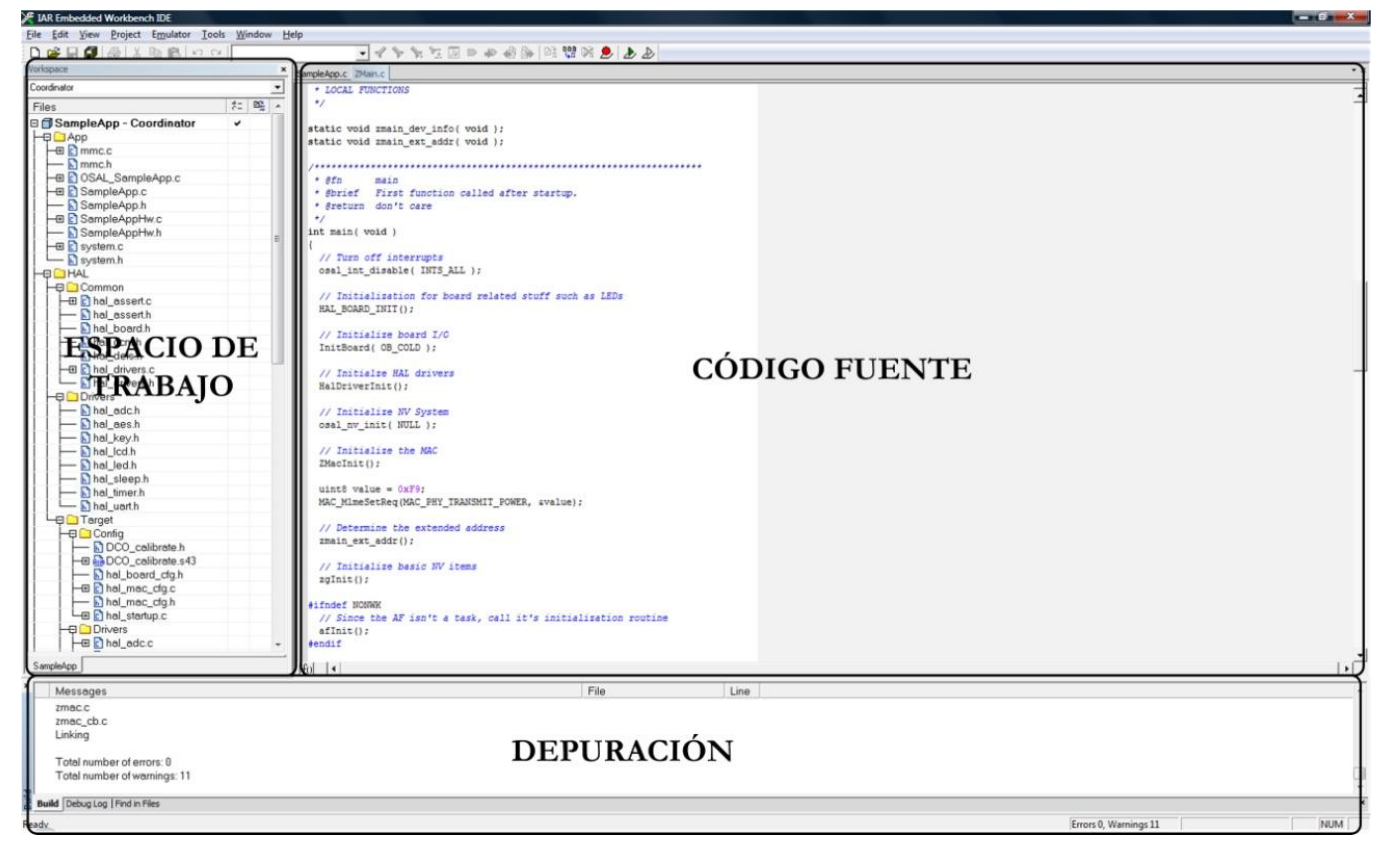

Figura 6.10 IAR Embedded Workbench.

\subsubsection{Elección de un protocolo de comunicación inalámbrica.}

TI proporciona varias soluciones, en cuanto a protocolo de comunicaciones se refiere, BasicRF, SimpliciTI, TIMAC y Z-Stack. Puesto que la tecnología de comunicaciones inalámbrica elegida fue ZigBee, tal y como se justificó en el apartado 5.2.2 del capítulo 5, se han evaluado estas cuatro alternativas de TI teniendo en cuenta los requisitos impuestos en el estándar de dicha tecnología, adoptando finalmente una de ellas como medio de trabajo. 
El protocolo Basic RF ofrece servicios para la transmisión y recepción de paquetes, y una comunicación segura mediante autenticación CCM-64 y encriptación de paquetes [swru137b]. Utiliza paquetes de reconocimiento y datos según el formato de IEEE 802.15.4 MAC. Sin embargo, no ofrece una implementación de la capa MAC completa, sólo una capa de enlace de datos para comunicación entre dos nodos. La sencillez de este protocolo y el alcance obtenido en las pruebas es lo que lo puede hacer atractivo, pero por el contrario, haciendo uso de esta solución, se debía implementar el estándar de ZigBee completo.

SimpliciTI es un protocolo sencillo enfocado para pequeñas redes RF. Este protocolo no soporta el módulo de comunicaciones range extender CC2591 incluido en el diseño hardware descrito en el apartado 6.2.1.2.1, y por tanto, fue descartado.

El protocolo de nivel MAC TIMAC es una implementación del estándar IEEE 802.15.4 que define el nivel físico y el control de acceso al medio de WPANs con bajas tasas de transmisión de datos. Con esta solución, aunque se obtuvieron distancias menores que con Basic RF, la implementación del estándar estaba resuelto.

Z-Stack es una implementación del estándar IEEE 802.15.14 de ZigBee de TI. Esta solución, en cuanto a cobertura se refiere, depende de la calidad del enlace programado. Con la penalización de la calidad del enlace, se obtienen distancias mayores. Y disminuyendo ésta última, se obtiene un enlace con mayores prestaciones.

Se realizaron pruebas de cobertura con las cuatro soluciones de TI. Se emplearon los equipos del kit de desarrollo expuesto en el apartado 6.2.1.1 y se utilizaron antenas omnidireccionales de $8 \mathrm{~dB}$ a una altura de 1,5 m sobre el nivel del mar. En la Tabla 6.3 se resumen las características significativas de cada protocolo y el alcance obtenido en las pruebas de cobertura realizadas.

Tabla 6.3 Pruebas de cobertura.

\begin{tabular}{ccccc}
\hline & Basic RF & SimpliciTI & TIMAC & Z-Stack \\
\hline IEEE802.15.4 & No & No & Sí & Sí \\
\hline Compatibilidad HW & Sí & No & Sí & Sí \\
\hline Alcance & $4 \mathrm{~km}$ & - & $3 \mathrm{~km}$ & $3 \mathrm{~km}$ \\
\hline
\end{tabular}

SimpliciTI ha sido descartada por incompatibilidad con los equipos diseñados, Basic RF ofrece un mayor alcance, tras ella TIMAC, y por último, Z-Stack, aunque con un alcance similar a TIMAC, es la que mayor restricción presenta. Aun siendo la última en alcance obtenido, ha sido la solución adoptada, puesto que, realizando la configuración de 
la pila Z-Stack descrita en el Anexo 1, se pueden obtener distancias mayores, y además, aporta la implementación del estándar de ZigBee completa.

\subsubsection{Modificaciones software de la pila Z-Stack de Texas Instruments.}

Z-stack proporciona una capa de abstracción hardware, que permite el acceso al hardware mediante el uso de funciones de más alto nivel, y una capa de abstracción del sistema operativo, que facilita la programación de aplicaciones. Se compone de una serie de funciones que la aplicación puede llamar para solicitar servicios, y una serie de Callbacks que consisten en funciones de la aplicación que hay que programar para tratar diferentes eventos. Es por ello que se trata de una programación orientada a eventos.

Las aplicaciones software que dotan de funcionalidad a los nodos, descritas más adelante, han sido implementadas con la versión de la pila ZStack-MSP2618-2.3.0-1.4.0. Se han realizado modificaciones a bajo nivel de dicha pila para cubrir las necesidades de la red de sensores, como por ejemplo, la gestión de reconexión de los distintos tipos de nodos ante la pérdida de conexión. Las modificaciones y aportaciones software se describen a continuación, y se recogen con más detalle en el Anexo 2 de la presente Tesis Doctoral.

\subsection{Gestión de pérdidas de conexión de los ZED con el nodo padre.}

El problema planteado en este apartado es la pérdida de conexión de un ZED con su nodo padre (ZR o ZC). Tal y como está implementada la versión de la pila de TI que se ha utilizado, cuando un ZED pierde la conexión con su padre, el ZED intenta conectarse durante un tiempo ilimitado hasta que consigue asociarse de nuevo. Esto conlleva un gran consumo de batería. Para solucionarlo se ha implementado la solución propuesta en [SupportTI 67205] cuya misión es evitar el polling constante por parte del ZED. Para ello, el ZED esperará un tiempo determinado en tiempo de programación entre los diferentes reintentos para asociarse al ZC o ZR. Las modificaciones software realizadas para este fin se detallan en el Anexo 2.

\subsection{Establecimiento de una dirección MAC de los nodos.}

Al iniciar el proceso de asociación de un nodo hijo con su nodo padre, ZR o ZC, el nodo hijo emite una trama Beacon Request. Los ZCs o ZRs que lo escuchan contestan con un Beacon, a cuya respuesta el nodo hijo le envía un mensaje de petición de asociación Association Request. Esta petición permite que el nodo padre conozca su dirección MAC y pueda asignarle una dirección corta (16 bits) y almacenar la información en su tabla de asociaciones.

El nodo padre contiene una tabla de asociaciones AssociatedDevList con las direcciones, entre otro tipo de información, que ha ido asociando a los hijos que se lo han 
solicitado. El tamaño de dicha tabla en la implementación Z-Stack de TI utilizada está limitado a 14. Si no se fija una dirección MAC a cada dispositivo de la red, ésta se genera de forma aleatoria cada vez que se inicie el nodo. Se ha comprobado que esto supone un problema ya que, el nodo padre, ante direcciones MAC diferentes otorga posiciones diferentes en su tabla de asociaciones suponiendo que está ante dispositivos físicos diferentes, cuando en realidad es el mismo. Puesto que el tamaño de la tabla de asociaciones del nodo padre está limitado, cuando se llena no admite más asociaciones. Por tanto, es necesario establecer una dirección MAC a cada uno de los dispositivos fabricados.

\subsubsection{Implementaciones software adicionales.}

Además de las modificaciones realizadas en la pila y explicadas en el apartado anterior, se han incluido algunas características software que ofrecen al sistema una mayor robustez. Éstas son las siguientes: obtención de la hora del RTC y programación de alarmas mediante la interrupción de éste, evitando así la implementación interna de un timer y optimizando el consumo del mote, y el almacenamiento de información en la microSD en formato FAT. Los detalles de implementación de ambas utilidades se detallan en el Anexo 2.

\subsection{RTC (Real-Time Clock).}

El RTC utilizado [RTC MAXIM] es un dispositivo de baja potencia con dos alarmas programables. La conexión del RTC se hace mediante un interfaz $\mathrm{I}^{2} \mathrm{C}$ y la información que proporciona es la siguiente: segundos, minutos, horas, día de la semana, día del mes, mes y año. Éste ha sido utilizado para dos fines. En primer lugar, para datar las muestras tomadas por los sensores. Y en segundo lugar, para la implementación de alarmas.

\subsection{Almacenamiento de información en formato FAT.}

Se han implementado las funciones necesarias, detalladas en Anexo 2, que permiten el almacenamiento de información en la microSD en formato FAT. Los nodos Sensores, almacenan los datos muestreados de sus sensores. Pero además, el nodo Coordinador de la red, junto con los datos que recibe de sus nodos hijos, almacena información referente a las comunicaciones en la red ZigBee. Se ha considerado de interés almacenar las conexiones y desconexiones de los nodos con el nodo Coordinador junto con el instante temporal en el que suceden. Estudiando estos datos se puede conocer el estado de la red completa.

\subsubsection{Aplicaciones software de los nodos.}

Para el desarrollo de la aplicación de los nodos se ha trabajado sobre la aplicación de ejemplo SampleApp [swra201]. En los siguientes apartados se describen las aplicaciones desarrolladas mediante los diagramas de flujo de las mismas. 


\subsection{Aplicación del nodo Sensor.}

En este apartado se presenta la aplicación software desarrollada en lenguaje C que dota de funcionalidad a un nodo Sensor o ZED. A modo de ejemplo, se detalla la aplicación desarrollada para un nodo que incluye dos sensores conectados mediante interfaces de conexión diferentes a la placa de interfaz MEWiN-SeaBoard. Un sensor se comunica a través de un interfaz RS232, y el otro sensor mediante 4-20 mA. Las características técnicas de ambos sensores serán detalladas más adelante en el presente capítulo.

El nodo Sensor está configurado en modo bajo consumo mediante la opción de compilación POWER_SAVING. Abandona este estado cuando lo requiere el flujo normal del programa, volviendo a éste cuando se termine dicho flujo. Para evitar que, durante la ejecución del programa principal, el nodo duerma, se ha añadido una variable booleana ocupado a bajo nivel de forma que, cuando esté a true, el nodo se mantiene despierto. Cuando se finaliza el muestreo, envío y almacenamiento de la información, dicha variable ocupado se fija a false volviendo el nodo a un estado dormido.

A continuación se describe el flujo del diagrama principal con ayuda de los diagramas de bloques de las Figura 6.11, Figura 6.12 y Figura 6.13.

En una red ZigBee, cuando un nodo ZED se inicia, se produce un intercambio de mensajes para el establecimiento de una asociación entre padre e hijo. Cuando esto ocurre, se produce el evento del sistema ZDO_STATE_CHANGE indicando un cambio en el estado de la red (ver Figura 6.11). Independientemente de si se establece o no dicha asociación, es necesario iniciar el funcionamiento del programa para el muestreo de los sensores, y aunque no sea posible realizar el envío de la información al nodo padre ( $\mathrm{ZC}$ o ZR), los datos se deben almacenar en la memoria microSD que incluye el nodo desarrollado. Así, se mantiene la preservación de los datos ante la imposibilidad de comunicación en la red.

En cualquier caso, inicialmente se realiza la configuración del hardware para un bajo consumo del nodo (se deshabilitan las líneas del micro mientras no se utilicen), se planifica el evento para el inicio del flujo del programa PROGRAMA_PRINCIPAL a los $10 \mathrm{~ms}$ y se programan las alarmas necesarias (ver Figura 6.11).

En cuanto al evento PROGRAMA_PRINCIPAL, cuando éste vence, se inicia el flujo indicado en la Figura 6.12. Sintetizando el procedimiento, y teniendo en cuenta que el diagrama de bloques muestra el flujo de un programa implementado para un nodo que incluye dos sensores (un sensor conectado al interfaz RS232 de la placa y otro al interfaz 4$20 \mathrm{~mA}$ ), el flujo del programa es el siguiente:

1. Se habilita la fuente para los sensores y el RS232. 
2. Se habilita la interrupción de la UART para recibir la respuesta y se envía el comando de solicitud de dato al sensor RS232.

3. Se procesan los datos recibidos (interrupción UART1 en Figura 6.13).

4. Se deshabilita el RS232 y se habilita la lectura del ADC para el sensor 4-20 mA, medición de batería y sensor de temperatura de la caja.

5. Lectura de los ADCs y del RTC.

6. Cuando la hora está disponible (interrupción $\mathrm{I}^{2} \mathrm{C}$ en Figura 6.13), se planifica el evento PROGRAMA_SD encargado de almacenar la información en la memoria microSD.

7. Se deshabilita la microSD y la fuente de los sensores y se envía la información completa al nodo padre.

El último evento que se contempla en el diagrama de la Figura 6.11 y queda por analizar es AF_INCOMING_MSG_CMD. El evento del sistema AF_INCOMING_MSG_CMD es indicación de la recepción de un mensaje. Los mensajes recibidos por un nodo son procesados en la función SampleApp_MessageMSGCB ( ) (ver Figura 6.13). En este caso, el nodo Sensor puede recibir únicamente mensajes para el cambio de su frecuencia de muestreo, por lo que se incluye el tipo de mensaje CMS_APP_FREC_MUESTREO.

\subsection{Aplicación del nodo Coordinador.}

El ZC es el encargado de gestionar la red y, aunque las líneas del micro que no se utilicen se deshabilitan para un menor consumo energético, está activo en todo momento.

Los eventos incluidos en esta aplicación son ZDO_STATE_CHANGE, AF_INCOMING_MSG_CMD y PROGRAMA_SD (ver Figura 6.14), similares a los explicados en la aplicación del nodo Sensor. Ante un cambio de estado en la red, en este caso que el nodo se establezca como ZC, se produce un evento ZDO_STATE_CHANGE, ante la llegada de un mensaje vía RF tiene lugar el evento AF_INCOMING_MSG_CMD, y PROGRAMA_SD se planifica para el almacenamiento de información en la memoria microSD.

El tipo de mensaje que el ZC puede recibir vía RF es CMS_APP_DATA (ver Figura 6.14). Éste corresponde a los mensajes de datos de los nodos $Z E D$, que los almacena en la memoria microSD y reenvía por el puerto RS232 a la aplicación de usuario.

Por otro lado, el ZC recibirá de la aplicación de usuario la orden de cambiar la frecuencia de muestreo de los nodos a través de la UART0. Para ello, enviará un mensaje del tipo CMS_APP_FREC_MUESTREO a los nodos que corresponda. 


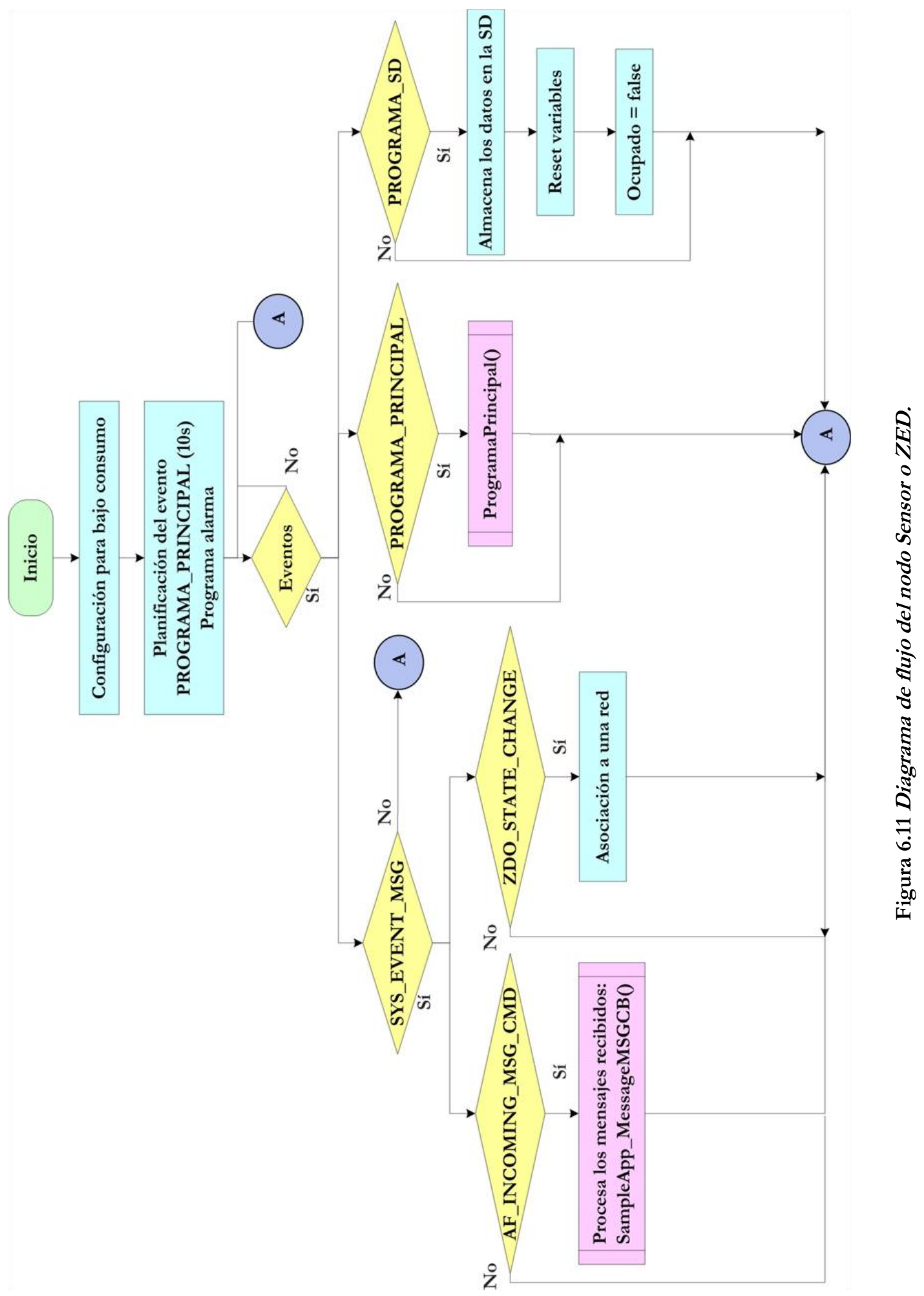




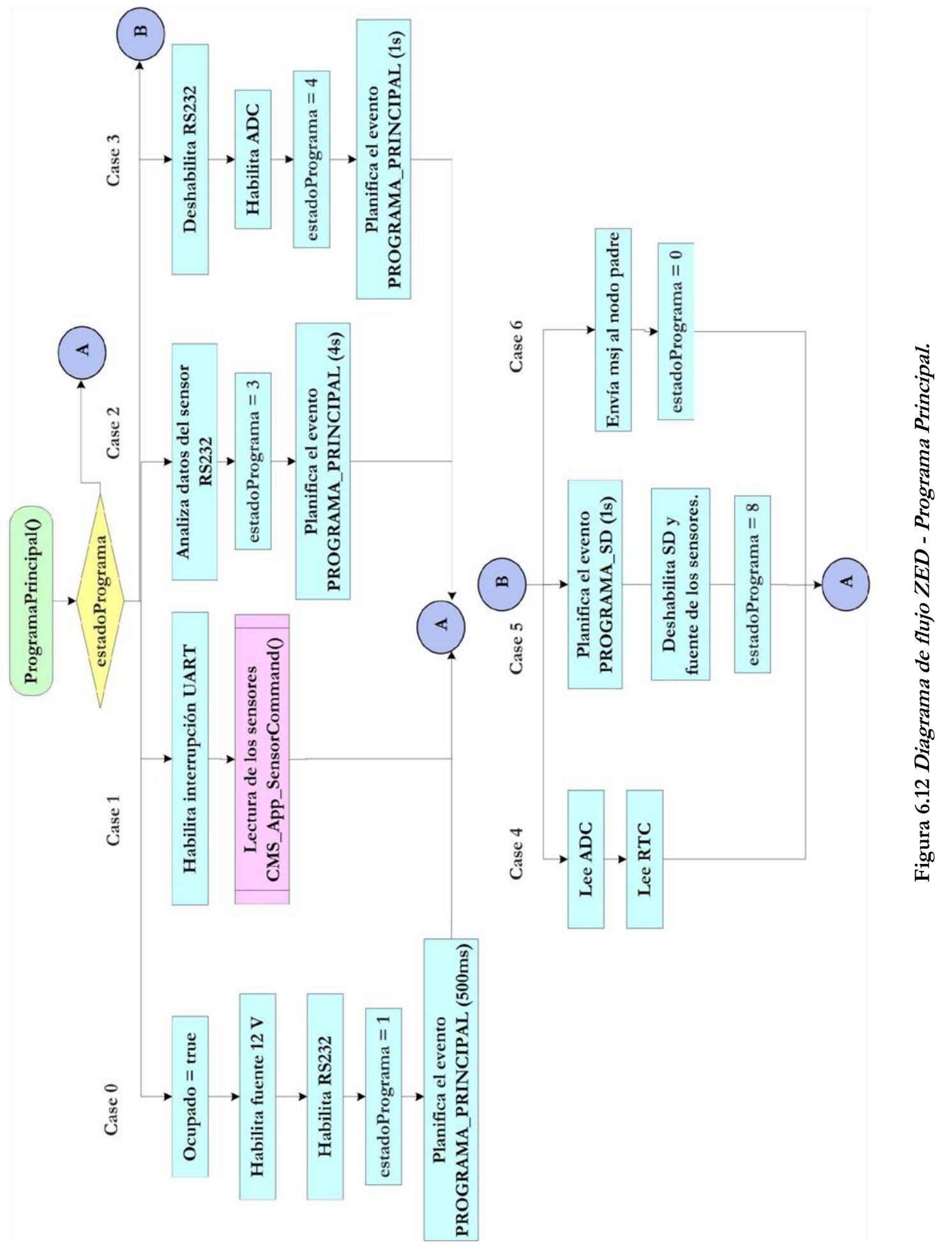



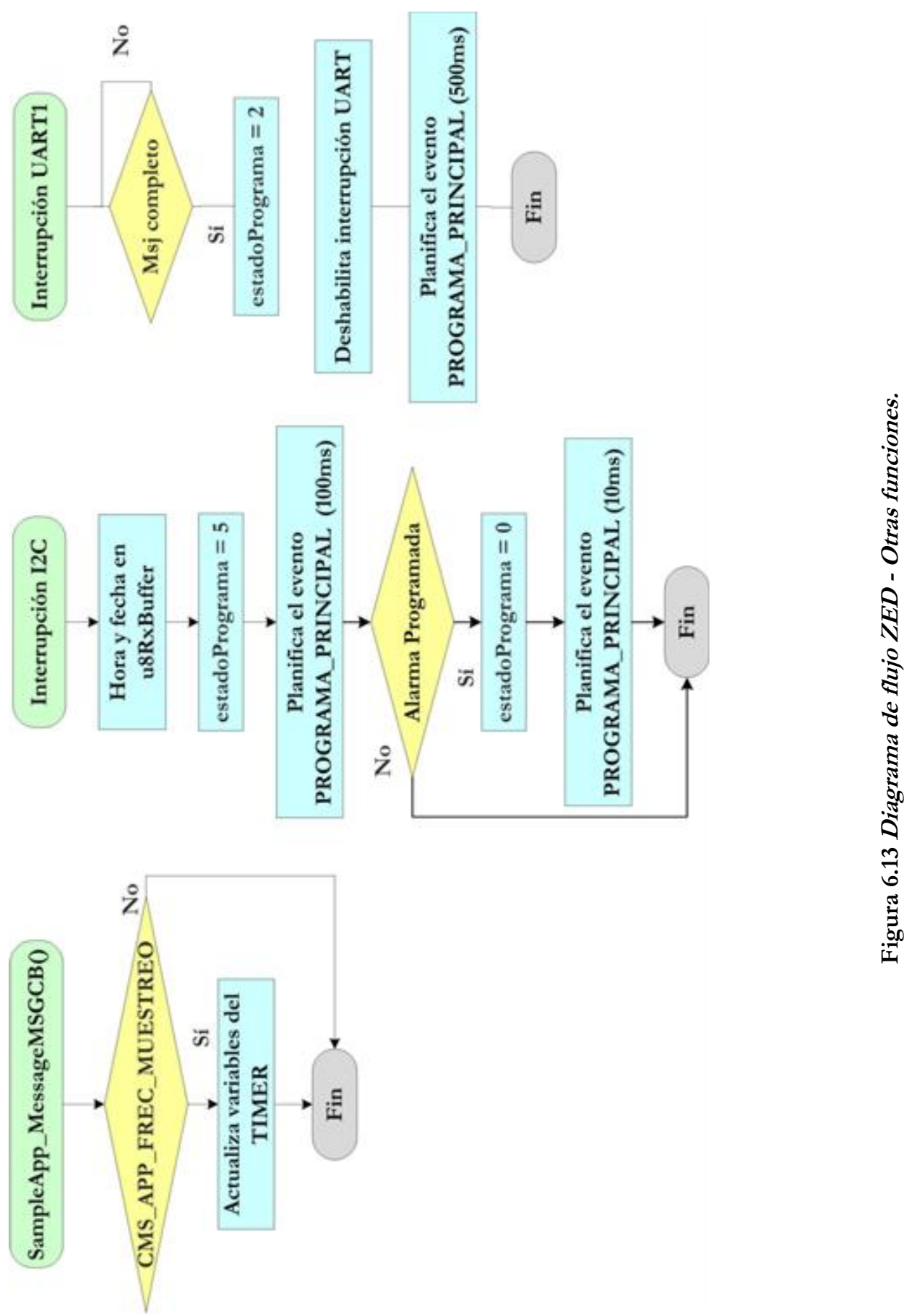


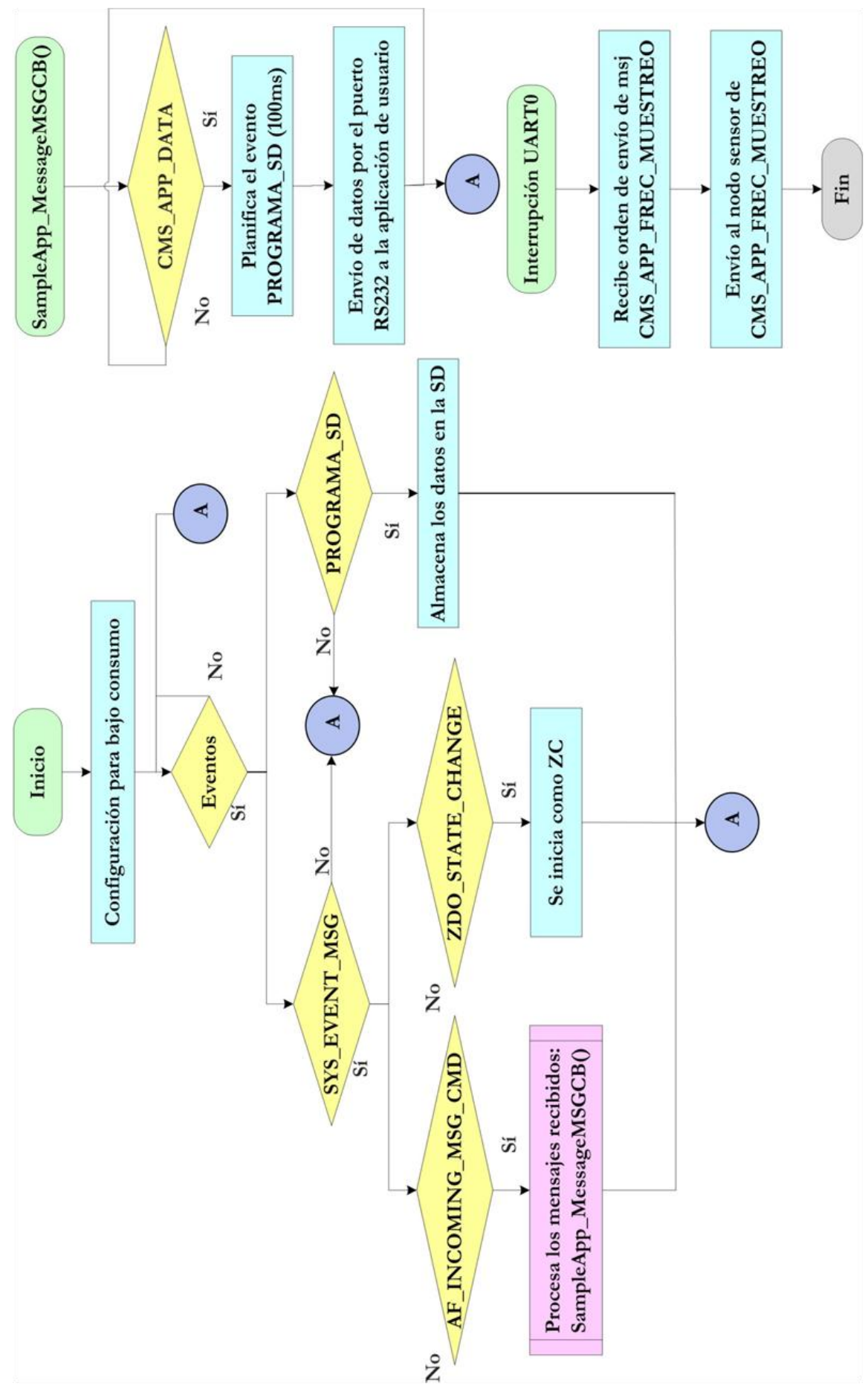

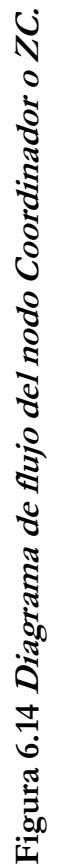




\subsubsection{Software de un nodo GPRS.}

Para el desarrollo software de la aplicación del nodo GPRS se ha utilizado el lenguaje de programación interpretado Phyton. En este apartado se describen sus principales características, y la ejecución del programa desarrollado en este lenguaje sobre el módulo Telit, presentado en el apartado 6.2.2.1. Finalmente, se muestra el diagrama de flujo de la aplicación del nodo GPRS.

\subsubsection{Lenguaje Phyton.}

Python es un lenguaje de programación interpretado o de script, lo que significa que no se necesita compilar el código fuente para poder ejecutarlo. Se ejecuta utilizando un programa intermedio llamado intérprete, en lugar de compilar el código a lenguaje máquina que pueda comprender y ejecutar directamente una computadora (lenguajes compilados).

La ventaja de los lenguajes compilados es que su ejecución es más rápida. Sin embargo, los lenguajes interpretados son más flexibles y portables. Python tiene, no obstante, muchas de las características de los lenguajes compilados, por lo que se podría decir que es semi interpretado. En Python, como en Java y muchos otros lenguajes, el código fuente se traduce, la primera vez que se ejecuta, a un pseudo código máquina intermedio llamado bytecode, generando archivos .pyc o pyo (bytecode optimizado), que son los que se ejecutarán en sucesivas ocasiones.

\subsection{Características de Python.}

A continuación se destacan las principales características del lenguaje de programación Python que ha sido utilizado para implementar la aplicación que dota de funcionalidad al nodo GPRS:

- Propósito general: Se pueden crear todo tipo de programas. No es un lenguaje creado específicamente para la web, aunque entre sus posibilidades sí se encuentra el desarrollo de páginas.

- Multiplataforma: Originalmente se desarrolló para Unix, aunque cualquier sistema es compatible con el lenguaje, siempre y cuando exista un intérprete programado para él.

- Interpretado: como se comentó anteriormente, interpretado significa que no se debe compilar el código antes de su ejecución. En realidad sí que se realiza una compilación, pero ésta se realiza de manera transparente para el programador. En ciertos casos, cuando se ejecuta por primera vez un código, se crean unos bytecodes que se guardan en el sistema, y que sirven para acelerar la compilación implícita que realiza el intérprete cada vez que se ejecuta el mismo código. 
- Interactivo: Python dispone de un intérprete por línea de comandos en el que se pueden introducir sentencias. Cada sentencia se ejecuta y produce un resultado visible, que puede ayudar a entender mejor el lenguaje y probar los resultados de la ejecución de porciones de código rápidamente.

- Orientado a objetos: La programación orientada a objetos está soportada en Python, y ofrece, en muchos casos, una manera sencilla de crear programas con componentes reutilizables.

- Funciones y librerías: Dispone de muchas funciones incorporadas en el propio lenguaje, para el tratamiento de strings, números, archivos, etc. Además, existen muchas librerías que se pueden importar en los programas para tratar temas específicos.

- Sintaxis clara: Python tiene una sintaxis muy visual, gracias a una notación identada (con márgenes) de obligado cumplimiento. En muchos lenguajes, para separar porciones de código, se utilizan elementos como las llaves o las palabras clave begin y end. Para separar las porciones de código en Python, se debe tabular colocando un margen al código que iría dentro de una función o un bucle. Esto ayuda a que todos los programadores adopten unas mismas notaciones y que los programas de cualquier persona tengan un aspecto muy similar.

\subsubsection{Python en el módulo Telit.}

Los scripts Python son archivos de texto que se almacenan en la NVM (Non-Volatile Memory) del módulo Telit. El módulo tiene un sistema de archivos que permite escribir y leer los archivos con diferentes nombres en un único nivel. Además, solo es posible arrancar un script Python a la vez.

El script Python se ejecuta en el módulo Telit con la prioridad más baja, asegurando de esta forma, que no se interfiera con las operaciones normales de GSM/GPRS. Esto permite, por ejemplo, que el puerto serie funcione independientemente del script Python.

Con la aplicación PythonWin (instalando previamente el paquete de Python adecuado, TelitPy1.5.2+_v4.1) se pueden crear scripts Python, y comprobar su funcionamiento como si el script se estuviese ejecutando en el módulo Telit. La Figura 6.15 muestra la interfaz gráfica de dicha aplicación.

Se distinguen 3 partes: en la zona superior, la barra de menú y de accesos rápidos a diferentes opciones; en la zona central, los script Python; y en la zona inferior, se encuentra la "zona interactiva", en la que se pueden introducir sentencias de código obteniendo un resultado inmediato. 


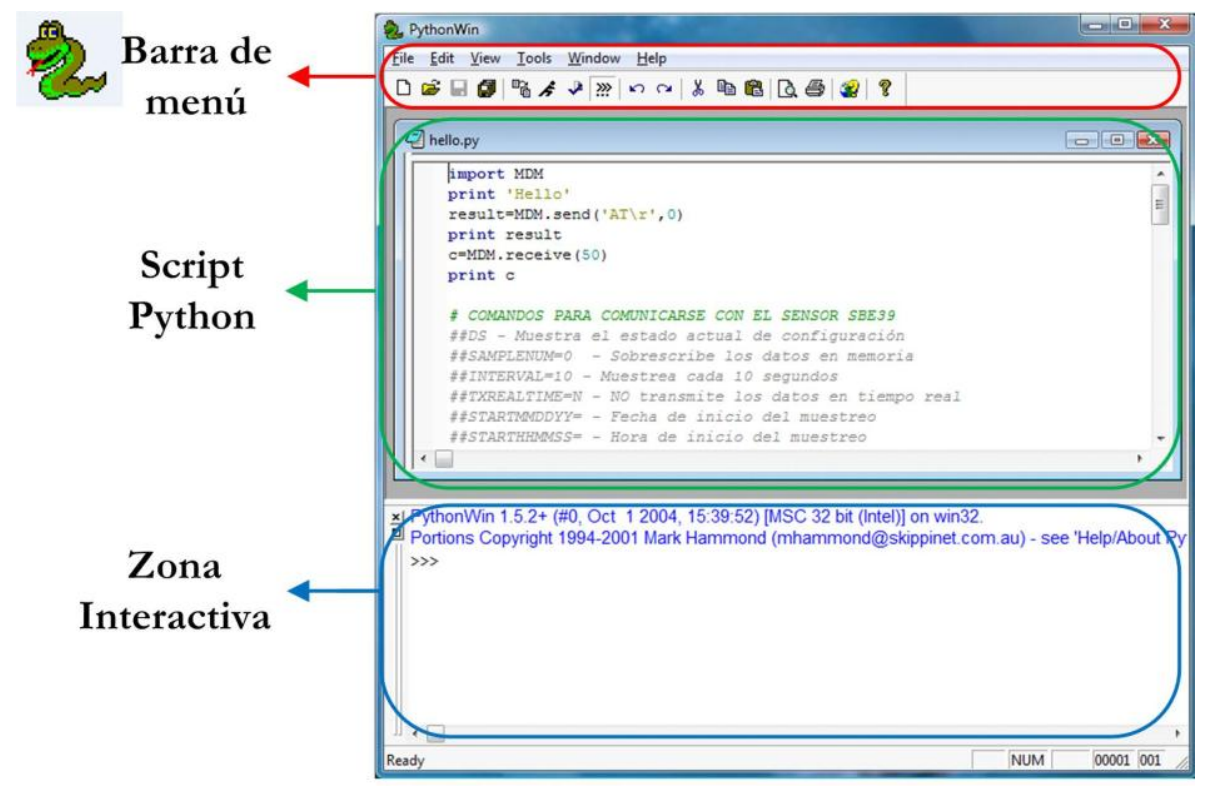

Figura 6.15 Aplicación PythonWin.

\subsubsection{Aplicación del nodo GPRS.}

El ciclo de trabajo de la aplicación desarrollada consiste en el muestreo del sensor a intervalos programables, el almacenamiento de datos en la memoria flash no volátil y su posterior envío a un servidor FTP a través de Internet y la red de acceso GPRS (ver Figura 6.16).

El dispositivo permanece en un estado de bajo consumo de energía ("Estado SLEEP” en la Figura 6.16), para preservar la carga de las baterías, hasta que se cumple un temporizador programado, según el intervalo de muestreo requerido, y hace efectiva una interrupción software que hace salir al sistema del estado de bajo consumo y pasar a un estado operativo pleno. En este momento, se procede a ordenar al sensor mediante comandos el abandono de su estado de reposo y el comienzo del muestreo de todas las magnitudes a medir. Una vez obtenidos los datos del sensor, se vuelve a pasar a éste a bajo consumo, y se comienza el registro en la red GSM a la que pertenece la tarjeta SIM insertada en el módulo. Si el registro es conseguido con éxito, se procede a la conexión GPRS. El siguiente paso es conectar a la red global Internet mediante protocolo TCP/IP y la obtención de una dirección IP propia. Para transmitir los datos recogidos se establece una conexión bidireccional con el servidor resolviendo su nombre de dominio mediante DNS, y empleando FTP como protocolo de transferencia. Si la transferencia finaliza con éxito, la conexión se cierra y el dispositivo vuelve a un modo de reposo hasta el siguiente ciclo. 


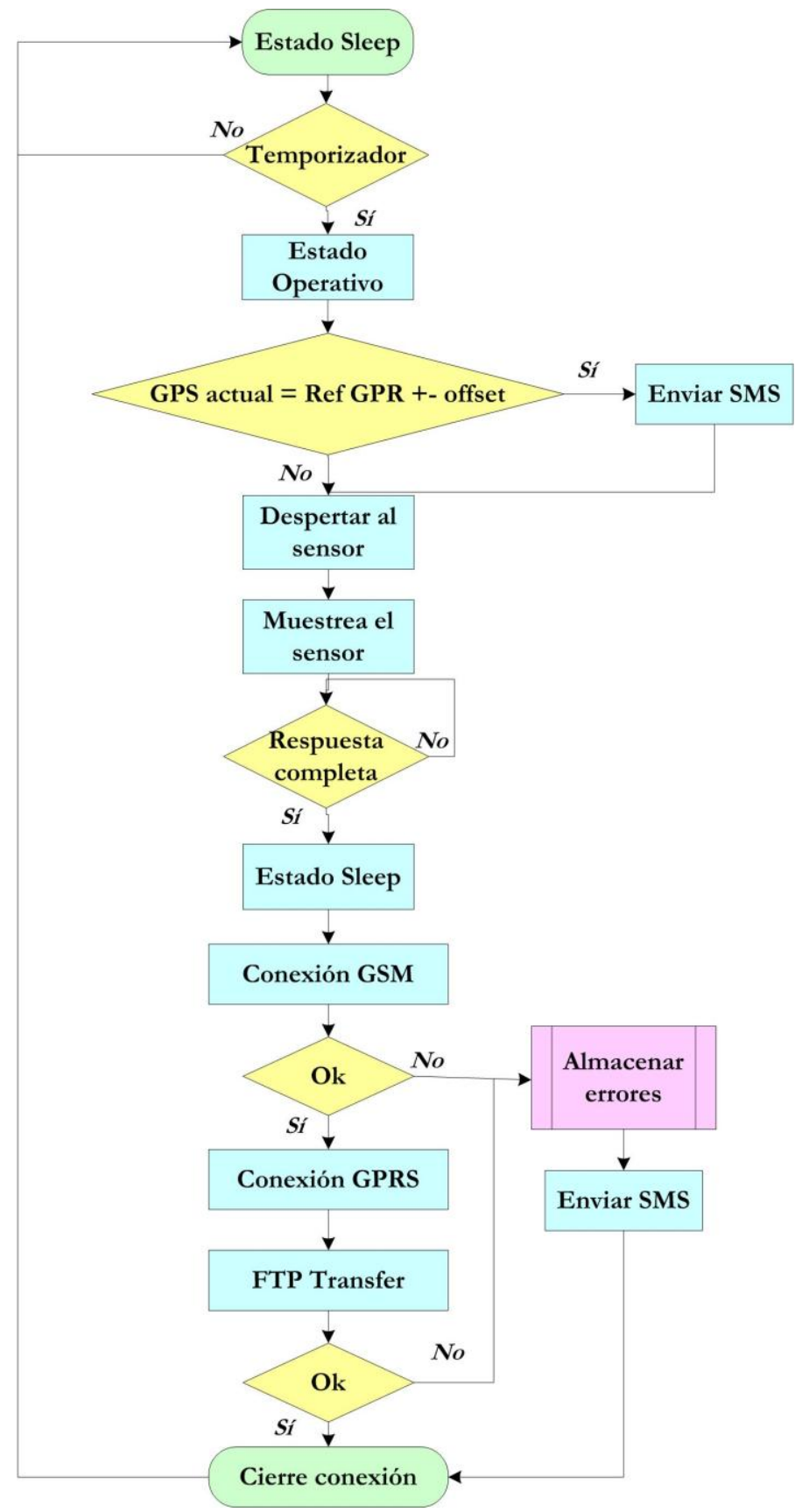

Figura 6.16 Diagrama de flujo del software del nodo GPRS.

En caso de errores en cualquier punto del proceso, estos son almacenados en un fichero de texto, enviados en la siguiente conexión satisfactoria o incluso si es posible y la gravedad lo requiere, se envían en forma de mensajes SMS al terminal configurado.

Además, el software monitoriza en cada ciclo la posición global del sistema haciendo uso del receptor GPS integrado. Esta se compara con una referencia de posición almacenada en el momento del despliegue de la boya, y si se detectan variaciones importantes se interpreta como un desplazamiento indeseado del sistema debido a rotura 
del cable de anclaje o sabotaje. En ese caso, se lanza una alarma mediante el envío de mensajes SMS con la posición actual.

\subsection{Estructura mecánica de la boya.}

Como se citó en la introducción, en la puesta en marcha de una WSN para aplicaciones oceanográficas se presentan nuevos retos y es por ello necesario la dedicación de un apartado al diseño de la estructura mecánica de la boya.

La estructura mecánica diseñada cumple con una serie de requisitos. La visibilidad de la boya al tráfico marítimo, una estructura formada por materiales no contaminantes, capaz de reducir los efectos de la condensación, la estabilidad de la boya ante condiciones atmosféricas adversas y la estanqueidad de la caja que contiene la electrónica son requisitos que debe cumplir la boya oceanográfica por el hecho de estar en el mar. Para hacer posibles despliegues lo más rápido y eficientemente posible, necesario por ejemplo en el caso de catástrofes, se diseñó una estructura ligera y de fácil montaje. Además, para poder obtener una gran resolución espacial con una pequeña inversión, la boya diseñada debía ser de bajo coste.

Teniendo en cuenta los elementos habituales utilizados en el diseño e implementación de un nodo sensor para una A-WSN citados en [Albaladejo et al., 2010a], en este apartado se realiza la descripción de la estructura mecánica de la boya oceanográfica mostrada en la Figura 6.17 cuyos planos se recogen en el Anexo 4.

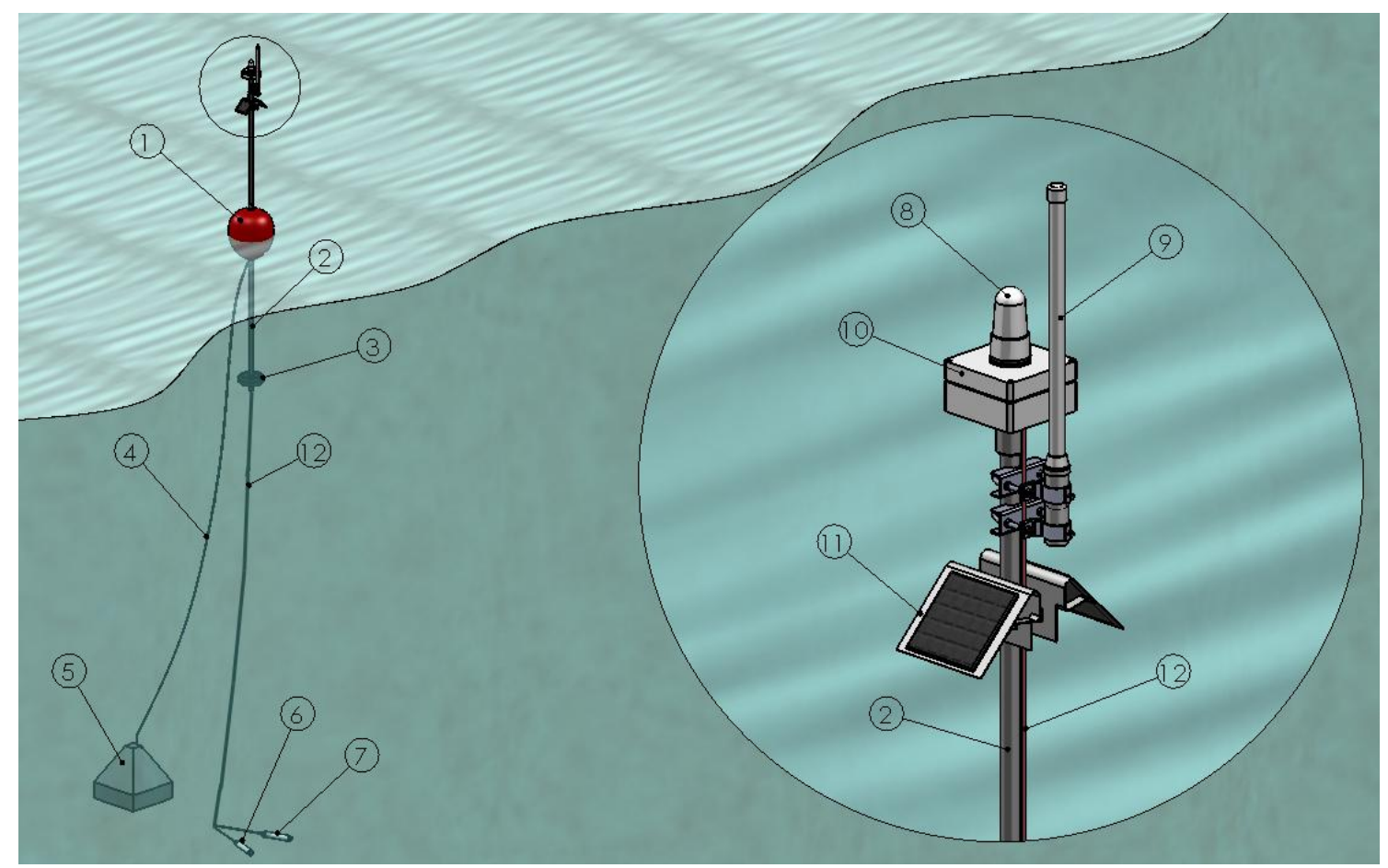

Figura 6.17 Estructura mecánica de la boya. 
Se trata de una estructura vertical formada por un tubo de acero inoxidable de $3 \mathrm{~m}$ de longitud y $25 \mathrm{~mm}$ de diámetro ((2) en Figura 6.17). Este tubo atraviesa un flotador (1) de $40 \mathrm{~cm}$ de diámetro dejando $1,5 \mathrm{~m}$ sobre dicho flotador y $1,5 \mathrm{~m}$ bajo éste.

En la parte superior de la boya se ubican los siguientes elementos: una caja estanca IP68 de dimensiones $12 \times 12 \times 7 \mathrm{~cm}(10)$, la antena de comunicaciones de $8 \mathrm{~dB}$ (9) y una baliza luminosa (8). La caja contiene la electrónica junto con la alimentación de la boya. Debajo de la caja estanca se sitúan dos paneles solares (11) con una inclinación de $45^{\circ}$ respecto al tubo vertical.

En la parte inferior de la estructura hay un peso (3) de $7 \mathrm{~kg}$ que dota de estabilidad a la boya manteniendo la estructura en posición vertical. Además, habrá un peso muerto en el fondo del mar y sujeto al centro de masas de la boya (5). Éste actuará de ancla para evitar grandes desplazamientos provocados por el movimiento del agua.

Finalmente, los sensores oceanográficos $(6,7)$ serán conectados mediante un cable a la electrónica en la parte superior. Normalmente la ubicación del sensor oceanográfico depende del tipo de medida que se quiera realizar. Si, por ejemplo, se desea estudiar el perfil de temperatura, los sensores se deberían ubicar a diferentes profundidades. En otros casos, el sensor se ubica en el fondo del mar.

El diseño mecánico de la boya ha sido validado mediante pruebas en el mar. La estructura ha estado sometida a días lluviosos y también muy calurosos, y no se han detectado problemas de estanqueidad ni de condensación en el interior de la caja con la electrónica. La estructura no presentó ningún desperfecto y el sistema de alimentación (la batería junto con los paneles solares) funcionó correctamente.

\subsection{Diseño de un protocolo para el intercambio de mensajes.}

En este apartado se presentan los diferentes tipos de tramas definidas (tramas de presentación y tramas de datos) y el formato diseñado que tienen los mensajes intercambiados, a nivel de aplicación, entre los nodos de una A-WSN y la aplicación de usuario. Los datos con el formato presentado a continuación, van encapsulados en el campo de datos de un tipo de mensajes definido en la pila Z-Stack de TI. El formato de los mensajes se ha definido de forma que, en cualquier aplicación de WSNs, pueda ser utilizado y perfectamente válido. Se caracteriza por ser un diseño escalable, sencillo y generalizado. 


\subsubsection{Trama de presentación.}

Para entender el concepto de trama de presentación, son necesarias algunas aclaraciones previas. En el proceso de asociación entre un ZED y un ZC se produce un intercambio de mensajes a tener en cuenta. El ZC cuando se inicia, crea la red y se mantiene a la espera de peticiones de asociaciones de nodos hijos (ZED o ZR). Éstos, cuando se inician, analizan el canal y seleccionan el ZC al que deben conectarse (del que mejor calidad de señal reciban, si hubiese varios). El ZC, acepta la solicitud de asociación, asigna una dirección de red al nodo asociado, y la almacena en una tabla de asociaciones. Esta dirección de red no cambiará si el nodo se desconecta y vuelve a conectarse. Además, cada nodo tendrá una dirección MAC univoca que lo identifica. Por tanto, para la identificación de un nodo en la red se usa el par [@ red, @ MAC]. El hecho de no usar la dirección MAC para identificar a cada nodo, puesto que ésta es única, es porque a bajo nivel se trabaja con la dirección de red asignada por el ZC.

Una vez analizado el procedimiento que tiene lugar al inicio de la red ZigBee, se define la trama de presentación. Ésta será enviada por un ZED al ZC cuando se inicia como tal en la red. Como ya se ha comentado, cada ZED tiene asignada una dirección MAC única, y una dirección de red asignada por el ZC de la red. Este par [@ red, @ MAC] será el que identifique a un nodo inequívocamente. El formato de la trama de presentación sigue la estructura indicada en la Tabla 6.4.

Tabla 6.4 Trama de presentación.

\begin{tabular}{cccccc}
\hline Inicio & ID & Dirección MAC & $\begin{array}{c}\text { Dirección de } \\
\text { red }\end{array}$ & Tipos de datos & Fin \\
C0 & $\mathrm{C} 1-\mathrm{C} 2$ & $\mathrm{C} 3-\mathrm{C} 18$ & $\mathrm{C} 19-\mathrm{C} 22$ & $\mathrm{C} 23-\mathrm{C}((22+2) * \mathrm{n})$ & $\mathrm{C}(((22+2) * \mathrm{n})+1)$ \\
\hline$:$ & 00 & $\mathrm{xx} \ldots \mathrm{x}(16$ Caracteres $)$ & $\mathrm{xxxx}$ & $\mathrm{xx} \ldots \mathrm{xx}$ (n elementos de 2 dígitos) & $\mathrm{CR}(13 \mathrm{~d})$ \\
\hline
\end{tabular}

El carácter ':' será el indicador de inicio de trama tanto en la trama de presentación como en la trama de datos. A continuación, 2 caracteres para identificar el tipo de trama, 16 para la dirección MAC, 4 para la dirección de red, los tipos de datos que, tras su presentación, enviará en el campo de datos de las tramas (cada tipo de datos identificado por 2 caracteres, según se explica a continuación), y finalmente, un retorno de carro (Carriage Return, en adelante CR) indicando fin de trama.

En definitiva, la información que el ZED le quiere transmitir al ZC en la trama de presentación es, ‘Quién soy' y los datos que el ZED enviará a partir de ese momento.

En cuanto al campo tipo de datos, con dos caracteres se podrán identificar 97 tipos de datos diferentes (02-99) puesto que, el valor '00' se reserva para identificar una trama de 
presentación y '01' para identificar una trama de datos. En la Tabla 6.5 se muestran algunos ejemplos de diferentes tipos de datos.

Tabla 6.5 Tipos de datos.

\begin{tabular}{cccc}
\hline Tipo & Descripción & Codificación & Unidades \\
\hline 00 & $\begin{array}{c}\text { Identifica la trama de } \\
\text { presentación }\end{array}$ & Ver descripción trama & -- \\
\hline 01 & $\begin{array}{c}\text { Identifica una trama con } \\
\text { datos }\end{array}$ & Ver descripción trama & -- \\
\hline 02 & Fecha y hora & ssmmhhdddmmaa & Hora/fecha \\
& & segundos y minutos (00-59); & \\
hh horas (00-23); \\
d día semana (1-7); \\
dd día mes (01-31); \\
mm mes (01-12); \\
\hline 03
\end{tabular}

Con la descripción realizada hasta el momento, se muestra un ejemplo de trama de presentación en la Tabla 6.6. Analizando dicho ejemplo, se inicia la trama con el carácter de inicialización ' $:$ ', tras él se indica el tipo de trama ('00’ para el caso de trama de presentación), la dirección MAC del ZED, la dirección de red que el ZC le ha otorgado al ZED en la fase de asociación, y los identificadores asociados en la Tabla 6.5 a los diferentes tipos de datos que posteriormente enviará. Los datos en este ejemplo son: la temperatura (Tipo 04) y presión (Tipo 05) del mar, la capacidad de ocupación de la microSD (Tipo 06), la calidad del enlace (Tipo 07), el nivel de batería (Tipo 03) y la fecha y hora en que se produce el muestreo (Tipo 02).

Tabla 6.6 Ejemplo trama de presentación.

\begin{tabular}{ccccccc}
\hline Inicio ID & Dirección MAC & $\begin{array}{c}\text { Dirección } \\
\text { de red }\end{array}$ & $\begin{array}{c}\text { Tipos de datos: } \\
\text { Temp, pres, SD, LQI, } \\
\text { batería, fecha y hora }\end{array}$ & Fin \\
\hline$:$ & 00 & 0000000000000001 & 3265 & 040506070302 & CR \\
\hline
\end{tabular}

\subsubsection{Trama de datos.}

La Tabla 6.7 muestra los campos de las tramas de datos. El inicio de trama, al igual que en el caso de la trama de presentación, viene determinado por el carácter '?’, seguido por el identificador de trama (los caracteres reservados '01'), la dirección de red que el ZC le 
asignó al ZED, los datos que el ZED anunció en su trama de presentación, con el mismo orden y formato definidos, y finalmente, el carácter CR.

Tabla 6.7 Trama de datos.

\begin{tabular}{ccccc}
\hline Inicio & ID & Dirección de red & Datos (Variable) & Fin \\
\hline C0 & C1-C2 & C3-C6 & $C 7-C(n)$ & $C(n+1)$ \\
\hline$:$ & 01 & xxxx & xx...xx (n elementos de 2 dígitos) & CR (13d) \\
\hline
\end{tabular}

Siguiendo con el ejemplo anterior, en la Tabla 6.8 se muestran los datos correspondientes a la presentación previa. Se inicia con el carácter ' $:$, el identificador de la trama de datos '01', la dirección de red, y los datos en el mismo orden en el que se presentaron y con el formato definido en la Tabla 6.5.

Tabla 6.8 Ejemplo trama de datos.

\begin{tabular}{ccccc}
\hline Inicio & ID & $\begin{array}{c}\text { Dirección } \\
\text { de red }\end{array}$ & $\begin{array}{c}\text { Temp, pres, SD, LQI, batería, fecha y } \\
\text { hora }\end{array}$ & Fin \\
\hline$: \quad 01$ & 3265 & $+25.5+8.50050803 .960015232250711$ & CR \\
\hline
\end{tabular}

El ZC llevará el control de los nodos que se conectan a él, mantendrá almacenada una tabla actualizada con los pares [@MAC, @Red] que identificarán a cada nodo, e informará de dicha actividad a la aplicación de usuario.

\subsection{Aplicación gráfica de usuario del sistema de monitorización.}

En el capítulo 5 se presentaron dos opciones para llevar a cabo la implementación de un sistema de monitorización que almacene y procese la información de una A-WSN. La opción basada en servidores remotos ha sido la desarrollada en esta Tesis Doctoral. Recordando la Figura 5.8 de dicho capítulo, existe una aplicación de usuario que se ejecuta en el servidor de datos encargada de almacenar la información que recibe, y de interactuar con el usuario para mostrarle la información requerida por éste. Además, el acceso a esta aplicación puede realizarse a través de Internet.

A continuación se detalla la aplicación de usuario desarrollada, describiendo previamente el entorno de trabajo utilizado para dicha implementación, LabVIEW.

\subsubsection{LabVIEW.}

La aplicación gráfica de usuario ha sido desarrollada en LabVIEW 2010. LabVIEW (Laboratory Virtual Instrumentation Engineering Workbench) es un entorno de desarrollo gráfico 
desarrollado por National Instruments. Los programas escritos en LabVIEW se denominan Instrumentos Virtuales (Virtual Instruments, en adelante VIs). Estas aplicaciones son independientes de la máquina en la que son desarrollados pudiendo ser transferidos entre diferentes sistemas operativos.

LabVIEW proporciona un potente entorno de desarrollo gráfico para el diseño de aplicaciones de adquisición de datos, análisis de medidas y presentación de datos, ofreciendo una gran flexibilidad gracias a un lenguaje de programación sin la complejidad de las herramientas de desarrollo tradicionales. En la Figura 6.18 se muestra la vista principal del entorno de LabVIEW en la que se pueden distinguir 3 partes: una parte dedicada a los ficheros que contiene la aplicación (librerías, SubVIs u otros archivos), el panel frontal formado por controladores (entradas) e indicadores (salidas) del programa, y por último, los diagramas de bloques, un conjunto de componentes cableados entre sí.

El principio que gobierna la ejecución de los VIs en LabVIEW se puede resumir en los siguientes puntos:

1) Un nodo se ejecuta solo cuando estén disponibles todos los datos en sus entradas.

2) El nodo transfiere los datos a sus salidas sólo cuando se termina la ejecución del nodo.

3) Los datos pasan inmediatamente del terminal fuente al terminal (o terminales) destino.

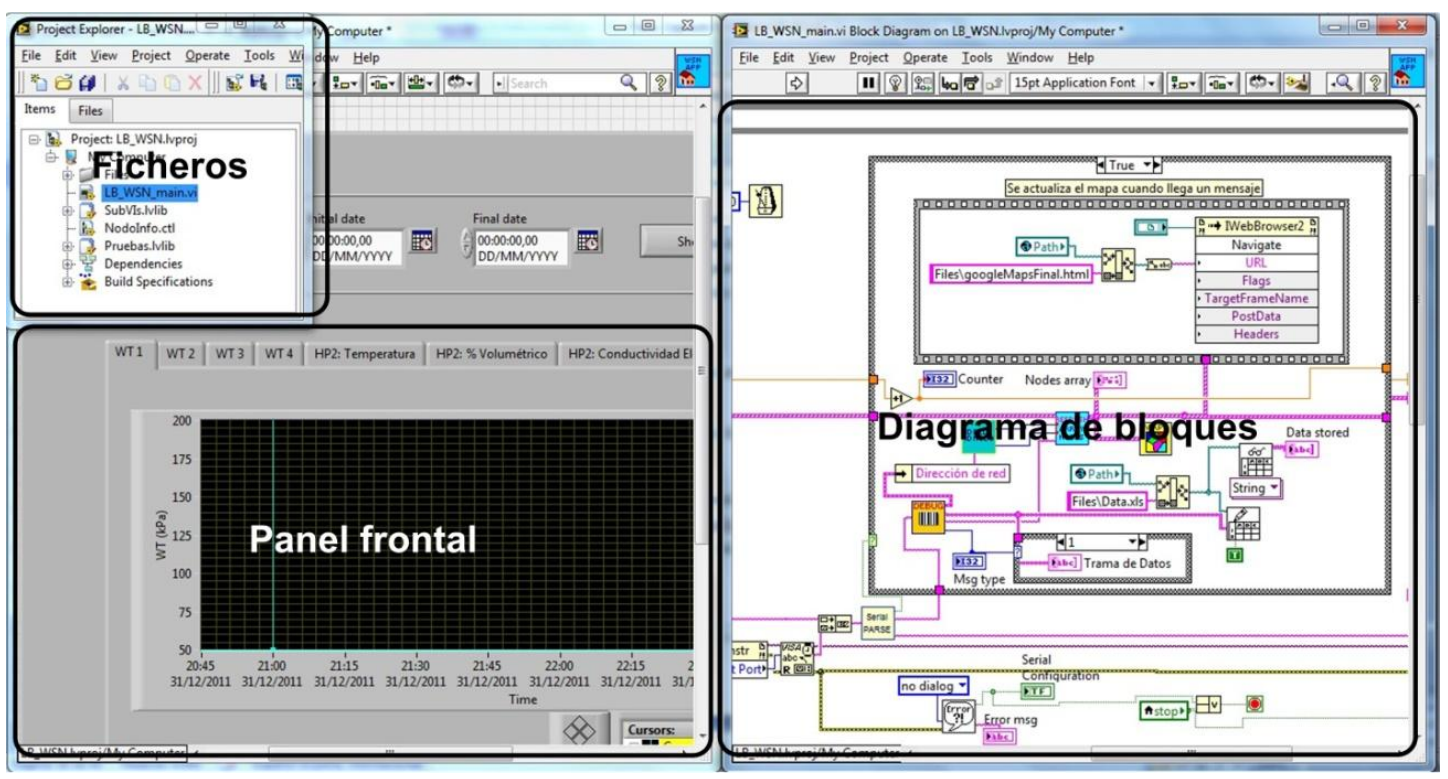

Figura 6.18 Entorno LabVIEW.

Para conocer más sobre este entorno se recomienda leer la referencia [LabVIEW, 2010]. 


\subsubsection{Aplicación desarrollada.}

El panel frontal de la aplicación desarrollada se muestra en la Figura 6.19. Se incluyen cuatro pestañas: 'Deployment View', 'Graph', 'Debug'y 'FTP'.

La primera opción Deployment View' permite visualizar la posición geográfica de cada nodo del despliegue haciendo uso del API de GoogleMaps. Los marcadores representan los nodos de las distintas redes identificados con su ID y su color correspondiente dependiendo de la red a la que pertenezcan. Cada identificador del nodo está formado por dos dígitos, el primero indica la red a la que pertenece, y el segundo el número de nodo dentro de dicha red. En el ejemplo de la Figura 6.19, el nodo seleccionado tiene el identificador ' 12 '. Se trata del nodo número 2 de la red 1 . Teniendo en cuenta dicha nomenclatura, el sistema podrá tener como máximo 9 redes (identificadas de 1 a 9) y cada una de ellas compuesta por 9 nodos sensores (identificados de 1 a 9) más el nodo coordinador (cuyo identificador reservado es el ' 0 '). Esta restricción no supone ninguna limitación para el despliegue realizado que se describe en el capítulo 7.

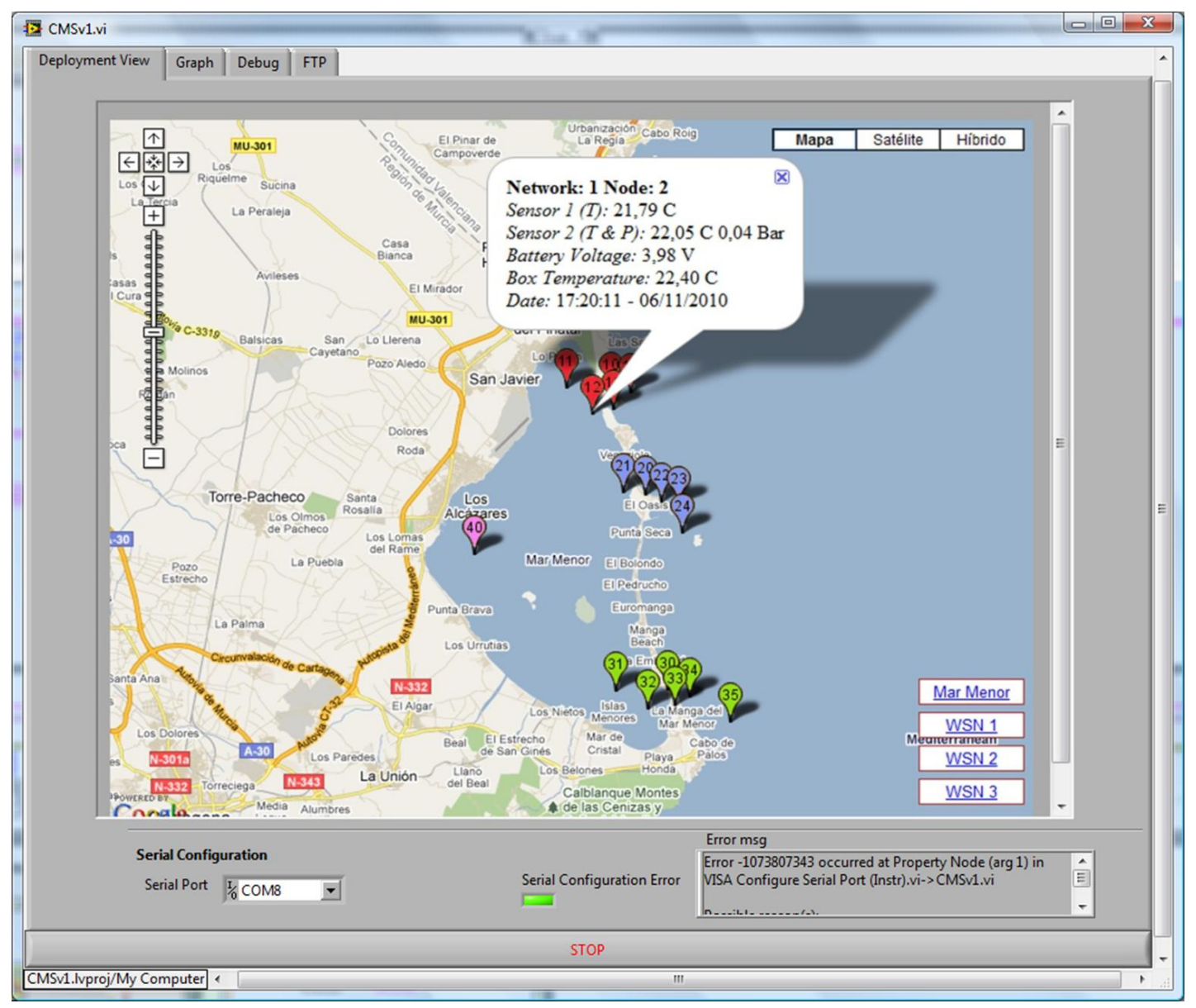

Figura 6.19 Aplicación gráfica de usuario - "Deployment View". 
Otra de las características de la vista de despliegue, es que haciendo clic en los marcadores de los nodos, estos muestran la información del último mensaje recibido por el nodo seleccionado. En el caso mostrado en la Figura 6.19, se muestra la identificación del nodo, los valores de los parámetros muestreados por los sensores, el valor del nivel de la batería junto con el instante temporal en el que se produjo el muestreo.

En la pestaña 'Graph' (ver Figura 6.20) se realiza la representación gráfica de los datos del nodo seleccionado. En este caso, el usuario deberá seleccionar el identificador del nodo y la red a la que pertenece dicho nodo, el intervalo temporal del que desea visualizar la evolución de los datos. Finalmente, haciendo clic en el botón Show se muestran los resultados. En el ejemplo de la Figura 6.20 se muestran los diferentes parámetros que miden las boyas oceanográficas diseñadas: temperatura y presión del mar, presión atmosférica, temperatura en el interior de la caja que contiene la electrónica, y el nivel de la batería del nodo.

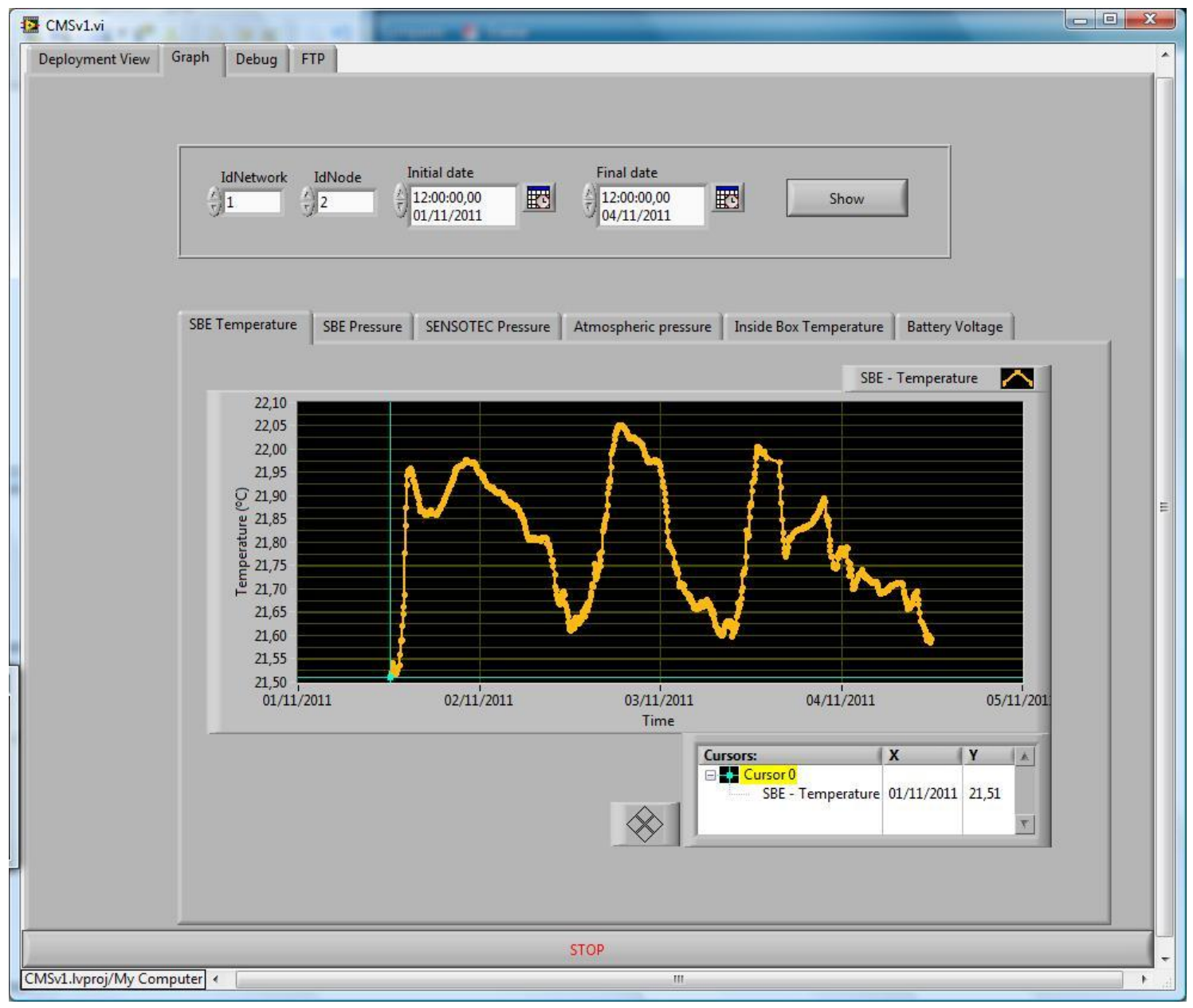

Figura 6.20 Aplicación gráfica de usuario - “Graph”.

La pestaña Debug' ha sido utilizada para depuración de la aplicación y de los mensajes recibidos de la red como se muestra en la Figura 6.21. Se detallan las coordenadas 
geográficas de los nodos del despliegue que han sido representados en la primera pestaña mediante GoogleMaps, el número de mensajes recibidos de la red de sensores, el último mensaje recibido, y además, incluye la opción de visualizar los últimos datos almacenados (especificados en 'Num Datos' de la Figura 6.21). En la parte inferior, se muestra la trama en bruto recibida por el puerto serie ('Mote frame') antes de ser procesada por la aplicación LabVIEW.

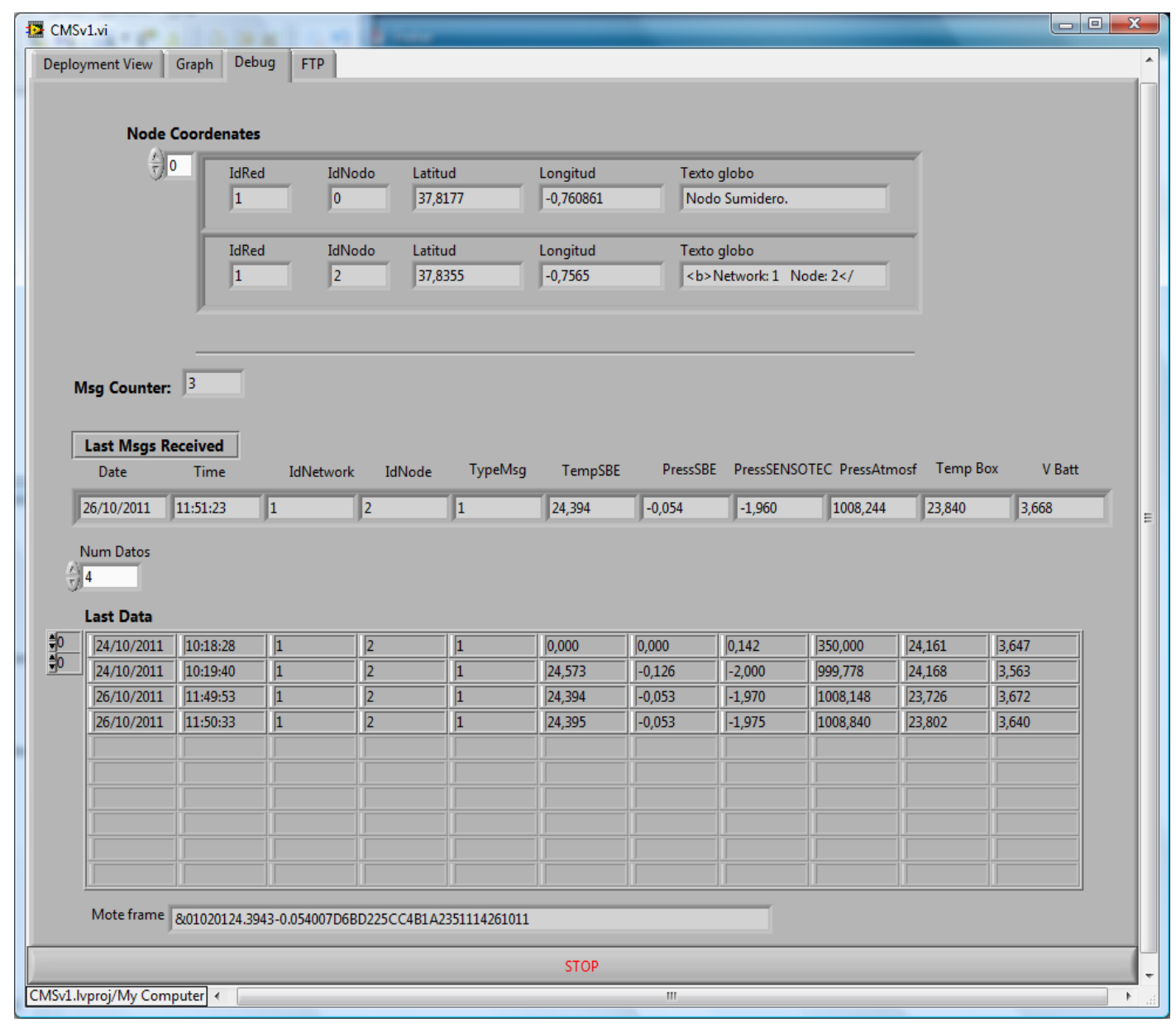

Figura 6.21 Aplicación gráfica de usuario - "Debug”.

Finalmente, la pestaña FTP' muestra el estado de la transferencia FTP realizada al servidor de datos (ver Figura 6.22). Cuando se recibe un mensaje de la A-WSN, además de almacenarse en el PC en el que se ejecuta la presente aplicación, se envía a un servidor FTP. La utilidad de esta opción será detallada en el capítulo 7. 


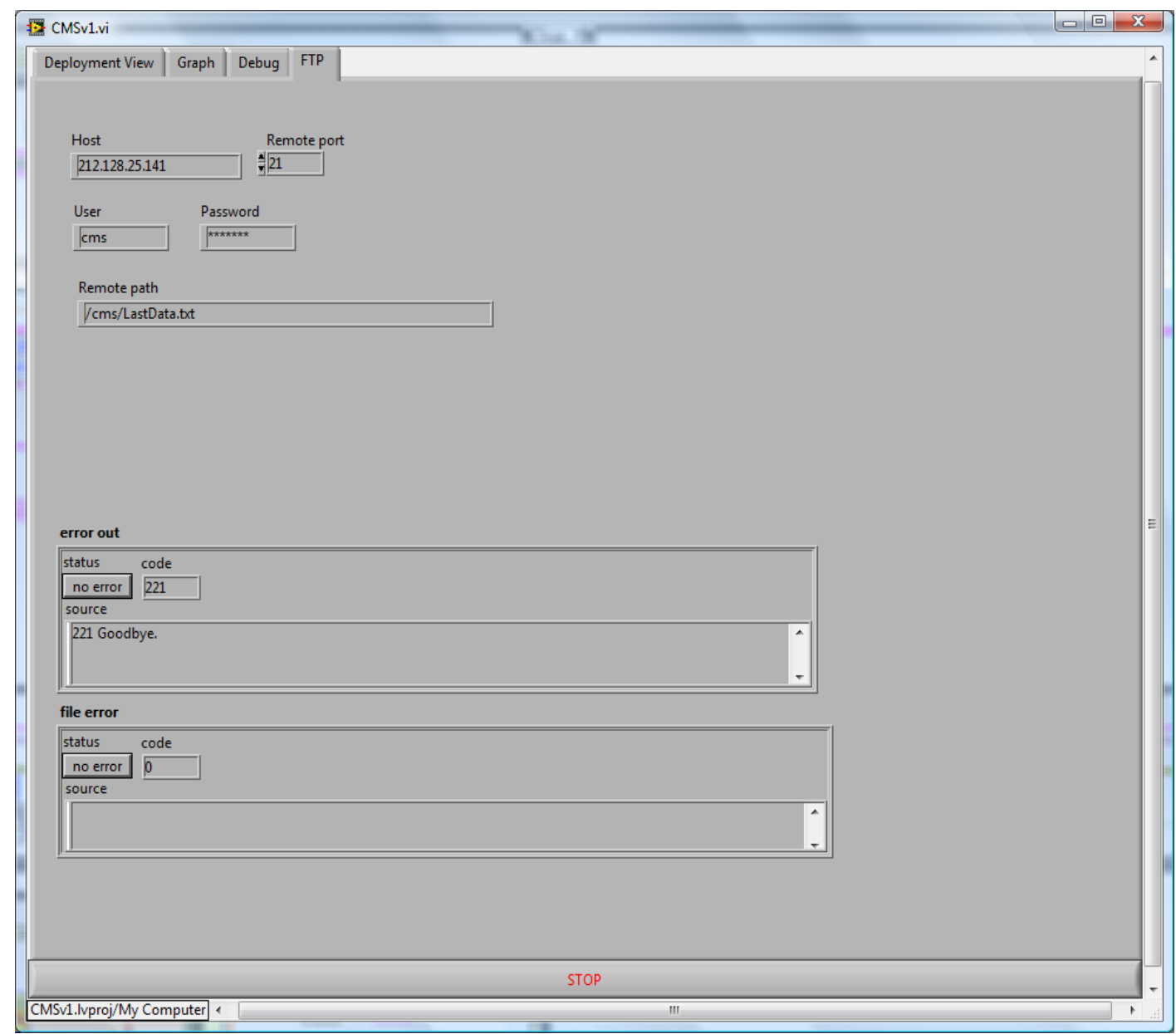

Figura 6.22 Aplicación gráfica de usuario - “FTP”.

El código o diagramas de bloques de los SubVIs que dan lugar a la aplicación gráfica descrita en este apartado, se pueden consultar en el Anexo 3.

\subsection{Pruebas de validación.}

Con objeto de evaluar el correcto funcionamiento de la solución propuesta, se ha planteado una metodología basada en dos fases experimentales de validación: pruebas en el laboratorio y pruebas de campo. El principal objetivo de las pruebas en el laboratorio es realizar una validación funcional de la arquitectura propuesta y los dispositivos desarrollados. En estas pruebas, se desplegó en el laboratorio una red similar a la que será desplegada eventualmente en el mar. Además, se ha realizado la validación funcional de la electrónica diseñada, verificando la correcta funcionalidad y autonomía del dispositivo mediante aplicaciones implementadas ad-hoc a las diferentes partes de éste. El objetivo de la segunda fase será comprobar el correcto funcionamiento de la red propuesta en condiciones reales, en el mar. 
La aplicación de las boyas diseñadas en esta Tesis ha sido para la medición de la presión del mar, como más adelante se detallará en los despliegues realizados en esta Tesis Doctoral. Para ello, se disponían de tres sensores: dos sensores de presión oceanográficos, el sensor SBE 39 del fabricante SeaBird Electronics y el sensor LMK 807 de SENSOTEC, y un sensor de presión atmosférica, el sensor YOUNG 61302L.

Para realizar una correcta medición de la profundidad del mar, es necesario realizar la compensación de la medida con la presión atmosférica. Hay sensores que incluyen un capilar para dicha compensación, como es el caso del sensor LMK 807 de SENSOTEC, y otros no, como el sensor SBE 39 de SeaBird. En este último caso, será necesario realizar la compensación de la medida con un sensor de presión atmosférica. Por tanto, existen dos tipos de boyas que incluyen sensores diferentes. La boya tipo ID1 incluye un sensor de presión oceanográfica sin compensación (SBE 39) y un sensor de presión atmosférica (YOUNG 61302L), y la boya tipo ID2 incorpora un sensor de presión oceanográfica con capilar de compensación (LMK 807 de SENSOTEC).

\subsubsection{Pruebas en el laboratorio.}

\subsubsection{Pruebas de la arquitectura de la WSN.}

En la red desplegada en el laboratorio se implementó una topología en estrella, tal y como se muestra en la Figura 6.23. La red estaba compuesta por tres nodos: dos nodos Sensores (tipo ID1 y tipo ID2) pertenecientes a la misma red, y un nodo Coordinador. En esta topología cada nodo Sensor envía la información directamente al nodo Coordinador.

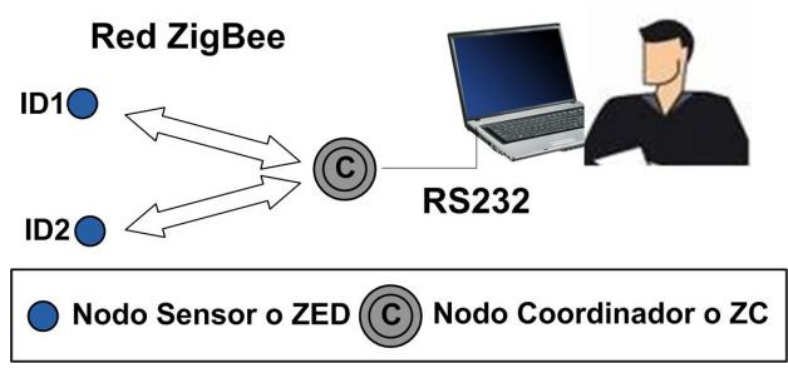

Figura 6.23 Arquitectura del sistema para las pruebas en el laboratorio.

La electrónica de ambos motes está formada por una placa MEWiN-MainBoard y una placa de interfaz MEWiN-SeaBoard conectada a la primera mediante los conectores de expansión. Como se ha descrito en el apartado 6.2.1.2, MEWiN-SeaBoard dispone de interfaces RS232 y 4-20 mA que permiten la conexión de diferentes sensores. En la Tabla 6.9 se especifican los sensores y características hardware de las pruebas realizadas en el laboratorio. 
El nodo tipo ID1 incluye dos sensores: un sensor oceanográfico de temperatura y presión marina, modelo SBE39, con interfaz de conexión RS232, y un sensor de presión atmosférica, modelo 61302L de YOUNG, con interfaz de conexión 4-20 mA. El nodo tipo ID2 incorpora un sensor de presión marina LMK 807 de SENSOTEC, con interfaz de conexión 4-20 mA, que incluye además un capilar para la compensación de presión.

Tabla 6.9 Resumen de los dispositivos usados en las pruebas en el laboratorio.

\begin{tabular}{|c|c|c|c|c|}
\hline Nodo & Sensores & Medidas & $\begin{array}{l}\text { Interfaz de } \\
\text { conexión }\end{array}$ & Hardware \\
\hline \multirow[t]{2}{*}{ Sensor ID 1} & Modelo SBE39 de SBE & $\begin{array}{c}\text { Temperatura y presión } \\
\text { del mar }\end{array}$ & RS232 & \multirow{2}{*}{$\begin{array}{l}\text { MEWiN-MainBoard } \\
\text { y MEWiN-SeaBoard }\end{array}$} \\
\hline & Modelo 61302L de YOUNG & Presión atmosférica & $4-20 \mathrm{~mA}$ & \\
\hline Sensor ID 2 & $\begin{array}{l}\text { Modelo LMK } 807 \text { de } \\
\text { SENSOTEC }\end{array}$ & $\begin{array}{l}\text { Presión marina (incluye } \\
\text { un capilar para la } \\
\text { compensación de } \\
\text { presión) }\end{array}$ & $4-20 \mathrm{~mA}$ & $\begin{array}{l}\text { MEWiN-MainBoard } \\
\text { y MEWiN-SeaBoard }\end{array}$ \\
\hline Coordinador & No incluye & No incluye & $\begin{array}{l}\text { RS232 con } \\
\text { el PC }\end{array}$ & MEWiN-MainBoard \\
\hline
\end{tabular}

En la Tabla 6.10 se recogen las características técnicas más importantes de los sensores empleados.

Tabla 6.10 Características de los sensores.

\begin{tabular}{|c|c|c|c|}
\hline \multirow{2}{*}{$\begin{array}{l}\text { CARACTERÍSTICAS } \\
\text { DE LOS SENSORES }\end{array}$} & \multicolumn{3}{|c|}{ SENSORES } \\
\hline & SBE39 & SENSOTEC LMK 807 & YOUNG 61302L \\
\hline Medida & Temperatura y presión del mar & Presión del mar & Presión atmosférica \\
\hline $\begin{array}{l}\text { Interfaz de } \\
\text { comunicación }\end{array}$ & RS232 & $4-20 \mathrm{~mA}$ & $4-20 \mathrm{~mA}$ \\
\hline Rango & $\begin{array}{c}\mathrm{T}:-5 \mathrm{a}+35^{\circ} \mathrm{C} \\
\mathrm{P}: 20 \mathrm{~m}\end{array}$ & $0-10 m$ & $500-1100 \mathrm{hPa}$ \\
\hline Alimentación & $9-30$ VDC & 12 VDC & 12 VDC \\
\hline Consumo & $\begin{array}{l}\text { Reposo: } 10 \mu \mathrm{A} \\
\text { Por muestra: } \\
\text { Ty hora } 0,018 \mathrm{~A} / \text { muestra } \\
\mathrm{T}, \mathrm{P} \text {, y hora } 0,023 \mathrm{~A} / \text { muestra } \\
\text { Muestreo continuo: } 15 \mathrm{~mA}\end{array}$ & $4-20 \mathrm{~mA}$ & $4-20 \mathrm{~mA}$ \\
\hline Fabricante & Sea-Bird Electronics & SENSOTEC & YOUNG \\
\hline URL & http://www.seabird.com/ & $\begin{array}{l}\text { http://www.sensotec- } \\
\text { instruments.com/ }\end{array}$ & http://www.youngusa.com \\
\hline
\end{tabular}

Las pruebas resultaron exitosas comprobando el correcto funcionamiento del hardware diseñado, tanto la placa principal como la placa de interfaz, para los dos tipos de nodos Sensores, y el Coordinador de la red. 


\subsubsection{Pruebas de consumo.}

Uno de los aspectos más importantes en redes de sensores es el consumo de los dispositivos. Éste debe ser mínimo para lograr aumentar la autonomía de los nodos y con ello la vida de la red. Por tanto, una vez comprobada la operatividad de cada una de las partes del mote, se verificó un consumo adecuado mediante pruebas en laboratorio.

Después de la validación funcional, para la que no se consideraron restricciones en el consumo, se desarrollaron nuevas aplicaciones software. Éstas fueron diseñadas con el objetivo de minimizar el consumo de los nodos para su validación de cara a la implementación final, haciendo pasar al nodo por todos sus estados de funcionamiento en una reducida ventana de tiempo.

Se han realizado dos estudios de consumo, uno para el nodo tipo ID1 y otro para el nodo tipo ID2. La Tabla 6.11 recoge los diferentes estados por los que pasan cada uno de los nodos. En ambos casos el procedimiento es similar, diferenciándose únicamente en que en el segundo estudio se omite el estado 5 puesto que no se utiliza ningún sensor con interfaz RS232.

Tabla 6.11 Estados del nodo Sensor.

\begin{tabular}{c|l}
\hline Estado & \multicolumn{1}{|c}{ Descripción } \\
\hline 1 & Búsqueda de nodo padre \\
\hline 2 & Standby \\
\hline 3 & Envío de mensajes periódicos 'Data request poll' \\
\hline 4 & Convertidor CC/CC habilitado \\
\hline 5 & Interfaz RS232 habilitado y muestreo de datos del sensor \\
\hline 6 & Interfaz 4-20 mA habilitado, muestreo de datos del sensor y lectura del RTC \\
\hline 7 & Almacenamiento de la información en la tarjeta SD \\
\hline 8 & Envío al Coordinador de la red \\
\hline
\end{tabular}

Las medidas de corriente presentadas en este estudio fueron realizadas con el watímetro digital WT210 de YOKOGAWA y el software WTVIEWER. Una vez obtenidos los datos de corriente del dispositivo durante su funcionamiento, éstos fueron procesados. Los resultados se presentan en la Figura 6.24 y Figura 6.25, las cuales muestran la demanda de corriente de los dispositivos en los diferentes estados contemplados en las tablas anteriores. 


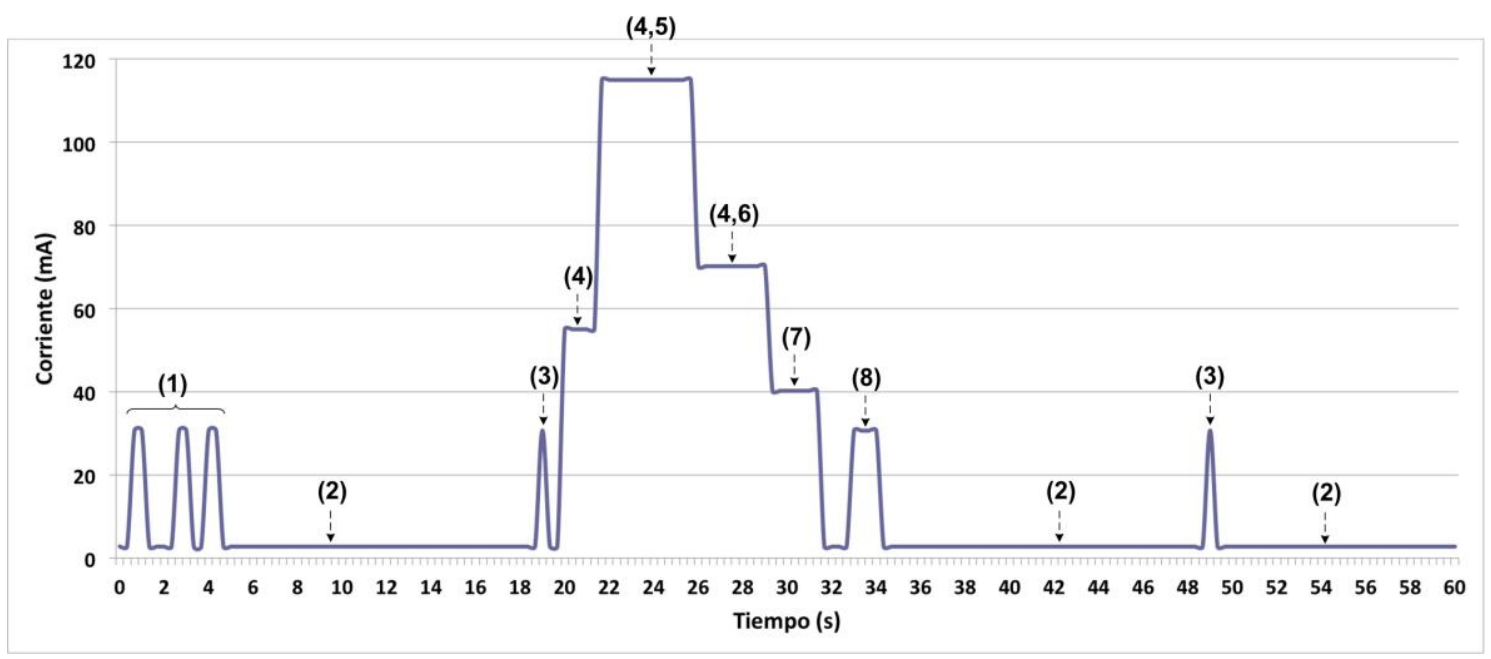

Figura 6.24 Consumo del nodo Sensor tipo ID1.

El cálculo de consumo realizado para el primero de los nodos Sensores (ID1) a partir de la Figura 6.24, se sintetiza en las siguientes expresiones:

$\bar{I}_{\text {Total Boya } 1}=\bar{I}_{\text {standby }}+\bar{I}_{\text {conexión }}+\bar{I}_{\text {DATA_REQUEST }}+\bar{I}_{D C D C}+\bar{I}_{S B E}+\bar{I}_{A D C}+\bar{I}_{S D}+\bar{I}_{\text {Envío }}+\bar{I}_{\text {Baliza }}$

Donde:

$$
\begin{gathered}
\bar{I}_{\text {standby }}=2,75 \mathrm{~mA} \\
\bar{I}_{\text {conexión }} \approx 3 * \frac{(30-2,75) \mathrm{mA} \cdot 0,7 \mathrm{~s}}{24 * 3600 \mathrm{~s}}=0,66 \mu \mathrm{A} \\
\bar{I}_{\text {DATA_REQUEST }} \approx \frac{(30-2,75) \mathrm{mA} \cdot 0,015 \mathrm{~s}}{15 \mathrm{~s}}=0,027 \mathrm{~mA} \\
\bar{I}_{D C D C} \approx \frac{(55-2,75) \mathrm{mA} \cdot 1,7 \mathrm{~s}}{300 \mathrm{~s}}=0,296 \mathrm{~mA} \\
\bar{I}_{S B E} \approx \frac{(115-2,75) \mathrm{mA} \cdot 4,5 \mathrm{~s}}{300 \mathrm{~s}}=1,684 \mathrm{~mA} \\
\bar{I}_{A D C} \approx \frac{(70,2-2,75) \mathrm{mA} \cdot 3,3 \mathrm{~s}}{300 \mathrm{~s}}=0,742 \mathrm{~mA} \\
\bar{I}_{S D} \approx \frac{(40,2-2,75) \mathrm{mA} \cdot 2,3 \mathrm{~s}}{300 \mathrm{~s}}=0,287 \mathrm{~mA} \\
\bar{I}_{\text {Envío }} \approx \frac{(30-2,75) \mathrm{mA} \cdot 1,3}{300 \mathrm{~s}}=0,121 \mathrm{~mA} \\
\bar{I}_{\text {Baliza }} \approx \frac{1}{2} * \frac{(100-2,75) \mathrm{mA} \cdot 0,5 \mathrm{~s}}{4 \mathrm{~s}}=6,078 \mathrm{~mA} \\
N \text { o días } \approx \frac{5000 \mathrm{~mA} \cdot \mathrm{h}}{\bar{I}_{\text {Total Boya } \mathrm{m}} \mathrm{mA} \cdot 24 \mathrm{~h}}=17,4 \mathrm{días}
\end{gathered}
$$

Para calcular la autonomía de la boya en ausencia de paneles solares, se han supuesto los casos más desfavorables en cada una de las mediciones. Así, la expresión (2) muestra el consumo del mote en reposo. 
Cada vez que se inicia un ZED en la red, se inicia en modo búsqueda de asociación con el nodo padre correspondiente. Dicha búsqueda se traduce en el envío de mensajes definidos a bajo nivel en la implementación de la pila de ZigBee. Para el estudio realizado, se ha considerado que se produce el envío de tres de estos mensajes hasta que se consigue con éxito la conexión. Además, se ha supuesto el caso de que una vez al día el nodo Sensor pierda la conexión y vuelva a conectar con al nodo padre. Por tanto, la ecuación (3) expresa el consumo promediado en modo conexión a la red para tres pulsos cada $24 \mathrm{~h}$.

Cuando un ZED está dormido, tiene la radio apagada y, por tanto, no puede recibir ningún mensaje de otro nodo de la red. Para evitar la pérdida de estos mensajes, cada $15 \mathrm{~s}$, establecido en la variable -DPOLL_RATE del archivo de configuración f8wconfig.cfg, el ZED consulta a su nodo padre si hay mensajes disponibles para él. Este tipo de mensajes se han tenido en cuenta en el estudio de consumo realizado en la expresión (4). La duración de éstos son de $15 \mathrm{~ms}$ cada $15 \mathrm{~s}$.

De igual forma se han calculado las expresiones de la (5) a la (9). Éstas hacen referencia a los estados del (4) al (8) indicados en la Tabla 6.11 y representados en la Figura 6.24. El intervalo entre muestras considerado en este estudio es de $5 \mathrm{~min}$, que es el peor caso penalizando así el consumo del sistema. En despliegues reales el periodo de muestreo medio es de $20 \mathrm{~min}$.

De forma paralela al estudio de consumo del mote con los sensores se realizaron mediciones del consumo de la baliza. Se ha considerado relevante incluirlo en este estudio puesto que la boya necesariamente debe disponer de una señal luminosa que alerte de su presencia durante la noche, y contribuye notablemente al consumo del sistema completo. Por tanto, la última de las contribuciones es la corriente promedio consumida por la baliza que incorpora la boya (ecuación (10)). Se ha considerado que la baliza está activa 12 horas al día (por lo que la corriente promedio se divide entre 2), produce destellos cada 4 s con una duración de 500 ms cada uno de ellos y con un consumo de 97,25 mA.

Finalmente, teniendo en cuenta que las baterías empleadas en el sistema tienen una capacidad de $5.000 \mathrm{~mA}$ h, y de la ecuación (1) se obtiene una corriente constante promedio de $12 \mathrm{~mA}$ aproximadamente, se obtiene una estimación de autonomía de 17,4 días.

El estudio de consumo para el nodo tipo ID2 es análogo al anterior a excepción del estado 5 definido en la Tabla 6.11, ya que este tipo de nodo no incluye ningún sensor con interfaz de conexión RS232. Por tanto, en la gráfica de la Figura 6.25 se mantienen el resto de estados de la demanda de corriente del nodo. 


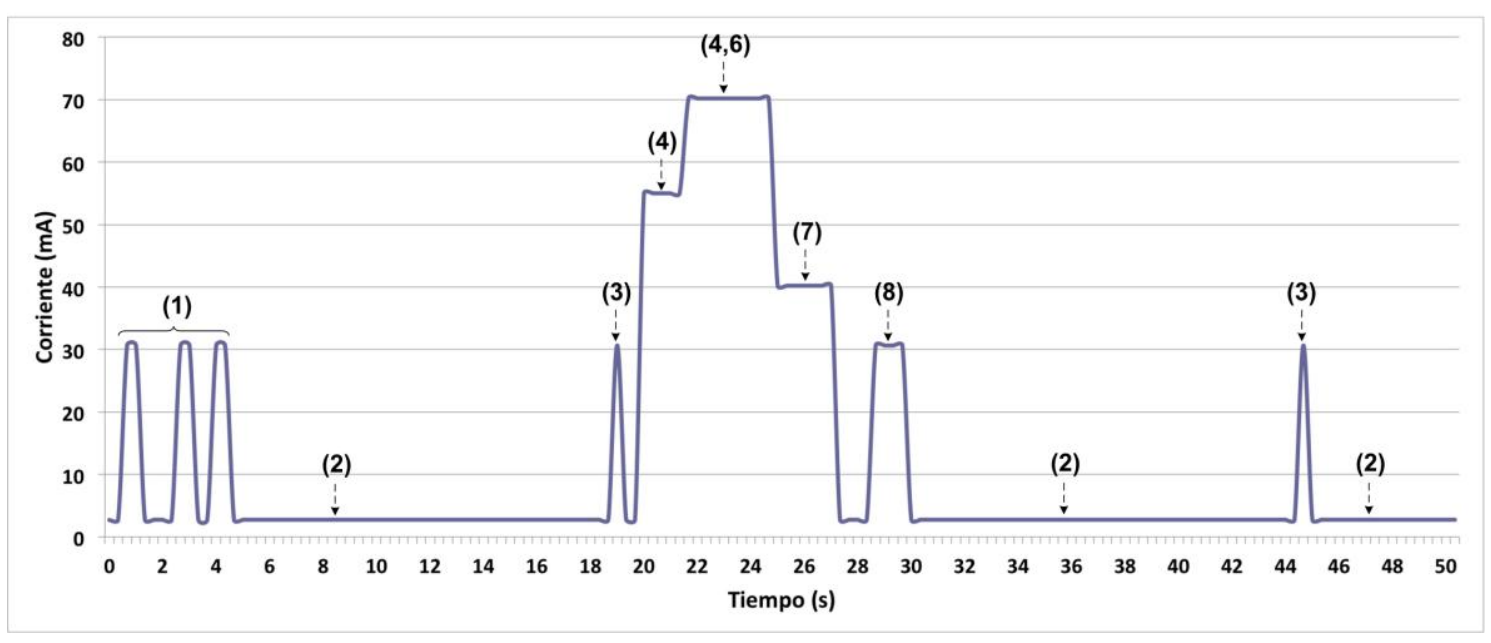

Figura 6.25 Consumo del nodo Sensor tipo ID2.

En este caso, la corriente promedio total se puede expresar mediante la ecuación (12). Y el número de días estimado de autonomía del nodo tipo ID2 es de 20,2 (ver ecuación (13)).

$$
\begin{gathered}
\bar{I}_{\text {Total Boya } 2}=\bar{I}_{\text {standby }}+\bar{I}_{\text {conexión }}+\bar{I}_{D A T A_{-} R E Q U E S T}+\bar{I}_{D C D C}+\bar{I}_{A D C}+\bar{I}_{S D}+\bar{I}_{\text {Envío }}+\bar{I}_{\text {Baliza }} \\
\text { № días } \approx \frac{5000 \mathrm{~mA} / \mathrm{h}}{\bar{I}_{\text {Total Boya } 2} \mathrm{~mA} \cdot 24 \mathrm{~h}}=20,2 \text { días }
\end{gathered}
$$

Con las estimaciones de consumo de los nodos obtenidas en este estudio, para ambos tipos de nodos, podría ser suficiente por ejemplo para despliegues en catástrofes. Pero para el caso que nos ocupa, en el que las campañas de monitorización marina son más duraderas incluso se requieren despliegues permanentes de boyas, es necesario dotar a éstas de un sistema de captación de energía, asegurando de este modo una autonomía "indefinida" de las baterías. Para este fin, se dotó a cada una de las boyas de dos paneles solares conectados en paralelo, siendo cada uno de ellos de $2,5 \mathrm{~W}$ (con una tensión nominal de $\mathrm{V}_{\text {nominal }}=8 \mathrm{~V} \mathrm{y}$ una corriente nominal de $\mathrm{I}_{\text {nominal }}=310 \mathrm{~mA}$ ). En las pruebas de campo presentadas en el siguiente apartado, se pondrá de manifiesto la robustez del sistema de alimentación formado por las baterías de polímero de litio y los paneles solares con las características citadas anteriormente.

\subsubsection{Pruebas en campo.}

Una vez testeada la electrónica y verificado un consumo adecuado de la misma, se procedió a las pruebas del sistema global en condiciones reales. Puesto que la importancia de estas pruebas residía en la validación del sistema de alimentación (la evolución de la carga de la batería junto con el harvesting system), el sistema de comunicaciones y la estanqueidad de la boya, y no en el valor de los datos muestreados por los sensores, se 
decidió ubicar una boya en uno de los pantalanes de la dársena del Puerto de Cartagena debido a la cercanía con las instalaciones de la UPCT. Para estas pruebas, la boya únicamente se dotó del sensor oceanográfico SBE39 cuyas características han sido detalladas en la Tabla 6.10.

En estas pruebas se emplearon dos nodos: un nodo Coordinador ubicado en las oficinas del Club de Regatas del Puerto de Cartagena, y un nodo Sensor en uno de los pantalanes del puerto, ubicado a $110 \mathrm{~m}$ de distancia como muestra la Figura 6.26.

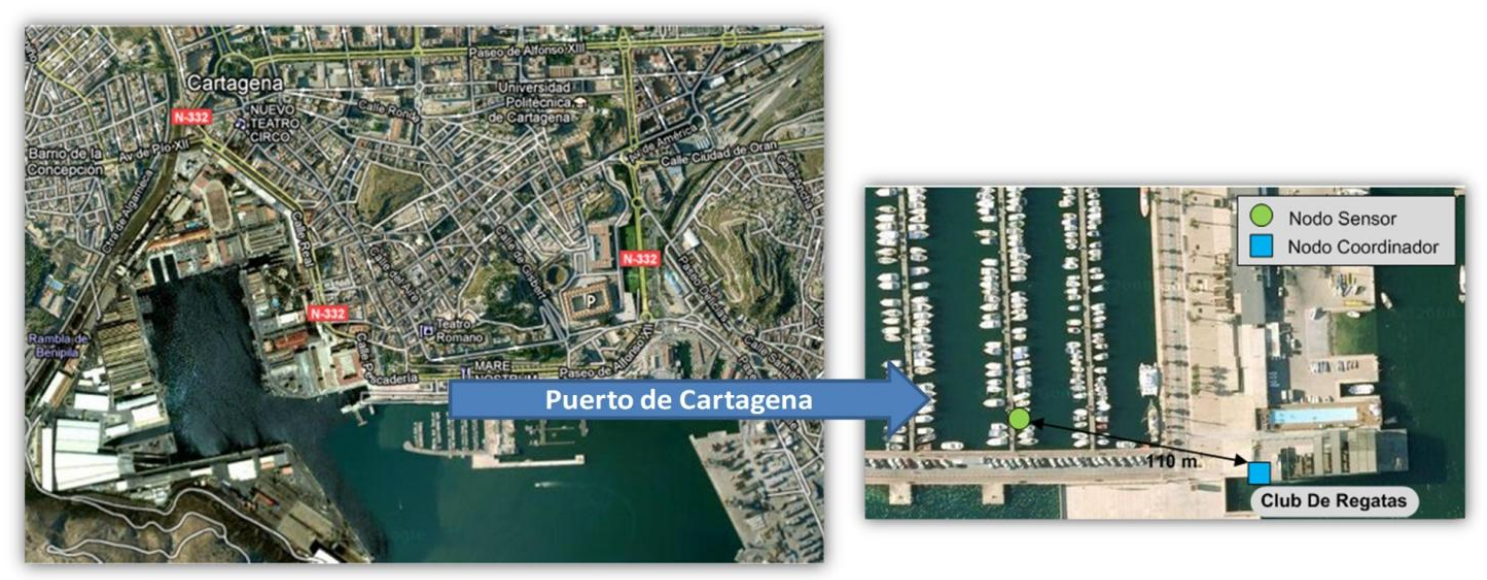

Figura 6.26 Ubicación de las pruebas en el Puerto de Cartagena.

Además de la tensión de batería monitorizada en la placa MEWiN Main-board, MEWiN Sea-Board incluye un sensor para la monitorización de temperatura en el interior de la caja.

Para ello, se ha implementado una aplicación en la que el nodo sensor despierta del modo POWER_SAVING, realiza el muestreo de la temperatura y presión del mar, realiza la lectura de la tensión de batería y la temperatura del interior de la caja, obtiene la hora del RTC, almacena toda la información en la microSD y la envía por radio al nodo Coordinador. El nodo coordinador, al recibir el mensaje, lo almacena también en la microSD. Éste está en todo momento activo a la espera de recibir mensajes del nodo sensor. El periodo de muestreo seleccionado para esta prueba fue de $10 \mathrm{~min}$. La batería del mote alimenta también a la baliza de señalización marina, cuyo funcionamiento es continuo en ausencia de luz solar.

Se presentan a continuación los resultados obtenidos de los parámetros más relevantes durante dos meses de pruebas en el Puerto de Cartagena, de mayo a junio de 2011.

En la gráfica de la Figura 6.27 se muestra la evolución de la batería, la cual fue instalada en el sistema con su máxima tensión de carga (4,2 V). En ella se puede observar cómo el harvesting system funciona correctamente cargando la batería, alcanzando su máxima carga en 
los días soleados. La descarga de ésta se ve muy acentuada durante la noche por el consumo de la baliza.

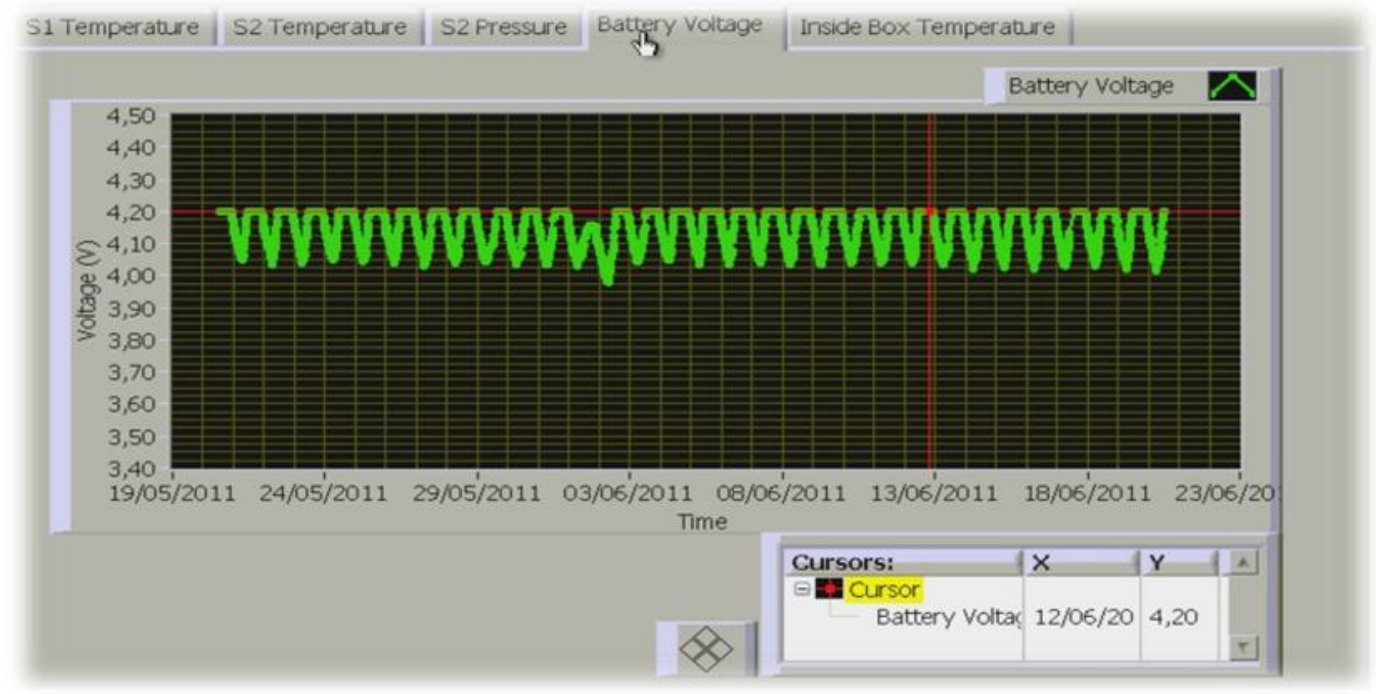

Figura 6.27 Evolución de la tensión de batería.

La Figura 6.28 representa la temperatura en el interior de la caja que contiene la electrónica.

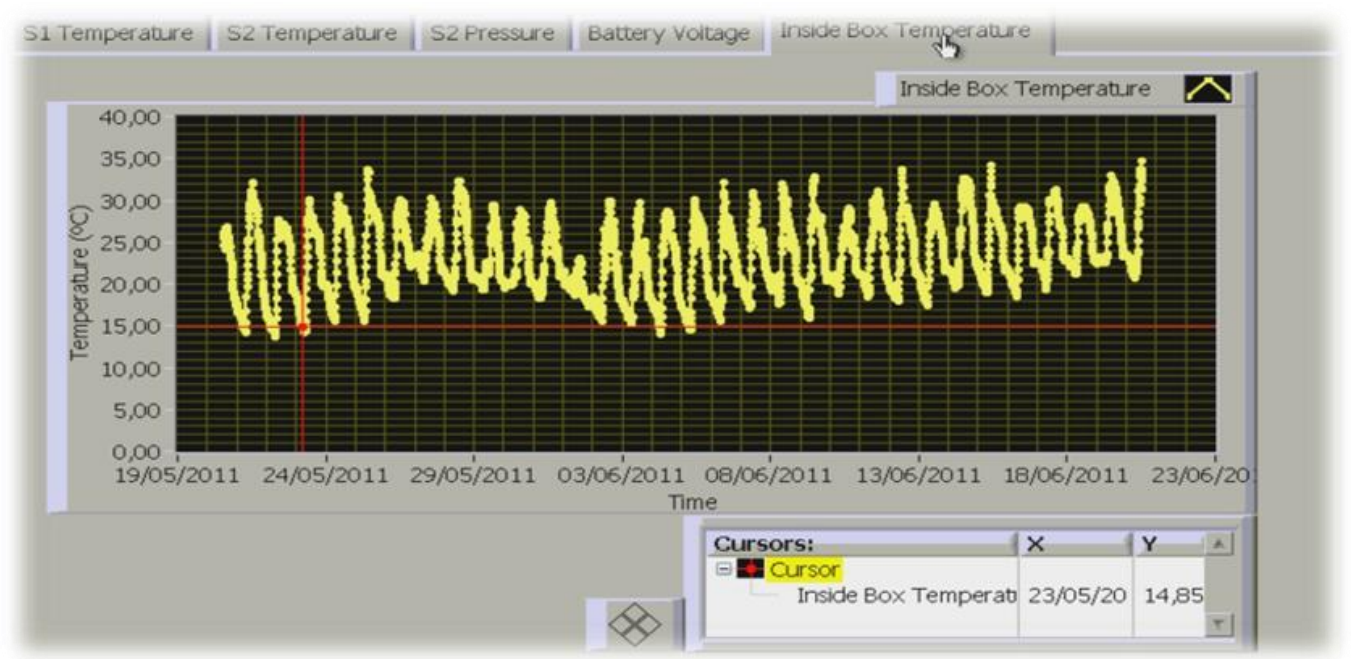

Figura 6.28 Evolución de la temperatura en el interior de la caja.

Tras los dos meses de pruebas, se ha podido comprobar también la robustez y estanqueidad del sistema, dado que éste ha estado sometido a viento y lluvia, no apreciándose ningún desperfecto en la boya, ni restos de humedad en el interior de la caja que contiene el mote. En la Figura 6.29 se muestran algunas imágenes de estas pruebas. 


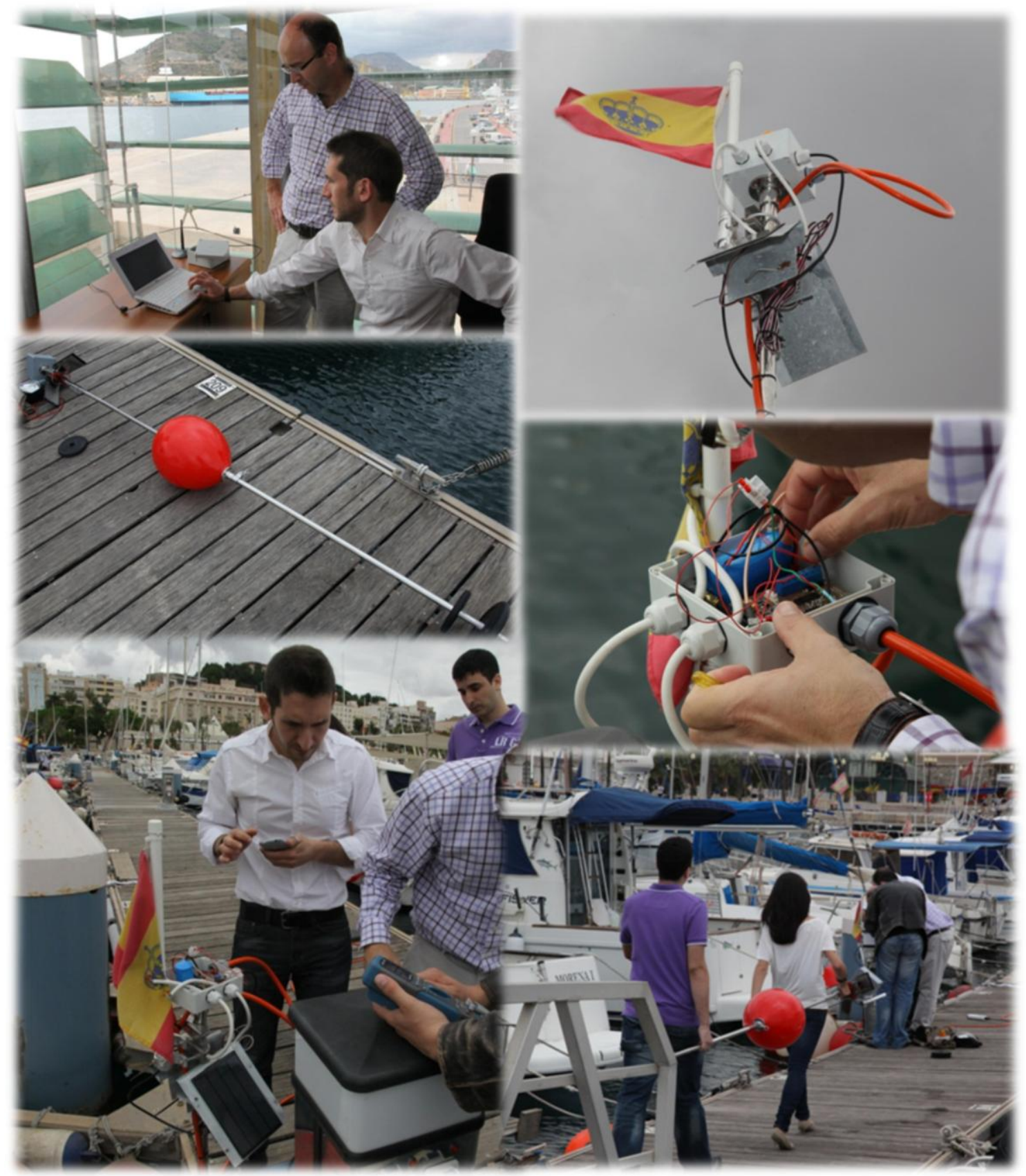

Figura 6.29 Pruebas en el Puerto de Cartagena.

\subsection{Conclusiones.}

En este capítulo se ha realizado la descripción de la implementación de una arquitectura de red de sensores. Se ha detallado tanto el hardware diseñado como el software que dota de funcionalidad a los distintos elementos que forman la red, los motes.

Se han diferenciado dos tipos de nodos o motes: nodos ZigBee y nodos GPRS. Los primeros son los nodos que forman una red ZigBee, es decir, nodos ZED, ZR y ZC, y los segundos, son nodos Sensores diseñados para la monitorización autónoma de zonas 
aisladas. Se ha detallado la implementación hardware de cada uno de estos nodos indicando también las herramientas de desarrollo empleadas para tal fin. De la fabricación de los nodos ZigBee se ha obtenido un producto denominado MEWiN, formado por una placa multipropósito y las placas de interfaz necesarias en función de la aplicación a la que vayan destinados. Una vez caracterizado el hardware desarrollado, se han descrito las aplicaciones software y modificaciones necesarias en la pila Z-Stack. En lenguaje C para los nodos ZigBee, y en lenguaje Python para los nodos GPRS.

Se han realizado modificaciones en la implementación de la pila Z-Stack de TI. Se han implementado algoritmos que solucionan los problemas de conectividad presentados en este capítulo, como la reconexión de los ZED de forma automática en una red ZigBee, la implementación del software necesario para gestionar el RTC (lectura de la hora y programación de alarmas), y por último, almacenar información relativa a la red de sensores en la microSD en formato FAT.

Tras el análisis del diseño del mote (diseño electrónico y software) se ha presentado la estructura mecánica de la boya que soporta el mote. Esta estructura ha sido diseñada para aguas poco profundas, como es la laguna costera del Mar Menor, y teniendo en cuenta las características que el medio marino impone.

Para optimizar la comunicación entre los nodos en una red ZigBee se ha presentado el diseño de un protocolo para el intercambio de mensajes. Este incluye dos tipos de tramas: 1) una trama de presentación enviada por el ZED hacia su nodo padre, indicándole quién es y cuál es su función en la red (qué sensores tiene y la información que le enviará y en qué orden), y 2) una trama de datos con los valores de las muestras tomadas y que en su presentación había anticipado.

Tan importante como implementar una red de sensores, es realizar el diseño del sistema de monitorización que alberga toda la información relativa a dicha red. La solución propuesta en esta Tesis Doctoral está basada en servidores remotos, y se ha presentado una aplicación gráfica desarrollada en LabVIEW. Esta aplicación estará accesible a través de Internet. Fueron varios motivos los que llevaron a la utilización de este entorno de desarrollo y no otro. Su lenguaje de programación gráfica es muy intuitivo y de rápido aprendizaje. Incluye Toolkits que ofrecen la posibilidad de realizar múltiples tareas, como por ejemplo, los utilizados en esta Tesis, Internet Toolkit que, entre otras cosas, permite el envío y recuperación de datos desde un servidor FTP, y NI-VISA Toolkit para comunicación serie.

Por último en este capítulo, se han presentado las pruebas realizadas tanto en el laboratorio como en campo. En primer lugar, en las pruebas en el laboratorio se verificó el funcionamiento del hardware diseñado reproduciendo a escala la A-WSN que más tarde se 
ubicaría en el mar. Además, tras la validación de la electrónica, se ha realizado un estudio de consumo de dos tipos de nodos con diferentes sensores: el nodo tipo ID1 con sensores SBE39 (temperatura y presión del mar) y YOUNG 61302L (presión atmosférica), y el nodo tipo ID2 con el sensor LMK 807 de SENSOTEC (presión del mar con capilar de compensación), ambos nodos para la medición de la presión del mar. Se ha calculado la corriente promedio en los dispositivos, presentando el consumo de éstos en cada uno de sus estados de funcionamiento. Una vez verificado el correcto funcionamiento de la electrónica desarrollada, se realizaron pruebas del sistema global en el Puerto de Cartagena. Éstas tuvieron como objetivo la validación del sistema de alimentación, del sistema de comunicaciones y de la estanqueidad de la boya diseñada. Tras dos meses de pruebas, se concluyó que el sistema estaba completamente operativo y en disposición de ser usado en despliegues reales en el mar.

En el siguiente capítulo, se presentan dos despliegues realizados y la planificación para un despliegue permanente que se llevará a cabo tras la presentación de esta Tesis. En uno de los despliegues que se presentarán más adelante, se han utilizado boyas del tipo ID1 para la monitorización de la presión del mar y la presión atmosférica para realizar la correspondiente compensación. Las boyas tipo ID2 serán desplegadas en el despliegue planificado para la campaña de invierno.

Los trabajos desarrollados en este capítulo han sido publicados en dos congresos internacionales [Albaladejo et al., 2011b; Albaladejo et al., 2011c], dos congresos nacionales [Albaladejo et al., 2010c; López et al., 2011b; Albaladejo et al., 2011c] y una revista nacional [Albaladejo et al., 2011a]. 
Propuesta de una Red de Sensores Inalámbrica para un Sistema de Observación Costero

Esta página se deja en blanco de forma intencionada. 


\section{Capítulo 7}

\section{Despliegues realizados}

\footnotetext{
$\Psi$ n este capitulo, se presentan los diferentes despliegues realizados en esta Tesis Doctoral. Dichos despliegues se han llevado a cabo en el marco del proyecto CMS citado en el capitulo 1, y en
} colaboración con las diversas tareas, que de forma paralela, se han realizado bajo el mismo proyecto. Los datos recogidos con el sistema boya desarrollado han servido como entrada a los modelos bidrodinámicos desarrollados en la Tesis Doctoral de D. Francisco López sobre el modelado del Mar Menor, dirigida por el Dr. D. Javier Gilabert Cervera del departamento de Ingeniería Química y Ambiental.

En cuanto a los despliegues presentados en este capitulo, el objetivo del primero fue verificar la operatividad del despliegue y repliegue de la A-WSN asi como su funcionamiento en el Mar Menor. Tras éste, se desplegó una boya para la colaboración en el evento "AUV 2011 Underwater Robotics Experiment", llevado a cabo en la laguna costera del Mar Menor. Finalmente, se presenta la planificación de un despliegue de una A-WSN permanente, cuyos resultados se esperan poder ser presentados en la defensa de la presente Tesis Doctoral. 


\subsection{Introducción.}

En paralelo con esta Tesis Doctoral, cuyo objetivo ha sido diseñar y desarrollar una red de sensores con capacidad de comunicación inalámbrica que permita la monitorización a tiempo real del Mar Menor, y al amparo del proyecto de investigación "Sistema de Monitorización Costera para el Mar Menor (Coastal Monitoring System, en adelante CMS)", se están llevando a cabo trabajos relacionados con el desarrollo de un modelo hidrodinámico de alta resolución para el Mar Menor, el análisis de los patrones espaciales y temporales de los principales peces que migran y se desarrollan en la laguna, y tareas para entrelazar la simulación numérica hidrodinámica con los procesos biológicos que se producen en la laguna.

Los trabajos realizados en el marco del proyecto CMS son coordinados por miembros de la UPCT (grupos de investigación dirigidos por el Dr. D. Andrés Iborra García y el Dr. D.Javier Gilabert Cervera) y de la Universidad de Murcia (grupo de investigación dirigido por Ángel Pérez Ruzafa). En el entorno de dichos trabajos, el "sistema boya" desarrollado en esta Tesis ha sido utilizado para la toma de datos que más tarde han sido usados para el cálculo de dicho modelo.

Hasta el momento se han realizado, bajo dicho proyecto y en relación con el mismo, dos despliegues reales. Previamente, en el primero de ellos se ha realizado la comprobación de la operatividad de diez boyas diseminadas en las proximidades de la Isla de la Perdiguera, en el Mar Menor. En el segundo despliegue, se ha utilizado una boya para la toma de datos durante un experimento de varios AUVs, para estudiar el área de influencia de las aguas del Mar Menor sobre el Mar Mediterráneo adyacente.

En los siguientes apartados se analizan las peculiaridades de la zona que es objeto de estudio en esta Tesis Doctoral, el Mar Menor. Tras dicho análisis, se detalla el alcance del proyecto CMS, describiendo los dos despliegues que se han llevado a cabo, junto con la planificación de un despliegue posterior de una A-WSN en las cercanías de la Isla del Ciervo.

\subsection{Laguna Costera E1 Mar Menor.}

Además de los valores ecológicos y socioeconómicos que ofrece el Mar Menor, la laguna posee un enorme potencial como banco de pruebas a mediana escala para el desarrollo y planteamiento de hipótesis científicas a resolver con desarrollos tecnológicos avanzados. Su fácil acceso, sus dimensiones, los procesos tanto físicos como químicos y biológicos que en ella se producen, hacen que pueda considerarse como un laboratorio de 
grandes dimensiones o como un mar a pequeña escala, singularidad que proporciona un valor añadido a este emblemático ecosistema.

A continuación, se realiza una descripción de dicha laguna y se presentan las características de diseño de una A-WSN para la monitorización completa del Mar Menor.

\subsubsection{Descripción.}

La principal característica que permite definir al Mar Menor es que se trata de una laguna costera cuyo origen está vinculado al mar adyacente, el Mar Mediterráneo, del que se mantiene separada por una franja arenosa de $24 \mathrm{~km}$ de longitud y entre 100 y $1.200 \mathrm{~m}$ de anchura, La Manga. El Mar Menor es una laguna de agua salada de 135,24 km², situada al sureste de la Península Ibérica, en la Región de Murcia. Está separada del Mar Mediterráneo por La Manga en la que existen tres canales (Las Encañizadas, El Estacio y Marchamalo), tal y como se muestra en la Figura 7.1. La profundidad máxima es de 6,8 $\mathrm{m}$ y presenta una salinidad entre 42 y $47 \mathrm{~g} / \mathrm{L}$, superior a la del Mar Mediterráneo cuya salinidad es de entre 36 y $37 \mathrm{~g} / \mathrm{L}$.

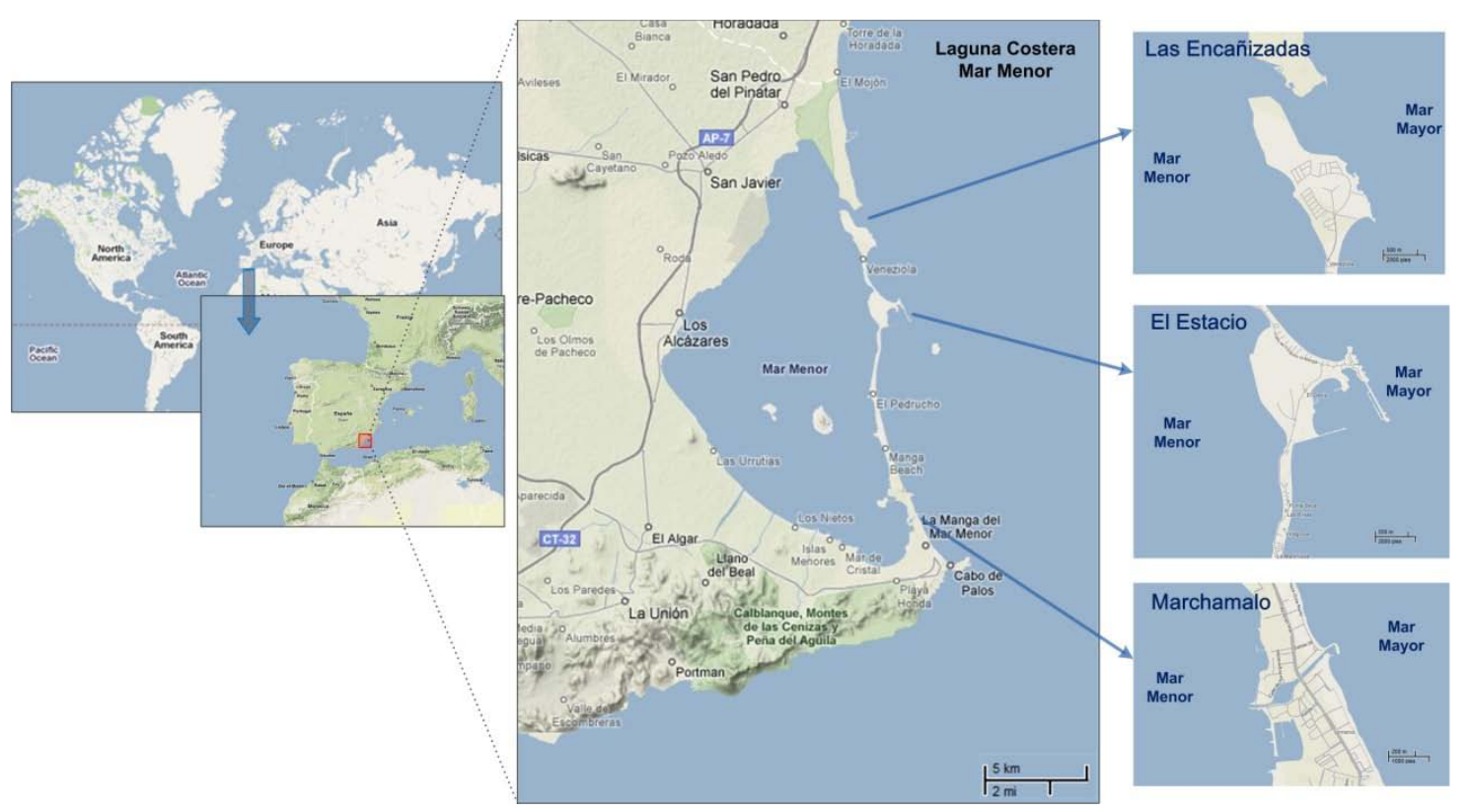

Figura 7.1 Laguna Costera Mar Menor. Canales de comunicación del Mar Menor con el Mar Mediterráneo.

\subsubsection{Diseño de una A-WSN para la monitorización completa del Mar Menor.}

Para llevar a cabo con precisión la observación del Mar Menor se requiere comprender los procesos hidrodinámicos que tienen lugar en la laguna, y los mecanismos físicos de intercambio y transporte de sustancias entre los distintos espacios. Así, se conocerán las 
zonas de mayor interés de la laguna y se podrá llevar a cabo la monitorización de las mismas.

El cordón litoral de La Manga limita el flujo de agua actuando de barrera, permitiendo el trasvase de agua solamente a través de las golas y haciendo que, por tanto, el Mar Menor se retrase al seguir el ritmo de variación del mar exterior.

El intercambio de agua entre el Mar Menor y el Mediterráneo se produce a través de los tres canales de La Manga. El Estacio es, con diferencia, el canal que mayor influencia tiene tanto en la entrada de agua del Mar Mediterráneo hacia la laguna como en su salida, más salada y por tanto más densa, del Mar Menor hacia el Mar Mediterráneo. Esto es de gran importancia para conocer la dinámica interna de la laguna y sus procesos ecológicos, y la influencia que ésta tiene sobre el Mediterráneo adyacente.

Según las necesidades de toma de datos establecidas por los biólogos y oceanógrafos para el cálculo del modelo hidrodinámico, y otros estudios de índole biológico del Mar Menor, se han definido las siguientes zonas de interés de la laguna: los tres canales en La Manga, las cubetas norte y sur y la desembocadura de la rambla del Albujón. Para la correcta monitorización de dichas zonas se han definido cuatro tipos de nodos Sensores que incluyen diferentes sensores, tal y como se especifica en la Tabla 7.1.

Tabla 7.1 Nodos Sensores para la monitorización completa del Mar Menor.

\begin{tabular}{|c|c|c|}
\hline Nodo Sensor & \multicolumn{2}{|c|}{ Sensores que incluye el nodo } \\
\hline Profundidad & \multicolumn{2}{|l|}{ - Presión marina } \\
\hline Correntímetro & \multicolumn{2}{|c|}{ - Velocidad de las corrientes } \\
\hline Completo & \multicolumn{2}{|c|}{$\begin{array}{l}\text { - Presión marina } \\
\text { - Velocidad de corrientes } \\
\text { - Salinidad } \\
\text { - Perfil de temperaturas }\end{array}$} \\
\hline Rambla & $\begin{array}{l}\text { - Temperatura } \\
\text { - Presión marina } \\
\text { - Salinidad }\end{array}$ & $\begin{array}{l}\text { - Turbidez } \\
\text { - Oxígeno disuelto } \\
\text { - Clorofila } \\
\text { - Nitratos }\end{array}$ \\
\hline
\end{tabular}

Los sensores que incorporan estos nodos toman medidas a una única profundidad. Los sensores se ubican en el fondo del mar conectados mediante cable submarino a la boya instrumental de la superficie. En cambio, para la monitorización del perfil de temperatura del mar se ubicarán varios sensores en la vertical con una separación entre ellos de $1 \mathrm{~m}$.

Teniendo en cuenta los nodos Sensores definidos, se propone la monitorización del Mar Menor mediante la implantación de tres subredes inalámbricas basadas en ZigBee y un nodo GPRS. Las subredes están formadas por dichos nodos Sensores, nodos Routers y nodos Coordinadores, con la disposición que se muestra en la Figura 7.2. Los nodos Coordinadores serán los encargados de transmitir la información que reciban de los nodos 
Sensores o Routers, y hacerla llegar hasta el servidor de datos. Los nodos Routers serán meramente nodos intermedios para lograr una mayor cobertura espacial en el despliegue. Además, el nodo GPRS se comunica directamente con el servidor de datos vía GPRS debido a la gran distancia que lo separa del resto de nodos.

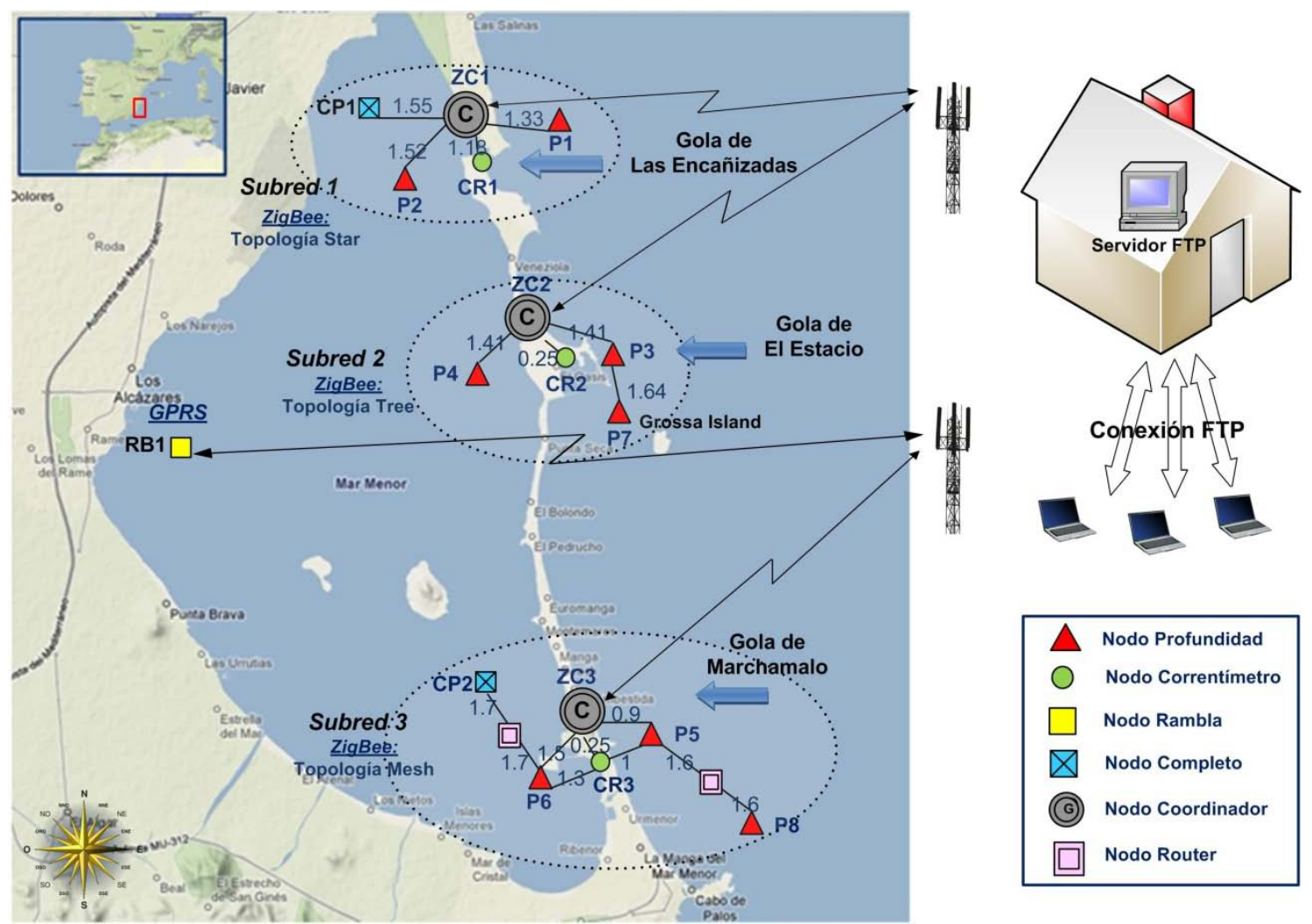

Figura 7.2 Despliegue de nodos en el Mar Menor.

La numeración de los nodos se ha realizado en función del tipo de nodo. Cada tipo de nodo se identifica mediante las abreviaturas P, CR, RB, CP, C (Profundidad, Correntímetro, Rambla, Completo, Coordinador respectivamente) seguido del número de nodo resultando ser el identificador del nodo. En cada una de las subredes se implementa una topología ZigBee (Star en la subred 1, Tree en la subred 2 y Mesh en la subred 3) cada una de las cuales ofrece diferentes características. En la topología Star, el Coordinador se sitúa en el centro de la red, en la topología Tree el Coordinador es la raíz del árbol, y en la topología Mesh al menos uno de los nodos tiene más de dos conexiones. Habrá nodos sensores que además de monitorizar la laguna actúen como Routers, contemplando además nodos que actuarán únicamente de Routers (Nodo Router en Figura 7.2) con el objetivo de cubrir toda la zona de monitorización.

Puesto que la única comunicación entre ambos mares, Mar Menor y Mar Mediterráneo, se realiza mediante los tres canales de La Manga, ante vientos de poniente y levante en ellos se produce un importante intercambio de aguas. Por tanto, para tener conocimiento de 
dicho fenómeno se ubica un nodo Correntímetro en la zona más estrecha de cada canal (CR1, CR2 y CR3 en Figura 7.2). En consecuencia, surge el interés de conocer la profundidad del mar en los extremos de cada una de los canales, y para ello se emplea un nodo Profundidad (P1-P6). Para obtener un estudio completo se estudian las aguas adyacentes a La Manga en el Mar Mediterráneo debido a que tanto las mareas, los vientos como las presiones atmosféricas influyen en la altura del mar. Para ello, se pueden emplazar dos nodos Profundidad, uno cercano a Isla Grosa (P7), y otro en Cabo de Palos (P8). Por otro lado, mediante los nodos Completo se tendrán monitorizadas las cubetas Norte (CP1) y Sur (CP2) para un mayor conocimiento de la laguna costera. Finalmente, con el nodo Rambla (RB1) se persigue controlar el agua vertida a la laguna procedente de la desembocadura de la rambla del Albujón, ya que ésta constituye el principal colector de agua de explotaciones agrícolas del Campo de Cartagena pudiendo afectar a ciertos parámetros de la laguna.

Todos los nodos del despliegue presentado, excepto el nodo RB1, son nodos ZigBee y siguen las especificaciones detalladas en el apartado 6.2.1 del capítulo 6. El nodo RB1 es un nodo GPRS, cuya implementación ha sido descrita en el apartado 6.2.2 del mismo capítulo.

El despliegue de la Figura 7.2 es el ideal, con el que se obtendría la información completa de los fenómenos que tienen lugar en la laguna. En esta Tesis se ha desarrollado el sistema que hace posible este despliegue: los dos tipos de nodos (ZigBee y GPRS), la estructura que soporta dichos nodos, así como el protocolo de comunicaciones y el sistema de monitorización. En referencia a los nodos Sensores, se han implementado dos tipos de nodos Sensores Profundidad, los tipos ID1 e ID2 definidos en el apartado 6.7 del capítulo 6. En el despliegue para un caso real descrito más adelante, se han utilizado un nodo Coordinador y un nodo Profundidad tipo ID1. Finalmente, en el despliegue planificado en la Isla del Ciervo se espera incluir un nodo Coordinador, un nodo Router y varios nodos Profundidad del tipo ID2.

A continuación se presentan los despliegues realizados en el Mar Menor, así como la planificación prevista para la campaña de invierno.

\subsection{Despliegue en el Mar Menor.}

En este apartado se describen las pruebas de despliegue que se han realizado en el Mar Menor. El objetivo de éstas fue comprobar el fácil despliegue de las boyas diseñadas y fabricadas, verificar el funcionamiento del sistema a nivel de comunicaciones y realizar el repliegue de las mismas. 
El despliegue realizado estaba formado por diez boyas con la estructura descrita en el capítulo 6, que contenían cada una de ellas una placa MEWiN-MainBoard e implementaban una topología en estrella, es decir, cada una de los nodos Sensores o boyas enviaban sus mensajes al nodo Coordinador, ubicado en la embarcación utilizada para las pruebas (ver Figura 7.3).

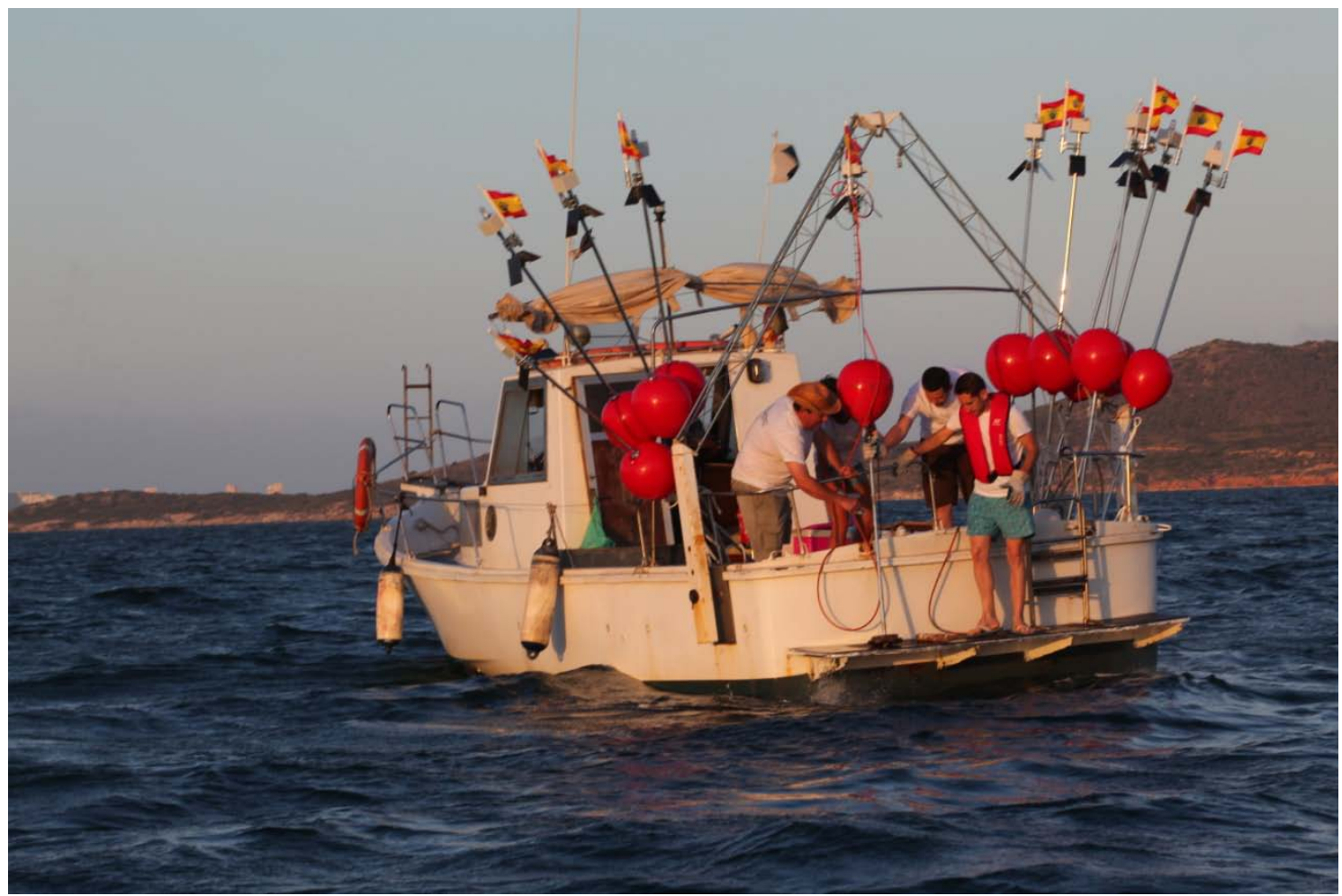

Figura 7.3 Embarcación utilizada para las pruebas de despliegue.

Todas las boyas fueron programadas con una aplicación software implementada ad-hoc para estas pruebas. Con un periodo de $5 \mathrm{~min}$, los nodos Sensores o boyas enviaban un mensaje fijo al nodo Coordinador. Éste, registraba dichos mensajes y, mediante una aplicación de usuario, se comprobaba la comunicación con las diferentes boyas. La distancia entre cada una de las boyas y la embarcación no superó en ningún momento la distancia de $500 \mathrm{~m}$. En la Figura 7.4 se muestran varias boyas desplegadas en el Mar Menor.

Estas pruebas tuvieron lugar en julio de 2011, un mes en el que el tránsito de embarcaciones de recreo es muy abundante. Por ello, y para evitar la sustracción de los equipos, una vez comprobada la operatividad del despliegue, se realizó el repliegue de las boyas en el mismo día. Además del interés investigador de estas pruebas, éstas también despertaron el interés social, prueba de ello son los reportes aparecidos en los medios de comunicación a los pocos días [La Opinión, 2011].

En estas pruebas se pudo comprobar la facilidad de despliegue de las boyas fabricadas así como su repliegue. Debido al peso ligero de la estructura diseñada, siendo éste de $10 \mathrm{~kg}$ 
aproximadamente, estas han sido fácilmente manejables entre una o dos personas. El tiempo invertido en el despliegue de las 10 boyas fue de aproximadamente 3 horas. Finalmente, la comunicación entre los nodos Sensores y el Coordinador fue satisfactoria.

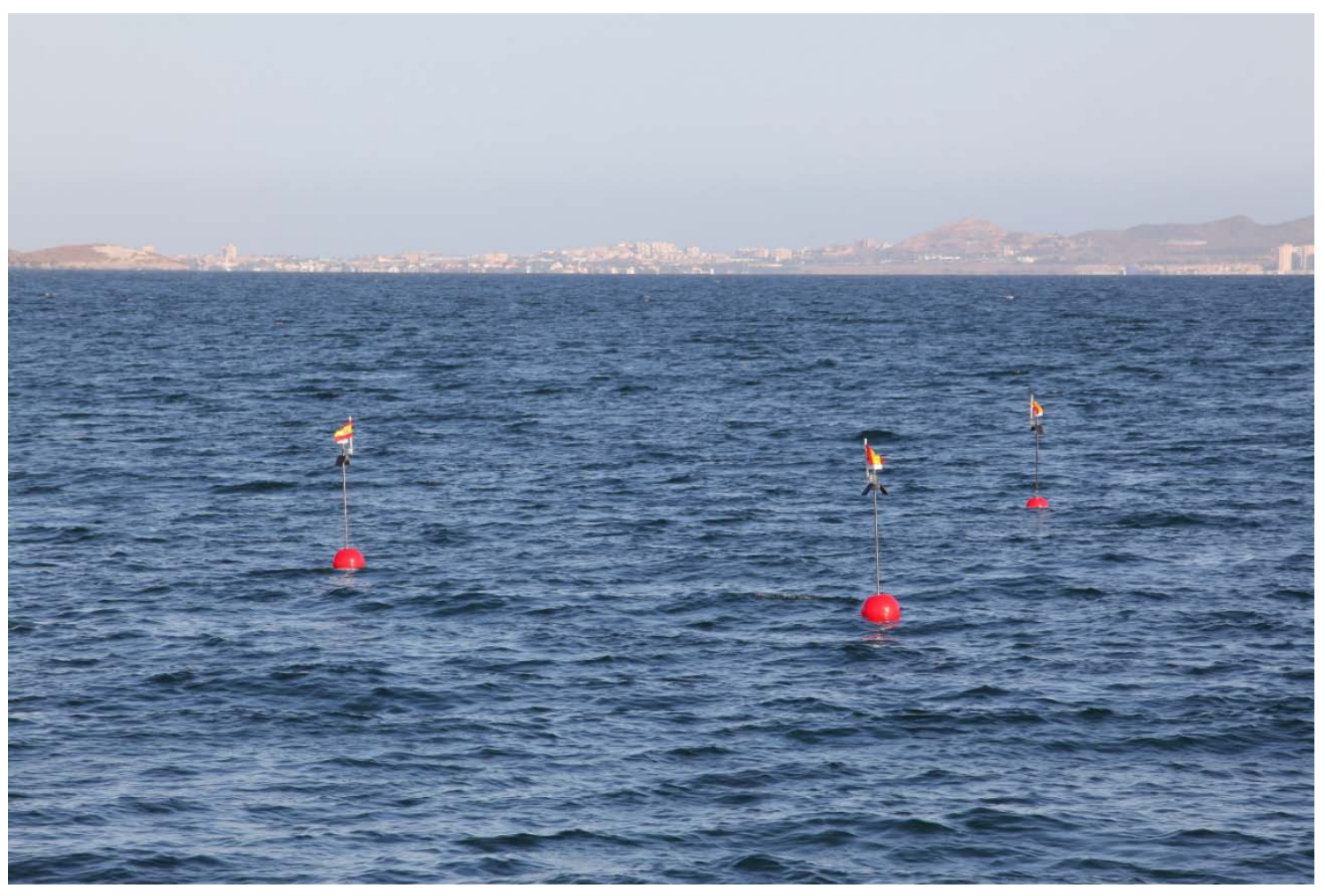

Figura 7.4 Despliegue de boyas en el Mar Menor.

En la página web del proyecto CMS [CMS, 2011] se pueden encontrar más imágenes y videos de las pruebas.

\subsection{Despliegue para un caso real.}

Las siguientes pruebas se llevaron a cabo en colaboración con el evento "AUV 2011 Underwater Robotics Experiment in the Mar Menor Coastal Lagoon” [Gilabert et al., 2011] organizado por la UPCT junto con el MBARI, del 2 al 10 de noviembre de 2011, en el marco del proyecto CMS. En él participaron las Universidades de Girona, Oporto, Politécnica de Cataluña (SARTI), Carlos III y el MBARI, este último, uno de los centro de referencia internacional en ingeniería y tecnología oceanográfica. Este experimento es fruto de la colaboración entre dicho proyecto, y el Campus de Excelencia Internacional Mare Nostrum 37/38 de las Universidades de Murcia y UPCT, donde uno de los ejes principales de actuación es la oceanografía y tecnología marina. 


\subsubsection{Objetivos.}

En cuanto al evento citado anteriormente, el objetivo principal fue determinar el área de influencia de la pluma hipersalina que fluye desde el Mar Menor, a través del canal de El Estacio, hacia el Mar Mediterráneo.

Para alcanzar este objetivo fueron necesarias dos tareas. En primer lugar, desplegar una flota de AUVs capaces de muestrear el área de estudio con una alta resolución, tanto espacial como temporal. Y en segundo lugar, obtener, validar e interpretar los datos registrados, no solo por los AUVs, sino también por el modelo en tres dimensiones del área de estudio que se ejecutó en tiempo real, y a través de una boya de registro fondeada en la zona durante la duración del experimento. La boya de registro fondeada fue la diseñada y fabricada en la presente Tesis Doctoral.

\subsubsection{Características del despliegue.}

En el capítulo 6 se definieron dos tipos de boyas, tipo ID1 y tipo ID2. Para el despliegue realizado se utilizó una boya tipo ID1, que incluía un sensor de presión oceanográfica SBE 39 de SeaBird y un sensor de presión atmosférica 61302L de YOUNG para realizar la compensación de presión. La boya oceanográfica fue fondeada en el Mar Mediterráneo, cercana al puerto de San Pedro del Pinatar, mientras que el nodo Coordinador y el PC que gestionaba la información, se ubicaron en las oficinas del Club Náutico del citado puerto. En la Figura 7.5 se muestran imágenes de los sensores que incorporaba, y la boya en el mar.

El despliegue del sistema completo, la boya y la estación base, comenzó a primera hora del día 1 de noviembre de 2011. Eran tres los requisitos que se tuvieron en cuenta: visión directa entre las antenas de emisor y receptor, una distancia adecuada entre boya sensora y nodo Coordinador para obtener una buena calidad de la comunicación, y una profundidad inferior a $7 \mathrm{~m}$, debido al sistema de fondeo realizado.

Por tanto, antes de decidir la ubicación final de la boya, se realizaron pruebas a diferentes distancias hasta obtener una ubicación óptima teniendo en cuenta las condiciones anteriores, siendo la ubicación final a $1,2 \mathrm{~km}$ de las oficinas, tal y como se muestra en la Figura 7.6. La duración del montaje del sistema completo (montaje de la boya tipo ID1, instalación de la estación base y despliegue de la boya) fue de 3 horas aproximadamente. 


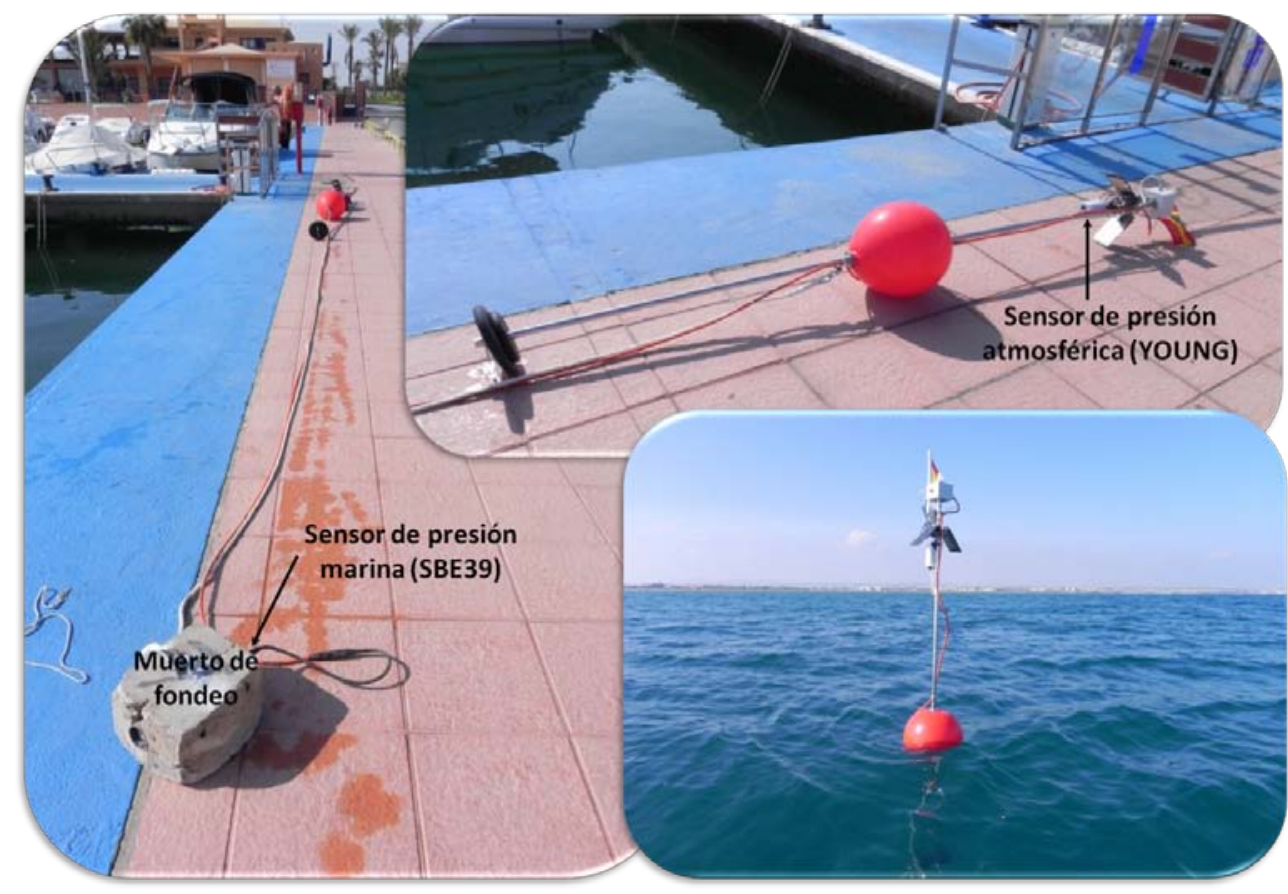

Figura 7.5 Boya sensora marina.

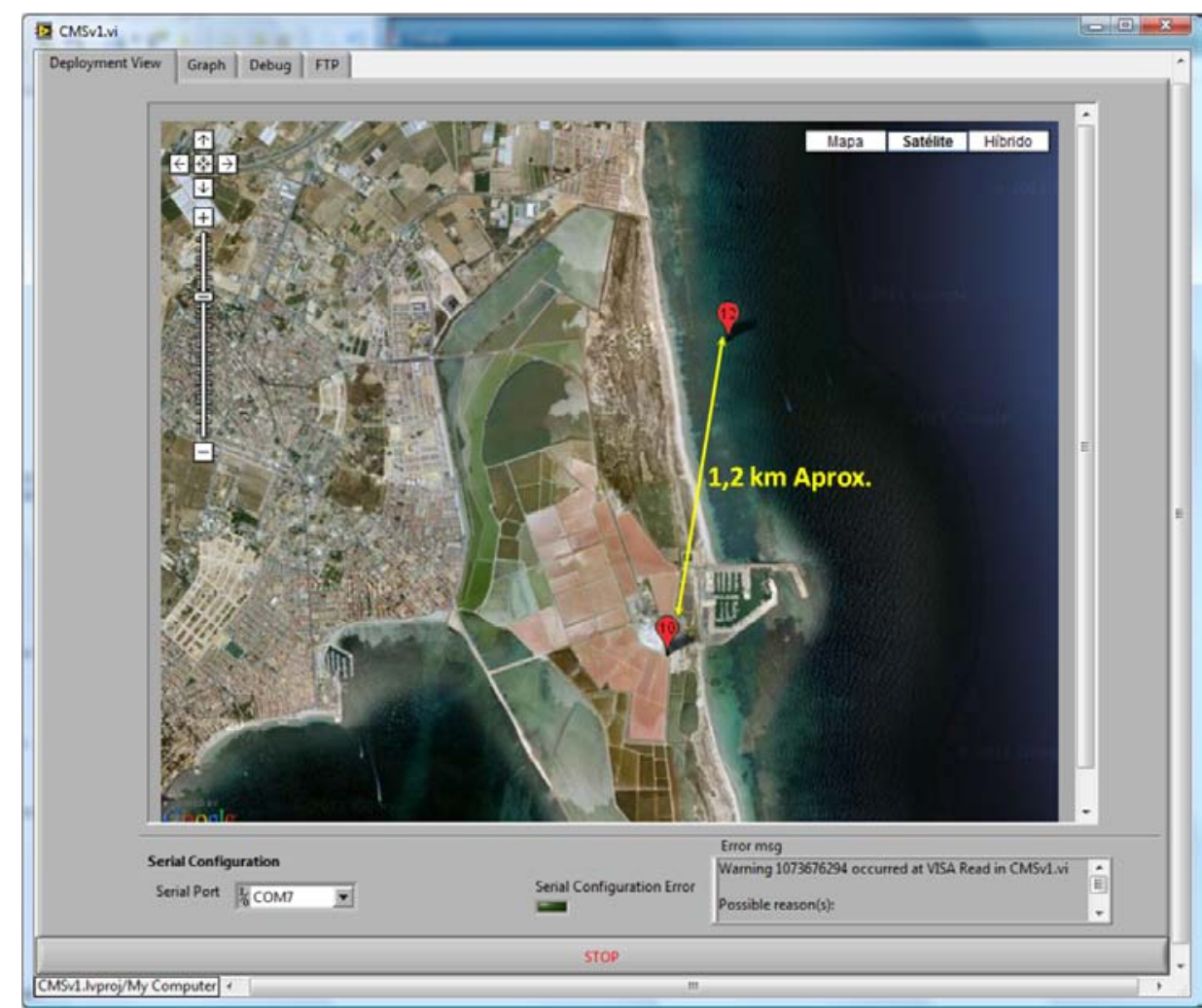

Figura 7.6 Ubicación geográfica del despliegue en San Pedro del Pinatar.

El despliegue se prolongó hasta el día 6 a las 3:16 a.m., hora en la que se dejaron de recibir datos por desaparición de la misma, como se pudo comprobar al día siguiente tras embarcarnos y rastrear las coordenadas GPS en las que se había ubicado la boya. La 
desaparición de la boya pudo deberse a varios factores. El temporal de viento de lebeche sufrido durante la madrugada del día 6 o el hurto son dos posibles hipótesis.

Los datos de presión marina y atmosférica muestreados durante los días del experimento se recogieron en la aplicación LabVIEW (ver Figura 7.7 y Figura 7.8). A su vez, ante la recepción de un dato, se realizaba el envío del mismo a un servidor de datos FTP, del cual eran leídos para su inserción en el modelo. En el siguiente apartado se presentan los resultados del modelo obtenidos a partir de los datos recogidos por la boya.

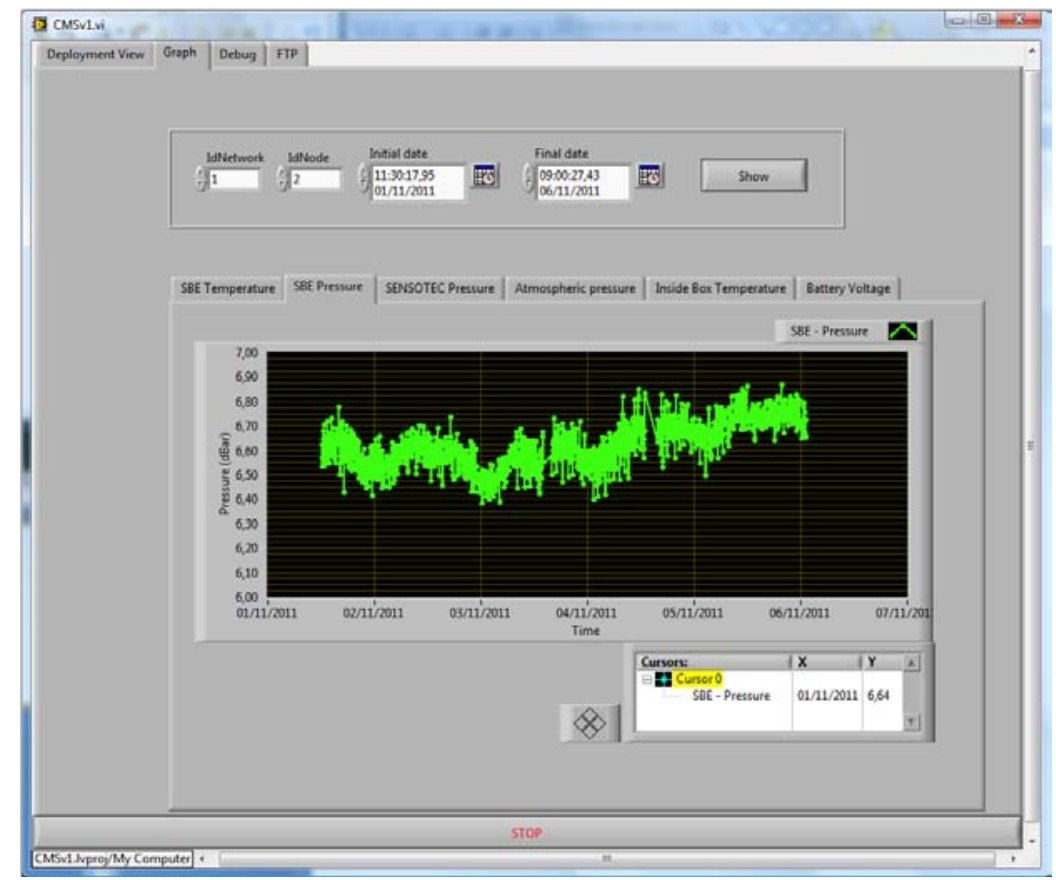

Figura 7.7 Datos de profundidad del mar de la boya en la aplicación LabVIEW.

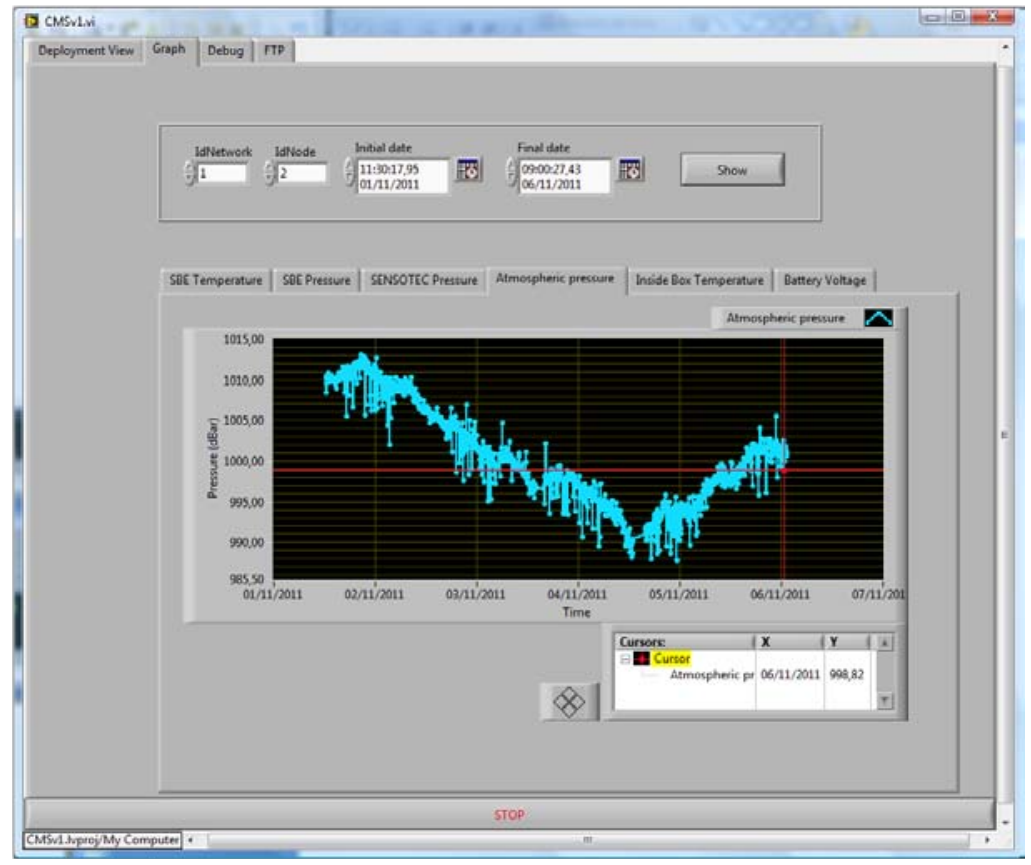

Figura 7.8 Datos de presión atmosférica de la boya en la aplicación LabVIEW. 


\subsubsection{Resultados.}

Los datos de elevación del nivel del mar recogidos por la boya se usaron como condición de contorno para el modelo hidrodinámico del Mar Menor desarrollado por el doctorando D. Francisco López. En la Figura 7.9 se puede observar el área modelizada así como la ubicación donde fue fondeada la boya, indicada con la etiqueta Sensor Buoy. Este modelo resuelve el campo de corrientes dentro de la laguna, así como el intercambio de agua entre el Mar Mediterráneo y el Mar Menor.

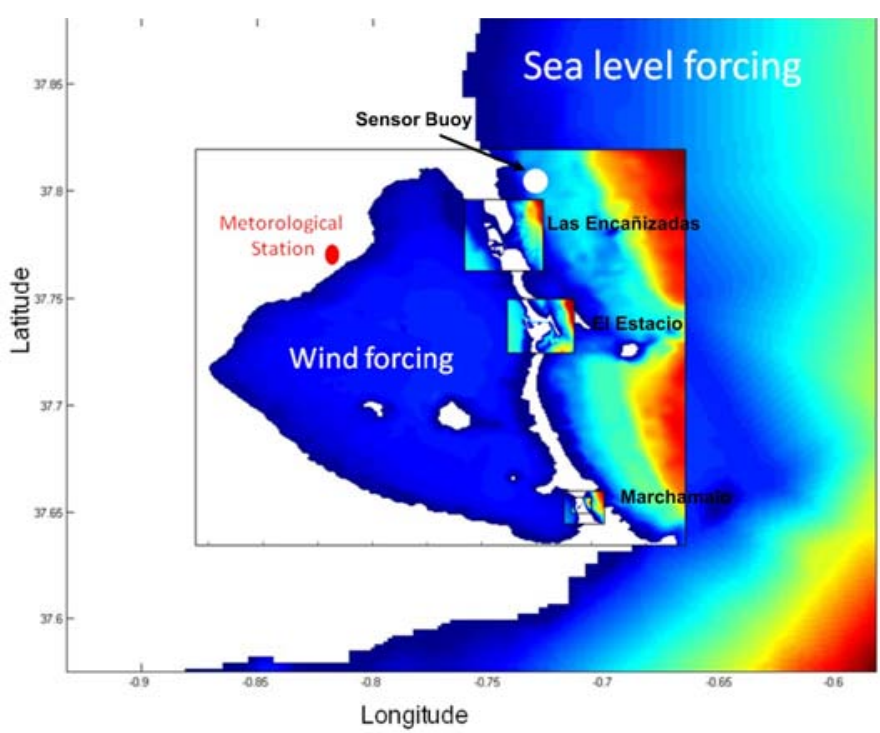

Figura 7.9 Modelado hidrodinámico del comportamiento del Mar Menor frente al Mar Mediterráneo.

Durante el experimento AUV 2011, gracias a los datos facilitados por la boya oceanográfica en tiempo real, se pudo conocer en cada momento las condiciones hidrodinámicas en el canal de El Estacio, y por tanto el comportamiento de la pluma hipersalina. En el ejemplo de la Figura 7.10 se muestra uno de los resultados obtenidos durante AUV 2011, observándose como el agua del Mar Mediterráneo entra en la laguna debido a desnivel existente entre la elevación del Mar Mediterráneo y el Mar Menor.

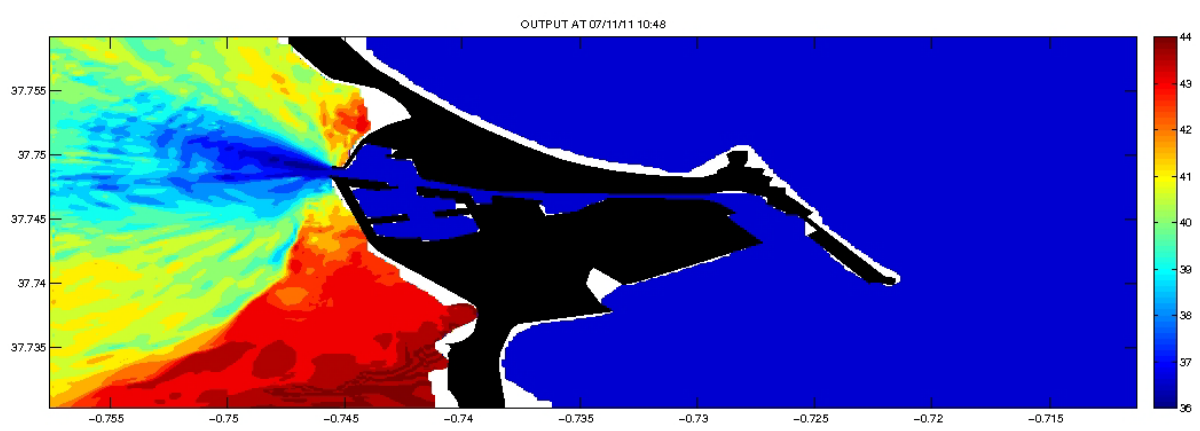

Figura 7.10 Comportamiento de la pluma hipersalina durante el experimento. 


\subsection{Planificación de un despliegue en el Mar Menor para la campaña de invierno.}

Tras realizar el despliegue temporal presentado en el apartado anterior, se ha planificado llevar a cabo un despliegue de larga duración en el Mar Menor. La zona de monitorización en este caso se centra en la cubeta sur de la laguna (ver Figura 7.11), centrando la observación en torno a la Isla del Ciervo, junto al Club Náutico Dos Mares.
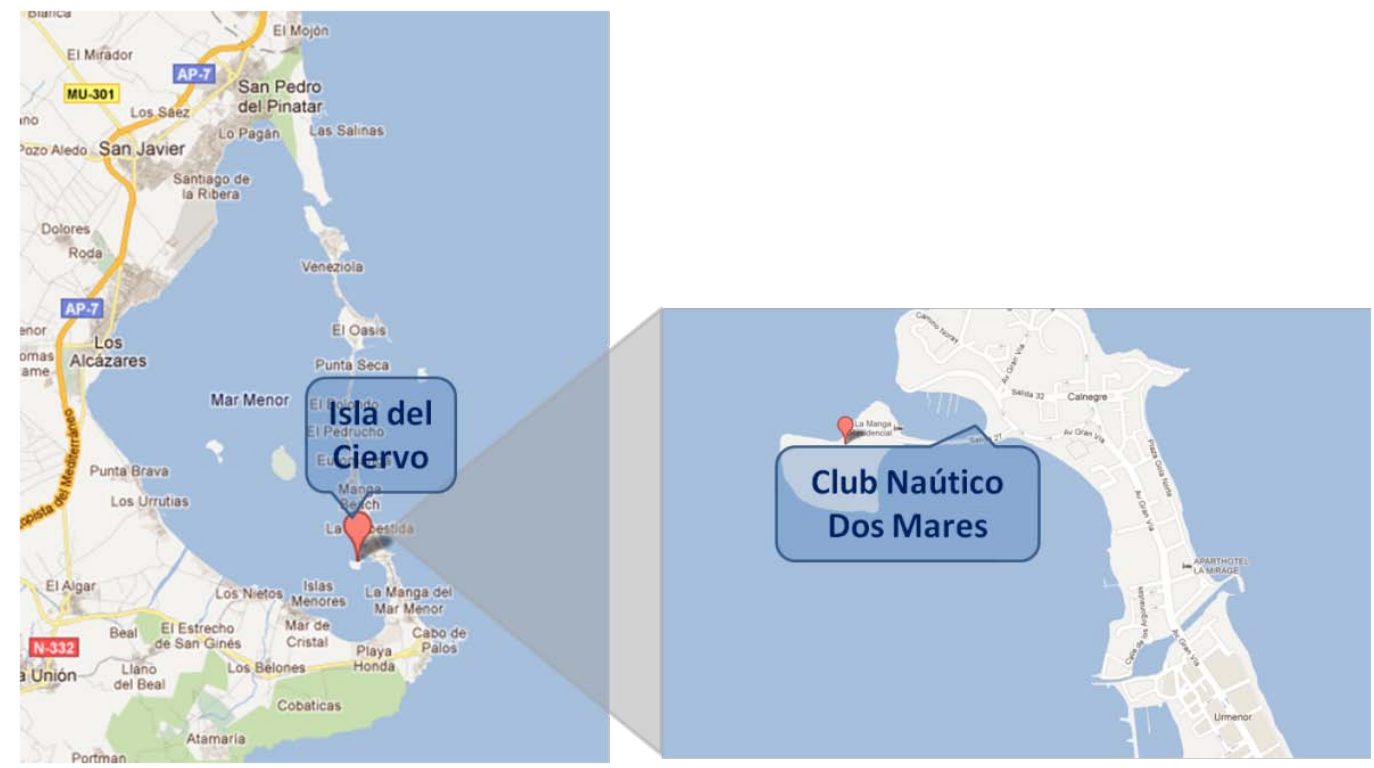

Figura 7.11 Ubicación geográfica del despliegue planificado.

El despliegue estará formado por cuatro boyas o nodos Sensores desplegados en las zonas próximas a la Isla del Ciervo, un nodo Router, y un nodo Coordinador ubicado en el Club Náutico Dos Mares. La topología implementada en este caso será en árbol, de forma que, tres de los nodos se conectarán directamente al nodo Coordinador, y el otro nodo Sensor se conectará a través de un nodo Router tal y como muestra la Figura 7.12.

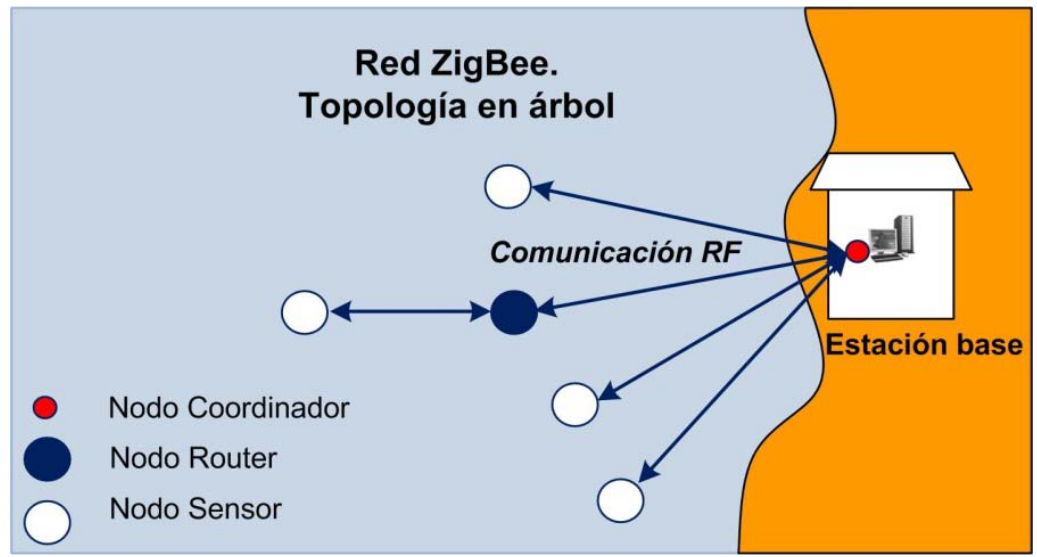

Figura 7.12 Arquitectura de una A-WSN con topología en árbol. 


\subsection{Conclusiones.}

En este capítulo, se han presentado los despliegues llevados a cabo en la Tesis Doctoral realizada bajo el proyecto CMS, en el seno del grupo de investigación DSIE. En el marco de dicho proyecto, además de la A-WSN diseñada en esta Tesis para la monitorización del Mar Menor, se han realizado trabajos sobre el desarrollo de modelos hidrodinámicos del comportamiento de la laguna frente al Mar Mediterráneo.

En primer lugar se han presentado las particularidades del Mar Menor y las ventajas de éste como medio de interés investigador. Se trata de una laguna hipersalina comunicada por el mar adyacente mediante tres canales, siendo uno de ellos, El Estacio, el que mayor intercambio de aguas presenta.

Teniendo en cuenta las zonas de interés de la laguna, se ha propuesto el despliegue de tres subredes ZigBee, y un nodo GPRS. Una red ZigBee, como se explicó en capítulos anteriores, está formada por un nodo Coordinador, nodos Sensores y, en ocasiones, nodos Routers. Para la monitorización de la laguna se han definido distintos tipos de nodos Sensores (Profundidad, Correntímetro, Completo y Rambla). En la presente Tesis se han implementado dos tipos de nodo Profundidad, tipo ID1 con el sensor de presión y temperatura SBE39 de Seabird y un sensor de presión atmosférica 61302L de YOUNG, utilizado en el despliegue para un caso real, y tipo ID2 con un sensor de presión LMK 807 de SENSOTEC, que se utilizará en el próximo despliegue planificado.

Se han presentado dos despliegues reales. Uno en el Mar Menor, en el que se verificó la operatividad del despliegue y repliegue de 10 boyas, y se comprobó la comunicación con éstas. Y otro realizado durante el evento "AUV 2011 Underwater Robotics Experiment in the Mar Menor Coastal Lagoon". En este último, se colaboró aportando datos tomados por una boya sensora con un sensor presión marina y uno de presión atmosférica. Dichos datos se tomaron como entrada a los modelos hidrodinámicos, permitiendo obtener un modelo en tiempo real del comportamiento de la zona monitorizada, en este caso el canal de El Estacio.

Con el sistema de redes inalámbricas propuesto para monitorización marina en esta Tesis se aportan ventajas respecto a los métodos tradicionales empleados. Hasta ahora, para la medición de parámetros oceanográficos se instalaba un sensor/registrador en la ubicación deseada (ver Figura 7.13), y una vez pasado el tiempo de muestreo, se volvía a la ubicación del fondeo, se recuperaba el sensor y se volcaban los datos al PC. Con el sistema diseñado e implementado en esta Tesis, los datos se obtienen para poder ser analizados en tiempo real. Además, con este sistema no se necesita el cambio de batería de los sensores, el cambio de sensores se realiza con mayor facilidad, y no sólo se pueden medir parámetros 
en el fondo del mar como con el método hasta ahora empleado, sino también en la columna de agua, en la superficie o parámetros ambientales.

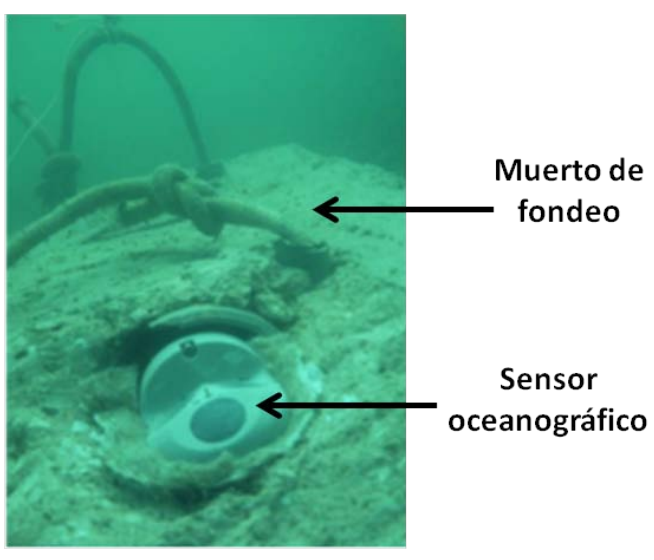

Figura 7.13 Sensor fondeado.

Para finalizar este capítulo, además de los despliegues presentados, se ha planificado un último despliegue de larga duración para la campaña de invierno. La zona de estudio se centrará en la Isla del Ciervo en el Mar Menor. Se desplegarán cuatro nodos Sensores Profundidad tipo ID2, un nodo Router y un nodo Coordinador ubicado en el Club Náutico Dos Mares.

Los trabajos desarrollados en este capítulo han sido publicados en un congreso internacional [Albaladejo et al., 2011c], un congreso nacional [Albaladejo et al., 2010c] y una revista nacional [Albaladejo et al., 2010b]. Está previsto publicar el sistema completo y los resultados de las pruebas experimentales del mismo en revistas internacionales listadas en el ISI, así como en congresos internacionales. 
Propuesta de una Red de Sensores Inalámbrica para un Sistema de Observación Costero

Esta página se deja en blanco de forma intencionada.

$-150-$ 


\section{Capítulo 8}

\section{Conclusiones, aportaciones y líneas de trabajo futuras}

$\amalg \begin{aligned} & n \text { este último capitulo, se hace una recopilación de los resultados obtenidos en cada uno de los } \\ & \text { capitulos anteriores. En primer lugar, se expondrán de forma resumida las conclusiones obtenidas }\end{aligned}$ en esta Tesis Doctoral. Le seguirá un apartado donde serán resaltadas las principales aportaciones que ofrece y los resultados concretos obtenidos durante su realización. Y para finalizar, se sugieren trabajos futuros de investigación relacionados con la materia aqui tratada. 


\subsection{Conclusiones.}

A continuación se enumeran algunas de las conclusiones más relevantes a las que se han llegado durante el desarrollo de esta Tesis Doctoral:

- En general, los SOCs están formados por componentes comunes: los nodos, que incorporan sensores oceanográficos o instrumentación marina ubicados en el mar, y una estación base en la que confluye el sistema completo. Existen observatorios tanto cableados como inalámbricos. Realizando una comparativa entre los sistemas cableados e inalámbricos, una de las principales ventajas de los primeros frente a un sistema autónomo, es el gran suministro de energía que se puede aportar al sistema junto con un mayor ancho de banda de comunicaciones. Por otro lado, los sistemas cableados conllevan un elevado coste. Es por ello por lo que surgen las A-WSNs con el objetivo de minimizar costes de infraestructura.

- Comparando el nivel de desarrollo tecnológico en los SOCs a nivel nacional e internacional, es en el ámbito internacional donde mayores infraestructuras y nuevas tecnologías se presentan. A nivel nacional, son las redes para control y observación marina las más desarrolladas tanto tecnológicamente como en cantidad de instrumentación marina que incorporan.

- La instrumentación oceanográfica empleada en los SOCs suele estar orientada a monitorizar una zona concreta del medio marino, capa superficial, columna de agua o fondo marino.

- Existen dos posibilidades inalámbricas para la monitorización del medio marino en función de las características de la zona a monitorizar, las UW-ASNs y las A-WSNs. Las UW-ASNs se utilizan únicamente cuando se requieren monitorizaciones a grandes profundidades, siendo las A-WSNs empleadas para el resto de situaciones.

- Las A-WSNs representan una alternativa importante para la monitorización de sistemas oceanográficos frente a soluciones clásicas como las utilizadas en los observatorios oceanográficos (por ejemplo boyas de aguas profundas, AUVs, gliders, y boyas lagrangianas). Los primeros, permiten una mayor resolución espacial y temporal de los parámetros monitorizados, y además, el despliegue de una red de este tipo requiere una inversión menor tanto en coste como en tiempo.

- El diseño de una A-WSN debe ser ad-hoc puesto que depende de diversos factores que la condicionan. Entre ellos, las características del medio marino, el alcance temporal del despliegue, el alcance espacial del despliegue y la resolución temporal de los datos recogidos.

- Las A-WSNs deben estar formadas por elementos lo más ligeros posible facilitando así la instalación de los mismos. El sistema de flotación del nodo debe ser robusto y 
estar formado por materiales no contaminantes y resistentes a las condiciones marinas y ambientales.

- La tecnología de comunicación inalámbrica más adecuada en un sistema basado en A-WSNs es ZigBee para la comunicación entre los nodos de la red de sensores, y GPRS cuando se requieren conexiones de mayor alcance.

\subsection{Principales aportaciones.}

A continuación se enumeran de manera resumida las principales aportaciones en esta Tesis Doctoral:

- Se ha realizado un estudio de los SOCs a nivel mundial y de las tecnologías marinas que estos incluyen, sintetizando las características de cada uno de ellos.

- Se ha realizado una revisión sistemática de la literatura de las WSNs para observación oceanográfica. Se ha ofrecido una visión global de la situación actual en dicho campo de estudio, identificándose los principales recursos que se han utilizado para implementar este tipo de redes. Además, se han detallado los retos y dificultades que hay que superar para conseguir desplegar con éxito una de estas redes.

- Se ha propuesto una arquitectura basada en A-WSNs para observación costera, se han analizado las tecnologías de comunicación inalámbrica disponibles en el mercado, y se han descrito de forma conceptual los requerimientos hardware de los distintos componentes que pueden formar una A-WSN (nodos Sensor, Router, Coordinador y/o Sumidero).

- Se ha diseñado e implementado un sistema de bajo coste y fácil despliegue basado en A-WSNs. A nivel nacional, no existen sistemas destinados a la monitorización de aguas costeras como el propuesto en la presente Tesis Doctoral. Es por ello que se considera una iniciativa de gran interés para futuras infraestructuras que se desarrollen en este ámbito en España.

- De la fabricación de los nodos ZigBee se ha obtenido un producto de diseño propio denominado MEWiN, formado por una placa multipropósito (MEWiN-Mainboard) y un placa de interfaz (MEWiN-Seaboard) para la conexión de sensores oceanográficos.

- Se han realizado numerosas aportaciones a la implementación de la pila Z-Stack de TI.

- Se ha diseñado una boya multitarea capaz de incorporar sensores para monitorizar parámetros ambientales, de la superficie del mar, de la columna de agua y del fondo marino para aguas someras. Con un conjunto de éstas se podrá implementar una AWSN. 
- Para optimizar la comunicación entre los nodos en una red ZigBee se ha presentado el diseño de un protocolo para el intercambio de mensajes. Este incluye dos tipos de tramas: una trama de presentación y una trama de datos.

- Se ha desarrollado una aplicación gráfica en LabVIEW accesible a través de Internet, para la gestión y representación de datos de una A-WSN.

- Se ha propuesto el despliegue de tres subredes ZigBee y un nodo GPRS para la monitorización completa de la laguna costera El Mar Menor.

- Se han llevados a cabo dos despliegues. Uno en el Mar Menor en el que se verificó la operatividad del despliegue y repliegue de 10 boyas con topología en estrella, y se comprobó la comunicación con éstas. Otro realizado durante el evento " AUV 2011 Underwater Robotics Experiment in the Mar Menor Coastal Lagoon", en el que se usó la boya presentada en esta Tesis Doctoral para la toma de datos con los que se obtuvo un modelo en tiempo real del comportamiento de la zona monitorizada, en este caso, el canal de El Estacio de La Manga.

\subsection{Divulgación de resultados.}

Los resultados obtenidos como parte de este trabajo, realizado en el seno del grupo de investigación DSIE de la UPCT, han sido publicados en las siguientes revistas y conferencias de ámbito nacional e internacional:

\section{Revistas internacionales listadas en el Journal Citation Reports.}

- C. Albaladejo, P. Sánchez, A, Iborra, F. Soto, J. A. López, y R. Torres, "Wireless Sensor Networks for Oceanographic Monitoring: A Systematic Review”, Sensors, vol. 10, pp. 6948-6968, 2010.

\section{Revistas nacionales.}

- C. Albaladejo Pérez, F. Soto, J.A. López Riquelme, y A. Iborra, “Arquitectura de una Red de Sensores Inalámbrica para la monitorización de la laguna costera del Mar Menor", AJICT, vol. 3, pp. 44-46 2010.

- C. Albaladejo, J.A. López, H. Navarro, y J. Rubio, "Sistema para Monitorizar Entornos Marinos basado en Redes Sensores Inalámbricas", AJICT, vol. 4, pp. 54-56, 2011. 


\section{Congresos internacionales.}

- J. Rubio, C. Albaladejo, F. Soto, H. Navarro, y A. Iborra, "Wireless Internet Link and Datalogger for Oceanographic Sensors", en Actas de Workshop MARTECH, vol. 4, pp. 33-34, 2011.

- C. Albaladejo Pérez, M. Jiménez, F. Soto, R. Torres, J.A. López, y A. Iborra, “A System for Monitoring Marine Environments based on Wireless Sensor Networks", en Actas de OCEANS IEEE Conference, pp. 1-6, 2011.

\section{Congresos nacionales.}

- C. Albaladejo, J.A. López Riquelme, F. Soto, P. Sánchez, y A. Iborra, "Plataforma de monitorización para una red de sensores en agricultura de precisión", en Actas de SAAEI, pp. 1-6, 2008.

- C. Albaladejo Pérez, F. Soto, J.A. López Riquelme, y A. Iborra, "Diseño de una red de sensores inalámbrica para un sistema de observación costero", en Actas de SAAEI, pp. 118-123, 2010.

- F. Soto Valles, P.J. Navarro Lorente, M. Jiménez, J.A. López Riquelme, C. Albaladejo, y A. Iborra, "Desarrollo de una Red Inalámbrica de Sensores para una Óptima Gestión del Riego”, en Actas de SAAEI, pp. 663-667, 2010.

- J.A. López Riquelme, F. Soto Valles, C. Albaladejo, A. Iborra, y J. Suardíaz, "GAIA 2: un mote multifuncional para agricultura de precisión", en Actas de SAAEI, pp. 124-129, 2010.

- C. Albaladejo, F. Soto, M. Jiménez, R. Torres, J.A. López, y A. Iborra, "Boya para una red de sensores oceanográfica”, en Actas de SAAEI, pp. 497-501, 2011.

- J.A. López Riquelme, F. Soto Valles, R. Torres Sánchez, C. Albaladejo Pérez, J. Suardíaz Muro, y H. Navarro Hellín, "MEWIN: un nodo sensor inalámbrico multientorno. Validación en agricultura de precisión" en Actas de SAAEI, pp. 503-508, 2011.

El trabajo realizado en esta Tesis Doctoral ha sido financiado mayoritariamente en el marco del proyecto "Monitorización Costera para el Mar Menor, CMS (ref. 463.0108_CLUSTER)" del Plan de Ciencia y Tecnología de la Región de Murcia 2007-2010. Además, se ha contado con la ayuda recibida en el marco de los proyectos CICYT EXPLORE (ref. TIN2009-08572) del Ministerio de Educación y Ciencia de España, SICORI (ref. 08754/PI/08) y MOTE-FRUT (ref. 08850/PI/08) de la Fundación Séneca de la Región de Murcia. 


\subsection{Líneas de trabajo futuras.}

Con relación a los resultados obtenidos en esta Tesis, a continuación se recogen algunas de las líneas de trabajo en las que se sigue trabajando en la actualidad, así como otras en las que resultaría de interés seguir profundizando en el futuro.

- Implementar las topologías en árbol y mallada de ZigBee.

- Continuar con el estudio de la pila de comunicaciones Z-Stack para optimizar el rendimiento de los nodos de la red.

- Realizar el despliegue de larga duración planificado para la campaña de invierno, cuya zona de estudio se centrará en la Isla del Ciervo en el Mar Menor. Se desplegarán cuatro nodos Sensores Profundidad tipo ID2, un nodo Router y un nodo Coordinador ubicado en el Club Náutico Dos Mares.

- Hacer pruebas de campo de una boya GPRS, e integrar los datos en la aplicación LabVIEW de la A-WSN diseñada.

- Desarrollar el resto de tipos de nodos Sensores definidos para ampliar la monitorización de la laguna.

- Estudiar la migración a otro tipo de tecnología inalámbrica que permita una mayor alcance de las comunicaciones. 


\section{Anexo 1}

\section{Configuración de la pila Z-Stack con los módulos CC2520 - CC2591EM}

工 a pila Z-Stack de Texas Instruments utilizada para la implementación de la red de sensores función de las necesidades de alcance requeridas por el sistema. En este primer anexo, se presentan las modificaciones realizadas, según las pruebas de cobertura realizadas con los módulos de radio CC2520 y el range extender CC2591, para obtener una mayor cobertura de la red de sensores, penalizando, en consecuencia, la calidad del enlace de comunicaciones entre dos nodos. 


\section{A1.1 Configuración de Z-Stack-MSP2618-2.3.0-1.4.0.}

A continuación se detallan las modificaciones realizadas en el código:

1) Para el uso conjunto del módulo de radio CC2520 y el amplificador CC2591, basta con definir en las opciones del proyecto realizado con el entorno IAR la macro HAL_PA_LNA. Con esta directiva se ejecutarán las porciones de código adecuadas para el funcionamiento de ambos módulos de radio.

2) La calidad del enlace de comunicaciones entre dos nodos puede ser de mayor o menor calidad según se seleccione en la variable gMIN_TREE_LINK_COST del archivo ../Components/stack/nwk/nwk_globals.c. La pila usa este umbral para determinar el menor valor de LQI (Link Quality Indicator) posible usado en el intercambio de mensajes. Las diferentes opciones que incluye Z-Stack se muestran en el archivo ../Components/zmac/f8w/zmac_internal.h y son las siguientes:

\begin{tabular}{|lll|}
\hline // LQI to COst mapping & \\
\#define MIN_LQI_COST_1 & 12 & $/ / 24$ \\
\#define MIN_LQI_COST_2 & 9 & $/ / 20$ \\
\#define MIN_LQI_COST_3 & 6 & $/ / 16$ \\
\#define MIN_LQI_COST_4 & 4 & $/ / 12$ \\
\#define MIN_LQI_COST_5 & 2 & $/ / 8$ \\
\#define MIN_LQI_COST_6 & 1 & $/ / 4$ \\
\#define MIN_LQI_COST_7 & 0 & $/ / 0$ \\
\hline
\end{tabular}

Este umbral por defecto está fijado a 6. Para las pruebas de cobertura realizadas en el Mar Menor se escogió el valor de 0, asociado a MIN_LQI_COST_7, con el que se obtiene un mayor alcance.

// Minimum lqi value that is required for association

uint8 gMIN_TREE_LINK_COST $=$ MIN_LQI_COST_7;

3) Otros parámetros modificados son los siguientes:

Con la macro MAC_RADIO_RECEIVER_SENSITIVITY_DBM se aumenta la sensibilidad del receptor, mientras que con MAC_RADIO_RECEIVER_ SATURATION_DBM se asegura que todos los dispositivos reciban dentro del rango LQI, y que el LQI no se detenga antes del máximo alcance. Estas variables pueden ser encontradas en el archivo ../MAC/Low Level/Dual Chip/ mac_radio_defs.h 
Anexo 1. Configuración de la pila Z-Stack

\#define MAC_RADIO_RECEIVER_SATURATION_DBM $\quad-4 \quad / /$ Inicial 10

Además, se ha modificado el valor de MAC_SPEC_ED_MIN_DBM_ABOVE_RECEIVER_SENSITIVITY para obtener mejores resultados. Esta variable se define en el archivo../MAC/High Level/mac_spec.h:

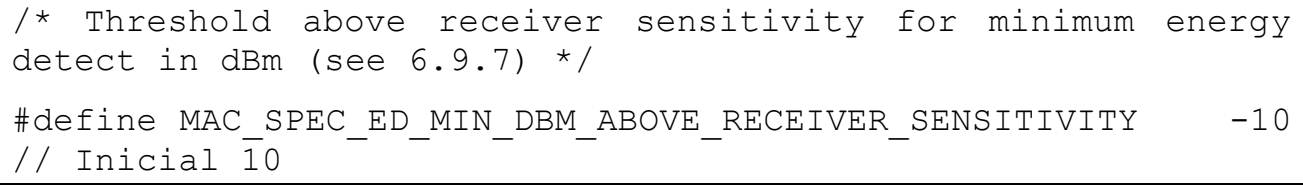

4) La potencia con la que transmite un mote puede ser configurada de la siguiente forma:

En la función MAC_INTERNAL_API void macRadioUpdateTxPower (void) del archivo ../MAC/LowLevel/Common/mac_radio.c, se utiliza la función MAC_RADIO_SET_TX_POWER $(0 \times F 9)$ pasándole como argumento la potencia deseada. Las potencias recomendables para los módulos de radio empleados se muestran en la Tabla A1.1 (ver más detalles en "Application Note AN065 - Page 5 of 8. $\left.T T^{\prime \prime}\right)$.

Tabla A1.1 Tabla de potencias de transmisión de un nodo.

\begin{tabular}{ccc}
\hline TXPOWER & Power $[\mathrm{dBm}]$ & Current $[\mathrm{mA}]$ \\
\hline 0xF9 & 17 & 136 \\
\hline 0xf0 & 16 & 121 \\
\hline 0xA0 & 14 & 102 \\
\hline 0x2C & 11 & 78 \\
\hline 0x03 & -1 & 57 \\
\hline 0x01 & -8 & 55 \\
\hline
\end{tabular}

Según se ha configurado la potencia, hay que tener en cuenta que la macro HAL_MAC_USE_REGISTER_POWER_VALUES no esté definida. Por tanto, en el archivo mac_radio_defs.h se debe modificar de la siguiente forma: 
Propuesta de una Red de Sensores Inalámbrica para un Sistema de Observación Costero

Esta página se deja en blanco de forma intencionada. 
Anexo 2

\section{Modificaciones realizadas en la pila Z- Stack de ZigBee}

\footnotetext{
$\square$ n la implementación del estándar de ZigBee realizada por Texas Instruments se han encontrado 1 dificultades en el proceso de formación de una red. En el presente anexo se describen las
} modificaciones realizadas en la pila Z-Stack y los algoritmos implementados con el fin de solventar dichos problemas. 


\section{A2.1 Gestión de pérdidas de conexión de los ZED con el nodo padre.}

A continuación se detallan las modificaciones realizadas en el código:

\section{1) Modificaciones a nivel de aplicación.}

En la función SampleApp_Init() del archivo de la aplicación, en este caso SampleApp.c, hay que añadir, antes de que se realice la llamada a ZDOInitDevice (0), lo siguiente:

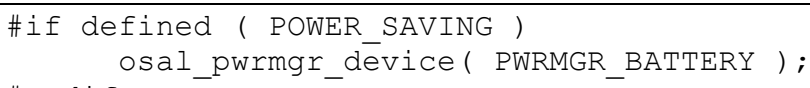

Además incluir el archivo:

\#include "OSAL_PwrMgr.h"

Con los cambios indicados, la función de inicialización quedaría con la siguiente estructura:

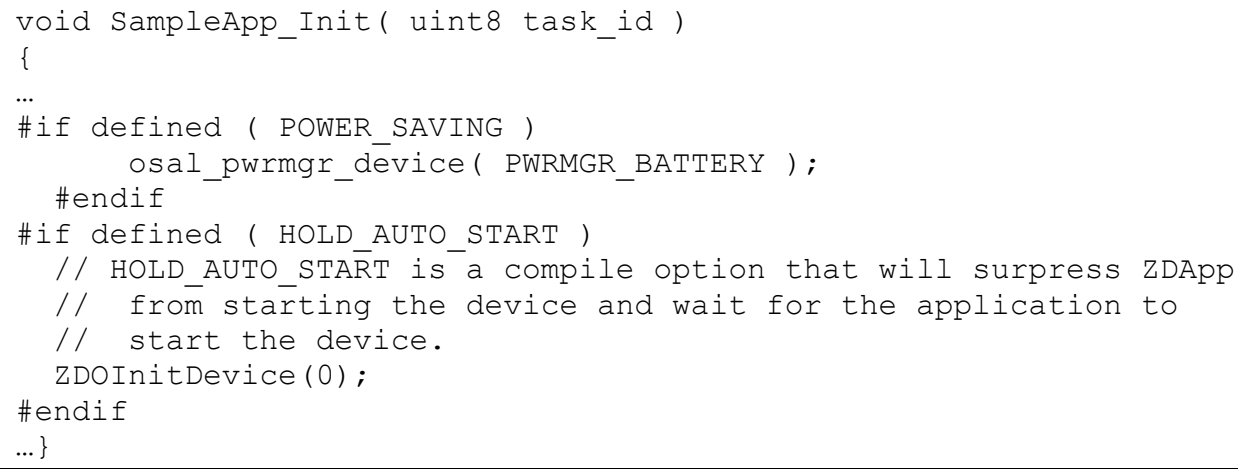

La llamada a esta función se establece aquí porque, tal y como está implementada la pila ZigBee de TI, sólo se entra en modo de bajo consumo a partir de que se haya realizado una conexión con el Coordinador. De esta forma se puede entrar en modo bajo consumo aunque no esté establecida la conexión con dicho Coordinador.

2) Modificaciones en el los archivos ZDApp.c y ZDApp.h ubicados en ../Components/stack/zdo.

a. Reconexión con el ZC cuando se enciende por primera vez el ZED.

La primera vez que se ejecuta el ZED, se intentará conectar con el Coordinador. Se producirá el evento ZDO_NETWORK_INIT dentro de la función uint16 
ZDApp_event_loop( uint8 task_id, uint16 events ) que se ejecutará indefinidamente hasta que el ZED consiga asociarse.

Para evitarlo se ha añadido el siguiente código:

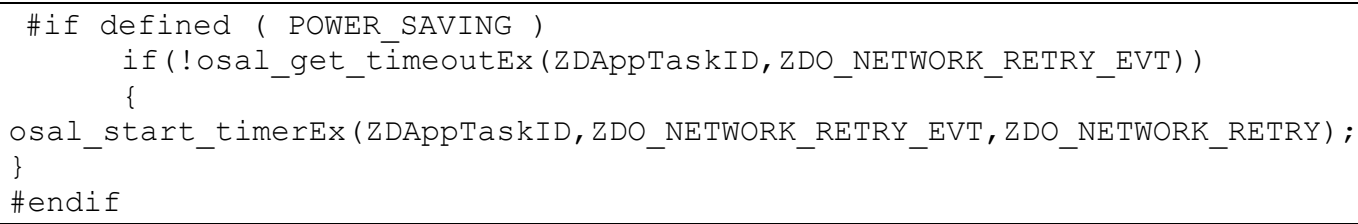

El condicional hace que se lance un timer sólo la primera vez que se produce el evento, el timer vencerá cuando pase ZDO_NETWORK_RETRY definido en ZDApp.h (valor programado de $15 \mathrm{~s}$ ).

Cuando pasen los 15 s, vencerá el timer y se ejecutará el evento ZDO_NETWORK_RETRY_EVT:

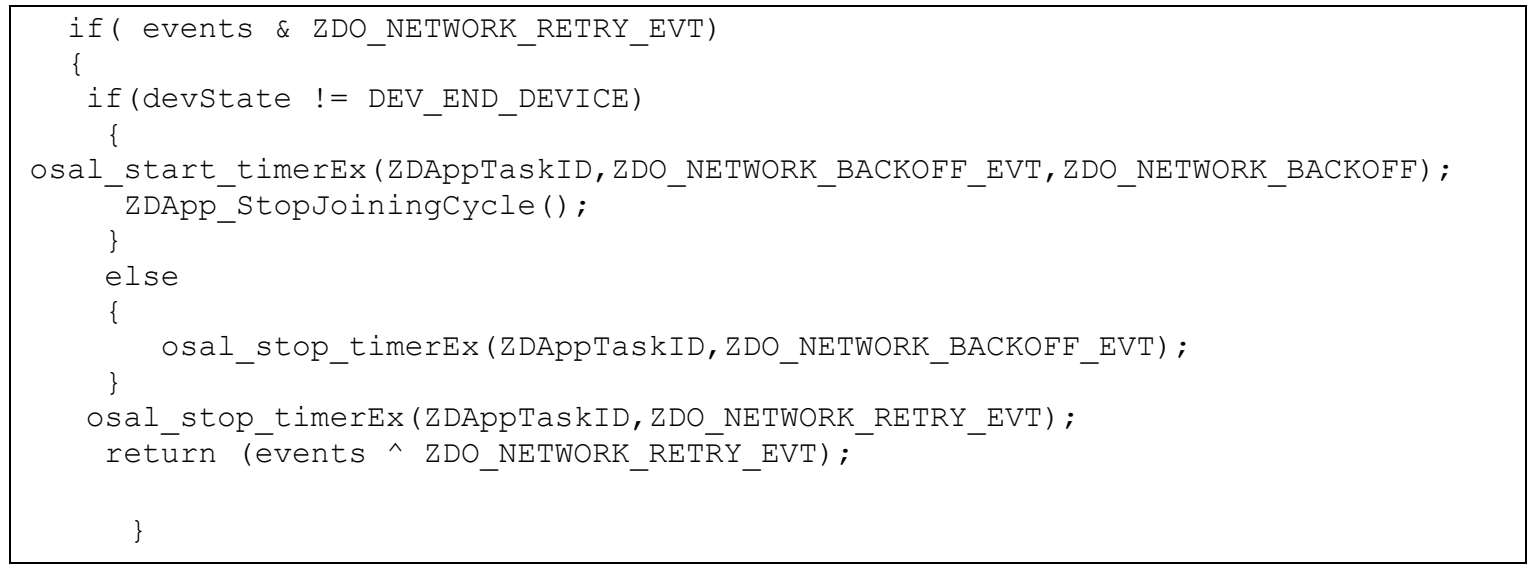

En este código, se comprueba si cuando vence el timer, el dispositivo ha conseguido conectarse correctamente (devState $==$ DEV_END_DEVICE), en caso contrario se para el proceso de conexión con el Coordinador (ZDApp_StopJoiningCycle ()) y se lanza un timer que se fija al valor de $60 \mathrm{~s}$ ( no puede ser mayor de $65 \mathrm{~s}$, definido en ZDApp.h).

Cuando expira el timer se produce el evento ZDO_NETWORK_BACKOFF_EVT:

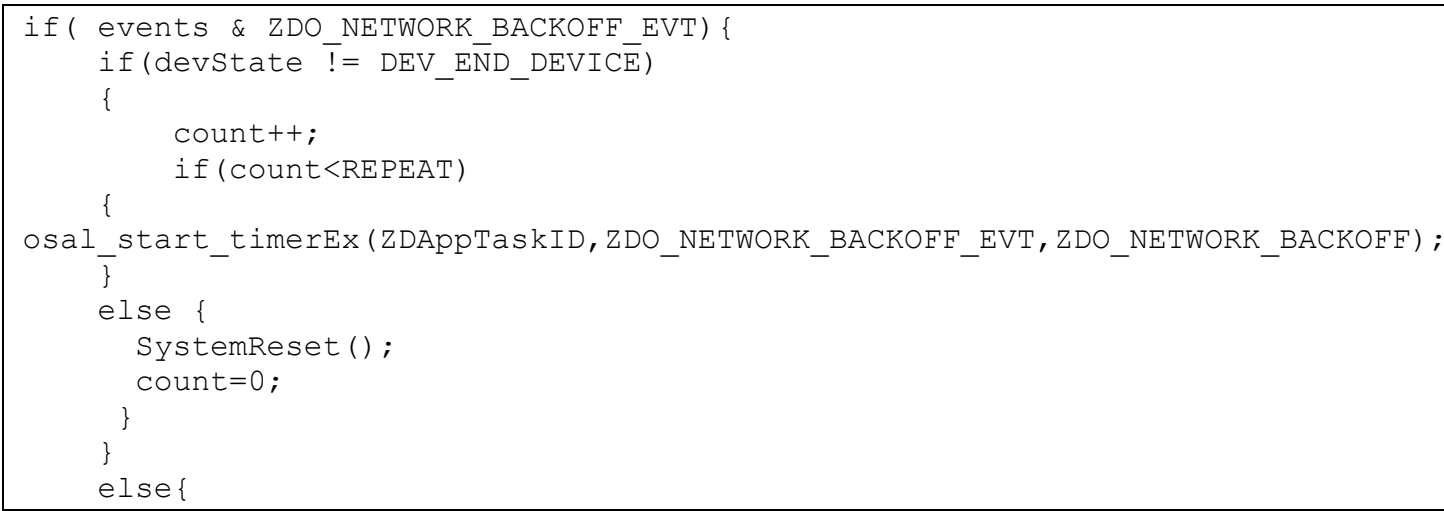




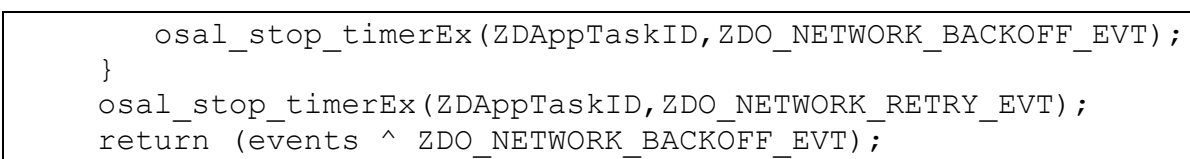

Si no está conectado al ZC ( if(devstate $!=$ DEV_END_DEVICE) ), se incrementa la variable count hasta que llegue al valor que se haya definido en REPEAT (por defecto 5 , obteniéndose 5 min entre intentos de reconexiones), lanzando de nuevo el timer de backoff. Cuando se hayan cumplido las 5 repeticiones, se resetea el sistema (SystemReset ()) y se intentará conectar de nuevo al Coordinador.

A partir de este momento el proceso comenzará desde el principio.

\section{b. Reconexión con el Coordinador cuando se pierde la conexión con éste.}

En este segundo caso el funcionamiento es el mismo, sólo cambia el evento inicial.

Cuando un ZED pierde la conexión con su nodo padre se ejecuta la función ZDO_SyncIndicationCB( uint8 type, uint16 shortAddr).

Por tanto, sólo hace falta añadir el siguiente código:

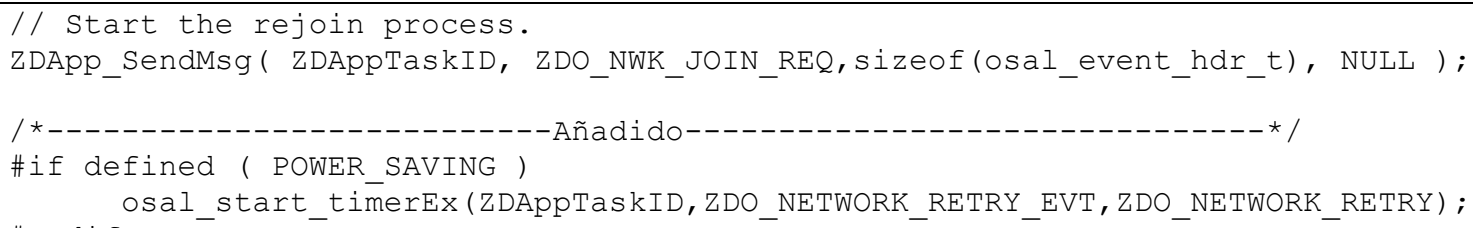

Una vez que se intenta reconectar al Coordinador, se lanza el timer que expirará en ZDO_NETWORK_RETRY (fijado por defecto en $15 \mathrm{~s}$ ). El resto del proceso es el mismo que para el caso a.

\section{A2.2 RTC (Real-Time Clock).}

En este apartado se detallan las modificaciones incluidas en la pila ZigBee para la utilización de un RTC.

En el archivo hal_mac_cfg.h se ha añadido la siguiente opción:

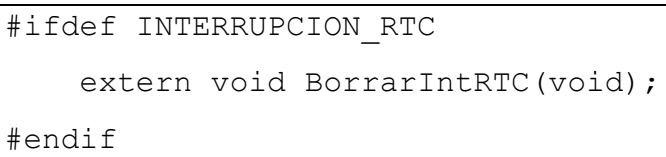

En el archivo hal_mac_cfg.c el código añadido es el siguiente: 


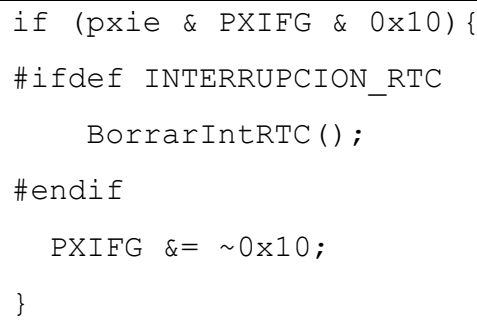

Para gestionar el RTC a nivel de aplicación se han implementación las siguientes funciones:

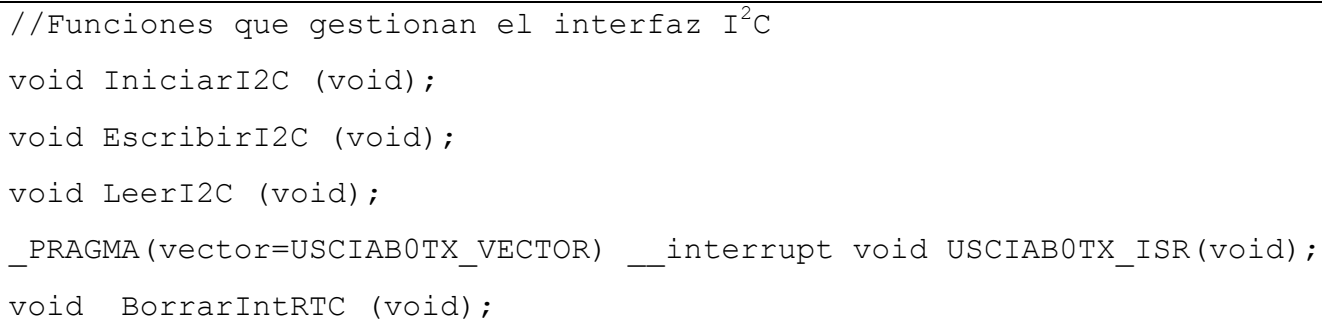

Con IniciarI2C() se inicializan los pines del micro correspondientes al interfaz I2C.

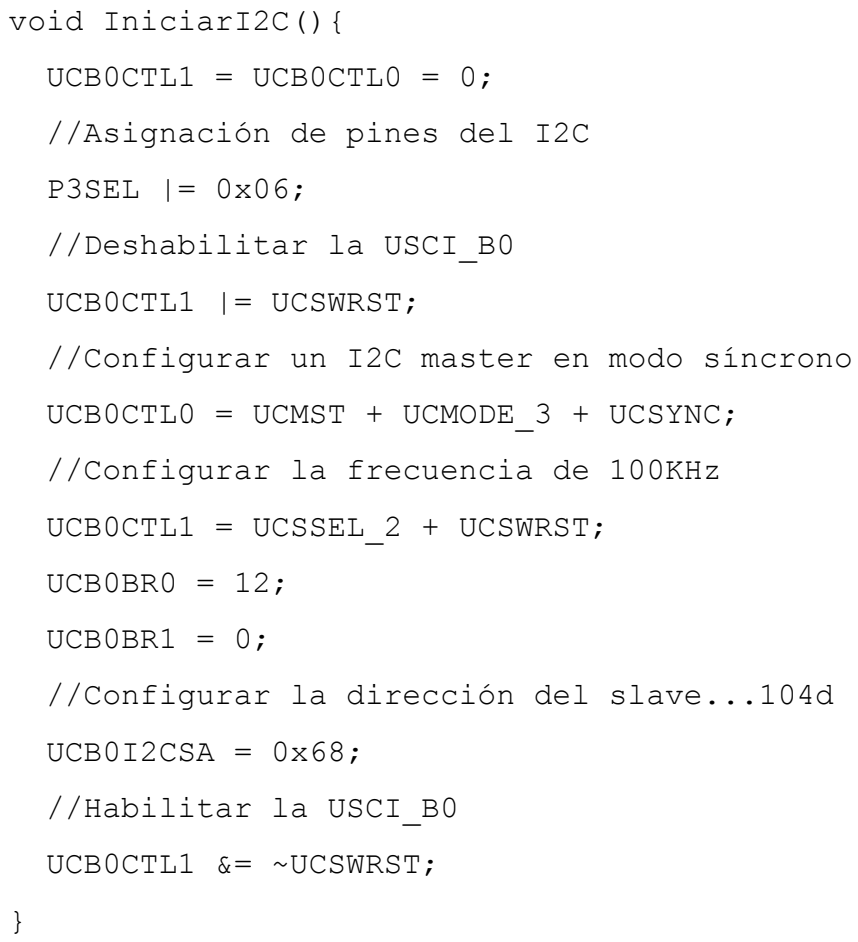

Para poner en hora el RTC se escriben los registros correspondientes en la función Escribirl2C(). Además, se pueden configurar las alarmas activando los bits adecuados de los registros A1M y AM2 (ver página 11 de [RTC MAXIM]).

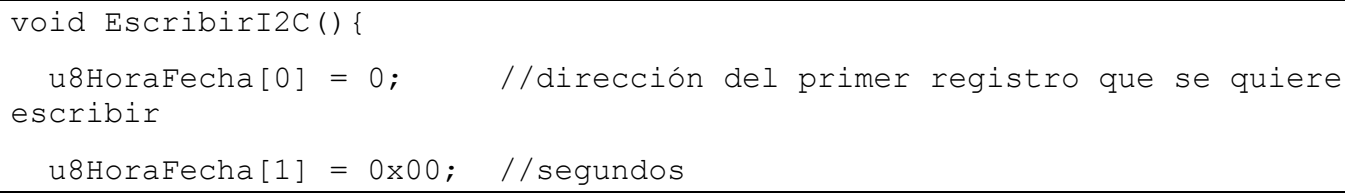




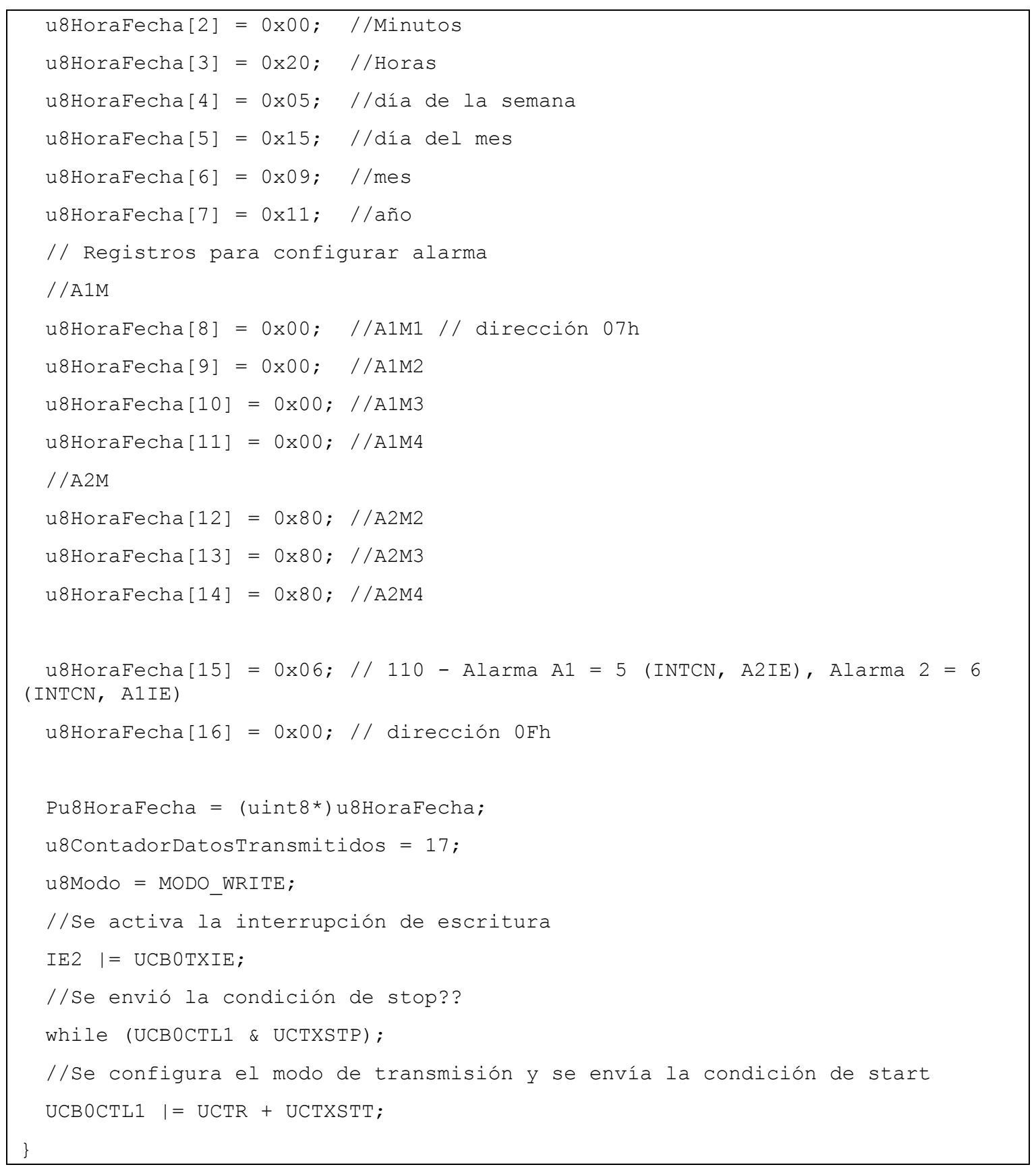

Cuando está disponible la hora o se cumple una alarma previamente programada, se produce una interrupción del RTC. Ante una lectura, el resultado se almacena en u8RxBuffer.

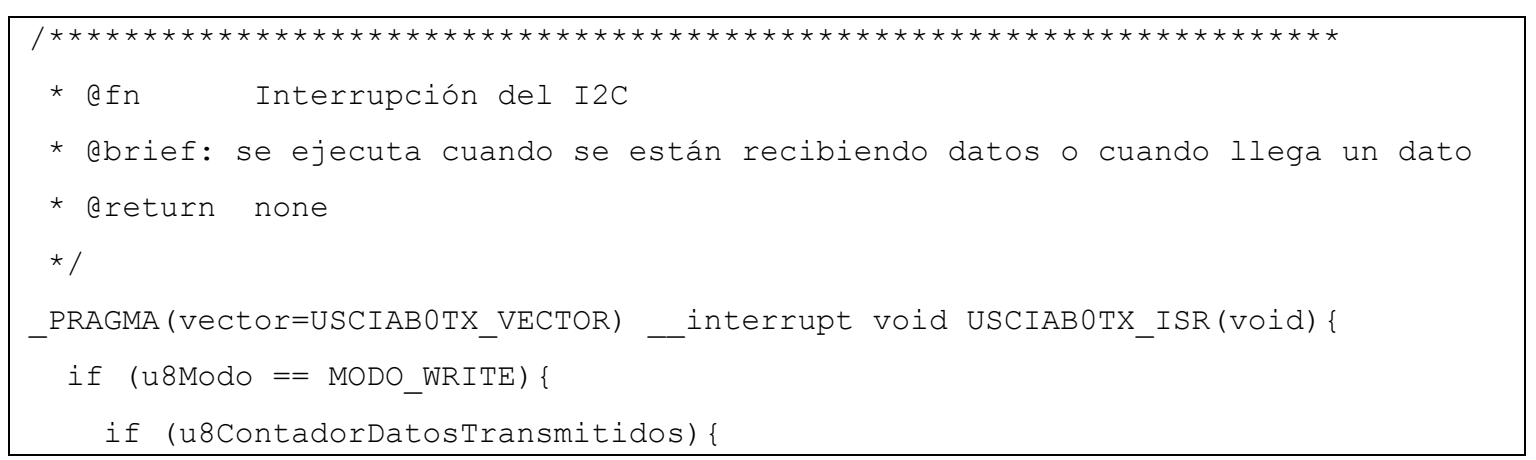




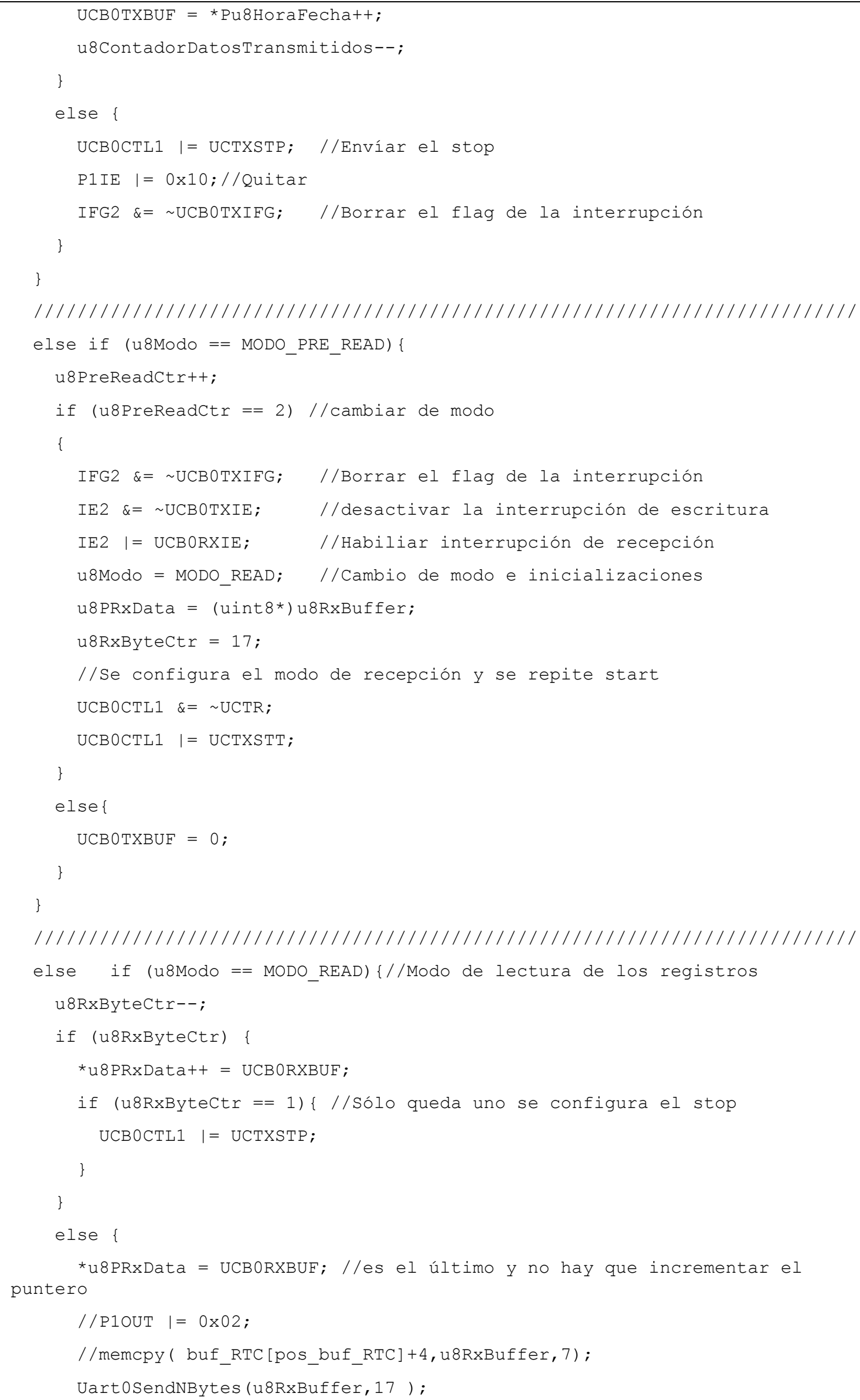


\}

\section{A2.3 Almacenamiento de información en formato FAT.}

Para la gestión de la información de la microSD en formato FAT han sido necesarias añadir el siguiente conjunto de librerías al proyecto de la aplicación:

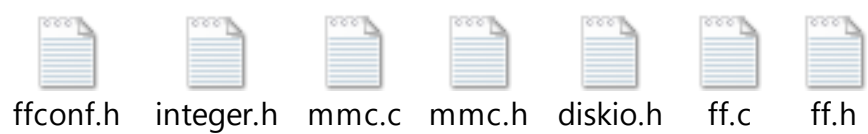

Éstas son utilizadas a nivel de aplicación. A continuación se muestra el ejemplo de una función que almacena el contenido de bufferSD, de tamaño BUFFer en el archivo F.

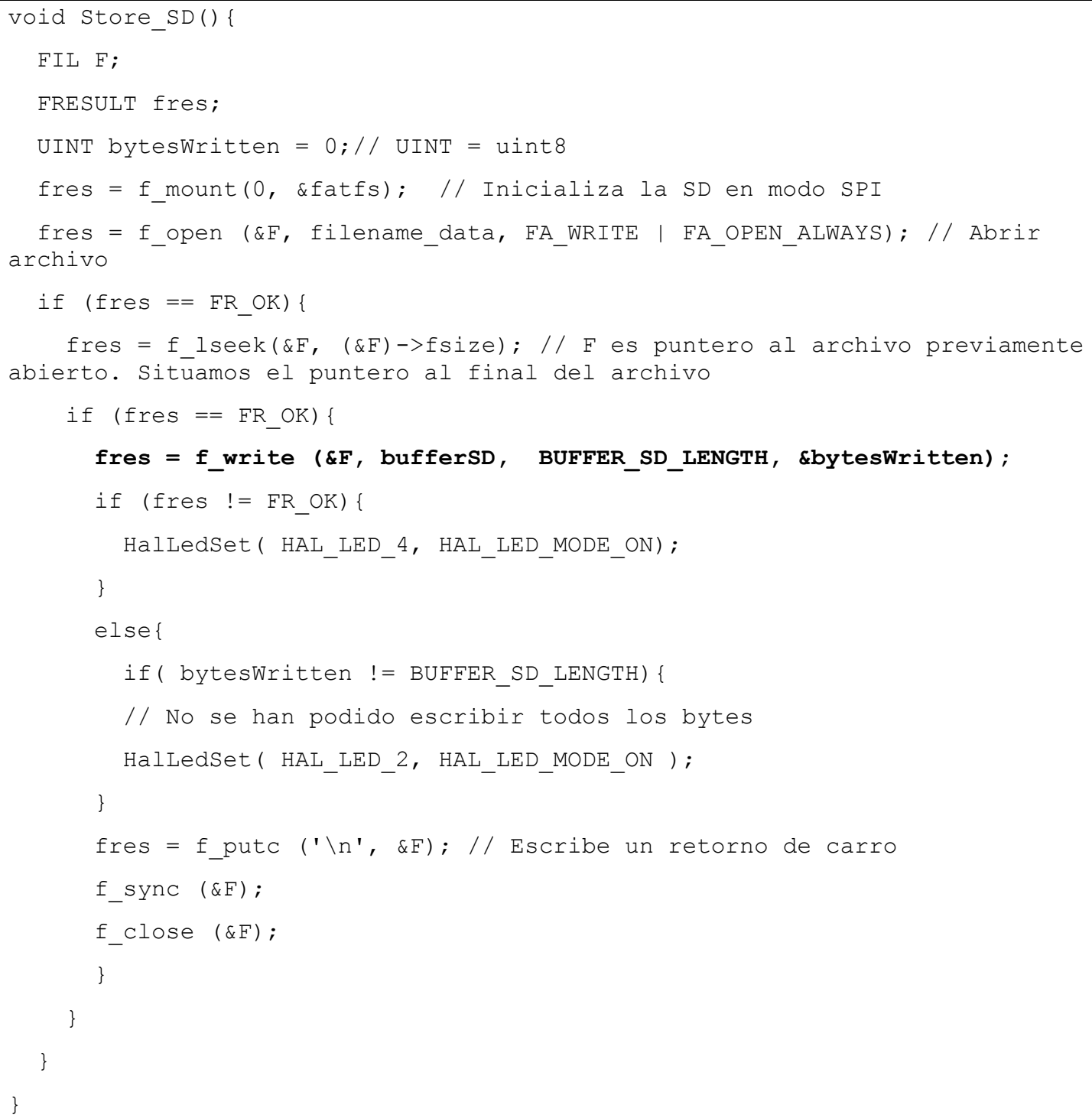


Anexo 3

\section{Diagramas de bloques LabVIEW de la interfaz gráfica del sistema de monitorización}

\footnotetext{
T a aplicación de usuario del sistema de monitorización se ha desarrollado en la plataforma LabVIEW por la sencillez de programación gráfica y por su potencia para crear interfaces. En el capitulo 6, se han presentado las diferentes partes de la interfaz, gráfica implementada y, en el presente anexo, se incluyen los diagramas de bloques diseñados. Para una mayor compresión de la misma, se ha implementado un VI principal que contiene diferentes subVIs.
} 


\section{A3.1 Panel frontal.}

En este apartado se detallan los diagramas de bloques del panel frontal de la interfaz gráfica presentada en el capítulo 6 .

En la Figura A3.1 se muestra el núcleo principal de la aplicación. Se realiza la configuración del puerto RS232 al que estará conectado el nodo Sumidero de la red de sensores (115.200 bps, 8 bits de datos, sin paridad, 1 bit de stop) y se mantiene a la espera de recibir mensajes. Una vez que recibe un mensaje (identificado por los caracteres de inicio ':' y fin 'CR (Carriage Return)'), se pasa al procesamiento del mismo mediante el subVI Debug. Tras procesarlo, se almacena en un archivo de texto, se envía a un servidor FTP, se muestra en la pestaña Debug', y se actualiza la información necesaria para presentar la última muestra recogida por el nodo procedente del mensaje en GoogleMaps, en la vista de despliegue de la aplicación.

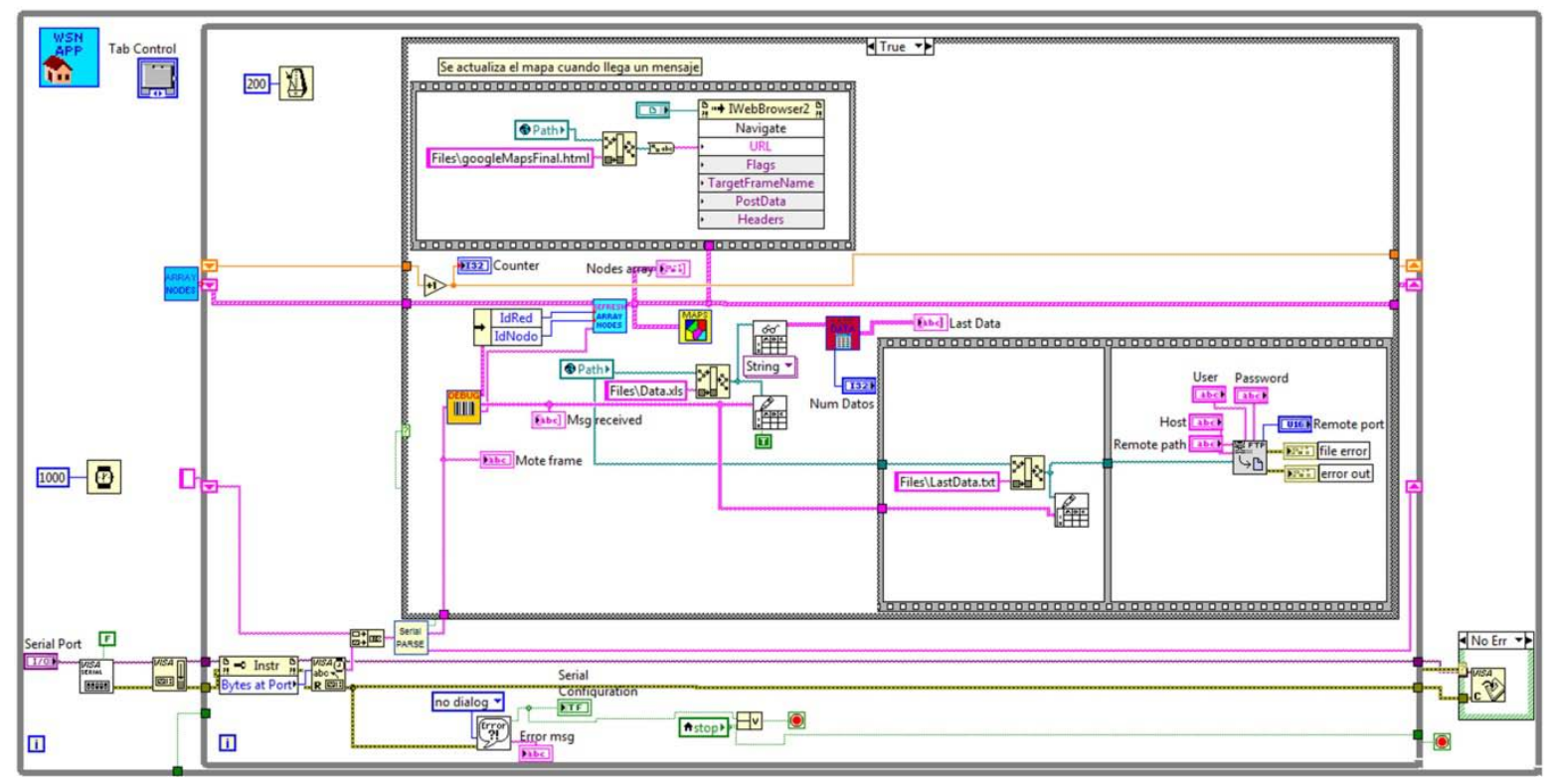

Figura A3.1 VI panel frontal 1.

La Figura A3.2 muestra el procesamiento necesario para la representación gráfica de los datos. Se obtienen los datos introducidos por el usuario (id nodo, id red, intervalo de fechas de la representación), mediante el subVI Graph se obtienen los datos que cumplen las condiciones especificadas, si los hay, y se representan gráficamente de forma individual. 


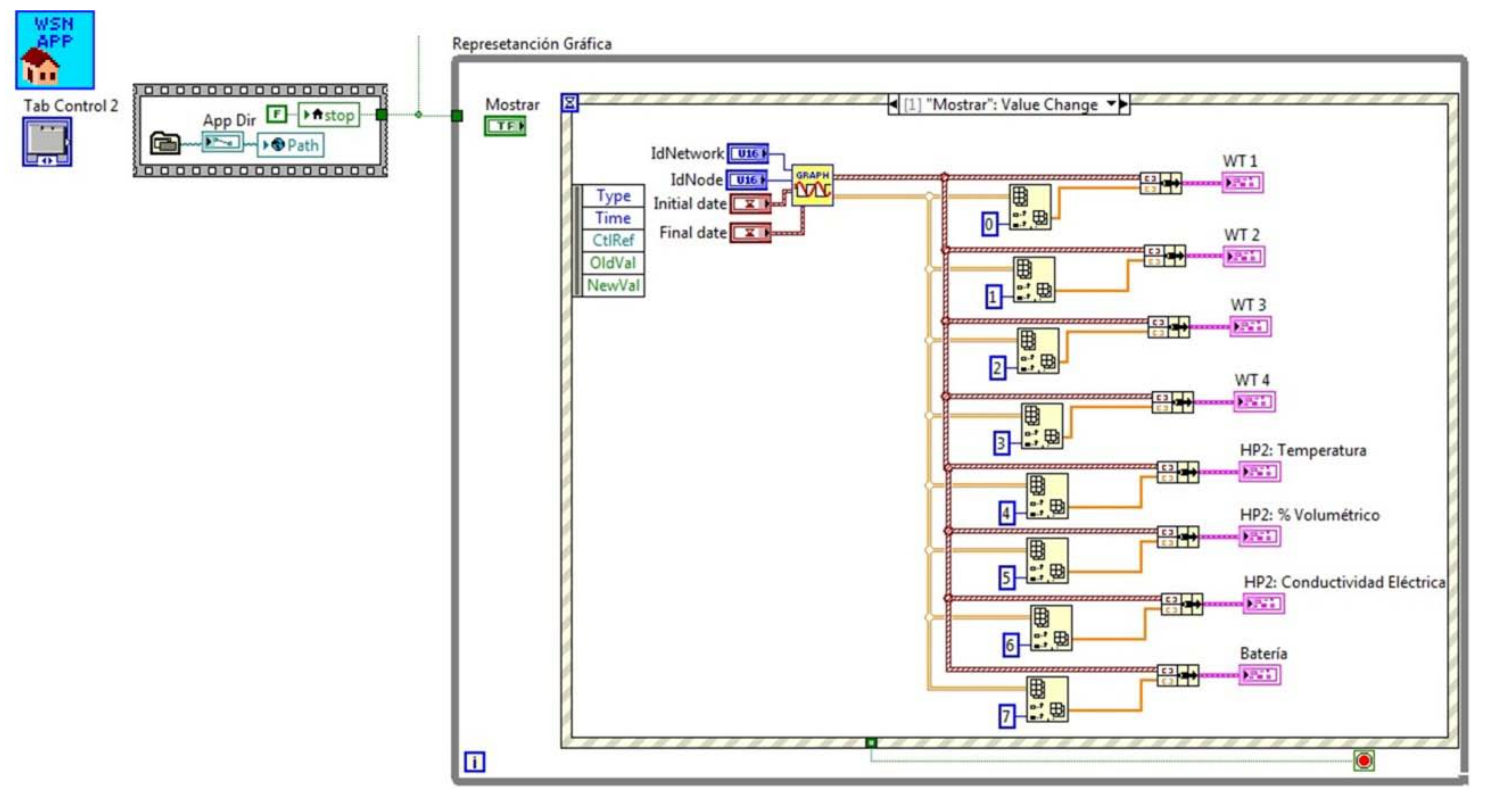

Figura A3.2VI panel frontal 2.

\section{A3.2 SubVIs.}

En este apartado se presentan los subVIs que se han considerado más relevantes para la comprensión del desarrollo de la aplicación presentada. En la Tabla A3.1 se especifican las entradas y salidas que incluyen cada uno de ellos.

Tabla A3.1 Entradas y salidas de los subVIs.

\begin{tabular}{c|cc}
\hline \multirow{2}{*}{ SubVI } & Entradas & Salidas \\
\hline \multirow{2}{*}{ Debug } & Mensaje & Cluster con los datos \\
\cline { 2 - 3 } & & Datos en formato Excel \\
\hline \multirow{2}{*}{ Map } & Datos en formato texto \\
\hline \multirow{2}{*}{ Msg_Type_1 } & Mensaje & Tipo de mensaje \\
\cline { 2 - 3 } & & Cluster con los datos \\
\hline TextNodeMaps & Cluster con los datos & Datos en formato texto \\
\hline \multirow{2}{*}{ Graph } & Id red & Datos en formato Excel \\
\hline & Id nodo & Array fechas \\
\hline & Fecha inicial & \\
\hline
\end{tabular}




\section{A3.2.1 Debug.}

El subVI Debug mostrado en la Figura A3.3 identifica, en primer lugar, el tipo de trama que recibe. Una vez identificada (en este ejemplo se trata de una trama de datos), la procesa y extrae la información necesaria para el siguiente paso.

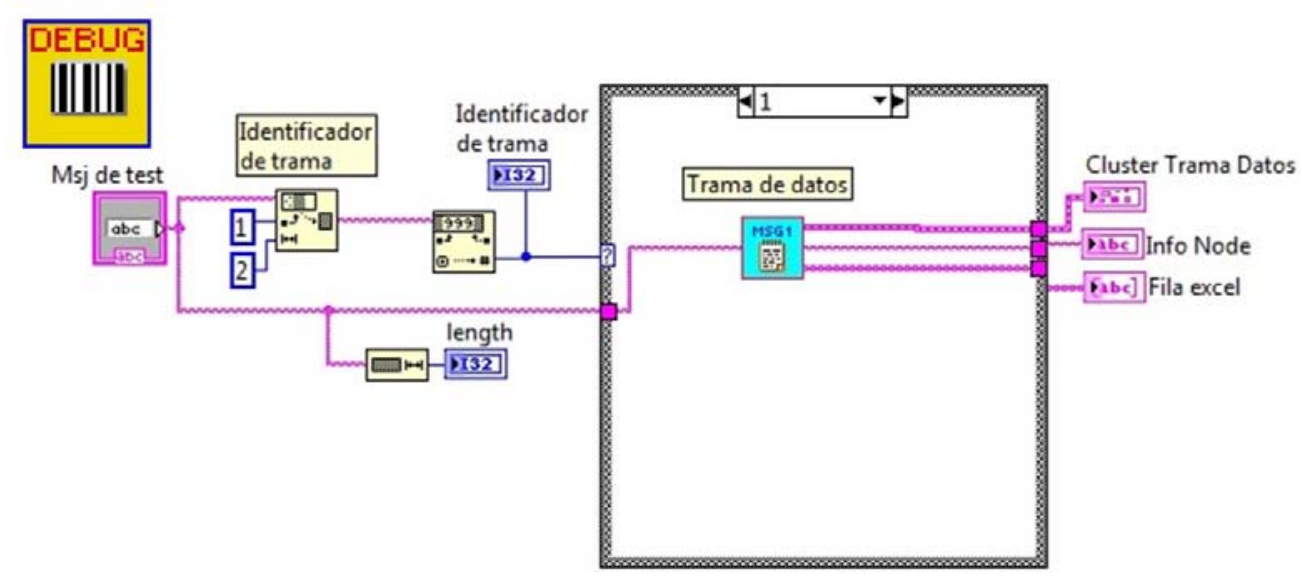

Figura A3.3 SubVI Debug.

Recordar que, en el diseño planteado en el apartado 6.5 del capítulo 6, se contemplan dos tipos de tramas. A modo de ejemplo, únicamente se muestra el diagrama para la trama de datos. Para la trama de presentación el diagrama es análogo sólo que el caso de la estructura case es el ' 0 ', y el subVI que éste incluiría es el que procesa la trama de presentación.

\section{A3.2.2 Map.}

En el subVI Map (ver Figura A3.4) se recopila la información necesaria para representar en un mapa, mediante GoogleMaps, los nodos que forman el despliegue junto con el último dato muestreado por cada nodo. El código que genera este subVI, código html y javascript, se escribe en el fichero googleMapsFinal.html como se muestra en el diagrama de bloques. 


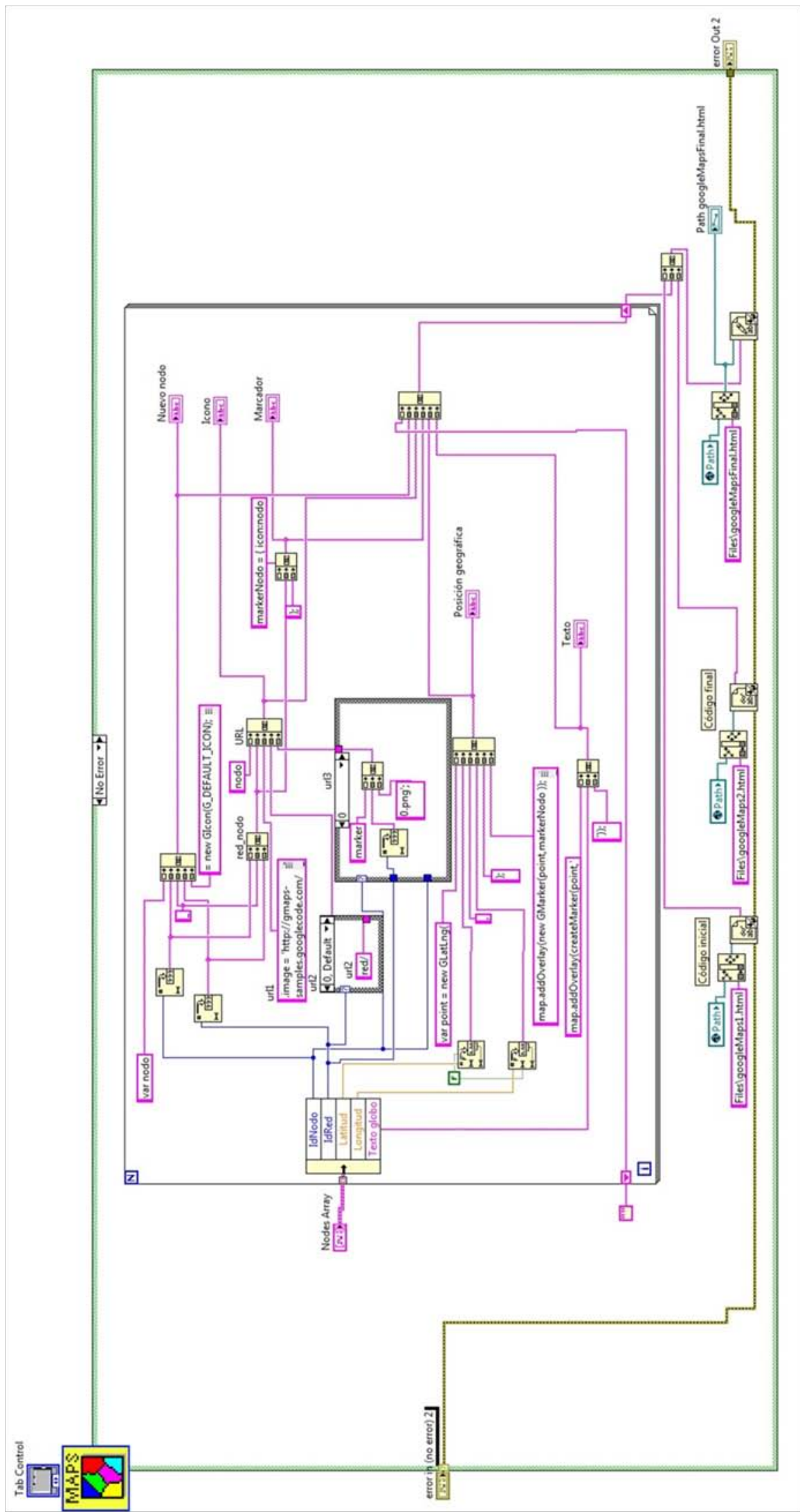

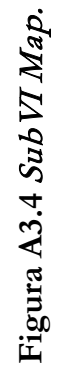




\section{A3.2.3 Msg Type 1.}

En el subVI Msg_type_1, cuyo diagrama de bloques se muestra en la Figura A3.5, se procesa un mensaje de datos. Una vez analizados los datos, se preparan para el subVI TextNodeMap.

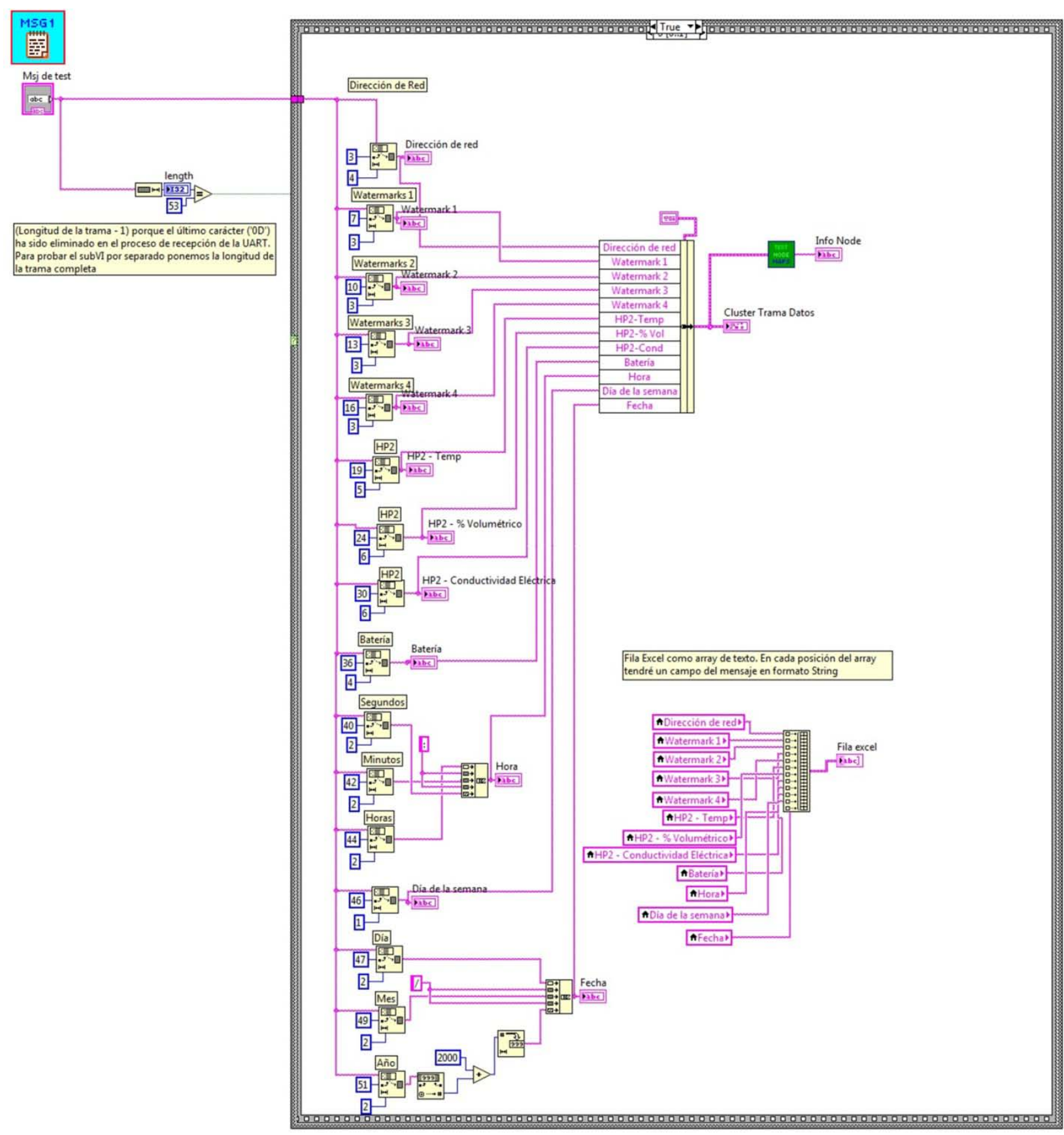

Figura A3.5 SubVI Msg Type 1. 


\section{A3.2.4 Text Node Map.}

El subVI TextNodeMap (ver Figura A3.6) tiene como objetivo formar la cadena que incluye información sobre el último dato del nodo para representarlo en GoogleMaps.

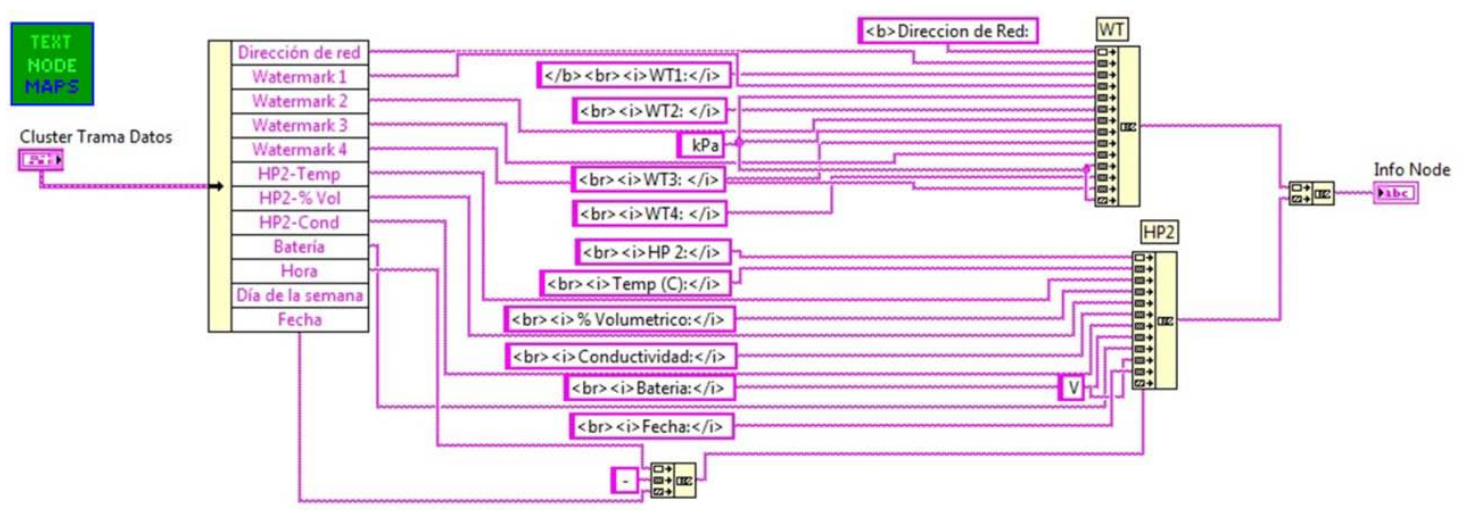

Figura A3.6 SubVI TextNodeMap.

\section{A3.2.5 Graph.}

En el subVI Graph se obtiene la información necesaria para la representación gráfica de los datos según las condiciones impuestas por el usuario en cuanto a red, nodo y fecha. Se analizan todos los datos almacenados en el archivo Data.xls. Para cada dato, si coinciden los identificadores de nodo y red seleccionados, se realiza la comparación de fechas. 


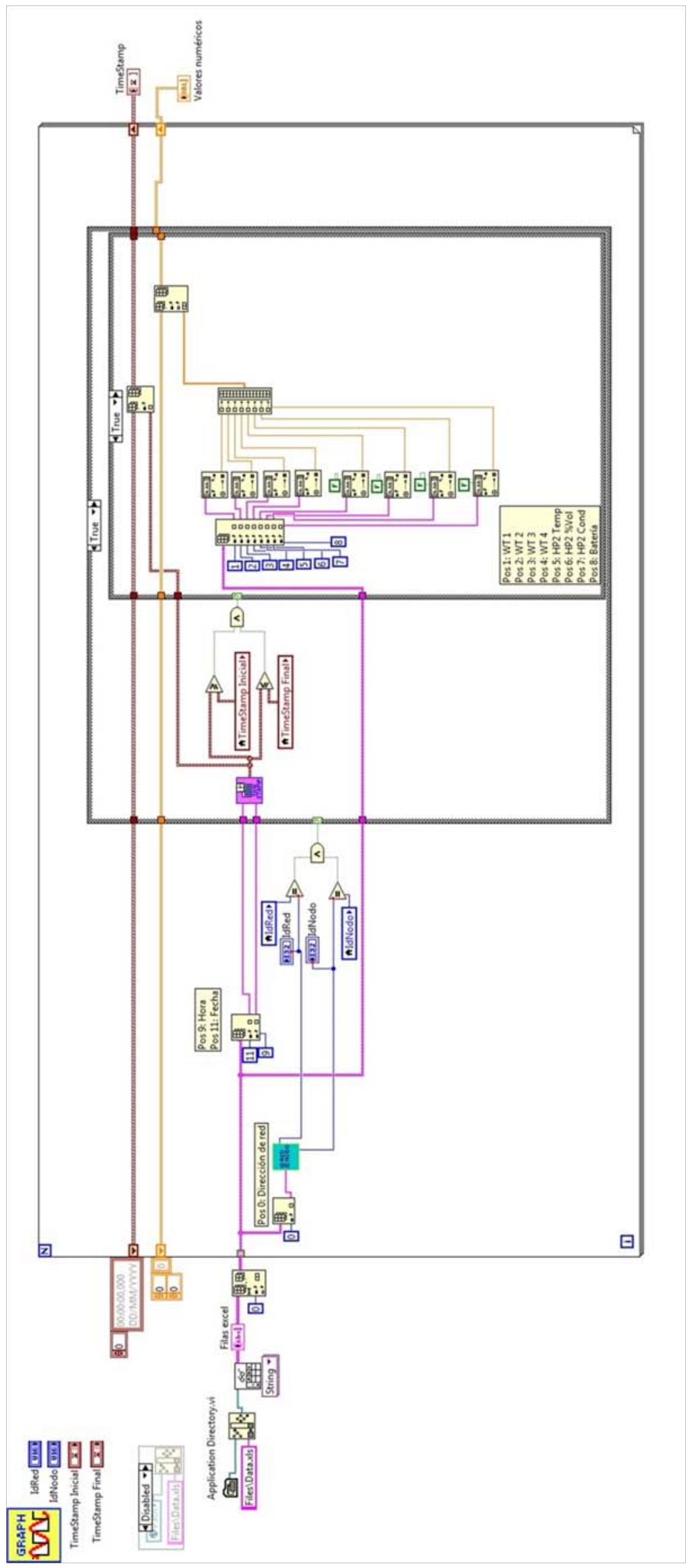

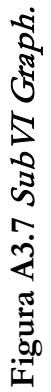


Anexo 4

\title{
Estructura mecánica de la boya
}

\author{
$\Psi$ n el anexo 4 se presenta el plano de la estructura mecánica diseñada.
}




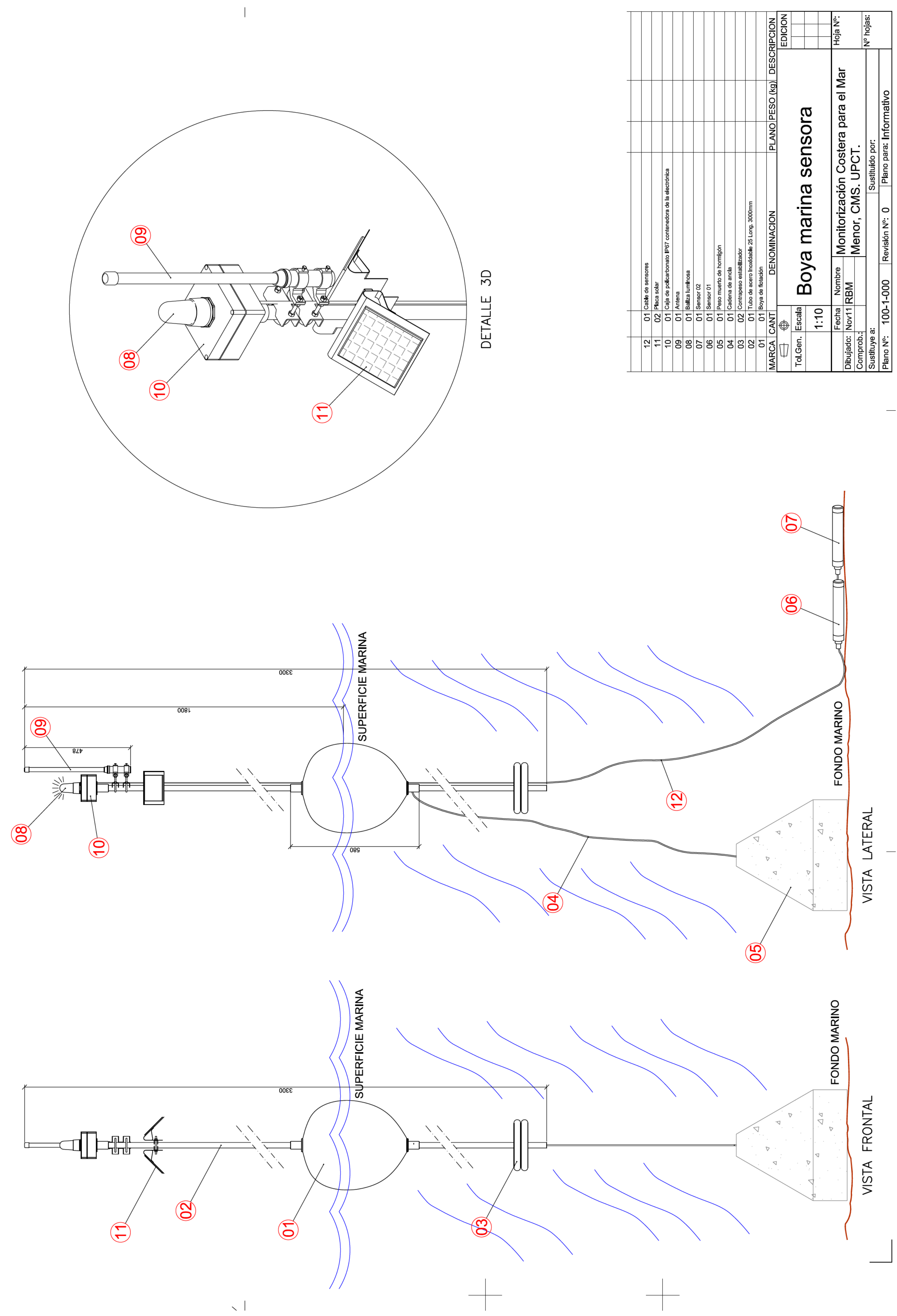



\section{Bibliografía}

[Akyildiz et al., 2002]

[Akyildiz et al., 2005]

[Albaladejo et al., 2010a]

[Albaladejo et al., 2010b]

[Albaladejo et al., 2010c]

[Albaladejo et al., 2011a]

[Albaladejo et al., 2011b]

[Albaladejo et al., 2011c]
I.F. Akyildiz, W. Su, Y. Sankarasubramaniam, y E. Cayirci, "Wireless sensor networks: A survey", Computer Network, vol. 38, pp. 393-422, 2002.

I.F. Akyildiz, D. Pompili, y T. Melodia, "Underwater acoustic sensor networks: research challenges”, Ad Hoc Networks, pp. 257-279, 2005.

C. Albaladejo, P. Sánchez, A. Iborra, F. Soto, J.A. López, y R. Torres, "Wireless Sensor Networks for Oceanographic Monitoring: A Systematic Review”, Sensors, vol. 7, pp. 69486968, 2010.

C. Albaladejo Pérez, F. Soto, J.A. López Riquelme, y A. Iborra, "Arquitectura de una Red de Sensores Inalámbrica para la monitorización de la laguna costera del Mar Menor", AJICT, vol. 3, pp. 44-46, 2010.

C. Albaladejo Pérez, F. Soto, J.A. López Riquelme, y A. Iborra, "Diseño de una red de sensores inalámbrica para un sistema de observación costero", en Actas de SAAEI, pp. 118-123, 2010.

C. Albaladejo, J.A. López, H. Navarro, y J. Rubio, "Sistema para Monitorizar Entornos Marinos basado en Redes Sensores Inalámbricas”, AJICT, vol. 4, pp. 54-56, 2011.

J. Rubio, C. Albaladejo, F. Soto, H. Navarro, y A. Iborra, "Wireless Internet Link and Datalogger for Oceanographic Sensors", en Actas de MARTECH, vol. 4, pp. 33-34, 2011.

C. Albaladejo Pérez, M. Jiménez, F. Soto, R. Torres, J.A. López, y A. Iborra, "A System for Monitoring Marine 
[Albaladejo et al., 2011d]

[Austin et al., 2002]

[Barnes et al., 2007]

[Barrera et al., 2009]

[BasicRF]

[Benjamin et al., 2008]

[Bioing, 2009]

[Buratti et al., 2009]

[Cano et al., 2010]
Environments based on Wireless Sensor Networks", en Actas de OCEANS, pp. 1-6, 2011.

C. Albaladejo, F. Soto, M. Jiménez, R. Torres, J.A. López, y

A. Iborra, "Boya para una red de sensores oceanográfica", en Actas de SAAEI, pp. 497-501, 2011.

T.C. Austin, J.B. Edson, W.R. McGillis, M. Purcell, R.A. Petitt, M.K. McElroy, C.W. Grant, J. Ware, y S.K. Hurst, “A Network-Based Telemetry Architecture Developed for the Martha's Vineyard Coastal Observatory", IEEE Journal of Oceanic Engineering, vol. 27, pp. 228-234, 2002.

C.R. Barnes, M.M.R. Best, B.D. Bornhold, S.K. Juniper, B. Pirenne, y P. Phibbs, "The NEPTUNE Project - a cabled ocean observatory in the NE Pacific: Overview, challenges and scientific objectives for the installation and operation of Stage I in Canadian waters", en Actas de Underwater Technology and Workshop on Scientific Use of Submarine Cables and Related Technologies, pp. 308-313, 2007.

C. Barrera, M.J. Rueda, M.D. Gelado, R. Moran, E. Azevedo, y O. Llinas, "Red ACOMAR: Real-time networking activities in the Macaronesian region as a contribution to the Coastal Ocean Observations Panel (COOP)", en Actas de OCEANS, pp. 1-11, 2009.

"CC2520 Software Examples User's Guide" Texas Instruments. Disponible online www.ti.com en septiembre 2011.

J.J. Martinez-Benjamin, J.M. Davila, J. Garate, P. Bonnefond, M.M. Garcia, M. Castellon, J. Talaya, G.R. Velasco, y B. Perez, "Monitoring sea level by radar altimeter and CGPS in the northwestern Mediterranean", en Actas de IGARSS, vol. 3, pp. 577-580, 2008.

Bioing. Arturo E. Melchiori, "Sensores aerotransportados para el estudio de los recursos naturales", en Actas de $S A B I$, pp. 1-4, 2009.

C. Buratti, A. Conti, D. Dardari, y R. Verdone, "An Overview on Wireless Sensor Networks Technology and Evolution", Sensors, vol. 9, pp. 6869-6896, 2009.

D. Cano, R. Somavilla, J.L. Arteche, C. Rodríguez, y A. Lavín, "Información Océano-meteorológica en el Mar Cantábrico: Boya AGL", en Actas de XXXI Jornadas Cientificas de la Asociación Meteorológica Española, 2010. 
[Carr, 2001]

[Cella et al., 2009]

[CMS, 2011]

[CODAR]

[Conforto, 2010]

[Consi et al., 2008]

[Davis et al., 1992]

[Delauney et al., 2009]

[Dewey et al., 2007]

[Duarte, 2006]
J. Carr, "Practical Antenna Handbook", McGraw-Hill, pp. 33-35, 2001.

U. M. Cella, N. Shuley, y R. Johnstone, "Wireless Sensor Networks in Coastal Marine Environments: a Study Case Outcome", en Actas de WUWNet, 2009.

Página Web del Proyecto "Sistema de Monitorización para el Mar Menor". Disponible en http://www.dsie.upct.es/proyectos/web_cms en diciembre 2011.

CODAR Ocean Sensors. Disponible on-line en http://www.codar.com/ en octubre 2011.

J.R. Conforto Sesto, CC AE, "Vehículos autónomos submarinos. Nuevos actores en las operaciones navales", Revista de Publicaciones Navales, pp. 139-147, 2010.

T.R. Consi, G. Anderson, G. Barske, H. Bootsma, T. Hansen, J. Janssen, V. Klump, R. Paddock, D. Szmania, K. Verhein, y J.T. Waples, "Real time observation of the thermal bar and spring stratification of Lake Michigan with the GLUCOS coastal observatory", en Actas de OCEANS, pp. 1-9, 2008.

[Danchenkov y Riser, 2000] M.A. Danchenkov y S.C. Riser, "Observations of currents, temperature and salinity in the Japan sea in 1999-2000 by palace floats", en publicaciones del Far Eastern Regional Hydrometeorological Research Institute (FERHRI), pp. 33-40, 2000 .

R. E. Davis, L. A. Regier, y J. Dufour, "The Autonomous Lagrangian Circulation Explorer (ALACE)", Journal of Atmospheric and Oceanic Technology, vol. 9, pp. 264-285, 1992.

L. Delauney, C. Compère, y M. Lehaitre, "Biofouling protection for marine environmental sensors", Ocean Sci. Discuss., vol. 6, pp. 2993-3018, 2009.

R. Dewey, A. Round, P. Macoun, J. Vervynck, y V. Tunnicliffe, "The VENUS Cabled Observatory: Engineering Meets Science on the Seafloor", en Actas de OCEANS, pp. 17, 2007.

Carlos M. Duarte, "Las ciencias y tecnologías marinas en España", Consejo Superior de Investigaciones Cientificas, Informes CSIC, Ed. Cyan, Proyectos y Producciones Editoriales, 2006. 
[Fitz et al., 2005]

[Fletcher et al., 2009]

[FOCE]

[Font et al., 2010]

[Forrester et al., 1997]

[Freitas et al., 2009]

[Fujiwara et al., 1998]

[Gilabert et al., 2011]

[Gislason, 2008]

[Guo et al., 2008]
S. Fitz, A. Gonzalez-Velazquez, I. Henning, y T. Khan, "Experimental investigation of wireless link layer for multihop oceanographic-sensor networks", Electronics Letters, vol. 41, pp. 1310-1311, 2005.

M. Fletcher, L. Leonard, J. Dorton, y J. Hanson, "Carolinas Regional Coastal Ocean Observing System (Carolinas RCOOS): A model for integration of sub-regional observing systems", en Actas de OCEANS, pp. 1-8, 2009.

FOCE Development. Disponible on-line en http://www.mbari.org/highCO2/foce/home.htm en octubre 2011.

J. Font, A. Camps, A. Borges, M. Martín-Neira, J. Boutin, N. Reul, Y.H. Kerr, A. Hahne, y S. Mecklenburg, "SMOS: The Challenging Sea Surface Salinity Measurement From Space", en Actas de IEEE, vol. 98, pp. 649-665, 2010.

N.C. Forrester, R.P. Stokey, C. von Alt, B.G. Allen, R.G. Goldsborough, M.J. Purcell, y T.C. Austin, "The LEO-15 Long-term Ecosystem Observatory: design and installation", en Actas de OCEANS, vol. 2, pp. 1082-1088, 1997.

D.M. de Freitas, S. Kininmonth, y S. Woodley, "Linking science and management in the adoption of sensor network technology in the Great Barrier Reef coast, Australia", Computers, Environment and Urban Systems, vol. 33, pp. 111121, 2009.

N. Fujiwara, H. Momma, K. Kawaguchi, R. Iwase, y H. Kinoshita, "Comprehensive deep seafloor monitoring system in JAMSTEC", en Actas de International Symposium on Underwater Technology, pp. 383-388, 1998.

Gilabert, J., Gomariz, S., Molino, E., del Rio, J., Manel, A., Carreras, M., Ridau, P., Sousa, J., Martins, R., Borrajo, D., Olaya, A., Garau, B., Gonzalez, I., Busquets, J., Guerrero, A., García-Córdova, F., Rajan, K., "AUV-2011-Underwater Robotics Experiment in the Mar Menor Coastal Lagoon”, en Actas de MARTECH, pp. 88-90, 2011.

Drew Gislason, “ZigBee Wireless Networking”, Ed. Newnes, 2008.

Z. Guo, F. Hong, Y. Feng, P. Chen, X. Yang, y M. Jiang, "OceanSense: Sensor Network of Realtime Ocean Environmental Data Observation and Its Development Platform", en Actas de WUWNet, 2008. 
[Hande et al., 2006]

[Hart y Martinez, 2006]

[Hochberg et al., 2003]

[Howarth et al., 2006]

[IAR IDE]

[IAR]

[IEEE 802.15.3, 2003]

[IEEE 802.15.4, 2006]

[ICTS 2010]

[IFREMER]

[Jaradat et al., 2008]

[Jeffery y Neidecker, 2010]
A. Hande, T. Polk, W. Walker, y D. Bhatia, "Self-powered wireless sensor networks for remote patient monitoring in hospitals", Sensors, vol. 6, pp. 1102-1117, 2006.

Jane K. Hart y Kirk Martinez, "Environmental Sensor Networks: A revolution in the earth system science?", ScienceDirect, vol. 78, pp. 177-191, 2006.

Eric J. Hochberg, Marlin J. Atkinson, y Serge Andréfouët, "Spectral reflectance of coral reef bottom-types worldwide and implications for coral reef remote sensing", Remote Sensing of Environment, vol. 85, pp. 159-173, 2003.

M.J. Howarth, R. Proctor, P.J. Knight, M.J. Smithson, y D.K. Mills, "The Liverpool Bay Coastal Observatory towards the goals", en Actas de OCEANS, pp. 1-6, 2006.

"MSP430 IAR EMBEDDED WORKBENCH. Tutorials", IAR Systems, 2000.

IAR Systems. Disponible on-line en www.iar.com en agosto 2011.

IEEE Standard 802.15.3-2003, "Wireless Medium Access Control (MAC) and physical layer (PHY) specifications for high rate wireless person area networks (WPANs)", 2003.

IEEE, Institute of Electrical and Electronics Engineer, "IEEE Standard for Information technologyTelecomunications and information exchange between systems - Local and metropolitan area networks - Specific requirements Part 15.4: Wireless Medium Access Control (MAC) and Physical Layer (PHY) Specifications for LowRate Wireless Personal Area Networks (WPANs)", IEEE Standard 802.15.4-2006.

Ministerio de Ciencia e Innovación, "Mapa de Instalaciones Científicas y Tecnológicas Singulares”, pp. 111-122, 2010.

Institut National de Recherches Marines. Disponible on-line en http://www.ifremer.fr/ en octubre 2011.

M.A.K. Jaradat, M.A. Alnimr, y M.N. Alhamad, "Smoke Modified Environment for Crop Frost Protection: A Fuzzy Logic Approach", Comput. Electron. Agric., vol. 2, pp. 104110, 2008.

K. Jeffery y B. Neidecker-Lutz, "The future of cloud computing", 2010. 
[Jiang et al., 2009]

[Kim et al., 2009]

[Knight et al., 2008]

[Kuang et al., 2008]

[La Opinión, 2011]

[LabView, 2010]

[Li y Yang, 2006]

[López et al., 2009a]

[López et al., 2009b]

[López et al., 2011a]

[López et al., 2011b]

[López, 2011]
P. Jiang, H. Xia, Z. He, y Z. Wang, "Design of a Water Environment Monitoring System Based on Wireless Sensor Networks", Sensors, vol. 9, pp. 6411-6434, 2009.

S. Kim, O. Guzide, y S. Cook, "Towards an Optimal Network Topology in Wireless Sensor Networks: A Hybrid Approach", en Actas de ISCA, pp. 13-18, 2009.

C. Knight, J. Davidson, y S. Behrens, "Energy Options for Wireless Sensor Nodes”, Sensors, vol. 8, pp. 8037-8066, 2008.

K.S.C. Kuang, S.T. Quek, y M. Maalej, "Remote Flood Monitoring System Based on Plastic Fibres and Wireless Motes", Sensors and Actuators A: Physical., vol. 2, pp. 449-455, 2008.

Diario La Opinión, "Unas boyas inteligentes desvelarán los secretos ocultos del Mar Menor”, agosto 2011.

Ronald Larsen, "Labview for Engineers: International Version”, 2010.

M. Li y B. Yang, "A Survey on Topology issues in Wireless Sensor Networks", en Actas de Wireless Networks, 2006.

J.A. López Riquelme, F. Soto, J. Suardíaz, P. Sánchez, A. Iborra, y J.A. Vera, "Wireless Sensor Networks for precision horticulture in Southern Spain", Computers and Electronics in Agriculture, vol. 68, pp. 25-35, 2009.

J.A. López, F. Soto, P. Sánchez, A. Iborra, J. Suardíaz, y J.A. Vera, "Development of a Sensor Node for Precision Horticulture”, Sensors, vol. 9, pp. 3240-3255, 2009.

J. A. López, A.J. García Sánchez, F. Soto, A. Iborra, F. García Sánchez, J. García Haro, "Design and validation of a wireless sensor network architecture for precision horticulture applications", Precision Agriculture, vol. 12, pp. 280-295, 2011.

J.A. López Riquelme, F. Soto Valles, R. Torres Sánchez, C. Albaladejo Pérez, J. Suardíaz Muro, y H. Navarro Hellín, "MEWIN: un nodo sensor inalámbrico multientorno. Validación en agricultura de precisión" en Actas de SAAEI, pp. 503-508, 2011.

J.A. López Riquelme, "Contribución a las Redes de Sensores Inalámbricas. Estudio e Implementación de Soluciones Hardware para Agricultura de Precisión", Tesis Doctoral, 2011. 
[Malone, 2003]

[Malone y Cole, 2000]

[MARS, 2009]

[MedGOOS]

[Morrison et al., 2000]

[Nogueras et al., 2009]

[O’Flynn et al., 2007]

[OCCMur]

[OceanColor]

[OOB]

$[\mathrm{OOI}$

$[\mathrm{OOV}]$
T.C. Malone: "The coastal module of the Global Ocean Observing System (GOOS): an assessment of current capabilities to detect change", Marine Policy, vol. 27, pp. 295302, 2003.

T.C. Malone y M.Cole, "Toward a Global Scale Coastal Ocean Observing System", Oceanography, vol. 13, n.1, 2000.

The Monterey Accelerated Research System. Disponible online en http://www.mbari.org/mars/ en octubre 2011.

The Mediterranean Global Ocean Observing System. Disponible on-line en http://www.medgoos.net/ en octubre 2011.

[Milagro y Los Santos, 2009] F. Milagro y A. Los Santos, "Redes inalámbricas de acceso. Comparativa de IEEE 802.11 e IEEE 802.16: capas física y de enlace”, Tesis Doctoral, 2009.

A.T. Morrison, J.D. Billings, y K.W. Doherty, "The McLane Moored Profiler: An Autonomous Platform for Oceanographic Measurements", en Actas de OCEANS, vol. 1, pp. 353-358, 2000.

M. Nogueras, C. Artero, J. del Rio, A. Mànuel, Y D. Sarrià, "Control and acquisition system design for an Expandable Seafloor Observatory (OBSEA)", en Actas de OCEANSEUROPE, pp. 1-5, 2009.

B. O’Flynn, F. Martínez-Català, S. Harte, C. O’Mathuna, J. Cleary, C. Slater, F. Regan, D. Diamond, H. MurpHy, "SmartCoast: A Wireless Sensor Network for Water Quality Monitoring", en Actas de 32nd IEEE Conference on Local Computer Networks, pp. 815-816, 2007.

Observatorio Oceanográfico Costero de la Región de Murcia, OCCMur. Disponible on-line en http://www.oocmur.es en octubre 2011.

OceanColor Web. Disponible online http:/ /oceancolor.gsfc.nasa.gov/ en septiembre 2011.

Observatoire Océanologique de Banyuls. Disponible on-line en http://www.obs-banyuls.fr/ en octubre 2011.

Ocean Observatories Initiative (OOI). Disponible on-line en http://www.ooi.washington.edu/ en octubre 2011.

Observatoire Océanologique de Villefranche sur mer. Disponible on-line en http://www.obs-vlfr.fr en octubre 2011. 
[ORCA]

$[\mathrm{PE}]$

Pettigrew y Neville, 2008]

[Phyton]

[Prandle, 2000a]

[Prandle, 2000b]

[Qiu et al., 2009]

[Red ICTS]

[RoundSolutions]

[RTC MAXIM]

[Ruberg et al., 2007]

$[$ Seanav $]$

[Seders et al., 2007]
ORCA's Eye-in-the-Sea. Disponible on-line en http://www.mbari.org/earth/mar_tech/EITS/eits.html en octubre 2011.

Puertos del Estado. Disponible on-line www.puertos.es en octubre 2011.

N.R. Pettigrew y F. Neville, "Gulf of Maine Ocean Observing System (GoMOOS): Current Measurement in an Integrated Ocean Observing System", en Actas de Current Measurement Technolog, pp. 143-150, 2008.

Python Programming Language - Official Website. Disponible online http://www.python.org/ en septiembre 2011.

David Prandle: "Operational oceanography - a view ahead”, Coastal Engineering, vol. 41, pp. 353-359, 2000.

David Prandle: "Introduction Operational oceanography in coastal waters", Coastal Engineering, vol. 41, pp. 3-12, 2000.

X. Qiu, H. Liu, D. Li, J. Yick, D. Ghosal, y B. Mukherjee, "Efficient Aggregation of Multiple Classes of Information in Wireless Sensor Networks", Sensors, vol. 9, pp. 8083-8108, 2009.

Web oficial de Red de ICTS Marinas. Disponible on-line en http://www.redictsmarinas.ieo.es/ en octubre 2011.

Round Solutions. Disponible online http:/ /www.roundsolutions.com en septiembre 2011.

DS1339, I2C Serial Real-Time Clock, MAXIM, 19-5770, Rev $4 / 11$.

S. A. Ruberg, R. W. Muzzi, S. B. Brandt, J. C. Lane, T. C. Miller, J. J. Gray, S. A. Constant, y E. J. Downing, "A Wireless Internet-Based Observatory: The Real-time Coastal Observation Network (ReCON)", en Actas de OCEANS, pp. 1-6, 2007.

Seanav. Disponible on-line en http://www.seanav.com/ en mayo 2010.

L.A. Seders, C.A. Shea, M.D. Lemmon, P.A. Maurice, y J.W. Talley, "LakeNet: An Integrated Sensor Network for Environmental Sensing in Lakes", Environm. Eng. Sci., vol. 24, pp. 183-191, 2007. 
[Shariat et al., 2008]

[Sonatech]

[Song et al., 2008]

[swra201]

[swru137b]

[swru138]

[Tateson et al., 2005]

[Telit]

[Tunnicliffe et al., 2008]

[Voigt et al., 2007]

[Wang et al., 2007]

[Willis, 2008]
S. Shariat Panahi, A. Mànuel, F. Alegria, X. Roset, A. Bermúdez, y V. Sallares, "Design, Characterization and Calibration of a Short-Period Ocean Bottom Seismometer (OBS)", en Actas de International Instrumentation and Measurement Technology Conference, 2008.

Sonatech. Disponible on-line en http://www.sonatech.com/ en mayo 2010.

G. Song, Y. Zhou, F. Ding, y A. Song, "A Mobile Sensor Network System for Monitoring of Unfriendly Environments”, Sensors, vol. 8, pp. 7259-7274, 2008.

"Z-Stack Sample Applications" Texas Instruments, 20062008.

"CC2520 Software Examples User's Guide" Texas Instruments, 2009.

"CC2520 Development Kit User's Guide" Texas Instruments, 2007.

J. Tateson, C. Roadknight, A. Gonzalez, T. Khan, S. Fitz, I. Henning, N. Boyd, I. Ltd, y C. Vincent, "Real World Issues in Deploying a Wireless Sensor Network for Oceanography", en Actas de Workshop on real-world wireless sensor networks REALWSN, 2005.

Telit Wireless Solutions. Disponible online http://www.telit.com/ en septiembre 2011.

V. Tunnicliffe, C.R. Barnes, y R. Dewey, "Major advances in cabled ocean observatories (VENUS and NEPTUNE Canada) in coastal and deep sea settings", en Actas de US/EU-Baltic International Symposium, pp. 1-7, 2008.

T. Voigt, F. Österlind, N. Finne, N. Tsiftes, Z. He, J. Eriksson, A. Dunkels, U. Bamstedt, J. Schiller, y K. Hjort, "Sensor Networking in Aquatic Environments - Experiences and New Challenges", Local Computer Networks, pp. 793-798, 2007.

X. Wang, L. Ding, D. Bi, y S. Wang, "Energy-efficient optimization of reorganization-enabled wireless sensor networks", Sensors, vol. 7, pp. 1793-1816, 2007.

Willis y S. Zdenka, "United States IOOS - Program update" en Actas de OCEANS, pp. 1-4, 2008. 
[Xia et al., 2007]

[XIOM]

[Xiping et al., 2002]

[Yang et al., 2002]

[Yang et al., 2009]

[Zeng et al., 2010]
F. Xia, Y. Tian, y Y. Sun, "Wirelles sensor/actuator network design for mobile control applications", Sensors, vol. 7, pp. 2157-2173, 2007.

Xarxa d' Instruments Oceanogràfics i Meteorològics, XIOM. Disponible on-line en www.xiom.cat en octubre 2011.

Y. Xiping, G.O. Keat, W.R. Dreschel, Z. Kefeng, C.S. Mungle, y C.A. Grimes, "Design of a Wireless Sensor Network for Long-term, In-Situ Monitoring of an Aqueous Environment", Sensors, vol. 2, pp. 445-472, 2002.

X. Yang, K. G. Ong, W. R. Dreschel, K. Zeng, C. S. Mungle, y C. A. Grimes, "Design of a Wireless Sensor Network for Long-term, In-Situ Monitoring of an Aqueous Environment”, Sensors, pp. 455-472, 2002.

H. Yang, H. Wu, y Y. He, "Architecture of Wireless Sensor Network for Monitoring Aquatic Environment of Marine Shellfish", en Actas de Asian Control Conference, pp. 1147-1151, 2009.

Y. Zeng, C.J. Sreenan, N. Xiong, L.T. Yang, y J.H. Park, "Connectivity and coverage maintenance in wireless sensor networks", Supercomputer, vol. 52, pp. 23-46, 2010. 